\title{
Employment, wages and working time
}

Citation for published version (APA):

de Regt, E. R. (2002). Employment, wages and working time. [Doctoral Thesis, Maastricht University]. Universiteit Maastricht. https://doi.org/10.26481/dis.20021219er

Document status and date:

Published: 01/01/2002

DOI:

10.26481/dis.20021219er

Document Version:

Publisher's PDF, also known as Version of record

\section{Please check the document version of this publication:}

- A submitted manuscript is the version of the article upon submission and before peer-review. There can be important differences between the submitted version and the official published version of record.

People interested in the research are advised to contact the author for the final version of the publication, or visit the DOI to the publisher's website.

- The final author version and the galley proof are versions of the publication after peer review.

- The final published version features the final layout of the paper including the volume, issue and page numbers.

Link to publication

\footnotetext{
General rights rights.

- You may freely distribute the URL identifying the publication in the public portal. please follow below link for the End User Agreement:

www.umlib.nl/taverne-license

Take down policy

If you believe that this document breaches copyright please contact us at:

repository@maastrichtuniversity.nl

providing details and we will investigate your claim.
}

Copyright and moral rights for the publications made accessible in the public portal are retained by the authors and/or other copyright owners and it is a condition of accessing publications that users recognise and abide by the legal requirements associated with these

- Users may download and print one copy of any publication from the public portal for the purpose of private study or research.

- You may not further distribute the material or use it for any profit-making activity or commercial gain

If the publication is distributed under the terms of Article $25 \mathrm{fa}$ of the Dutch Copyright Act, indicated by the "Taverne" license above, 


\title{
Employment, Wages and Working Time
}

\author{
E.R. de Regt
}




\section{Employment, Wages and Working Time}

\section{PROEFSCHRIFT}

ter verkrijging van de graad van doctor

aan de Universiteit Maastricht, op gezag van de Rector Magnificus,

Prof. dr. A.C. Nieuwenhuijzen Kruseman,

volgens het besluit van het College van Decanen,

in het openbaar te verdedigen op

donderdag 19 december 2002 om 16.00 uur

door

Erik Ronald de Regt 


\section{Employment, Wages and Working Time}

\section{PROEFSCHRIFT}

ter verkrijging van de graad van doctor aan de Universiteit Maastricht, op gezag van de Rector Magnificus,

Prof. dr. A.C. Nieuwenhuijzen Kruseman, volgens het besluit van het College van Decanen, in het openbaar te verdedigen op donderdag 19 december 2002 om 16.00 uur

door

Erik Ronald de Regt 


\section{Promotor:}

Prof. dr. J. Muysken

\section{Beoordelingscommissie:}

Prof. dr. P.J.J. Herings (voorzitter)

Prof. dr. C.R.J. de Neubourg

Prof. dr. J.J.M. Theeuwes (Universiteit van Amsterdam) 
Preface ix

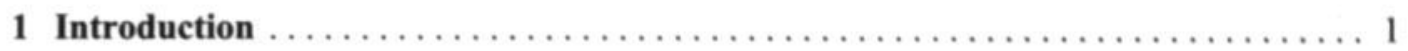

1.1 The evolution of annual working time $\quad 1$

1.1.1 Hours and productivity 5

$\begin{array}{lll}\text { 1.1.2 The work-sharing debate } & 7\end{array}$

$\begin{array}{ll}1.2 \text { The present study } & 11\end{array}$

1.2.1 Aim 11

$\begin{array}{lll}1.2 .2 & \text { Structure } & 12\end{array}$

$\begin{array}{lll}1.2 .3 & \text { The chapters } & 12\end{array}$

1.2.4 Place in the literature $\quad 14$

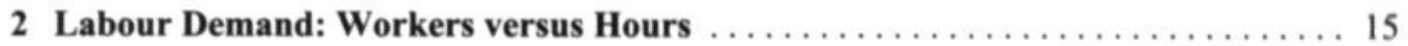

$\begin{array}{ll}2.1 \text { Introduction } & 15\end{array}$

2.2 Labour and capital services $\quad 16$

$\begin{array}{lll}2.2 .1 & \text { Labour services } & 16\end{array}$

$\begin{array}{lll}\text { 2.2.2 Capital services } & 18\end{array}$

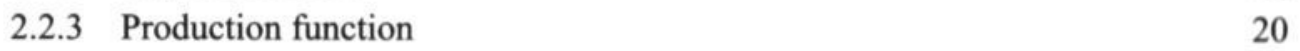

2.3 Cost minimisation $\quad 21$

$\begin{array}{lll}2.3 .1 & \text { Short run } & 21\end{array}$

2.3.2 Long run $\quad 22$

2.4 Hours demand $\quad 24$

2.5 Profit maximisation $\quad 29$

2.6 Market demand for workers $\quad 35$

2.7 A numerical example $\quad 36$

2.8 Conclusion $\quad 38$

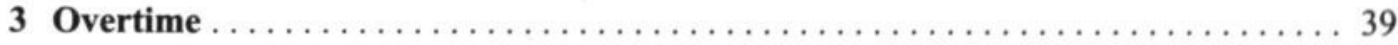

$\begin{array}{ll}3.1 \text { Introduction } & 39\end{array}$

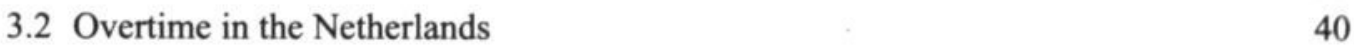

$\begin{array}{ll}3.3 \text { Overtime and absenteeism } & 45\end{array}$

$\begin{array}{lll}3.3 .1 & \text { The model } & 46\end{array}$

3.3.2 Interior solution $\quad 51$

3.3.3 Corner solution $\quad 52$

3.4 Uncertainty $\quad 53$

3.5 Empirical analysis $\quad 56$

$\begin{array}{ll}3.6 \text { Conclusion } & 61\end{array}$

4 Shiftwork, Operating Time and Working Time $\ldots \ldots \ldots \ldots \ldots \ldots \ldots \ldots$

$\begin{array}{ll}4.1 \text { Introduction } & 63\end{array}$

$\begin{array}{ll}4.2 \text { The model } & 67\end{array}$ 
$\begin{array}{ll}4.3 \text { Short-run cost minimisation } & 70\end{array}$

$\begin{array}{lll}4.3 .1 & \text { Interior solution } & 71\end{array}$

$\begin{array}{lll}\text { 4.3.2 Corner solutions } & 74\end{array}$

4.4 Long-run cost minimisation 75

$\begin{array}{lll}4.4 .1 & \text { Interior solution } & 76\end{array}$

$\begin{array}{ll}\text { 4.4.2 Corner solutions } & 79\end{array}$

$\begin{array}{ll}4.5 \text { Sensitivity analysis } & 79\end{array}$

$\begin{array}{ll}4.6 \text { Competitiveness } & 81\end{array}$

4.7 Conclusion $\quad 83$

5 Wage Bargaining, Working Time and Unemployment $\ldots \ldots \ldots \ldots \ldots \ldots \ldots \ldots$

$\begin{array}{lll}5.1 & \text { Introduction } & 85\end{array}$

$\begin{array}{ll}5.2 \text { The monopoly union model } & 87\end{array}$

$\begin{array}{llr}5.2 .1 & \text { Firms } & 87\end{array}$

5.2.2 Worker utility 91

5.2.3 Monopoly union wage setting 93

5.2.4 Working time reduction 96

5.3 Right-to-manage bargaining 97

$\begin{array}{lll}\text { 5.3.1 Wage bargaining } & 97\end{array}$

$\begin{array}{ll}\text { 5.3.2 Working time reduction } & 99\end{array}$

5.3.2.1 Remuneration and hourly wages $\quad 99$

$\begin{array}{ll}\text { 5.3.2.2 Employment and welfare } & 102\end{array}$

$\begin{array}{lll}5.3 .3 & \text { A numerical example } & 105\end{array}$

$\begin{array}{ll}5.4 \text { Efficient bargaining } & 107\end{array}$

5.5 Labour market equilibrium $\quad 109$

5.5.1 Wage determination 110

$\begin{array}{ll}\text { 5.5.2 Unemployment } & 111\end{array}$

$\begin{array}{lll}5.5 .3 & \text { Extensions } & 114\end{array}$

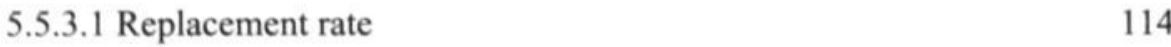

$\begin{array}{ll}\text { 5.5.3.2 Labour supply } & 115\end{array}$

$\begin{array}{ll}\text { 5.5.3.3 General equilibrium } & 116\end{array}$

$\begin{array}{lll}5.5 .4 & \text { A numerical illustration } & 117\end{array}$

$\begin{array}{ll}5.6 \text { Conclusion } & 118\end{array}$

6 Bargaining over Hours or Effort $\ldots \ldots \ldots \ldots \ldots \ldots \ldots \ldots \ldots \ldots \ldots \ldots \ldots \ldots \ldots \ldots \ldots \ldots$

$\begin{array}{ll}6.1 \text { Introduction } & 121\end{array}$

6.2 A taxonomy of hours and effort bargaining $\quad 122$

$\begin{array}{ll}6.3 \text { Hours determination } & 127\end{array}$

$\begin{array}{lll}6.3 .1 & \text { Individuals } & 127\end{array}$

$\begin{array}{llr}6.3 .2 & \text { Firms } & 129\end{array}$ 
$\begin{array}{lll}6.3 .3 & \text { Efficient hours } & 132\end{array}$

6.3.4 Union hours 134

$\begin{array}{ll}\text { 6.3.5 Bargaining over hours } & 136\end{array}$

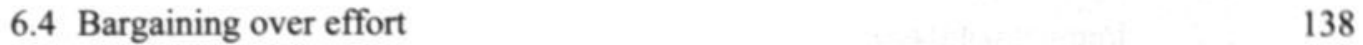

$\begin{array}{ll}6.5 \text { Wage bargaining } & 139\end{array}$

$\begin{array}{ll}\text { 6.6 Simultaneous wage and hours bargaining } & 141\end{array}$

6.6.1 Remuneration and effort 141

6.6.2 Hours and effort bargains compared 143

$\begin{array}{lll}\text { 6.6.3 A labour contract } & 144\end{array}$

$\begin{array}{lll}\text { 6.6.4 Work-sharing } & 145\end{array}$

$\begin{array}{ll}\text { 6.7 Sequential bargaining: Hours first } & 147\end{array}$

$\begin{array}{ll}6.8 \text { Productivity and hours in general equilibrium } & 150\end{array}$

$\begin{array}{ll}6.9 \text { Summary and conclusion } & 153\end{array}$

7 Hourly Wages and Working Time in the Dutch Market Sector 1962-1995 . . . . 155

$\begin{array}{lll}7.1 & \text { Introduction } & 155\end{array}$

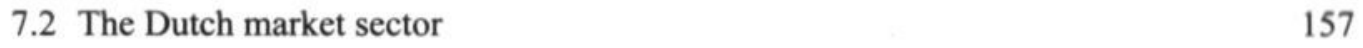

$\begin{array}{lll}7.3 & \text { Theoretical background } & 160\end{array}$

$\begin{array}{lll}7.3 .1 & \text { Wage determination } & 161\end{array}$

$\begin{array}{ll}\text { 7.3.2 Hours determination } & 162\end{array}$

$\begin{array}{lll}7.3 .3 & \text { Reduced form } & 164\end{array}$

$\begin{array}{ll}7.4 & \text { Data and estimation procedure }\end{array}$

$\begin{array}{lll}7.5 & \text { Estimation results } & 167\end{array}$

$\begin{array}{ll}7.6 \text { Work-sharing or productivity-sharing } & 176\end{array}$

$\begin{array}{ll}7.7 \text { Summary and conclusions } & 177\end{array}$

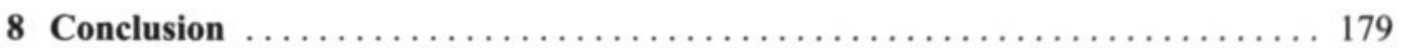

$\begin{array}{lr}8.1 \text { Conclusions } & 179\end{array}$

$\begin{array}{ll}8.2 \text { Future work } & 180\end{array}$

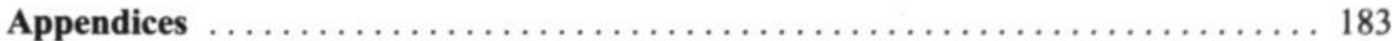

$\begin{array}{lll}\text { Appendix A } & \text { Comparative statics labour demand } & 185\end{array}$

$\begin{array}{ll}\text { A.1 Long-run cost minimisation } & 185\end{array}$

$\begin{array}{lll}\text { A.2 Demand for hours } & 186\end{array}$

$\begin{array}{llr}\text { A.3 Profit maximisation } & 186\end{array}$

$\begin{array}{llr}\text { Appendix.B } & \text { Critical hours } & 188\end{array}$

$\begin{array}{lll}\text { Appendix C } & \text { CES-Approximations } & 191\end{array}$ 
$\begin{array}{lll}\text { Appendix D } & \text { A labour aggregator function with teamwork } & 193\end{array}$

$\begin{array}{lll}\text { Appendix E } & \text { The compensation schedule } & 195\end{array}$

E.1 Spot market 195

E.2 Implicit contracts 196

$\begin{array}{lll}\text { Appendix F } & \text { Comparative statics overtime models } & 199\end{array}$

$\begin{array}{lll}\text { F.1 Certainty } & 199\end{array}$

$\begin{array}{ll}\text { F.2 Uncertainty } & 200\end{array}$

$\begin{array}{lll}\text { Appendix G Data overtime } & 203\end{array}$

Appendix H Comparative statics shiftwork 205

$\begin{array}{lll}\text { Appendix I Iso-employment and iso-profit elasticities } & 207\end{array}$

$\begin{array}{lll}\text { Appendix J } & \text { Bargaining } & 208\end{array}$

$\begin{array}{lll}\text { Appendix K } & \text { General equilibrium } & 211\end{array}$

$\begin{array}{lll}\text { Appendix L } & \text { Data appendix }\end{array}$

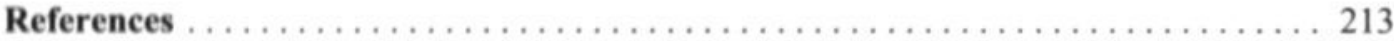

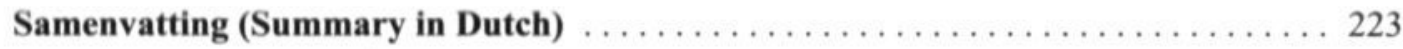

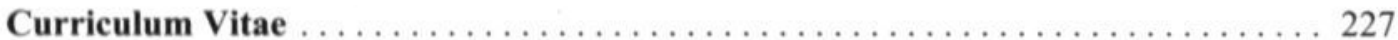




\section{LIST OF FigURES}

Figure 1.1 Annual hours per employed person 3

$\begin{array}{lll}\text { Figure 1.2 Annual working hours full-time employees } & 3\end{array}$

$\begin{array}{lll}\text { Figure 1.3 Annual hours and hourly productivity } & 6\end{array}$

$\begin{array}{lll}\text { Figure 1.4 Annual hours and collective bargaining } & 7\end{array}$

$\begin{array}{llr}\text { Figure 1.5 Annual hours and unemployment } & 9\end{array}$

Figure 1.6 Annual hours and GDP per capita 11

$\begin{array}{lll}\text { Figure 2.1 Efficiency hours } & 17\end{array}$

Figure 2.2 Capital-labour substitution and reduced hours $\quad 23$

Figure 2.3 Second-order condition hours elasticity 25

$\begin{array}{lll}\text { Figure 2.4 Workers versus hours } & 26\end{array}$

Figure 2.5 Labour demand and reduced hours 31

$\begin{array}{lll}\text { Figure 2.6 Hours demand } & 34\end{array}$

$\begin{array}{lll}\text { Figure 3.1 Weekly hours Dutch manufacturing } & 40\end{array}$

$\begin{array}{lll}\text { Figure } 3.2 & \text { Overtime and cyclical indicators } & 43\end{array}$

$\begin{array}{lll}\text { Figure 3.3 Overtime, short-time and utilisation rate } & 44\end{array}$

$\begin{array}{lll}\text { Figure } 3.4 & \text { Overtime and efficiency hours } & 47\end{array}$

$\begin{array}{lll}\text { Figure } 3.5 & \text { Overtime schedule } & 49\end{array}$

Figure 3.6 Overtime premium and corner solution 53

$\begin{array}{lll}\text { Figure 4.1 Operating time and working time in Dutch manufacturing } & 65\end{array}$

$\begin{array}{lll}\text { Figure 4.2 Employment and shiftwork } & 71\end{array}$

$\begin{array}{lll}\text { Figure 4.3 Capital-intensity and shiftwork } & 77\end{array}$

$\begin{array}{lll}\text { Figure 4.4 Capital-labour substitution } & 79\end{array}$

$\begin{array}{lll}\text { Figure 4.5 Initial working time and working time reduction } & 81\end{array}$

$\begin{array}{lll}\text { Figure 5.1 Iso-employment and iso-profit elasticities } & 91\end{array}$

$\begin{array}{lll}\text { Figure 5.2 The monopoly union model } & 95\end{array}$

Figure 5.3 Union utility, remuneration and working time reduction 97

$\begin{array}{lll}\text { Figure 5.4 Remuneration elasticity } & 101\end{array}$

$\begin{array}{lll}\text { Figure 5.5 Hourly wages and working time } & 102\end{array}$

$\begin{array}{lll}\text { Figure 5.6 Critical working times and work-sharing } & 104\end{array}$

$\begin{array}{lll}\text { Figure 5.7 Critical working times } & 112\end{array}$

$\begin{array}{lll}\text { Figure 5.8 Unemployment and work-sharing } & 113\end{array}$

$\begin{array}{lll}\text { Figure 6.1 Efficient hours } & 133\end{array}$

$\begin{array}{lll}\text { Figure } 6.2 & \text { Union hours } & 136\end{array}$

$\begin{array}{lll}\text { Figure 6.3 } & \text { Bargained hours } & 137\end{array}$

$\begin{array}{lll}\text { Figure } 6.4 & \text { Bargained effort } & 141\end{array}$ 
$\begin{array}{lll}\text { Figure } 6.5 & \text { Simultaneous bargaining } & 143\end{array}$

$\begin{array}{lll}\text { Figure 6.6 Models compared } & 146\end{array}$

$\begin{array}{lll}\text { Figure 6.7 Sequential bargaining } & 148\end{array}$

$\begin{array}{lll}\text { Figure 6.8 General equilibrium hours and technical progress } & 152\end{array}$

$\begin{array}{lll}\text { Figure 7.1 Full-time working hours } & 156\end{array}$

$\begin{array}{lll}\text { Figure 7.2 Unemployment and labour share } & 158\end{array}$

$\begin{array}{llr}\text { Figure 7.3 Hourly wages and productivity } & 159\end{array}$

$\begin{array}{lll}\text { Figure } 7.4 \text { Cointegrating vectors } & 172\end{array}$

$\begin{array}{lll}\text { Figure B.1 Critical hours } & 190\end{array}$

$\begin{array}{lll}\text { Figure E.1 Constant (marginal) utility compensation schedules } & 197\end{array}$

$\begin{array}{lll}\text { Figure J.1 Second-order conditions } & 209\end{array}$ 


\section{LIST OF TABLES}

Table 1.1 Annual hours worked per employed person

Table 1.2 Part-time incidence 4

Table 1.3 Full-time annual working time 4

Table 1.4 Annual growth rates hourly productivity and hours 5

$\begin{array}{lll}\text { Table 2.1 Numerical working time elasticities } & 37\end{array}$

$\begin{array}{lll}\text { Table } 3.1 & \text { Overtime incidence } & 41\end{array}$

$\begin{array}{lll}\text { Table } 3.2 & \text { Overtime hours full-time workers } & 41\end{array}$

Table 3.3 Unit root tests overtime equation, 1962-1994 58

$\begin{array}{lll}\text { Table } 3.4 & \text { Overtime equation, 1962-1994 } & 60\end{array}$

$\begin{array}{lll}\text { Table 4.1 Shiftwork incidence, Dutch manufacturing } & 64\end{array}$

Table 4.2 Weekly working time and operating time, Dutch manufacturing 64

$\begin{array}{lll}\text { Table } 4.3 & \text { Parameter values } & 72\end{array}$

$\begin{array}{lll}\text { Table 4.4 Numerical elasticities, interior solution } & 73\end{array}$

$\begin{array}{lll}\text { Table 4.5 Elasticities with respect to working time and corner solutions } & 75\end{array}$

Table 4.6 Sensitivity analysis elasticities with respect to working time 80

$\begin{array}{lll}\text { Table 5.1 Numerical working time elasticities: partial equilibrium } & 106\end{array}$

$\begin{array}{lll}\text { Table 5.2 Numerical working time elasticities: market equilibrium } & 118\end{array}$

$\begin{array}{lll}\text { Table 6.1 A taxonomy of some hours and effort models } & 124\end{array}$

$\begin{array}{lll}\text { Table } 6.2 & \text { Hours and effort bargaining models } & 125\end{array}$

$\begin{array}{lll}\text { Table 6.3 Comparative statics working time } & 135\end{array}$

$\begin{array}{lll}\text { Table } 6.4 & \text { Comparative statics remuneration } & 140\end{array}$

$\begin{array}{lll}\text { Table } 6.5 & \text { Comparative statics simultaneous bargaining } & 142\end{array}$

$\begin{array}{lll}\text { Table 7.1 Key indicators } & 157\end{array}$

$\begin{array}{lll}\text { Table } 7.2 & \text { Granger causality tests } & 160\end{array}$

$\begin{array}{lll}\text { Table 7.3 Reduced form wage and working time elasticities } & 164\end{array}$

$\begin{array}{lll}\text { Table 7.4 Unit root tests } & 166\end{array}$

$\begin{array}{lll}\text { Table 7.5 } & \text { Cointegration tests } & 167\end{array}$

$\begin{array}{lll}\text { Table 7.6 } & \text { Diagnostic tests unrestricted reduced form } & 168\end{array}$

$\begin{array}{lll}\text { Table } 7.7 & \text { Cointegration tests just-identified model } & 171\end{array}$

$\begin{array}{lll}\text { Table 7.8 } & \text { Parsimonious estimation results } & 173\end{array}$

$\begin{array}{lll}\text { Table 7.9 } & \text { Long-run reduced form elasticities } & 176\end{array}$

$\begin{array}{lll}\text { Table J.1 Properties } \mu_{Y} \text { and } \mu_{H} & 210\end{array}$ 

Writing this thesis took long, too long I should add. Nevertheless, I hope it was worth waiting for. During the eighties I had three seemingly mild head injuries, which unfortunately all resulted in postconcussive syndromes lasting two to three years each. Doing academic research while suffering, amongst others, from concentration problems proved to be very hard. Fortunately, I fully recovered and was able to resume the research, leading to this book.

But to be honest, I should have graduated before the 1990s. Too,often, however, I postponed writing down my research results. There always seemed to be some unanswered and interesting questions that needed answering first, even though my supervisors repeatedly tried to convince me that this wasn't the right strategy to pursue. But I was too selfopinionated and stubborn to accept their advice.

The research project started in 1981, when, in the aftermath of the first two oil shocks, the Dutch economy was in disarray. Reduced working time, work-sharing for short, was suggested as a possible cure. Twenty years and a few economic cycles later, the work-sharing debate appears to be countercyclical, reappearing often during recessions. So this may be an appropriate time to conclude. I hope to provide a balanced view of the pro's and the con's.

I started the project under supervision of Wouter Siddré at the Erasmus University Rotterdam. I owe a lot to Wout: he was an inspiring teacher when I was an undergraduate student and spurred my interest in doing academic research. He first offered me a job as student assistant, and finally provided the opportunity to start the research project.

Four years later Joan Muysken convinced me to come to Maastricht. A step I don't regret, although it weakened the incentives to keep in touch with my supervisor. When I suffered from the postconcussive syndrom, it was decided to supervise me in Maastricht. First, Hans Maks and later Joan Muysken, tried to get me writing. They had a hard time. I would like to thank them for their efforts and comments.

Moreover, I would like to thank the Faculty of Economics and Business Administration and, in particular, the Department of Economics for their faith and trust in me. Despite prolonged periods of partial disability, they always expressed their confidence in my comeback. Moreover, I also would like to thank ETIL for their hospitality: when I needed a separate and quiet room taking up my research in 1998, I was welcome in their nice building.

I am also grateful for the various comments and advice given at different stages of the research. With the risk that time erased some of the names from my memory, I want to thank in particular Bertrand Candelon, Denis de Crombrugghe, Peter de Gijsel, Clemens Kool, Jean-Pierre Urbain, Tom van Veen, Maarten Vendrik, Guido Wolfs, Thomas Ziesemer and Thomas Zwick for their suggestions. I would also like to thank my former students Marco de Rooij, Mark van der Velden, Allard Bruinshoofd, Alex Herzog-Stein and Jeanine Thal for 



\section{PREFACE}

Writing this thesis took long, too long I should add. Nevertheless, I hope it was worth waiting for. During the eighties I had three seemingly mild head injuries, which unfortunately all resulted in postconcussive syndromes lasting two to three years each. Doing academic research while suffering, amongst others, from concentration problems proved to be very hard. Fortunately, I fully recovered and was able to resume the research, leading to this book.

But to be honest, I should have graduated before the 1990s. Too often, however, I postponed writing down my research results. There always seemed to be some unanswered and interesting questions that needed answering first, even though my supervisors repeatedly tried to convince me that this wasn't the right strategy to pursue. But I was too selfopinionated and stubborn to accept their advice.

The research project started in 1981, when, in the aftermath of the first two oil shocks, the Dutch economy was in disarray. Reduced working time, work-sharing for short, was suggested as a possible cure. Twenty years and a few economic cycles later, the work-sharing debate appears to be countercyclical, reappearing often during recessions. So this may be an appropriate time to conclude. I hope to provide a balanced view of the pro's and the con's.

I started the project under supervision of Wouter Siddré at the Erasmus University Rotterdam. I owe a lot to Wout: he was an inspiring teacher when I was an undergraduate student and spurred my interest in doing academic research. He first offered me a job as student assistant, and finally provided the opportunity to start the research project.

Four years later Joan Muysken convinced me to come to Maastricht. A step I don't regret, although it weakened the incentives to keep in touch with my supervisor. When I suffered from the postconcussive syndrom, it was decided to supervise me in Maastricht. First, Hans Maks and later Joan Muysken, tried to get me writing. They had a hard time. I would like to thank them for their efforts and comments.

Moreover, I would like to thank the Faculty of Economics and Business Administration and, in particular, the Department of Economics for their faith and trust in me. Despite prolonged periods of partial disability, they always expressed their confidence in my comeback. Moreover, I also would like to thank ETIL for their hospitality: when I needed a separate and quiet room taking up my research in 1998, I was welcome in their nice building.

I am also grateful for the various comments and advice given at different stages of the research. With the risk that time erased some of the names from my memory, I want to thank in particular Bertrand Candelon, Denis de Crombrugghe, Peter de Gijsel, Clemens Kool, Jean-Pierre Urbain, Tom van Veen, Maarten Vendrik, Guido Wolfs, Thomas Ziesemer and Thomas Zwick for their suggestions. I would also like to thank my former students Marco de Rooij, Mark van der Velden, Allard Bruinshoofd, Alex Herzog-Stein and Jeanine Thal for 
their research assistance. Finally, I would like to thank the members of the reading committee, Jean-Jaques Herings, Chris de Neubourg and Jules Theeuwes, for their effort.

Last, but certainly not least, I would like to thank my family for their patience and continued support. Lies without your help, love and understanding, this would not have been possible. Moreover, thank you for the proof-reading. Dorien, Margot and Karin, the future is yours, I hope you will be able to enjoy the leisure you want.

Cadier en Keer, September 2002 




\section{Introduction}

This thesis is about working time and the economy. For more than a century economists have been analysing the impact of reductions of working time on (un-)employment and the performance of the economy. Although the tone of the debate has been consistently sceptical towards the merits of reductions on working time, actual hours have been reduced gradually by almost 50 percent since 1870: our ancestors would claim that nowadays everybody is working part-time.

The first section describes in some more detail the international evolution of annual working time in industrial nations over the last century. I also look at the relations between working time and other relevant economic variables, such as productivity, GDP per capita and unemployment. As one might expect, these relations are not very robust, nor is their causality clear. Against this background, the second section presents the aim and structure of my thesis.

\subsection{THE EVOLUTION OF ANNUAL WORKING TIME}

During the $20^{\text {th }}$ century annual working hours declined steadily in capitalist countries: starting from roughly 2700 hours a year in 1900, see Maddison(1982), to somewhat below 1600 hours in 1992. Table 1.1 illustrates the development for a few large Western countries and the Netherlands. The decline is obvious, although the timing has been different for the various countries.' In 1936, under Blum's Front Populaire, France was the first country to introduce the 40 -hour week. The New Deal policy of the 1930s in the United States also involved a reduction of working hours.

During the period of reconstruction after the Second World War, working hours remained rather high in most European countries, whereas the 40-hour week was introduced in the USA. During the high growth period of the 1960s and early 1970s, however, working times were substantially reduced in (continental) European countries. So before the oil shocks of the 1970s, standard working times were fairly harmonized in Western industrialized countries, just as in the beginning of the $20^{\text {th }}$ century.

1 For a more detailed account of the development of working time in industrialized countries, see e.g., Bosch, Dawkins et al. (1994), Hunt (1998), OECD (1998) and their update Evans, Lippoldt et al. (2001) or Roche, Fynes et al. (1996). 


\section{Table 1.1 Annual hours worked per employed person}

\begin{tabular}{lccccc}
\hline & France & Germany & Netherlands & UK & USA \\
\hline 1929 & 2297 & 2297 & 2260 & 2286 & 2342 \\
1938 & 1848 & 2316 & 2244 & 2267 & 2062 \\
1950 & 1926 & 2316 & 2208 & 1958 & 1867 \\
1960 & 1919 & 2081 & 2051 & 1913 & 1795 \\
1970 & 1888 & 1907 & 1910 & 1735 & 1707 \\
1973 & 1771 & 1804 & 1751 & 1688 & 1717 \\
1979 & 1727 & 1719 & 1679 & 1617 & 1607 \\
1987 & 1543 & 1620 & 1387 & 1557 & 1608 \\
1992 & 1542 & 1563 & 1338 & 1491 & 1589 \\
\hline
\end{tabular}

Source: Maddison (1982), Maddison (1991) and Maddison (1995).

After 1973, annual hours worked declined further. The smallest decreases are found for the USA and the UK, larger reductions are observed for the continental European countries, with the Netherlands at the top. Figure 1.1 - based on estimates of Maddison (1995) - illustrates the development of annual hours during the second half of the last century for a wider set of developed countries. The countries are ordered according to their 1992 levels of annual working hours. In all countries working hours have fallen, although the decrease is not uniformly distributed. English speaking countries typically started at rather low levels, with subsequent small decreases. Other countries had longer hours in 1950 , but then, hours declined substantially afterwards.

Up to the 1970s the reduction of annual hours can be attributed to a decline in full-time hours. After 1973, however, the trend of falling working time can be explained by two separate factors: first, a decrease in full-time hours; and second, an increase in part-time work. Tables 1.2 and 1.3 give some indication of the size of both effects. For the UK' and the USA, part-time incidence has slightly increased, whereas annual full-time hours almost remained constant. ${ }^{2}$ This suggests that for these countries the observed decrease since 1973 in annual hours worked of Table 1.1, is mainly

2 In the USA, for example, the 1995 full-time hours of Table 1.3 are roughly at the same level as the 1950 average annual hours worked of Table 1.1. Schor (1991) even claims an increase in working time. Coleman and Pencavel (1993) conclude, however, that median weekly hours were virtually constant from 1940 to 1988 . The debate is still going on and focusses on measurement issues. 


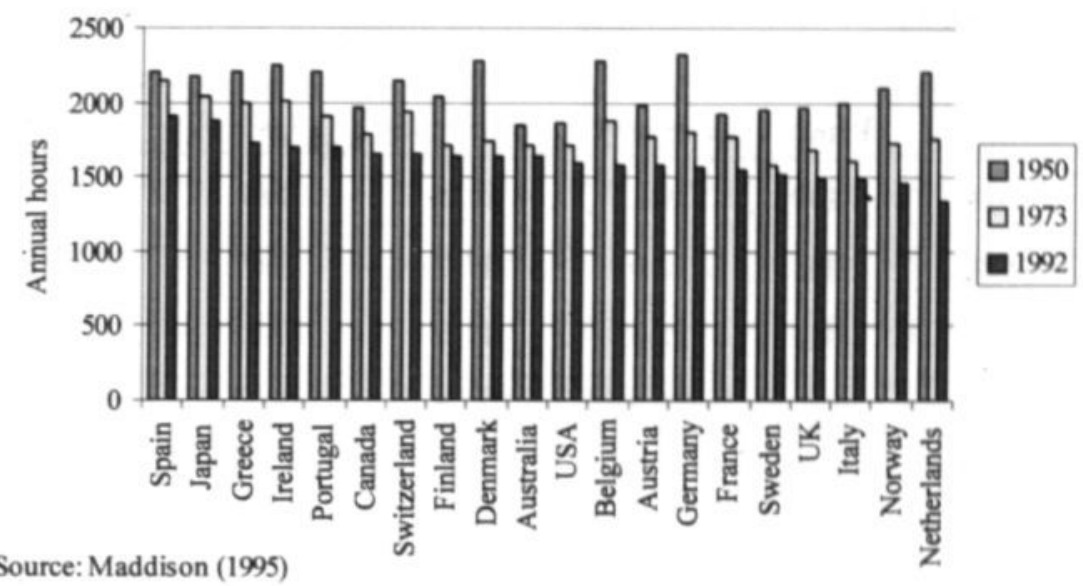

Figure 1.1 Annual hours per employed person

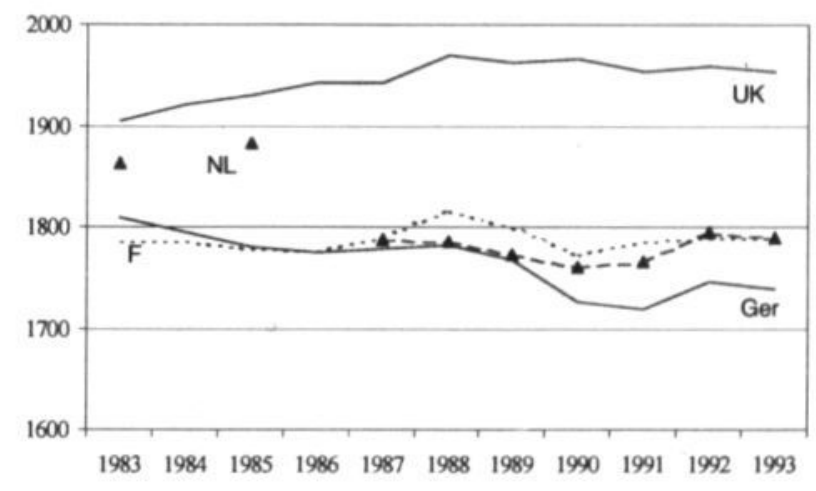

Source: Eurostat (1995)

Figure 1.2 Annual working hours full-time employees

due to an increase in part-time incidence. Indeed Figure 1.2 - based on estimates of Eurostat (1995) - confirms that full-time hours in the UK did not decline in the $1980 \mathrm{~s}^{3}$

3 The different numbers in Table 1.3 and Figure 1.2 illustrate how hard it is to find international comparable data for annual hours. Definitions are different, methods of collection differ, some sources include overtime and deduct absenteeism, others don't, etc. Unfortunately, there are some missing observations for the Netherlands in Figure 1.2. 


\section{Table 1.2 Part-time incidence}

\begin{tabular}{lccccc}
\hline & France & Germany & Netherlands & UK & USA \\
\hline 1973 & 5.9 & 10.1 & $16.6^{\mathrm{a}}$ & 16.0 & 15.6 \\
1983 & 9.6 & 12.6 & 21.0 & 18.9 & 18.4 \\
1990 & 11.9 & 15.2 & 31.6 & 21.3 & 16.9 \\
1995 & 14.8 & 16.3 & 37.4 & 24.0 & 18.6 \\
\hline
\end{tabular}

a. 1979

Source: OECD, Employment Outlook, various issues.

Table 1.3 Full-time annual working time

\begin{tabular}{lccccc}
\hline & France & Germany & Netherlands & UK & USA \\
\hline 1984 & 1784 & 1760 & 1807 & 1785 & 1898 \\
1990 & 1763 & 1643 & 1709 & 1769 & 1904 \\
1995 & 1755 & 1602 & 1717 & 1762 & 1896 \\
1997 & 1771 & 1573 & 1715 & 1774 & 1904 \\
\hline
\end{tabular}

Source: Data are from the Bundesvereinigung der Deutschen Arbeitgebeverbände (www.arbeitgeber.de). Also used in Bell and Freeman (1995) and Hunt (1998).

The incidence of part-time employment also increased in the three continental European countries, the largest increase being observed for the Netherlands, see Table 1.2, by now the world champion part-time employment. But, as Table 1.3 illustrates, there has been a simultaneous reduction in full-time hours: a modest one in France, but larger reductions in the Netherlands and Germany. ${ }^{4}$ This pattern can also be observed in Figure 1.2. ${ }^{5}$ So for these continental European countries, both part-time incidence and reductions in full-time hours played a role in the observed decline of annual hours since 1973.

For this thesis, the main stylised fact to be distilled from the above discussion is that full-time hours have declined substantially throughout the previous century. Although there is some evidence

4 The data for Germany typically refer to the former Western Germany.

5 The sharp reduction in working hours in the Netherlands in 1986 was bargained by the unions, see Section 1.1.2. 
Table 1.4 Annual growth rates hourly productivity and hours

\begin{tabular}{lccccccccccc}
\hline & \multicolumn{2}{c}{ France } & \multicolumn{2}{c}{ Germany } & \multicolumn{2}{c}{ Netherlands } & \multicolumn{2}{c}{ UK } & \multicolumn{2}{c}{ USA } \\
\hline & prod. & hours & prod. & hours & prod. & hours & prod. & hours & prod. & hours \\
& & & & & & & & & & & \\
$1929-1938$ & 2.8 & -2.4 & 1.1 & 0.2 & -0.1 & -0.1 & 0.8 & -0.1 & 1.6 & -1.4 \\
$1938-1950$ & 0.5 & 0.3 & -0.8 & 0.0 & 0.3 & -0.1 & 2.3 & -1.2 & 3.2 & -0.8 \\
$1950-1973$ & 5.1 & -0.4 & 6.0 & -1.1 & 4.8 & -1.0 & 3.1 & -0.6 & 2.7 & -0.3 \\
$1973-1992$ & 2.7 & -0.7 & 2.7 & -0.8 & 2.2 & -1.4 & 2.2 & -0.7 & 1.1 & -0.4 \\
\hline $1929-1992$ & 3.2 & -0.6 & 3.0 & -0.6 & 2.4 & -0.8 & 2.4 & -0.7 & 2.2 & -0.4 \\
\hline
\end{tabular}

Source: Calculated from Maddison (1995).

that the reduction has levelled off for English speaking countries, this does not seem to be true for continental European countries. Moreover, at least in Europe, reductions in working time were not confined to high growth periods, but also occurred during the high-unemployment era after the oil shocks.

\subsubsection{Hours and productivity}

The long-term evolution of full-time hours worked is typically attributed to the increased productivity, see e.g., Bosch and Lehndorff (2001). The gains of productivity growth have been allocated between wage increases and increases in leisure time. The data of Table 1.1 illustrate, for example, that annual hours fell by roughly $30 \%$ since 1929. During the same 1929-1992 period, hourly productivity tripled in the USA and the UK and was 5 to 6 times higher in France and Germany. Table 1.4 illustrates this pattern of increasing productivity and reduced hours with the annual growth rates of these variables. Whereas hourly productivity increased on average by 2 to 3 percent, annual hours decreased on average by 0.6 to 0.8 percent. Looking at the sub-periods, it is once again clear that the timing was dissimilar in different countries.

Instead of looking at the time series behaviour, Figure 1.3 illustrates the negative correlation between annual working times and hourly productivity for a cross-section of OECD countries. The first panel uses the hours data by Maddison (1995), the corresponding correlation coefficient is $-0.62 .{ }^{6}$ Notice, however, that the countries with annual hours between 1600 and 1700 hours

6 The correlation coefficients for 1950 and 1973 are -0.56 and -0.61 , respectively. So the crosscountry correlation appears rather robust. 

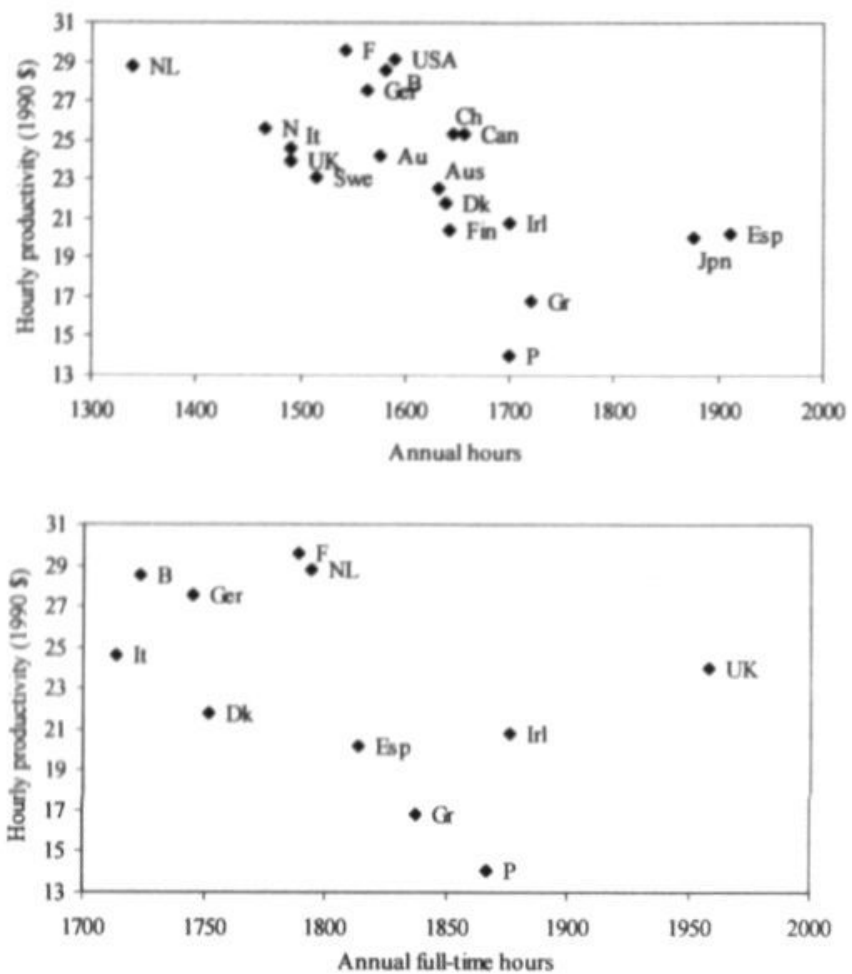

Source: Eurostat (1995) and M addison (1995)

Figure 1.3 Annual hours and hourly productivity (1992)

exhibit a fairly large variation in hourly productivity. So, there are presumably many other factors that determine annual hours worked. The second panel of Figure 1.3 uses the Eurostat (1995) estimates of full-time annual hours. Once again there appears to be a negative correlation, the correlation coefficient being $-0.46{ }^{7}$ So part of the negative correlation in the first panel can be attributed to the occurrence of part-time labour in the more productive countries. Finally, the figure illustrates that there is a large variation of full-time working hours even within the European Union. So there may be other factors explaining this.

According to OECD (1998) collective bargaining, and thus unionisation, is one of these factors, as in countries where collective bargaining is more developed working hours have shown a faster decline. Figure 1.4 illustrates the correlation between Maddison's annual hours and two OECD indicators of collective bargaining. The correlation coefficient between the 1990 trade union density and 1992 annual hours is -0.24 , whereas this coefficient is -0.27 for bargaining coverage. Using

7 The Southern European countries Portugal and Greece have rather low productivity and relatively low full-time annual hours. Eliminating them from the sample, the correlation drops to -0.35 . 

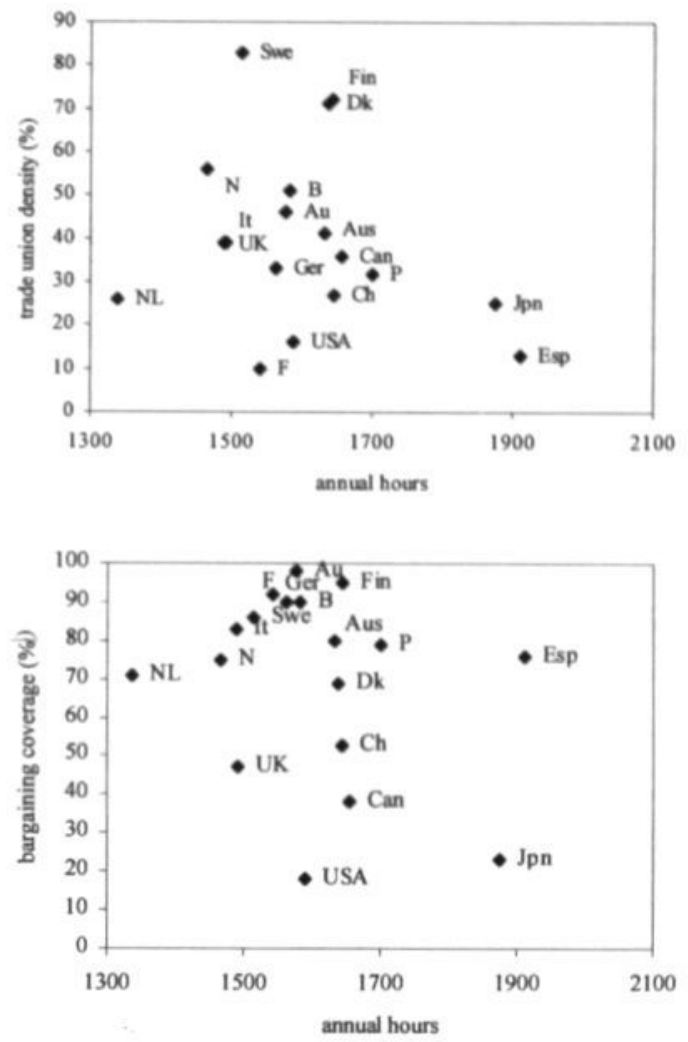

Source: Maddison (1995) and OECD

\section{Figure 1.4 Annual hours and collective} bargaining

the full-time Eurostat hours, rather similar results are found. So indeed, unions appear to have an impact on annual hours worked.

\subsubsection{The work-sharing debate}

Besides institutional factors as unionisation, the unemployment rate could be another candidate for explaining the observed difference in hours worked. Indeed, in times of high unemployment, there is often a call for reduced hours, the so-called work-sharing strategy, i.e. 'redistributing work amongst people so as to reduce involuntary unemployment, Drèze (1986, p. 562). Two early examples were already mentioned: French introduction of the 40-hour week in 1936, under Blum's Front Populaire; and the reduction of working time as part of the New Deal policy of the 1930s in the United States.

After the Second World War, work-sharing was no longer an issue, but it reappeared in Europe after the oil-crises of the 1970 s when unemployment increased dramatically. In the USA it remained 
a non-issue, however. Among others, Bosch, Dawkins et al. (1994), Bosch and Lehndorff(2001), Hunt (1998), Kapteyn, Kalwij et al. (2000) and Roche, Fynes et al. (1996) provide an overview of countries involved and the various approaches taken. ${ }^{8}$ For example:

- Towards the end of the $1970 \mathrm{~s}$, Belgium was one of the first countries to try to reduce the workweek from 40 to 36 hours, in combination with some wage moderation.

- In 1981 the French socialist government aimed at a reduction from 40 to 35 hours a week and increased holidays. The first year the workweek was reduced to 39 hours, with full wage compensation, but the program was stopped as a failure, as competitiveness fell dramatically.

- In the UK the unions bargained for the 39-hour week in the engineering industry around 1981.

- In the Netherlands unions bargained for the 38-hour week between 1983 and 1986, reducing their wage claims.

- Finally, in Germany, after major strikes, weekly hours started to decline during the second half of the 1980s.

With France as the prime example, some countries tried to reduce hours by legislation, whereas in other countries - especially Germany and the Netherlands - unions bargained for shorter standard workweeks (and longer holidays).

More recently, there appears to be a revival of the work-sharing debate. Again France is the prime example of government involvement. In 2000, the socialist Jospin government enacted the law 'Aubry' reducing the statutory workweek to 35 hours, although longer hours are allowed but at the cost of an overtime premium. But in Germany and the Netherlands unions tried - and succeeded in most cases - to implement standard workweeks of 35 or 36 hours.

Whether these reductions in annual hours were successful in reducing unemployment or increasing employment is debated. Layard, Nickell et al. (1991, Ch. 10) are very sceptical. They illustrate their position by a scatter diagram relating changes in the unemployment rate to relative changes in working time. The correlation is negative and their interpretation is that countries that reduced working hours most had the strongest increase in unemployment. ${ }^{9}$ Figure 1.5 , using the standardised OECD unemployment rates, replicates such a graph, although using levels for 1973 and 1992, respectively. As in Layard, Nickell et al. (1991), the 1973 panel suggests a negative correlation between hours and unemployment, the correlation coefficient being -0.32 . The 1992 panels seem to

8 Most of the these countries also implemented measures for early retirement. In the anticipation of the greying of the labour force during the $21^{\text {st }}$ century, these countries now try to reverse the trend of lower participation of older workers. In this thesis, however, 1 will only focus on a reduction of (full-time) annual hours.

9 Mind you, the causality may also work in the opposite direction: the countries with the highest (increase in) unemployment had most incentives to reduce hours. 

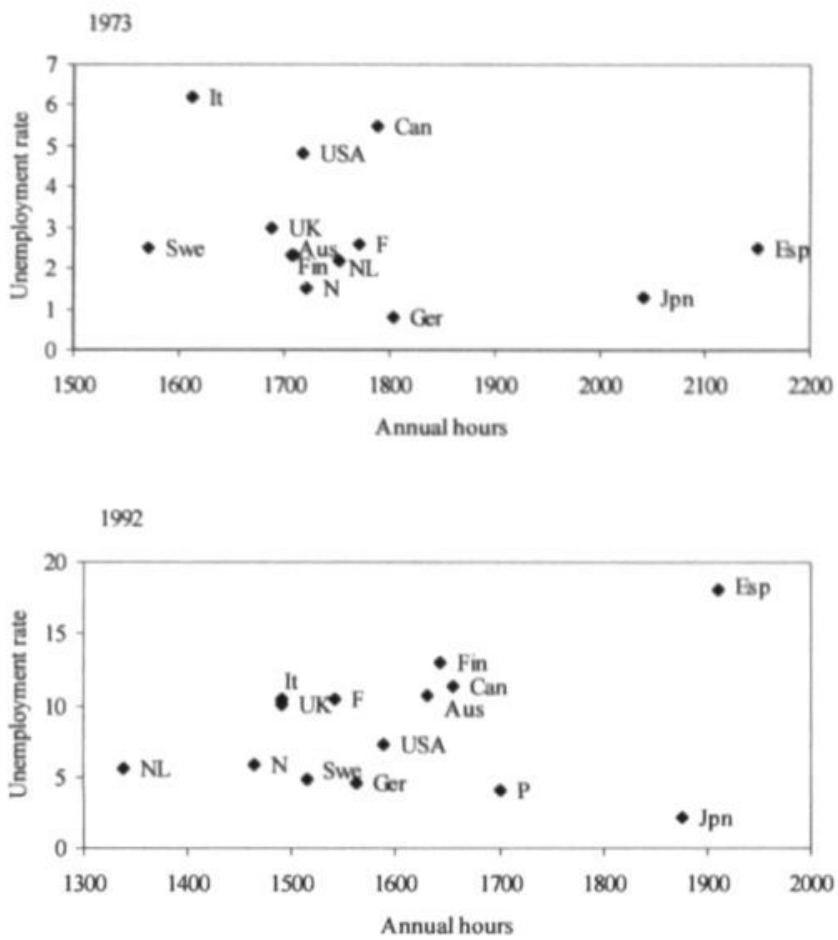

1992

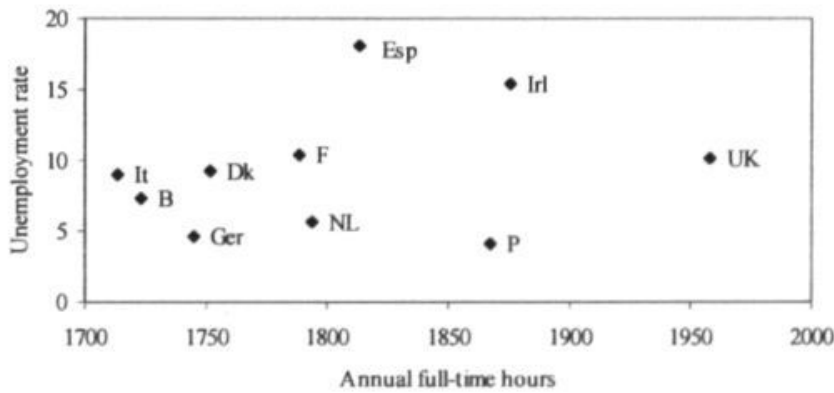

Source: Eurostat (1995), Maddison (1995) and OECD

\section{Figure 1.5 Annual hours and unemployment}

suggest a positive correlation, however. ${ }^{10}$ In the middle panel, using Maddison's (1995) average hours, the correlation coefficient is 0.27 , but it turns negative, -0.17 , once Spain with its high unemployment and long hours is eliminated from the panel. Finally, the lower 1992 panel uses

10 Similarly, changing the period from the original 1975-1988 to 1983-1993, the correlation between the changes becomes positive. 
Eurostat's (1995) estimates of full-time hours, resulting in a correlation coefficient of 0.25 . Eliminating the high unemployment countries Ireland and Spain, the coefficient drops to 0.08 . All-inall Figure 1.5 yields no clear-cut evidence in favour of or against work-sharing. The relation between unemployment and hours appears to be more complex.

Looking at empirical evidence with respect to employment, the results are mixed. Hunt (1999) is rather sceptical, and concludes that the negotiated reductions in working time in Germany have reduced employment. Similarly, Kapteyn, Kalwij et al. (2000) do not find evidence for the proposition that work-sharing would promote employment. On the other hand, Bosch and Lehndorff (2001, p. 227), surveying the literature, conclude that 'most empirical studies confirm that collective working-time reductions can be expected to have positive employment effects'. But they continue to state that 'the most important thing to agree on is on the kind of conditions that have to be created if the employment policy pursuad is to be as successful as possible in creating jobs'. More or less similarly, Freeman (1998) co icludes from the empirical literature that work-sharing generated by market forces can increase employment, but that government legislated policies tend to have limited or negative effects. So the evidence seems to indicate that work-sharing might work, at least under certain conditions. However, the estimates also indicate that the increase in employment is typically less than proportional, reducing total worker-hours.

In any case, work-sharing is in general not a popular measure among professional economists to cure unemployment. The major argument is the so-called lump-of-labour fallacy, see Layard, Nickell et al. (1991, Ch. 10). ${ }^{11}$ Krugman (1997) called this the global-glut doctrine. The lump-of-labour fallacy refutes the idea that there is a fixed amount of work that can be redistributed at will. On the contrary, employment - and thus unemployment - is determined by demand and supply factors or in a more modern context by price and wage setting behaviour. Reductions in working time, may affect both price setting and wage setting, and the final impact on unemployment is uncertain. Moreover, even when employment increases, worker-hours and output tend to decrease, so worksharing makes a country poorer. Figure 1.6 illustrates the latter effect: GDP per capita tends to be lower when annual hours are lower, the correlation coefficient being 0.34 . This is not a purely arithmetic observation. Obviously, at given hourly productivity and participation rate, GDP (per capita) is lower; but, as was illustrated in Figure 1.3, hourly productivity tends to be higher for countries with lower annual hours. Moreover, employment may increase due to work-sharing, increasing the participation rate. But these effect are insufficient to fully compensate the direct impact of fewer working hours.

The decrease in GDP per capita need not to be welfare decreasing, however, as individuals in countries with shorter working times have more leisure time available. Therefore, there is a choice to

11 Walker (2000) provides a critique on this critique of work-sharing. 


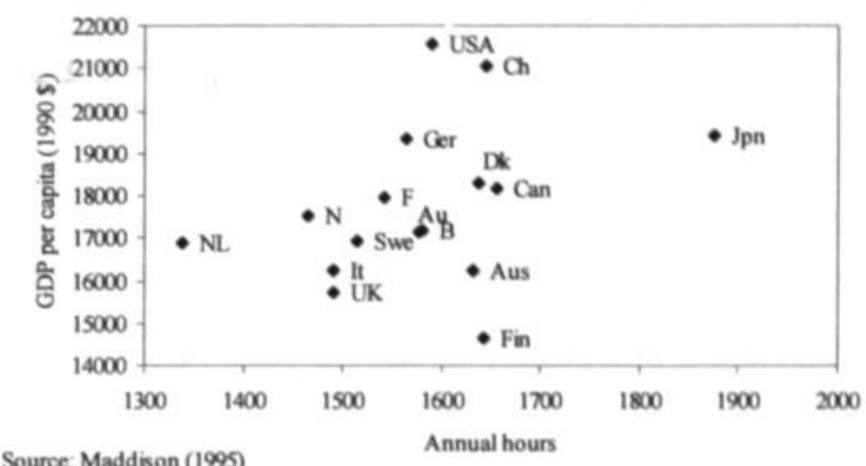

Figure 1.6 Annual hours and GDP per capita (1992)

be made, and countries - at least their citizens - may differ in their preferences to this respect. Indeed, Bell and Freeman (1995), show that even though Americans tend to have longer hours than Germans in 1989, United States employees showed a relatively strong preference for "more hours and more pay", whereas German workers showed a relatively strong preference for "less hours and less pay". ${ }^{12}$ Sousa-Poza and Henneberger (2000), using the same ISSP 1989 data set, consider a wider set of nine OECD countries, and conclude that the length of the working week does not explain differences in hours constraints. On the other hand, the $\operatorname{OECD~(1998,~p.~166)~presents~}$ evidence based on a 1994 Eurostat survey that within Europe 'countries in which average annual hours of work per person are already relatively low tend to be those in which the average preference for fewer hours is relatively strong, and that for higher earnings relatively weak'. So there is pervasive heterogeneity in the preferences for leisure and income.

\subsection{THE PRESENT STUDY}

\subsubsection{Aim}

The previous section illustrated a number of important relations between working hours and other economic variables: hourly productivity, employment, unemployment, GDP per capita and union involvement. Their causal links remained rather unclear, however. Take productivity, for example. On the one hand, it has often been argued that the length of the workday or workweek may affect hourly productivity: start-up times leading to a positive correlation; fatigue having a negative impact.

12 Bell and Freeman (1995) suggest that the underlying reason is the higher earnings inequality in the USA. Bell and Freeman (2001) provide some new evidence if favour of this hypothesis. 
On the other hand, increased productivity through technological progress makes us richer, and provides room for reduction in working hours. The causality may thus run either way, even though the mutual relations between these two variables are fairly obvious.

For the other variables the relations with working time may be less obvious, however. Take unemployment, as another example. One of the issues in the literature is how working hours do affect unemployment, but the work-sharing debate illustrates that increased unemployment may also affect the determination of hours. Again, the causality may run either way, but the mechanisms behind these links are more involved than for productivity.

The aim of the thesis is to get a better understanding of the relationship between working time and a number of other economic variables, in particular employment and unemployment. For both variables, the system of wage determination is an important ingredient. Against the background of continental European labour markets, this also raises the issue of the impact of unions on wages and working time.

\subsubsection{Structure}

To investigate the relations between the various variables, the thesis mainly uses a theoretical approach. The core of the book consists of two or three parts, depending on the approach taken.

Regarding causality, the first four chapters consider the impact of a given reduction in working time on variables such as employment (Chapter 2), overtime (Chapter 3), shiftwork (Chapter 4) and wages and unemployment (Chapter 5). The next two chapters basically reverse the causality. Chapter 6 provides an overview of models of hours determination. This is followed in Chapter 7 by an empirical study of the joint determination of wages and annual working time in the Netherlands.

Alternatively, the chapters can be classified according to their partial or equilibrium approaches used. Chapters 2 to 4 focus on labour demand, ignoring interactions with wage setting and labour supply. As from Chapter 5, however, union wage determination is incorporated in the model, leading to equilibrium labour market results in Chapters 5 and 6 . The third part is the empirical investigation of a wage and hours equation in Chapter 7.

\subsubsection{The chapters}

In some more detail the contents and structure of the chapters is the following. In Chapter 2 I start with the relation between working time and labour demand. This has been studied before, but too often the impact of hours worked on capital services is ignored. Taking the impact on capital services into account, reduces the scope for work-sharing policies, as productivity is more adversely affected. Moreover, in the long run capital is now affected by the length of the workweek. Nevertheless, the model identifies a critical level of hours for which work-sharing may increase employment. The labour demand model of this chapter, is used throughout the thesis. 
Most labour demand models allowing for overtime, predict adverse effects of work-sharing on actual hours worked, at least when overtime is worked. On the other hand, empirical work suggests that actual hours and standard hours move (almost) proportionally. Chapter 3 takes up this issue, extending the model of Chapter 2 with overtime. Part of the explanation may be found in measurement errors, where observed overtime may overstate actual hours worked. That being the case, we might end up in the corner solution, where actual hours coincide with the standard working week. Another reason may be that overtime is due to factors outside the standard model. In Chapter $3 \mathrm{I}$ investigate the role of demand uncertainty and uncertain absenteeism. Indeed, the stochastic nature of attendance and demand, increases average hours. A brief empirical analysis for the Dutch manufacturing industry confirms that absenteeism and demand are important factors explaining overtime. No impact was found for the standard workweek. As I focus on long-run issues, I assume in the remainder of the thesis that hours worked correspond to standard hours.

Chapter 4 considers issues of shiftwork. Even though the weekly working time of employees has decreased, the operating time of capital has remained rather constant. A logical extension of the model in Chapter 2 including capital services is thus to investigate the link between shiftwork and the standard workweek. Indeed, the model illustrates that work-sharing provides incentives to increase shiftwork.

An important determinant of the effectiveness of work-sharing policies is the impact on hourly and annual wages. Chapter 5 uses a union bargaining set-up to analyse this issue. The model predicts a U-shaped relation between hours worked and hourly wages. Moreover, annual earnings tend to fall. As a consequence, there is also a U-shaped relation between hours worked and the unemployment rate in the equilibrium. Hence, the effectiveness of work-sharing policies depends on the initial length of the workweek.

It then is important to understand how the standard working week is determined. This is the topic of Chapter 6. There are many models in this regard, varying from labour supply to hours set by firms. I focus on the impact of unions on hours worked. With higher unemployment unions tend to bargain for lower hours; in other words, in times of high unemployment unions have an incentive to put work-sharing on the agenda. With regard to the level of hours, the institutional detail and the bargaining power of each party may lead to a wide variation in outcomes. Given the U-shaped pattern between unemployment and working time, the effectiveness of work-sharing policies depends on the institutional characteristics of the economy.

Notwithstanding the large variety of models of hours determination, the equilibrium models of Chapter 6 can be used to investigate the impact of productivity growth on hours worked and wages. The general prediction is that hours worked tend to decline and wages tend to increase, even when hours supply is moderately increasing in wages. 
Chapter 7 presents an empirical investigation of the joint determination of wages and annual hours in the Dutch market sector. Using cointegration techniques, I find that hourly wages do not increase significantly when hours worked are reduced. So reduced working hours have lead to wage moderation in the Netherlands. Hourly wages on the other hand, have a quite significant negative impact on annual hours. However, no impact could be found for unemployment on annual hours. So the observed downward trend in hours should be attributed to productivity growth, and not to work-sharing.

The study concludes in Chapter 8 with a brief summary.

\subsubsection{Place in the literature}

This is certainly not the first book on the impact of working hours on the labour market and the economy. An early Dutch example is Verdoorn (1947). Hart (1987) focusses mainly on labour demand issues and Owen (1989) takes an American perspective. More recently, Contensou and Vranceanu (2000) survey the literature. ${ }^{13}$

The structure of the book more or less follows the history of the literature. When the worksharing debate came up in the 1970s and 1980s, the first set of papers investigated the impact on labour demand, Hart (1984b) being a typical example. Chapters 2 to 4 provide extensions to this literature, emphasizing the role of capital. Starting with Calmfors (1985), the second set of papers studied the impact of work-sharing on wages. This is the topic of Chapter 5, where I broaden the results to incorporate capital services and extend the results to various bargaining structures. More recently, see Marimon and Zilibotti (2000) and Rocheteau (2002), the debate includes the determination of hours worked. In Chapter 61 provide an overview of various hours determination models and show that many outcomes are possible.

Finally, empirical models describing the time-series behaviour of standard hours, as in Chapter 7, are scarce. Dur (2001) has a model for the Netherlands and Kapteyn, Kalwij et al. (2000) present some international evidence.

13 Although their title suggests a general treatment, Rubin and Richardson (1997) mainly consider a case study in the UK shipbuilding and engineering industry. 


\section{Labour Demand: Workers versus Hours}

\subsection{INTRODUCTION}

During the $20^{\text {th }}$ century the industrialised world has witnessed a long-term decrease in annual hours worked per employed person. In the beginning of that century the annual working time was around 2700 hours, see Maddison (1982), whereas in 1995 full-time annual hours of industrialised countries vary somewhere between 1700 and 1900 hours, see Hunt (1998). Around 1700 hours seems typical for northern continental European countries like Germany and the Netherlands, whereas American workers tend to work around 1900 hours a year. The strong reduction in working time over the last century has had an enormous impact on the demand for labour. Similarly, the differences in working times between countries may affect labour demand. This is the topic of this chapter, where I analyse the impact of exogenous changes in working time on the demand for workers.

The standard textbook analysis of labour demand typically ignores the distinction between the number of workers and the number of hours worked by these workers. Labour input is then typically synonymous to worker-hours, the product of the number of workers and their average number of hours worked. In such a simple world, firms are not interested in the division between bodies and hours, and labour supply decisions govern hours worked. In such an ideal world, reductions in working time lead to proportional increases in the demand for the number of workers.

For some issues this overly simplistic view is innocent, but for many questions the distinction is important. This is obviously the case when analysing the impact of hours worked on labour demand, i.e. the number of workers. It is highly unlikely that two workers each working eight hours a day produce the same output as one worker working 16 hours, or eight workers working two hours a day. Therefore, it is often recognised in labour economics that the distinction between the intensive margin (hours) and the extensive margin (workers) of labour input is important. This is not only true for the revenue side, but also for the cost side. For example, labour costs are not simply equal to the hourly wage cost multiplied by worker-hours as overtime commands a higher remuneration. Moreover, some labour costs such as paid holidays do not vary with the length of the working day, but only with the number of workers. Hart (1987) gives an extensive survey of these and related issues and provides further references. 
This chapter elaborates on these issues and derives the impact of changes in working time on employment, measured by the number of workers. It serves two purposes: first, it provides an overview of the main issues involved; and second, it introduces the main labour demand model used throughout the book. Traditionally, the question is dealt with in models focussing on labour services, with capital playing no role whatsoever. The main contribution of this chapter is to illustrate how a proper account of capital services affects the results. The model is deliberately kept as simple as possible: it encompasses the structure of most existing models, but also allows for a basic introduction of capital services. Extensions are dealt with in the next chapters.

The static model of firm behaviour describes a representative profit maximising firm, facing a known downward sloping demand curve for its product. The firm produces a single product with two production factors: capital and labour. The services obtained from these inputs depend not only on the homogeneous stocks involved - the capital stock and the number of workers - but also on the utilisation of these stocks - the operating time of capital and the working time of workers. In the absence of shiftwork, operating time and working time are equal. From a long-run perspective, actual hours worked follow normal hours quite closely. Therefore, this chapter also ignores overtime and treats working time as exogenous to the firm. Changing working time influences labour costs, which include quasi-fixed costs of labour.

The chapter is organised as follows. In Section 2.2 I discuss the impact of working time on the production function. Thereby it is important to distinguish between labour services and capital services. Section 2.3 considers the case of cost minimisation. At given output, working time reduction leads to higher labour demand, but the impact on unit costs is ambiguous. This leads to a discussion of the optimal demand for hours in Section 2.4. Profit maximisation at given hours is discussed in Section 2.5, followed by a brief extension to partial equilibrium effects in Section 2.6. Section 2.7 gives a simple numerical illustration, followed by the conclusions in Section 2.8.

\subsection{LABOUR AND CAPITAL SERVICES}

\subsubsection{Labour services}

In labour demand models it is increasingly recognized that labour services depend not only on the number of workers, but also on the working time of each worker employed. This has led authors such as Ball and St. Cyr (1966) and Ehrenberg (1971) to specify labour services $L$ according to

$$
L=L(N, H), \quad 0<L_{N}, L_{H}
$$

where $N$ represents the number of workers and $H$ average hours worked per employee. Partial derivatives are denoted by subscripts, e.g. $L_{N}=\partial L / \partial N$. The simplest example of $(2.1)$ is replacing 


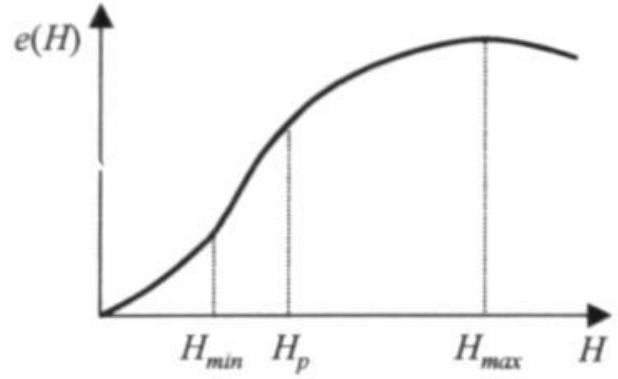

(a)

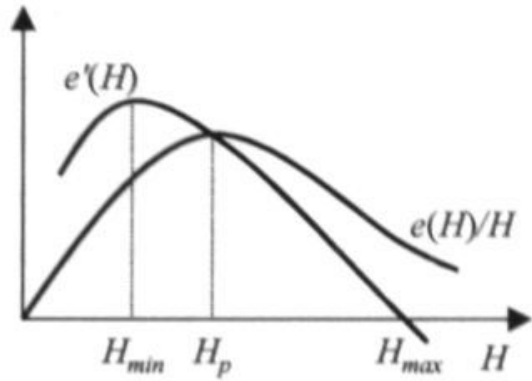

(b)

Figure 2.1 Efficiency hours

labour services $L$ by worker-hours $E \equiv N H$, the sum of all individual hours. A drawback of this specification is that it ignores productivity effects of hours worked. This can be remedied replacing clock hours by so-called efficiency hours $e(H)$, see e.g., Andersen (1987) and Booth and Ravallion (1993), leading to

$$
L=N e(H) . \quad 0<e^{\prime}(H)
$$

What can plausibly be said about efficiency hours $e(H)$ ? Figure 2.1, panel (a), depicts a typical locus and follows arguments presented among others by Chapman (1909), Barzel (1973), Feldstein (1967) and Lewis (1969). ' For small values of $H$ increasing returns may prevail, for example due to non-productive hours such as morning start-up times and coffee breaks. Eventually, however, lengthening the workweek will have diminishing returns because of increased worker boredom and fatigue. For still longer hours physical exhaustion dominates and efficiency hours fall. With the present moderate levels of working hours in industrialized countries, the latter situation seems unlikely to prevail. Thus in the relevant range, efficiency hours will be assumed to increase in hours, $e^{\prime}(\cdot)>0$, though probably at a decreasing rate, $e^{\prime \prime}(\cdot)<0$. This corresponds to the concave part between $H_{\min }$ and $H_{\max }$ in panel (a).

Panel (b) depicts the same properties in terms of average and marginal efficiency hours. Due to start-up times, marginal productivity $e^{\prime}(H)$ first increases up to $H_{\min }$, then it declines and eventually becomes negative at $H_{\max }$. As a result hourly productivity, i.e. average efficiency hours $e(H) / H$, follow a hump-shaped pattern, with a maximum at $H_{p}$ (with $H_{\min }<H_{p}<H_{\max }$ ). For longer hours average productivity falls, though total efficiency hours $e(H)$ rise up to $H_{\max }$, where output per worker is maximised. In Section $2.4 \mathrm{I}$ will show that the relevant range of hours for firms is $\left[H_{p}, H_{\max }\right]$.

1 See also Contensou and Vranceanu (2000, Ch. 5), Hart (1987, pp. 73-74) and Walker (2000). 
Let $\eta^{e} \equiv H e^{\prime}(H) / e(H)$ denote the elasticity of efficiency hours with respect to clock-hours. ${ }^{2}$ At $H_{p}$ average ęfficiency hours are maximised and hence $\eta^{e} \gtrless 1$ for $H \lessgtr H_{p}$ : the elasticity of efficiency hours exceeds unity only if hours worked fall below $H_{p}$. Moreover, $\eta^{\epsilon}=0$ at $H_{\max }$. This suggest that the elasticity of efficiency hours with respect to working time $\eta^{e}$ is decreasing in working time (at least locally). Accordingly, I assume that the elasticity of efficiency hours with respect to working time $\eta^{e}$ is decreasing in working time, so $\gamma_{H} \equiv-\frac{\partial \ln \eta^{*}}{\partial \ln H}>0$. ${ }^{3}$ This sets an upperbound to $e^{\prime \prime}(\cdot)$, illustrating that efficiency hours should not increase too quickly. ${ }^{4}$

Efficiency hours will remain unspecified in the sequel, but it may be useful to consider some examples. In applied work the constant elasticity case $e(H)=H^{\gamma}, 0<\gamma<1$, is mostly used. This is best seen as a local approximation of a more general specification. To incorporate fixed nonproductive time $S>0$, Hart (1987) uses $e(H)=(H-S)^{\gamma}$. This specification implies $\eta^{e}=\gamma H /(H-S)$, so $H_{p}=S /(1-\gamma)$ and $\gamma_{H}=S /(H-S)>0$. Another example satisfying all the above criteria, is the translog efficiency hours function

$$
\ln e(H)=\gamma_{1} \ln H-1 / 2 \gamma_{2}(\ln H)^{2} . \quad 0<\gamma_{1}, \gamma_{2}
$$

This yields $\eta^{e}=\gamma_{1}-\gamma_{2} \ln H$ and $\gamma_{H}=\gamma_{2}>0.5$

\subsubsection{Capital services}

To obtain a relation between output and working time, labour services are typically substituted into a standard neoclassical production function. With capital and labour as the only two production factors, the typical production function used is, see Hart (1984b), for example,

$$
Q=F(K, L), \quad 0<F_{K}, F_{L}
$$

2 More generally, I will use the notation $\eta^{\varepsilon} \equiv x g^{\prime}(x) / g(x)$ for the elasticity of an arbitrary function $g(x)$.

3 The estimates presented in Galeotti, Maccini et al. (2002)"suggest that the hours elasticity $\eta^{\circ}$ falls with output. As long as hours are positively correlated to output, this is consistent with my assumption.

4 Notice that $\frac{\partial \ln \eta^{\circ}}{\partial \ln H}=1-\eta^{e}+\frac{B e^{\prime \prime}(H)}{e^{\prime}(H)}$, hence the upperbound is given by $\frac{B e^{\prime \prime}(H)}{e^{\prime}(H)}<\eta^{e}-1-\gamma_{H}$. At optimal hours $H^{d}$ for the firm the elasticity satisfies $\eta^{e}<1$, see equation (2.10) below. So $e^{\prime \prime}(\cdot)<0$ and efficiency hours are concave in the optimum.

5 Moreover, $\ln H_{\min }=\frac{2 \gamma_{1}-1-\sqrt{1+4 \gamma_{2}}}{2 \gamma_{2}}, \ln H_{p}=\left(\gamma_{1}-1\right) / \gamma_{2}$ and $\ln H_{\max }=\gamma_{1} / \gamma_{2}$. 
where $Q$ is output and $K$ is the homogeneous capital stock. There appears the be a serious omission in this specification of the production function (2.3), however: the flow of capital services is proportional to the capital stock, which ignores the operating time of the capital stock, i.e. the number of hours a plant or a machine is in operation. But obviously, given a fixed capital stock, capital services fall when the duration of operations is reduced, see also Georgescu-Roegen (1970) and Leamer (1999). The production function should not fail to incorporate this.

The problem is easily remedied introducing capital services, instead of the capital stock, as an input in the production function, see for example Abel (1981), Bosworth (1981), Fair (1969), Nadiri and Rosen (1969) or Winston and McCoy (1974). Analogous to labour services, the flow of capital services $M$ can be modelled as a function of the capital stock $K$ and the operating time of machinery. As shiftwork will not be considered in the present chapter, but see Chapter 4 , the operating time of capital and the working time of labour are of identical length. Hence capital services can be written as

$$
M=M(K, H) . \quad 0<M_{K}, M_{H}
$$

As in the labour services function (2.2), operating time, and thus working time $H$, is used as a conversion factor, transforming the inputs from stocks to flows, see Leslie and Wise (1980).

Following similar arguments as in Ehrenberg (1971), capital services are further specified to be multiplicative separable, compare (2.2),

$$
M=K m(H) \quad 0<m^{\prime}(H)
$$

It is hard to be very specific about efficiency operating time $m(H)$. On the one hand, a straightforward alternative is simply to use the operating time $H$, equating capital services $M$ to total capitalhours $\mathrm{KH}$. On the other hand, similar arguments as presented for efficiency hours could hold, for example due to maintenance time and wear and tear. A useful benchmark may be the case of fixed factor proportions. For example, if there are fixed factor proportions in the technology $F(\cdot)$, it seems appropriate to use the same functional form for efficiency operating time $m(H)$ and efficiency hours $e(H)$. In general any positively sloped function satisfying $e(H) \leq m(H) \leq H$ might be appropriate.

In de Regt (1988) the general specification $m(H)$ is used. Here I simplify the analysis, however, assuming $m(H)=e(H)^{\kappa}$, with $0 \leq \kappa$. This assumption reduces the algebra, without changing the qualitative comparative static results. 


\subsubsection{Production function}

Replacing the capital stock $K$ in the production function (2.3) by the above capital services $M$, the production function becomes $Q=F(M, L)=F\left(e(H)^{\mathrm{K}} K, e(H) N\right)$. Assuming as usual that $F(\cdot)$ is linear homogeneous in its arguments, the production function can be written as

$$
Q=N e(H) f(k),
$$

where $k \equiv e(H)^{\alpha-1} K / N$ is the capital-intensity, i.e. the capital-worker ratio in efficiency hours, and $f(k) \equiv F(k, 1)$ is the per capita instantaneous production function, satisfying $f^{\prime \prime}(k)<0<f^{\prime}(k)<$ $f(k) / k$. The instantaneous production function $f(k)$ characterizes the substitution possibilities between the stocks, the substitution elasticity being

$$
\sigma \equiv-\frac{f^{\prime}(k)\left[f(k)-k f^{\prime}(k)\right]}{k f(k) f^{\prime \prime}(k)}>0 .
$$

The specification (2.5) looks like a kind of putty-clay assumption. At the beginning of the day (or week), the capital-intensity $k$ is chosen and, even though it may depend on working time $H$, this is maintained throughout the day. Output (per capita) depends on the duration of operations, see Georgescu-Roegen (1970) and Contensou and Vranceanu (2000), as characterized by efficiency hours. Finally the scale of operation is determined by the number of workers $N$.

Accordingly, using working time as a conversion factor from stocks to flows, I am able to impose more structure on the general production function $Q=G(K, N, H)$ used by Feldstein (1976) and Bernanke (1986). For $K=0$, the model reduces to the often used, but I my view misspecified, labour services model. For $\mathrm{K}=1, k$ corresponds to the capital-labour ratio measured in bodies. This corresponds basically to the model recently advocated by Leamer (1999).

Comparing (2.5) with the original specification (2.3) illustrates that the elasticity of hours worked in the production function changes. Let $\eta^{\prime} \equiv k f^{\prime}(k) / f(k)$ denote the elasticity of output with respect to capital services and $1-\eta /$ the elasticity of output with respect to labour services, then the elasticity of output with respect to hours increases from $\left(1-\eta^{\prime}\right) \eta^{e}$ in $(2.3)$, to $\left(1-(1-\kappa) \eta \eta^{\prime}\right) \eta^{e}$ in the preferred (2.5). The reason is simply that, as working hours also affect capital services in the latter, working hours have a larger impact on output in that model. ${ }^{6}$

6 This is most easily illustrated in a Cobb-Douglas production function, combined with a constant elasticity specification $e(H)=H^{\gamma}$ for efficiency hours. The labour services specification (2.3) is $Q$ $=A K^{1-\alpha}\left(N H^{\gamma}\right)^{\alpha}$, whereas for $\kappa=1(2.5)$ corresponds to $Q=A K^{1-\alpha} N^{\alpha} H^{\gamma}$. The elasticity of hours in the production function increases from $\alpha \gamma$ in (2.3) to $\gamma$ in (2.5). Notice that both specifications are observational equivalent. This equivalence ceases to hold for production functions with a nonunitary elasticity of substitution $\sigma$. 


\subsection{Cost MiNimisAtioN}

Having specified the production function, let me briefly introduce the cost structure. With respect to capital costs, it is simply assumed that the firm faces the familiar user cost of capital $R$. This user cost is assumed to be known and fixed. Possible links between the user cost of capital and working time, as suggested by Bosworth (1981) and Nadiri and Rosen (1969), are ignored. It complicates the algebra without virtually changing the comparative static results. They will be introduced when discussing shiftwork in Chapter 4 , however.

With respect to labour costs, it is well documented since the seminal papers by Becker (1964) and $\mathrm{Oi} \mathrm{(1962)} \mathrm{that} \mathrm{firms} \mathrm{face} \mathrm{quasi-fixed} \mathrm{labour} \mathrm{costs} \mathrm{besides} \mathrm{their} \mathrm{variable} \mathrm{labour} \mathrm{costs.} \mathrm{These}$ non-wage labour costs vary only with the number of workers, not with the average working time. Hart (1984a) and Hamermesh (1993) provide extensive discussions. These non-wage costs $V$ consist of such things as fringe benefits, (discounted) hiring, firing and training costs and administrative costs or clothing expenditures. Moreover, Bell (1982) has argued that, due to ceilings, part of the social security contributions may be included. In the present paper, quasi-fixed labour costs are assumed to be proportional to the number of workers. For a more general specification, see Plessner and Yitzhaki (1983) and Hashimoto and Zhao (2000).

The second component of labour costs consists of wage payments, the remuneration depending on the hours of work of the employed. In this chapter working time is considered fixed for the firms. It is best interpreted as standard hours either set by the government or, more realistically, determined in the bargaining between firms and unions, see Chapter 6. Moreover, I assume here that firms do not use overtime. Although the impact of reductions in working time on employment may depend on the use of overtime, see Chapter 3, the evidence seems to suggest that actual hours vary proportionally with standard hours, see Hunt (1998).

Let $W$ denote the hourly wage cost, then each worker's remuneration corresponds to $Y=W H$. As the firm also incurs fixed costs, labour costs per worker are $V+Y$. The share of fixed costs in labour costs is denoted $\varphi_{V} \equiv V /(V+Y)$. The distinction between hourly wages $W$ and remuneration $Y$ will be important when discussing working time reductions. Two extreme cases will be considered: with full wage compensation, remuneration $Y$ will remain constant; without wage compensation the hourly wage rate $W$ is fixed.

\subsubsection{Short run}

Ignoring overtime, the firm can not adjust hours in the short run. Hence the only variable factor is the number of workers. Any exogenous reduction in working time reduces capital and labour services, 
which has to be compensated by an appropriate increase in the number of workers, see (2.5). In terms of elasticities this can be expressed as?

$$
\varepsilon_{\text {NHQK }}=-\eta^{e} \frac{1-(1-\boldsymbol{k}) \eta^{f}}{1-\eta^{f}} \leq-\eta^{e}<0 .
$$

The second part of the elasticity illustrates that the number of workers have to increase more than proportionally (except for $\mathrm{K}=0$ ), as the reduction in hours reduces both capital and labour services. Potential hourly productivity gains are reflected in the first part, reducing the impact of working time on the demand for workers, at least if hours do not fall below $H_{p}$. This accounting expression forms the basis of the basic intuition of many layman that a reduction of working time boosts employment.

Obviously, this is not a convincing story, because most of the crucial variables are considered fixed and exogenous. Even if I do not consider general equilibrium repercussions, equation (2.6) directly shows that one should consider the impact on output and on the capital stock. I start with the latter and will deal with the output effect in section 2.5 .

\subsubsection{Long run}

In the long run, the firm can adjust its capital stock, leading to substitution effects. The cost minimisation problem of the firm then corresponds to

$$
\begin{gathered}
\min _{K, N} C=R K+(V+Y) N \\
\text { subject to (2.5). }
\end{gathered}
$$

The first-order conditions for cost minimisation reduce to the output constraint (2.5) and

$$
e(H)^{\mathrm{x}-1} \frac{f^{\prime}(k)}{f(k)-k f^{\prime}(k)}=\frac{R}{V+W H}
$$

The left-hand side corresponds to the marginal rate of substitution between capital and workers and the right-hand side is the marginal cost ratio between capital and the numbers of workers. The second-order condition is satisfied for $\sigma>0$.

7 I will use the notation $\varepsilon_{z X}$ to denote the elasticity of the endogenous variable $Z$ with respect to the exogenous variable $X$. Similarly, $\varepsilon_{z X Y Y}$ denotes the same elasticity, but conditional on variable $Y$. 


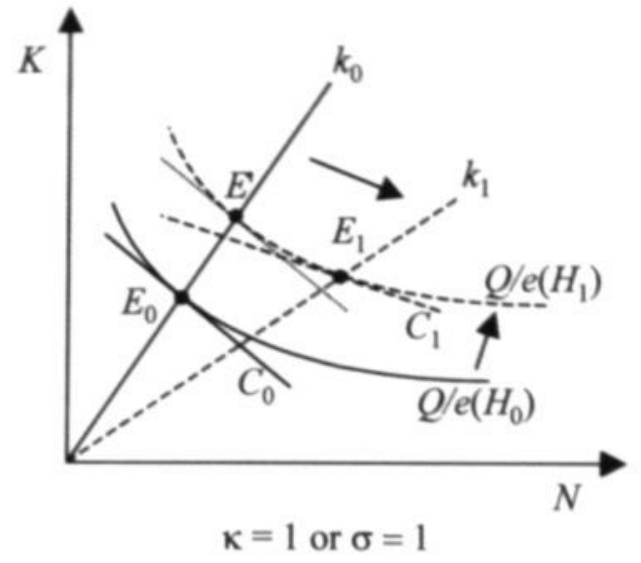

(a)

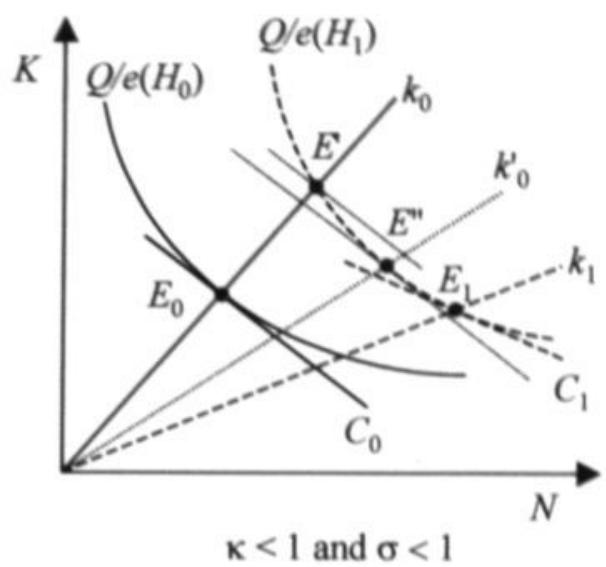

(b)

\section{Figure 2.2 Capital-labour substitution and reduced hours}

Figure 2.2 illustrates the model in the capital-worker space. Using the production function (2.5), the isoquants can be represented in per efficiency hour terms. Suppose that originally $H_{0}$ hours are worked. In the equilibrium $E_{0}$, the slope of the isoquant $Q / e\left(H_{0}\right)$ equals the slope of the isocost curve $C_{0}$, satisfying the first-order condition (2.7). This equation defines the capital-intensity $k$ as a downward sloping function of the generalized cost ratio $\frac{\operatorname{Re}(H)^{1-\mathrm{x}}}{V+Y}$. In the figure this is represented by the ray $k_{0}{ }^{8}$

Consider a reduction of the working time from $H_{0}$ to $H_{1}$. As a consequence efficiency hours fall, shifting the isoquant upward to $Q / e\left(H_{1}\right)$. This raises both the capital stock and the number of workers, see $E^{\prime}$ in panel (a) of Figure 2.2. For $\kappa=1$ or $\sigma=1$, a reduction of hours at given remuneration $Y$ is similar to neutral technical regress and raises costs. For $\kappa<1$ (and $\sigma<1$ ) as in panel (b), however, reduced hours affect labour services more than capital services, and is thus similar to biased labour using technical regress. This is illustrated by the rotated isoquant $Q / e\left(H_{1}\right)$ and lower capital-labour ratio at $E^{\prime \prime}$.

Finally, there is an effect from the cost side. With constant hourly wages labour costs per worker decline. In Figure 2.2 this is represented by the flatter slope of the isocost curve $C_{1}$. According to (2.7) this triggers a substitution effect towards more employment. The new equilibrium is $E_{1}$, with a lower capital-labour ratio $k_{1}$. For the number of workers the effects work in the same direction and employment increases. However, the impact on the capital stock is ambiguous, as the effects

8 These rays correspond to the capital-labour ratio in bodies $(K / N)$, which is different from the capital-intensity $k$, unless $\kappa=1$. 
operate in opposite directions. In terms of the figure, it is not clear whether the capital stock at $E_{1}$ is higher or lower than its initial level $E_{0}$. For rather long hours the isoquant will not shift out very much, accordingly the substitution effect through lower remuneration dominates and the capital stock declines.

Appendix A presents the derivation of the comparative statics. The elasticity of the number of workers with respect working time is equal to

$$
\varepsilon_{N H Q}=-\eta^{e}\left[1-(1-\kappa) \sigma \eta^{\prime}\right]-\left(1-\varphi_{\nu}\right) \sigma \eta^{f}<0 .
$$

The first part reflects the reduction in efficiency hours, including the possible labour using bias; the second part measures the substitution effect. The latter part corresponds to the elasticity of worker demand with respect to remuneration $\varepsilon_{N Q_{Q}}=-\left(1-\varphi_{V}\right) \sigma \eta$. The higher the non-wage costs, the lower is the absolute value of this elasticity of labour demand.

The impact of a reduction of hours worked on unit costs is ambiguous. The outward shift in the isoquant increases costs, but at constant hourly wages the remuneration per worker declines. Let $c$ $=C / Q$ denote the unit costs, then using (2.5) and (2.7) the elasticity of unit costs with respect to working time is given by

$$
\varepsilon_{c H}=-\eta^{e}\left[1-(1-\kappa) \eta^{\prime}\right]+\left(1-\varphi_{V}\right)\left(1-\eta^{\prime}\right)
$$

The sign depends typically on the size of the elasticity of efficiency hours, and hence on the length of the working time.

\subsection{HOURS DEMAND}

So far the analysis treats working time $H$ as exogenous to the firm, but the model can also be used to determine the optimal demand for hours. The corresponding cost minimisation problem is

$$
\begin{gathered}
\min _{K, N, H} C=R K+(V+W H) N \\
\text { subject to (2.5). }
\end{gathered}
$$

The first-order conditions of this problem reduce to the production function (2.5), optimal capitalintensity (2.7) and the additional hours equation

$$
\frac{e^{\prime}(H)}{e(H)} \frac{f(k)-(1-\kappa) k f^{\prime}(k)}{f(k)-k f^{\prime}(k)}=\frac{W}{V+W H} .
$$




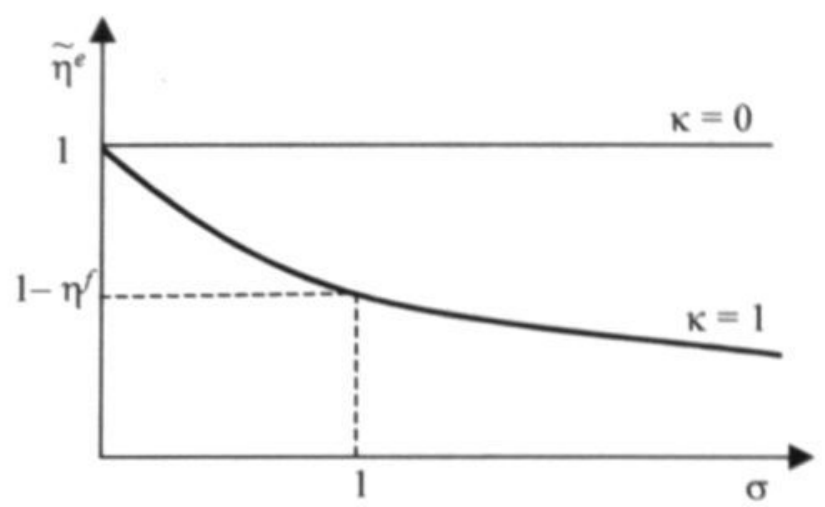

Figure 2.3 Second-order condition hours elasticity

The firm chooses the number of workers $N$ and their hours of work $H^{\mathrm{d}}$ in order to equate the ratio of marginal productivities to the ratio of marginal costs. ${ }^{9}$

In short-hand the hours equation can be rewritten as $\eta^{e}=\left(1-\varphi_{V}\right)\left(1-\eta^{\prime}\right) /\left[1-(1-\kappa) \eta^{\prime}\right]$. Using (2.9) it is obvious that unit costs are minimised at hours demand $H^{d}$. Moreover, it is easily checked that $0<\eta^{e} \leq 1-\varphi_{V}<1$ in the optimum and hence $H_{p}<H^{d}<H_{\max }$ as predicted earlier.

The second-order condition can be expressed as $\tilde{\eta}^{e}<\eta_{H}$, where

$$
\tilde{\eta}^{e} \equiv \frac{\eta^{e}}{1+\gamma_{H}} \leq \eta^{e} \text { and } \eta_{H} \equiv \frac{\left[1-(1-\kappa) \eta^{f}\right]\left(1-\eta^{f}\right)}{\left[1-(1-\kappa) \eta^{f}\right]^{2}-(1-\sigma) \kappa^{2} \eta^{f}} \text {. }
$$

The adjusted elasticity of efficiency hours with respect to hours $\tilde{\eta}^{e}$ takes into account that the elasticity of efficiency hours $\eta^{e}$ varies with the level of working time $\left(\gamma_{H}>0\right)$. The second-order condition sets an upperbound $\eta_{H}$ to the (adjusted) elasticity of efficiency hours. This upperbound is a decreasing function of the elasticity of substitution $\sigma$, as is illustrated for $\kappa=1$ in Figure 2.3. Consider, for example, a Cobb-Douglas production function $(\sigma=1)$, let efficiency hours be such that $\eta^{e}$ is constant and let $K=1$. The second-order condition then implies that the elasticity of output with respect to hours is smaller than the elasticity of output with respect to the number of workers. This is the usual condition, see Hart (1987). However, in case of lower substitution possibilities $(\sigma<$ 1), $\eta^{e}$ may be higher. This could reconcile the empirical observation of many studies, see the surveys by Contensou and Vranceanu (2000), Hamermesh (1993) or Hart (1987), that returns to hours are

9 Strictly speaking both the left-hand side and the right-hand side should be multiplied by $N$, for this interpretation to be valid. 


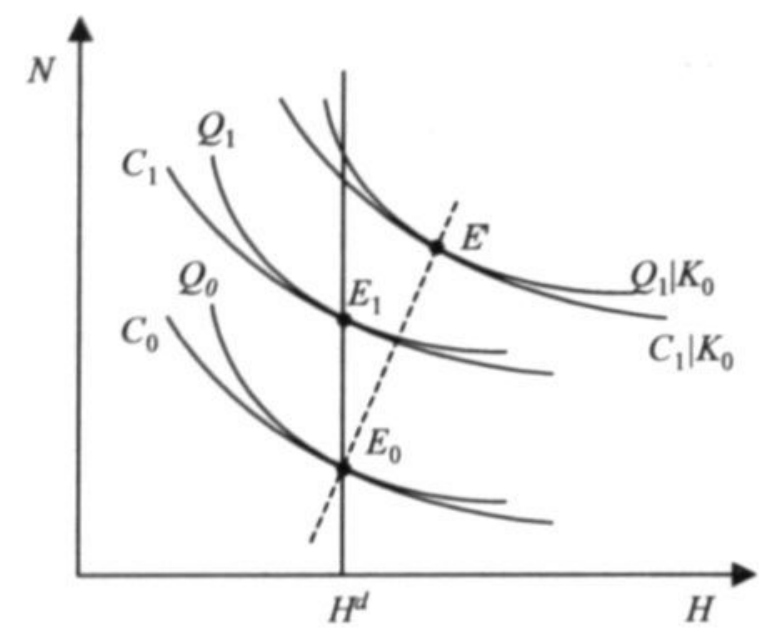

Figure 2.4 Workers versus hours

larger than the returns to workers, with the theoretical requirements. However, even in the limiting case of fixed factor proportions, $\sigma=0$, the (adjusted) hours elasticity may not exceed one.

The first-order condition (2.10) adds a substitution effect within labour services to the model. Figure 2.4 provides a graphical illustration, the original equilibrium being $E_{0}$. It is fairly standard, except for the fact that both the isocost line $C_{0}$ and isoquant $Q_{0}$ are convex curves. The secondorder condition guarantees that the isoquant is more convex than the isocost line.

As argued by Ehrenberg (1971), it seems plausible to assume that hours are invariant to scale in the long run. Figure 2.4 also illustrates the impact of an exogenous increase in output from $Q_{0}$ to $Q_{1}$. This shifts the isoquant outwards. In Appendix $\mathrm{A}$ it is shown that hours are indeed invariant to output in the long run, the new equilibrium being $E_{1}$, implying a vertical expansion path. However, the capital stock increases along this expansion path, say from $K_{0}$ to $K_{1}$. Conditional on the old capital stock $K_{0}$, the new solution would be something like $E^{\prime}$, where both employment and hours worked increase. ${ }^{10}$

In the labour services model $(\kappa=0)$, the long-run invariance to scale of working time even holds in the short run. This is easily seen setting $K=0$ in (2.10), yielding

$$
\frac{e^{\prime}(H)}{e(H)}=\frac{W}{V+W H},
$$

10 The impact on working time $H$ depends crucially on the elasticity of substitution $\sigma$, as $\varepsilon_{H Q X} \gtrless 0$ for $\sigma \lessgtr 1$. 
or $\eta^{e}=1-\varphi_{r}$. As a consequence working time only depends positively on $V / W$ and is independent of the capital stock. Hence short-run and long-run demand hours are the same and hours are always independent of output. This rather implausible result stresses the importance of incorporating working time in capital services.

Ehrenberg (1971)also showed in his labour services model that, within the class of mulplicative separable labour services functions, hours are invariant to output if and only if labour services can be written as $L=N^{\mu} \mathrm{e}(H)$. This condition is no longer sufficient in a model where hours are allowed to influence capital services. It can be shown, however, that within the class of multiplicative separable labour and capital services functions, hours are invariant to scale in the long run if and only if labour and capital services can be written as $L=N^{\mu} e(H)$ and $M=K^{\mu} m(H){ }^{11}$ These conditions are satisfied (with $\mu=1$ ) in the production function (2.5).

Having determined that optimal hours are independent of scale in the long run, consider the properties with respect to the factor costs. As usual in factor demand analysis, hours demand is linear homogeneous in all factor prices. Hence the demand function can be written as

$$
H^{t}=H(V / W, R / W) \text {. }
$$

The comparative statics are derived in Appendix A, differentiating the first-order equations (2.7) and (2.10). The partial derivatives satisfy

$$
\frac{\partial H^{d}}{\partial(V / W)}>0 \text { and } \frac{\partial H^{d}}{\partial(R / W)} \lessgtr 0 \text { for } \sigma \gtrless 1 .
$$

The first term is rather obvious as an increase in non-wage labour costs makes the isocost curves flatter in Figure 2.4. This entails a substitution effect towards longer hours.

The impact of an increase in the user cost of capital $R$ on hours worked is ambiguous, however. In the labour services specification $(\kappa=0)$ capital costs don't matter, recall equation $\left(2.10^{\prime}\right)$. In more general specifications the impact depends on the size of the substitution elasticity $\sigma$. As Winston and McCoy (1974, p. 424) argue:

If the elasticity [of substitution] is less than one ... it pays to economize on capital stock by using it more of the time. More specifically, a higher relative capital price increases the importance in costs - the relative share - of capital, thereby increasing the incentive for high capital utilization... If the elasticity is greater than one ... it pays to economize

11 An even more general statement is that long-run hours are invariant to scale if the generalized production function $Q=G(K, N, H)$ is homogeneous of an arbitrary degree $\mu$ in the capital stock $K$ and employment $N$. In that case the production function can be written as $Q=N^{\mu} G(K / N, 1, H)$ 
on labor (as the now-larger share of costs) even though it means using the capital stock less of the time.

Almost all of the empirical evidence, see e.g., Hamermesh (1993, Ch. 3), suggests that $\sigma \leq 1 .{ }^{12} \mathrm{For}$ the Netherlands, recent evidence suggests that $\sigma$ is rather low, see Broer, Draper et al. (1999). So the expected impact is positive. In terms of Figure 2.4, the labour for capital substitution induced by an increase in $R$ tends to make the isoquants steeper (as long as $\sigma<1$ and $\mathrm{K}>0$ ), leading to substitution within labour services towards longer working times.

The impact of hourly wages $W$ on the long-run demand for hours combines the two effects above: substitution within labour services and substitution between capital and labour for $K>0$. As long as $\sigma<1$ both effects tend to reduce the demand for hours. So working time is negatively related to hourly wages for any reasonable value of $\sigma .{ }^{13}$ Moreover, using the first-order condition (2.10), $\lim _{W_{10}} \eta^{e}=0$ and hence $\lim _{W_{0} 0} H^{t}=H_{\max }$. Figure 2.6, see p. 34 below, illustrates these properties. Hours demand is decreasing in the hourly wage, but will always be between $H_{p}$ and $H_{\max }$.

To illustrate the long-run demand for hours, consider the CES production function $f(k)=$ $\left(a_{K}{ }^{1+\rho} k^{-\rho}+a_{N}{ }^{1+\rho}\right)^{-1 / p}$, where $\rho=(1-\sigma) / \sigma$. Moreover let efficiency hours be given by $e(H)=$ $(H-S)^{\gamma}$, where $S \geq 0$ represents non-productive start-up time. Combining the first-order conditions (2.7) and (2.10) gives the following implicit equation for hours

$$
\gamma\left[a_{N}(V+W H)+\kappa a_{K} R^{1-\sigma}(V+W H)^{\sigma}(H-S)^{\gamma(1-\kappa)(1-\sigma)}\right]=a_{N} W(H-S) .
$$

Unfortunately this equation cannot be solved analytically, except for a few specific parameter constellations. For the limiting case of a Cobb-Douglas production function $(\sigma=1)$, the demand for hours is given by the familiar

$$
H^{d}=\frac{\alpha W S+\gamma V}{(\alpha-\gamma) W}
$$

where $\alpha \equiv a_{N} /\left(a_{N}+\kappa a_{K}\right) \leq 1$. The same expression follows for the traditional labour services specification ( $\kappa=0$, implying $\alpha=1$ ). With fixed factor proportions $(\sigma=0)$ and no differences between efficiency operating time and efficiency hours $(\kappa=1)$ hours demand is given by

12 However, see Caballero and Hammour (1999) for a different opinion. Using a putty-clay approach they argue that the value of the substitution elasticity could well be about 4 .

13 The substitution within labour services dominates as long as $\sigma<\sigma_{V} \equiv 1+\frac{\varphi_{V}}{1-\varphi_{V}} \frac{1-(1-\kappa) \eta^{f}}{\kappa \eta^{f}}$. 


$$
H^{d}=\frac{\alpha W S+\alpha \gamma V+(1-\alpha) \gamma R}{\alpha(1-\gamma) W} .
$$

Finally, the model can also be solved explicitly for $V=S=0$ (at least if $\sigma \neq 1$ and $\kappa \neq 0$ ) yielding

$$
H^{d}=\left(\left[\frac{(1-\alpha) \gamma}{\alpha(1-\gamma)}\right]^{1 /(1-\sigma)} \frac{R}{W}\right)^{1 /[1-\gamma(1-\mathrm{\kappa})]}
$$

These examples illustrate that the long-run demand for hours $H^{d}$ is increasing in quasi-fixed labour $\operatorname{costs} V$, decreasing in hourly wages $W$ and most likely increasing in user cost of capital $R$.

\subsection{Profit MAXIMISATION}

Hours demand establishes a benchmark for the impact of reduced working time on unit $\operatorname{costs} c$. Since $H^{d}$ is determined as to minimise costs, equations (2.9) and (2.10) imply that $\varepsilon_{c h} \gtrless 0$ for $H \gtrless$ $H^{d}$. Hence an exogenous reduction in working time increases unit costs if hours fall below hours demand. The possible impact of a reduction of working time on unit costs, may trigger a scale effect in a profit maximising framework. In this section I will establish the size of this effect, assuming that the output market is characterized by monopolistic competition.

The downward sloping demand curve for firm $i$ is given by the constant elasticity specification

$$
Q_{i}=\left(P_{i} / P\right)^{-\tau} D, \quad \tau>1
$$

where $P_{i}$ is the price set by the $i$-th firm, $P$ is the average price in the market and $D$ is a demand shift variable, which may depend on the average price $P$. Substituting out the firm-specific price $P_{i}$ using (2.13), the profit of a typical firm can be written as

$$
\Pi_{i}=P D^{1-v} Q^{v}-(V+W H) N-R K
$$

The parameter $0<\boldsymbol{v} \equiv 1-1 / \tau<1$ is positively related to competitiveness of the output market. Perfect competition corresponds to the limiting case $v=1$, and for lower values the firm specific demand curve becomes steeper.

As the qualitative results for short-run and long-run profit maximisation are similar, I will concentrate on the latter and discuss the short-run results in footnotes. 
Maximising profit (2.14) with respect to the capital stock $K$ and the number of workers $N$, using the production function (2.5), gives the first-order conditions

$$
\begin{gathered}
v P D^{1-v} e(H)^{v+k-1} N^{v-1} f(k)^{v-1} f^{\prime}(k)=R, \\
v P D^{1-v} e(H)^{v} N^{v-1} f(k)^{v-1}\left[f(k)-k f^{\prime}(k)\right]=V+W H .
\end{gathered}
$$

The left-hand sides correspond to the marginal revenue product of capital and workers, respectively. The second-order condition is satisfied for $\sigma>0$ and $v<1$. Dividing (2.15) and (2.16) gives the first-order condition (2.7) of the long-run cost minimisation problem. The comparative static results are derived in Appendix A.

The long-run remuneration elasticity of worker demand is given by

$$
\varepsilon_{N Y}=-\left(1-\varphi_{V}\right)\left[\tau\left(1-\eta^{\prime}\right)+\sigma \eta^{f}\right]<0 \text {. }
$$

An increase in remuneration obviously reduces the demand for workers. Because of the negative

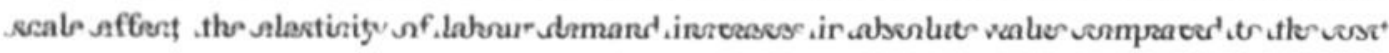
minimisation case $\left(\boldsymbol{\varepsilon}_{N Y}<\boldsymbol{\varepsilon}_{N \eta Q}<0\right)$. The first term in the right-hand side of $\boldsymbol{\varepsilon}_{N Y}$ measures the impact of remuneration on labour costs; labour costs increase less then proportionally through the existence of quasi-fixed $\operatorname{costs} V$. The second term between brackets measures the elasticity of labour demand with respect to labour costs. As usual in Marshallian rules of factor demand, it consists of a scale $(\tau)$ and a substitution effect $(\sigma)$.

The downward sloping labour demand function is depicted in the north-east and south-west panels of Figure 2.5. The figure uses small letters to denote natural logarithms of the corresponding variables. The north-east panel uses remuneration $Y$ as the relevant labour cost variable. The southeast panel is the employment identity, and the south-west panel depicts once again labour demand, but now in terms of hourly wages $W$. As working time is given exogenously, this makes no difference for labour demand. The north-west panel of the figure links remuneration to hourly wages. In log's this corresponds to $45^{\circ}$-line, where the intercept on the $y$-axis corresponds to the log of hours $h$. The higher curve in the north-west quadrant thus corresponds to longer hours. Using hourly wages and remuneration in one graph, provides the opportunity to compare two extreme cases of working time reduction: with full wage compensation, thus constant remuneration $Y$, and with constant hourly wage $W$.

Given the use of logarithms, the slope of the labour demand curve is the reciprocal of the elasticity $\varepsilon_{N r}$. The logarithmic labour demand curve is concave in Figure 2.5. This is because the absolute value of the labour demand elasticity $\varepsilon_{N Y}$ increases with the level of remuneration $Y$. The reason is twofold: first, with higher remuneration the share of quasi-fixed costs in labour $\operatorname{costs} \varphi_{v}$ falls; second, higher remuneration changes the optimal share of labour costs in total 


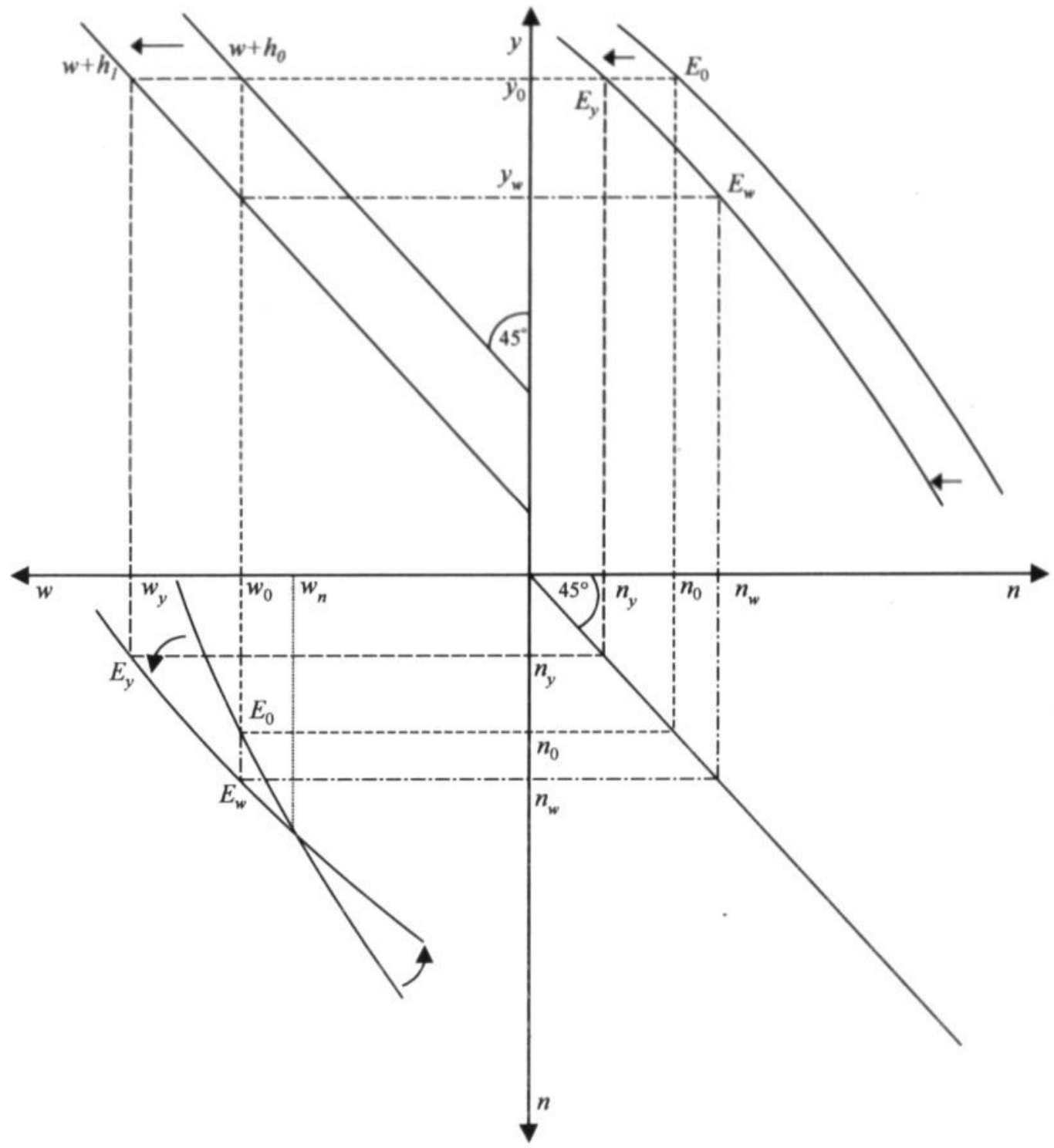

Figure 2.5 Labour demand and reduced hours 
costs. The sign of the latter effect depends on the size of the elasticity of substitution $\sigma$. This is best illustrated assuming that the substitution elasticity is constant. ${ }^{14}$ The relative change in the labour demand elasticity is then given by

$$
\gamma_{N} \equiv \frac{Y}{\varepsilon_{N Y}} \frac{d \varepsilon_{N Y}}{d Y}=\varphi_{V}+\left(1-\varphi_{V}\right) \frac{(1-\sigma)(\tau-\sigma) \eta^{f}\left(1-\eta^{\gamma}\right)}{\tau\left(1-\eta^{f}\right)+\sigma \eta^{f}}
$$

Considering $\sigma \leq 1$, both terms are positive and $0<\varphi_{V} \leq \gamma_{N}<1 .{ }^{15}$ Accordingly, the logarithmic labour demand function is concave to the origin. This is also true for the short-run labour demand curve. $^{16}$

Next, consider the impact of a working time reduction on labour demand. Due to the inclusion of efficiency hours and their impact on capital services, I am able to get more specific results than Calmfors (1985), who basically assumes that employment will increase at constant hourly wages. The present model allows me to derive the condition for this to be true. Moreover, the model allows for a neat decomposition into a productivity effect (at given remuneration) and a cost effect (at given efficiency hours).

At given remuneration $Y$, a reduction in working time is similar to technological regress. With imperfect competition on the goods market, this leads to a negative scale effect on output. So in terms of the earlier Figure 2.2, the profit maximising isoquant shifts downward, reducing the impact on the number of workers. It is easy to derive from equations (2.7) and (2.16) that the corresponding labour demand elasticity with respect to hours is given by ${ }^{17}$

$$
\varepsilon_{N H Y}=\eta^{e}\left[(\tau-1)-(1+\kappa)(\tau-\sigma) \eta^{f}\right] .
$$

14 Strictly speaking, this only holds for CES instantaneous production functions. For the more general case, I need to impose restrictions on $f^{\prime \prime \prime}(k)$ to derive definite results on the concavity of the logarithmic labour demand function.

15 Proof: For $\sigma \in(0,1]$, we have $\partial \gamma_{N} / \partial \sigma<0$. As $\gamma_{\text {No-0 }}=\varphi_{V}+\left(1-\varphi_{V}\right) \eta^{\prime}<1$ and $\gamma_{\text {Mo-1 }}=\varphi_{V}>0$, this implies $\gamma_{N} \in\left[\varphi_{n}, 1\right)$.

16 For the short-run labour demand, at given capital stock $K$, the conditional labour demand elasticity is given by $\varepsilon_{N Y K}=-\left(1-\varphi_{V}\right) \frac{\tau \sigma}{\tau \eta^{f}+\sigma\left(1-\eta^{\gamma}\right)}$. Hence $\varepsilon_{N Y}<\varepsilon_{N Y K}<0$. The relative change in this elasticity is given by $\gamma_{M K K} \equiv \varphi_{V}-\varepsilon_{N \eta K} \frac{(1-\sigma)(\tau-\sigma) \eta^{f}\left(1-\eta^{f}\right)}{\left[\tau \eta^{f}+\sigma\left(1-\eta^{f}\right)\right] \sigma}>0$. As a consequence, the logarithmic short-run labour demand function is also concave.

17 In the short-run model, with capital fixed, the elasticity is $\varepsilon_{N H Y K}=\eta^{e} \frac{(\tau-1) \sigma-(1-\kappa)(\tau-\sigma) \eta^{f}}{\tau \eta^{f}+\sigma\left(1-\eta^{f}\right)}$, yielding similar qualitative results. 
This is the productivity effect. When efficiency hours affect capital services and labour services in the same way, so for $\mathrm{K}=1$, a reduction in working time at given remuneration is tantamount to neutra! technical regress, reducing labour de.nand. The north-east panel of Figure 2.5 illustrates: the loge hmic labour demand curve in the upper-right panel shifts inward, but keeps the same slope. ${ }^{18}$ So at remuneration $y_{0}$, a working time reduction reduces the number of workers from $n_{0}$ to $n_{y}$. As the elasticity of efficiency hours $\eta^{e}$ is decreasing in working time, the productivity effect is larger for shorter hours. Moreover, the impact is also larger in more competitive goods markets ( $\tau$ large).

When labour services are affected more than capital services $(\kappa<1)$, as for example in the labour services model in the bulk of the literature $(K=0)$, a labour using bias is added - compare panel (b) of Figure 2.2 - working in the opposite direction. As long as goods demand is sufficiently elastic $\left(\tau>\tau_{0} \equiv \frac{1-\sigma \eta^{f}}{1-\eta^{f}} \geq 1\right)$ the productivity effect still reduces labour del. nd. But for rather inelastic demand curves ( $\tau<\tau_{0}$ ) the labour using bias dominates if (and only if) $\kappa<\kappa_{0} \equiv$ $\frac{\left(\tau_{0}-\tau\right)\left(1-\eta^{f}\right)}{(\tau-\sigma) \eta^{f}}<1 / \tau<1$. So in the labour services specification, the labour using bias could, in principle, dominate. However, for reasonable parameter values it seems most likely that the productivity effect reduces labour demand. ${ }^{19}$ In terms of the north-east panel of Figure 2.5 , the labour using bias implies that the labour demand curve still shifts in, but less, and also becomes more elastic. $^{20}$

At given hourly wages, the impact of reduced hours on labour demand is ambiguous. First, we have the technical regress effect as above, but second, total remuneration falls, increasing labour demand. This cost effect corresponds to a move along the new labour demand curve in the northeast panel of Figure 2.5, for example from $E_{y}$ to $E_{w}$. Calmfors (1985) assumes that employment will increase at constant hourly wages, as for example in $n_{w}$, but in general the impact is ambiguous; whether employment increases or falls depends on the length of working time. More specifically, the productivity effect dominates for short working times and the cost effect for long working times.

This can be shown as follows. The net elasticity of working time on labour demand at given hourly wages is given by $\varepsilon_{N H}=\varepsilon_{N H Y}+\varepsilon_{N Y}$, which cannot be signed a priori as both terms are of opposite sign. ${ }^{21}$ Hovever, this net elasticity is negatively related to working time, see Appendix $\mathrm{B}$ for

18 For $\kappa=1$ the labour demand elasticity $\varepsilon_{N Y}$ only depends on hours $H$ through its impact on remuneration $Y$.

19 For example, let $\eta^{\prime}=0.3$ and $\sigma=0.25$, then $\tau_{0} \approx 1.32$, which is rather low for a firm specific goods demand elasticity. For higher values of the substitution elasticity $\sigma$ or wer values of the capital share $\eta^{f}, \tau_{0}$ is even lower.

20 The change in the labour demand elasticity is $\left.\frac{\partial \varepsilon_{N Y}}{\partial \ln H}\right|_{Y}=(1-\kappa)\left(1-\varphi_{V}\right)(1-\sigma)(\tau-\sigma) \eta^{f}\left(1-\eta^{f}\right) \eta^{e}$ $\geq 0$. As $\varepsilon_{N Y}$ is negative, working time reduction makes labour demand more elastic.

21 Except for the unlikely case that $\tau<\tau_{0}$ and $0 \leq \kappa<\kappa_{0}$, where the productivity and the cost effect both lead to higher demand for labour. 


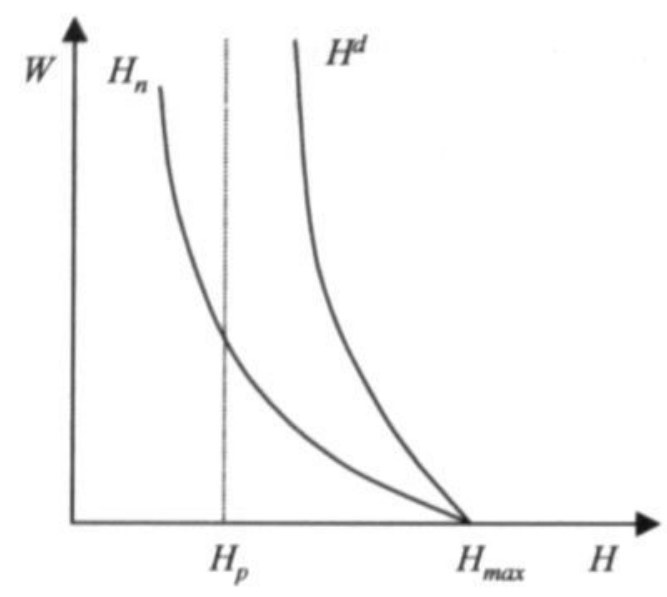

Figure 2.6 Hours demand

details. Define $H_{n}$ as the working time where, given the hourly wage, the demand for workers is maximised. So the critical level of hours $H_{n}$ is defined implicitly by $\varepsilon_{N H}=0$. As $\partial \varepsilon_{N H} / \partial H<0$, then $\boldsymbol{\varepsilon}_{N H} \gtrless 0$ for $H \lessgtr H_{n}$. In words, employment is positively (negatively) related to hours worked for

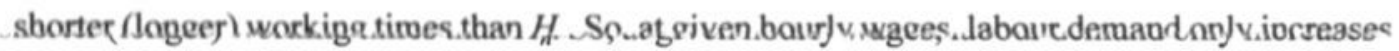
with a working time reduction, if hours are not too short.

Appendix B investigates the properties of critical hours $H_{n}$. First, one can show that $H_{n}<H^{d}$, so in the neighbourhood of hours demand a working time reduction leads to higher demand for workers. Second, $H_{n}$ increases with the demand elasticity $\tau$, so the critical level of hours increases with competitiveness. Third, $H_{n}$ depends on the hourly wage rate. The sign of this effect depends on the parameter $\kappa$. As long as the labour using bias is not too strong ( $\kappa \geq 1 / \tau$ or $\sigma=1$ ), $H_{n}$ is downward sloping in terms of the wage rate $W$, as is illustrated in Figure 2.6. ${ }^{22}$ The graph also illustrates that $H_{n}$ typically falls below $H_{p}$ for sufficiently high hourly wages.

As long as $H_{n}$ is negatively related to the hourly wage rate, the condition $\boldsymbol{\varepsilon}_{N H} \gtrless 0$ can also be formulated as $W \lessgtr W_{n}$. In other words, working time reduction increases labour demand at given hourly wages only if hourly wages are high enough. The intuition for this result is that for low wages the quasi-fixed labour costs become the bulk of labour costs. A reduction in working time still reduces productivity, and thus employment, but labour costs are no longer sufficiently lowered to compensate for this. This can also be seen from the south-west panel of Figure 2.5; working time reduction rotates the labour demand curve around the critical hourly wage $W_{n}$, becoming less elastic. For higher wages employment is increased, for lower wages employment will fall. Notice that the

22 If the labour using bias is stronger $(0 \leq \kappa<1 / \tau$ and $\sigma<1), H_{n}$ is no longer monotonous in $W$ : it is decreasing for low wages and increasing for high wages. 


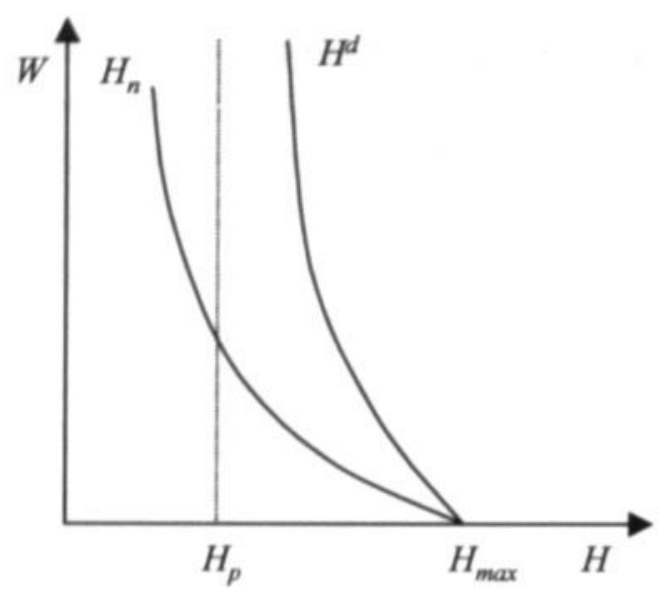

Figure 2.6 Hours demand

details. Define $H_{n}$ as the working time where, given the hourly wage, the demand for workers is maximised. So the critical level of hours $H_{n}$ is defined implicitly by $\varepsilon_{N H}=0$. As $\partial \varepsilon_{N H} / \partial H<0$, then $\boldsymbol{\varepsilon}_{N H} \gtrless 0$ for $H \lessgtr H_{n}$. In words, employment is positively (negatively) related to hours worked for

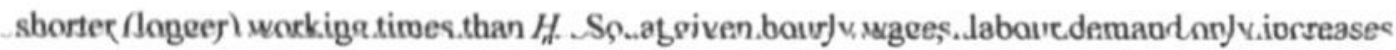
with a working time reduction, if hours are not too short.

Appendix B investigates the properties of critical hours $H_{n}$. First, one can show that $H_{n}<H^{d}$, so in the neighbourhood of hours demand a working time reduction leads to higher demand for workers. Second, $H_{n}$ increases with the demand elasticity $\tau$, so the critical level of hours increases with competitiveness. Third, $H_{n}$ depends on the hourly wage rate. The sign of this effect depends on the parameter $\kappa$. As long as the labour using bias is not too strong $(\kappa \geq 1 / \tau$ or $\sigma=1), H_{n}$ is downward sloping in terms of the wage rate $W$, as is illustrated in Figure $2.6 .^{22}$ The graph also illustrates that $H_{n}$ typically falls below $H_{p}$ for sufficiently high hourly wages.

As long as $H_{n}$ is negatively related to the hourly wage rate, the condition $\boldsymbol{\varepsilon}_{N H} \gtrless 0$ can also be formulated as $W \lessgtr W_{n}$. In other words, working time reduction increases labour demand at given hourly wages only if hourly wages are high enough. The intuition for this result is that for low wages the quasi-fixed labour costs become the bulk of labour costs. A reduction in working time still reduces productivity, and thus employment, but labour costs are no longer sufficiently lowered to compensate for this. This can also be seen from the south-west panel of Figure 2.5; working time reduction rotates the labour demand curve around the critical hourly wage $W_{n}$, becoming less elastic. For higher wages employment is increased, for lower wages employment will fall. Notice that the

22 If the labour using bias is stronger $(0 \leq \kappa<1 / \tau$ and $\sigma<1), H_{n}$ is no longer monotonous in $W$ : it is decreasing for low wages and increasing for high wages. 


\subsection{A NUMERICAL EXAMPLE}

To illustrate the working of the model, this section provides a brief numerical illustration of the main effects of a work-sharing policy in the labour demand models. I use a rather crude calibration of the parameters of the model.

For $\eta$, which corresponds to the share of capital costs in total costs, I took 0.3 , as in Pissarides (1998). Hart (1984a) documents that the share of quasi-fixed costs in labour costs $\varphi_{v}$ is nonnegligible. In line with Hart and Kawasaki (1988), I set $\varphi_{v}=0.2$. As suggested before, the evidence indicates that the substitution elasticity between capital and labour $\sigma$ is below one, so I adopted $\sigma=$ 0.5. This is higher than the recently found low estimate of Broer, Draper et al. (1999) for the Dutch economy. Estimates of the elasticity of output with respect to hours are rather imprecise, see Contensou and Vranceanu (2000, Ch. 4), Freeman (1998) and Hamermesh (1993), but the empirical results seem to indicate that returns to hours exceed returns to workers. DeBeaumont and Singell (1999) suggest, however, that this finding is due to aggregation bias, and they provide evidence that return to hours may be lower than returns to workers. As a benchmark, I assume that the hours elasticity in the production function is equal to the worker elasticity. Hence $\eta^{\prime}=$ $\left(1-\eta^{\prime}\right) /\left[1-(1-\kappa) \eta^{\prime}\right]$ and the value of $\eta^{e}$ depends on $\kappa$. For this parameter, I use two distinct alternatives: $\boldsymbol{K}=0$ corresponds to the traditional labour services specification; $\boldsymbol{K}=1$ corresponds the specification used in most of the other chapters. Incorporating the impact hours on capital services, Shepard and Clifton (2000) find that a $10 \%$ increase in overtime hours decreases hourly productivity in the 2 to 4 per cent range. The value $\eta^{e}=0.7$ for $\kappa=1$, implies $30 \%$ productivity gains, corresponding with the middle of this interval. For the firm specific elasticity of goods demand $\tau$, I used 5.0 as the benchmark. For the corresponding market demand elasticity $\eta$ I used the lower value of 1.5 These last two values are within the range adopted by Bovenberg, Graafland et al. (2000) in their applied general equilibrium model for the Netherlands.

Table 2.1 gives the implied working time elasticities. First, consider the cost minimisation case. An exogenous reduction of working time leads to an increase in employment (i.e. the number of workers) and in the capital stock. The impact on employment is larger than on the capital stock, due to the implied reduction in wage costs, as was illustrated in Figure 2.2. For the labour services model $(\kappa=0)$, the impact on employment is larger and almost proportional to working time, whereas capital remains almost constant. Notice, however, that unit costs increase in any case. This is due to the choices of the hours elasticity $\eta^{e}$, which imply that $H<H^{d}$ and firms would like to have longer hours. ${ }^{23}$ As firms tend to oppose working time reductions, this seems a rather natural situation to consider.

23 The parameter values imply $\eta \oint_{H=H^{d}}=0.56<0.7$ for $\mathrm{K}=1$ or $\eta \oint_{H=H^{d}}=0.8<1$ for $\mathrm{K}=0$. 


\section{Table 2.1 Numerical working time elasticities}

\begin{tabular}{|c|c|c|c|c|c|c|c|c|c|c|c|c|c|c|c|c|}
\hline \multicolumn{2}{|c|}{ Parameters } & \multicolumn{3}{|c|}{ Cost minimisation } & \multicolumn{3}{|c|}{$\begin{array}{l}\text { Short-run profit } \\
\text { maximisation }\end{array}$} & \multicolumn{6}{|c|}{ Long-run profit maximisation } & \multicolumn{3}{|c|}{ Partial equilibrium } \\
\hline$\kappa$ & $\eta$ & $\varepsilon_{\sin }$ & $\varepsilon_{\mathrm{es}}$ & 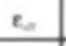 & $\varepsilon_{\operatorname{sen} x}$ & $\varepsilon_{\operatorname{mex}}$ & $\varepsilon_{\text {ens }}$ & $\varepsilon_{\text {mox }}$ & $\varepsilon_{n}$ & $\varepsilon_{-\infty}$ & $\varepsilon_{\text {cour }}$ & $\varepsilon_{v}$ & $\varepsilon_{\mathrm{er}}$ & $c_{m}$ & $\varepsilon_{8,}$ & 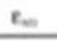 \\
\hline 0 & 1 & 0.97 & 0.07 & 0.14 & 0.35 & 108 & 0.73 & 265 & 2.92 & 0.27 & 3.15 & 2.52 & 063 & 0.20 & 0.96 & 0.76 \\
\hline 1 & 0.7 & 0.82 & 0.42 & -0.14 & 0.76 & 108 & 0.32 & 280 & 292 & 0.12 & 280 & 2.52 & 0.28 & 0.35 & 0.96 & 0.61 \\
\hline
\end{tabular}

Other parameter values: $\eta^{\prime}=0.3, \sigma=0.5, \varphi_{V}=0.2, \tau=5$ and $\eta=1.5$.

Next consider the profit maximisation case. Besides the long-run results discussed in Section 2.5, the table also includes short-run numerical elasticities at given capital stock. The productivity effect $\varepsilon_{N H Y}$ of reduced working time reduces employment, but as was to be expected less in the short run and also less in the labour services model (due to labour using bias). At the same time the productivity effect reduces the capital stock in the long run, the most in the labour services model (again due to the labour using bias).

The labour demand elasticities $\boldsymbol{\varepsilon}_{N Y}$ are rather high, compared to the range of empirical estimates in Hamermesh (1993). This is due to the choice of $\tau$, leading to rather large scale effects. The same parameter also implies that the mark-up of prices over marginal (and average) costs is 1.25 , which is rather high compared to observed profit rates. To reduce this mark-up, $\tau$ should be increased, but this would further increase the absolute value of the labour demand elasticities. Notice, however, that the partial equilibrium labour demand elasticity is more in line with the empirical estimates. As most of these estimated elasticities are based on industry or more aggregated data, thus including the partial equilibrium effects of Section 2.6, this supports the numerical calibration.

Combining the productivity and cost effects, the latter dominates, leading to an increase in employment at given hourly wage rate. This is again due to the choices of the $\eta^{e}$ elasticity, which also imply that $H>H_{n}{ }^{24}$ In all cases labour demand increases less than proportionally, so workerhours decrease. The capital stock also declines. In the partial equilibrium the scale effect is much less dominant, as all competitors face the same increase in unit costs. Nevertheless, the increase in employment remains less than proportional compared to the reduction in working time.

24 The parameter values imply $\eta \oint_{H_{n} H_{*}}=0.73>0.7$ for $\mathrm{K}=1$ or $\eta \oint_{H_{n} H_{*}}=1.10>1$ for $\mathrm{K}=0$. 
Comparing the labour services specification $K=0$ with $K=1$, the impact of working time reduction on employment is smaller in the latter case. This is due to the larger productivity effect, as capital services are reduced in line with labour services.

\subsection{Conclusion}

One of the key determinants of the impact of work-sharing policies on employment, is the direct impact on the number of workers. This has been the main focus of this chapter. In most of the existing literature, the focus is on so-called labour services models, where hours worked influence labour services, but not capital services. I have argued that these models may be misspecified: in the absence of shiftwork, the operating time of capital and working time of workers are clearly linked. Therefore, I have allowed for such a link in my labour demand model. Except for the Cobb-Douglas case, it matters a lot in theoretical work whether hours worked are allowed to influence capital services or not. The numerical calibration, suggests, however, that the impact on the corresponding elasticities may be rather small.

The impact of hours worked on capital services reduces the scope for work-sharing policies, as productivity is more adversely affected. Nevertheless, the chapter shows that there is a critical working time above which work-sharing policies tend to increase the number of workers employed. This critical level typically depends negatively on the hourly wage rate. It then becomes an empirical question whether reduced working times increase employment. Reviewing the experience of the last 15 years, Bosch and Lehndorff (2001) conclude that there is a broad range of results, but that most studies confirm that working time reductions can be expected to have positive employment effects.

This chapter ignores a number of issues that will be taken up in the subsequent chapters. First, although I discussed the long-run demand for hours, I did not incorporate the possibility of overtime hours in the model. Overtime hours will be dealt with in Chapter 3. Second, reductions in working hours may lead firms to introduce shiftwork or to change the number of shifts. This will be covered in Chapter 4 . Third, the current chapter takes the hourly wage rate as given. This assumption will be dropped in Chapter 5. Finally, the normal level of working time was exogenously given. Chapter 6 will elaborate on the determination of working hours. 


\section{Overtime}

\subsection{INTRODUCTION}

In the previous chapter, working time was considered to be given for the firm. In practice this is not the case. Standard hours may be fixed by collective labour contracts, but the firm may use overtime to differentiate actual hours from standard hours. Indeed most indicators suggest that on average overtime is used. Hence, for an adequate analysis of the impact of a reduction in standard hours on employment, it is important to incorporate the possible effects on both the extensive margin - the number of workers - and the intensive margin - actual hours per worker. This has been done a number of times in the literature, see e.g., Calmfors and Hoel (1988), Hart (1984b) or Hunt (1999). The general conclusion is that, given that overtime is actually worked, a reduction in standard hours tends to increase actual hours. The reason simply is that a reduction in standard hours does not affect the marginal cost of (overtime) hours, but increases wage costs per employee, as more hours have to be remunerated with an overtime premium. This leads to a substitution of more hours for workers and reduces the potential of work-sharing policies.

The available empirical evidence on the impact of standard hours on actual hours seems to indicate, however, that actual hours follow standard hours fairly closely. For the UK Hart and Sharot (1978) found an elasticity of actual hours with respect to contractual hours of 0.92 . More recently, Kalwij and Gregory (2000) also have found an elasticity close to one for Britain. Using German micro-data Hunt (1999) has estimated the elasticity to be between 0.88 and 1.14 . In a time series analysis, de Regt (1988) found an elasticity of 0.89 for the Dutch manufacturing sector. Thus, actual hours seem to move (almost) proportionally with standard working time. This is illustrated in Figure 3.1 for the Dutch manufacturing sector and confirmed by the empirical results of this chapter.

The conclusion must be that the available empirical evidence contradicts the above mentioned basic theoretical predictions. The challenge for this chapter is to reconcile the theory with observed stylised facts. Besides a measurement problem, the main argument will be that although we typically observe overtime, this is not due to a structural cost minimising choice. It is the uncertain environment which leads firms to the use of overtime. The main sources of uncertainty considered, are stochastic demand shocks and fluctuations in absenteeism. Contrary to the claim by Ehrenberg (1970), it is the stochastic nature of absenteeism (and demand) that leads to increased overtime. 


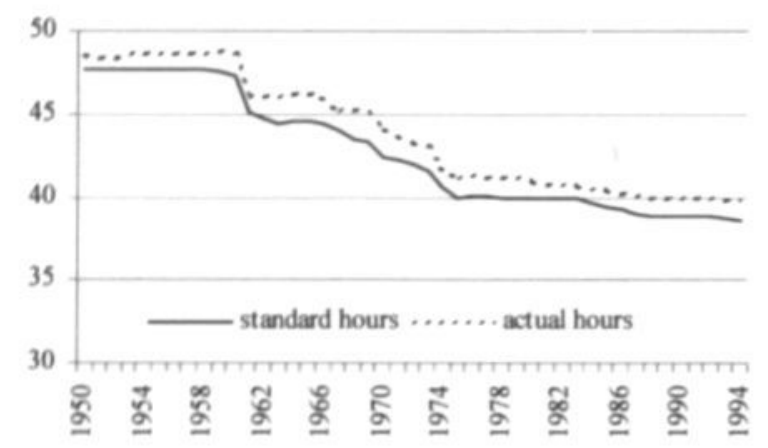

Figure 3.1 Weekly hours Dutch manufacturing

The chapter is set up as follows. In Section $3.2 \mathrm{I}$ briefly illustrate the main characteristics of Dutch overtime. Section 3.3 presents the basic model under certainty. It is an extension of the standard models to include absenteeism. The impact of the two sources of uncertainty is modelled in Section 3.4. Section 3.5 then presents a time series analysis of Dutch manufacturing overtime. I conclude with a few remarks in Section 3.6.

\subsection{OVERTIME IN THE NETHERLANDS}

Figure 3.1 illustrates that for Dutch manufacturing, actual hours follow standard working time quite closely. In the long run they appear to be proportional. The figure also illustrates that in the Netherlands, average overtime is rather low. Since the late seventies, weekly overtime is just above one hour per week. Moreover, overtime incidence is rather low. Although there are no time series available, Table 3.1 gives some recent data. Overtime incidence is only about $10 \%$ in the Netherlands. This is lower than the $20 \%$ in 1993 for Germany or for the UK recently reported by Bell, Hart et al. (2000). Overtime incidence in the Netherlands is concentrated among male full-time workers. It is the highest in the manufacturing sector and especially in transport. Table 3.2 gives the overtime hours worked for the same years as in Table 3.1. Except for transportation, average overtime for all workers is about 1 hour per week, but those working overtime tend to work about 5 hours overtime per week. This is about the same number as for Germany, but in the UK overtime workers tend to work almost 10 hours of overtime per week, see Bell, Hart et al. (2000). Only in the Dutch transport sector overtime hours are of the same order of magnitude.

All in all, these observations suggest that overtime is not a major structural phenomenon in the Dutch labour market, except perhaps for a few sectors such as transportation. 
Table 3.1 Overtime incidence ( $\%$ of workers)

\begin{tabular}{rrrr}
\hline & 1995 & 1996 & 1997 \\
\hline Total & 10.4 & 9.7 & 9.7
\end{tabular}

by gender

$\begin{array}{lrrr}\text { Male } & 13.9 & 13.0 & 13.1 \\ \text { Female } & 5.1 & 4.7 & 4.8\end{array}$

by contract

$\begin{array}{lrrr}\text { Full-time } & 13.9 & 13.2 & 13.4 \\ \text { Part-time } & 4.8 & 4.5 & 4.5 \\ \text { Flexible } & 3.6 & 3.5 & 3.6\end{array}$

by sector "

\begin{tabular}{llll} 
Manufacturing & 19.5 & 18.5 & 19.3 \\
Transport & 39.2 & 37.2 & 35.2 \\
\hline
\end{tabular}

Source: CBS, Sociaal-economische maandstatistiek, various issues

a Manufacturing corresponds to SBI'93 sectors 15-37 and transport to sector 60 .

Table 3.2 Overtime hours full-time workers

\begin{tabular}{|c|c|c|c|c|c|c|}
\hline & \multicolumn{2}{|c|}{1995} & \multicolumn{2}{|c|}{1996} & \multicolumn{2}{|c|}{1997} \\
\hline & $\begin{array}{c}\text { All } \\
\text { workers }\end{array}$ & $\begin{array}{l}\text { Overtime } \\
\text { workers }\end{array}$ & $\begin{array}{c}\text { All } \\
\text { workers }\end{array}$ & $\begin{array}{c}\text { Overtime } \\
\text { workers }\end{array}$ & $\begin{array}{c}\text { All } \\
\text { workers }\end{array}$ & $\begin{array}{c}\text { Overtime } \\
\text { workers }\end{array}$ \\
\hline All & 0.8 & 5.7 & 0.7 & 5.3 & 0.7 & 5.2 \\
\hline \multicolumn{7}{|l|}{ by sector } \\
\hline Manufacturing & 0.9 & 4.6 & 0.9 & 4.9 & 0.9 & 4.7 \\
\hline Transport & 5.1 & 13.0 & 5.4 & 14.5 & 5.3 & 14.5 \\
\hline
\end{tabular}

Source: Calculated from CBS, Sociaal-economische maandstatistiek, various issues 
Figure 3.2 looks at the cyclical properties of overtime in manufacturing. The first scatter-diagram illustrates that relative overtime, i.e. weekly overtime divided by standard hours, is positively correlated to the utilisation rate. Indeed the corresponding correlation coefficient is 0.74 . The second diagram uses the vacancy duration in months as an indicator of labour market tightness. ' Again, there appears to be a positive correlation, the partial correlation coefficient being 0.67 . Notice, however, that with 0.61 the correlation coefficient between the utilisation rate and vacancy duration is also rather high. The last diagram correlates relative overtime with absenteeism. There is no clear correlation and the correlation coefficient is small but negative $(-0.21)$. Although not shown, changes in relative overtime seem to be positively correlated with changes in absenteeism ( 0.45$)$.

The bottom line is that there is an important cyclical component in overtime hours. This is even more obvious in Figure 3.3, which presents the time series of relative overtime and the utilisation rate of Dutch manufacturing. Upturns, peaks and downturns of both series correspond rather well, but the troughs of relative overtime are less clear-cut, especially in the deep recessions after the first oil crisis. This can be corrected by subtracting observed short-time hours from reported overtime hours, see the dotied line. ${ }^{2}$ The aim of the Dutch short-time working scheme is to enable firms with temporary economic problems to maintain their work force, while their employees get partial unemployment benefits. The regulation concerning short-time is rather strict, however, see Delsen and Jacobs (1999). On average over the period 1960-1994, weekly short-time hours per operative in manufacturing amounted only about 0.07 hour (thus less then 5 minutes), ${ }^{3}$ whereas on average 1.25 overtime hours were used. ${ }^{4}$ During the deep recessions after the oil shocks, short-time became much more important, however, with a maximum of 0.56 hour per week in 1975 . Since the second half of the eighties, the quantitative impact of short-time is again negligible.

The discussion on short-time reveals the importance of measurement issues for overtime. As already suggested by Fair (1969) and Mendis and Muellbauer (1984), observed overtime is likely to overstate actual hours worked. The basic idea is that observed hours typically correspond

1 Using the vacancy rate yields a rather similar picture, but there seems to be no correlation when I use the unemployment rate. This difference can probably be explained by the well-known shifts in the Beveridge curve in the seventies and the eighties. So overtime behaviour seems more related to labour demand than to labour supply.

2 Figure 3.2 also uses the overtime hours corrected for short-time.

3 Excluding the peak years of 1967, 1974-1978 and 1981-1983, where short-time per operative exceeds 0.1 hour per week, the average is about 1 minute per week.

4 As for overtime, it would be interesting to distinguish between the incidence of short-time and the reduced hours per short-time worker. This is beyond the scope of the present chapter, however. 

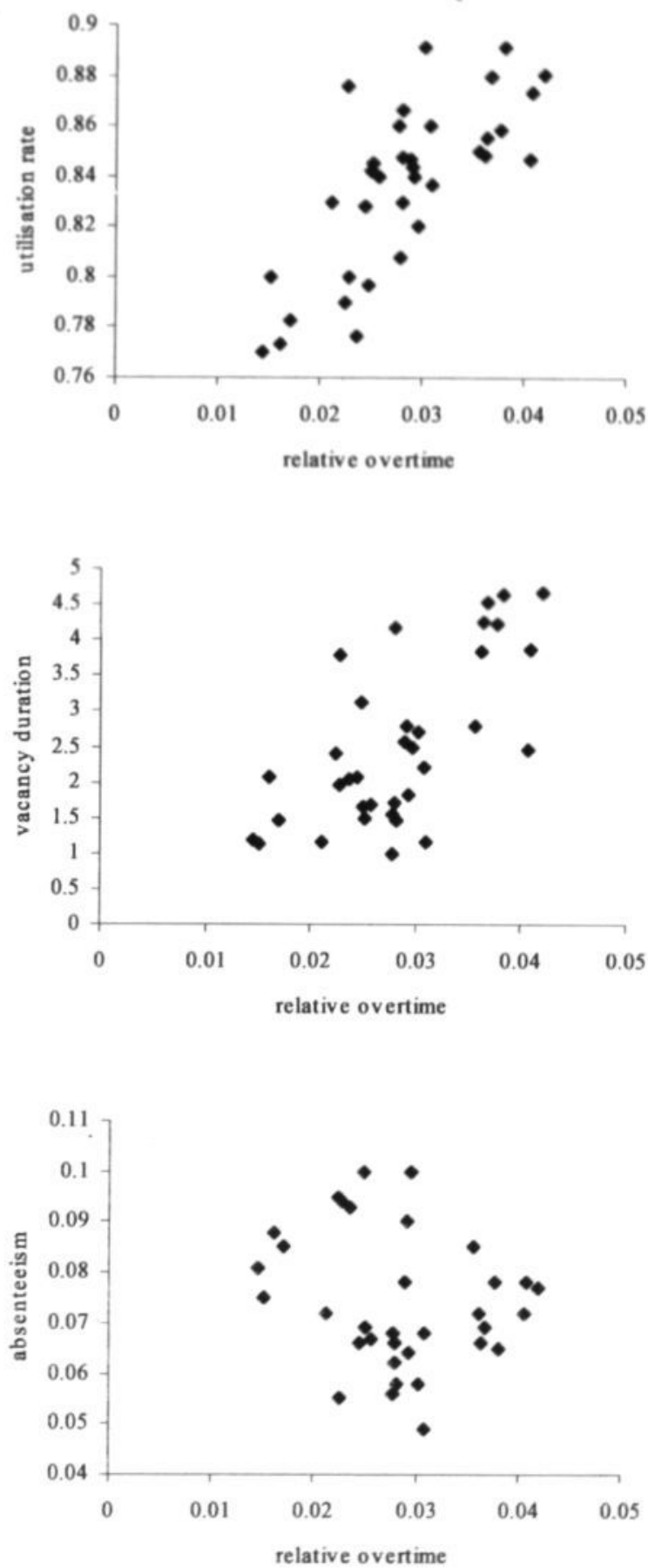

Figure 3.2 Overtime and cyclical indicators

(Dutch manufacturing) 


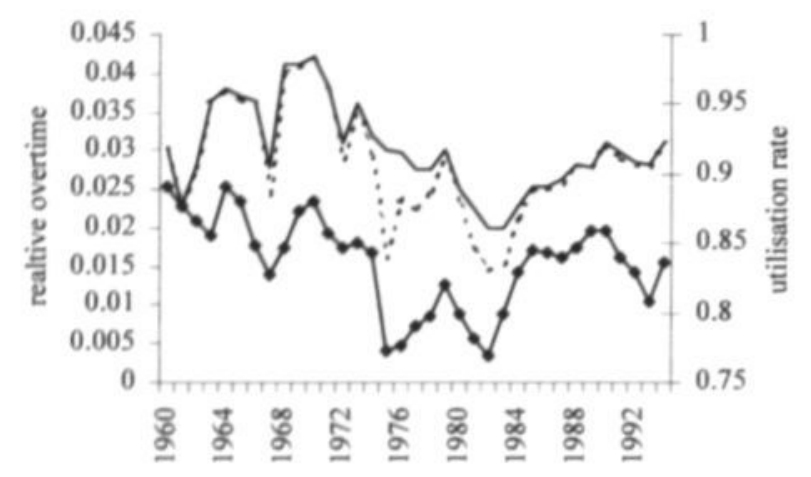

rel. overtime

utilisation rate

Figure 3.3 Overtime, short-time and utilisation rate

to paid hours, and most overtime hours are paid. ${ }^{5}$ But typically no corresponding information is available for undertime - actual hours below normal hours - since most workers still get paid for their standard week. Short-time is the exception, as firms have to register in order to be eligible. Due to the strict eligibility conditions, see Delsen and Jacobs (1999), short-time is likely to underestimate actual undertime.

To cope with the measurement problem of overtime hours, Mendis and Muellbauer (1984) use the so-called 'aggregation by integration' approach, as used in the aggregate disequilibrium models of Kooiman (1986), Lambert (1988), Sneessens (1983) and others. Assuming undertime is not observed and assuming that relative overtime hours in firms follow a Student $t$-distribution, Mendis and Muellbauer (1984) argue that the aggregate actual relative hours $\tilde{H}$ and observed relative hours $\hat{H}$ are related as

$$
\tilde{H}=\hat{H}-\xi /(\hat{H}-1)<\hat{H}, \quad \xi>0
$$

where $\xi$ reflects the spread of the distribution of relative overtime hours. Estimating British production functions, they find $\xi=0.016$. This estimate implies that if actual hours correspond to standard hours $(\tilde{H}=1)$, we still would observe a significant amount of overtime $(\hat{H}=1.126$, which corresponds to 5 hours overtime for a normal week of 40 hours). Remember, however, that British observed overtime is much larger than in the Netherlands.

An alternative specification uses the more common CES approximation of Lambert (1988) and Sneessens (1983). Although the CES-function is typically used as an approximation of the minimum

5 Bell, Hart et al. (2000) stress the role of unpaid overtime, however. 
of two variables, Appendix $\mathrm{C}$ shows that it is also applicable for the maximum of two variables. Assuming again that observed hours correspond to the maximum of actual and standard hours and assuming that relative hours are lognormally distributed with standard deviation $\sigma$, the aggregate observed relative hours are given by

$$
\hat{H}=\left(1+\tilde{H}^{1 / \xi}\right)^{\xi}>\tilde{H} . \quad 0<\xi<1
$$

For small values of $\sigma$, the parameter $\xi$ roughly corresponds to $0.6 \sigma$. To mimic the example of 5 hours observed overtime in equilibrium, $\xi$ should be 0.17 , implying a rather large standard deviation of $\sigma=0.29$ for relative hours.

In Dutch manufacturing, the average observed relative overtime for the period 1960-1994 was only 0.03 . This would correspond to zero actual overtime hours for $\xi=0.043$ or $\sigma=0.07$. Although I am not aware of any evidence in this respect, this standard deviation does not seem unreasonably high. So even if small amounts of overtime are observed, this could be attributed to measurement errors, as undertime is typically not reported (paid hours often corresponding to standard hours in such cases). Hence one should be careful with predictions based on models assuming that overtime is a structural phenomenon.

\subsection{OVERTIME AND ABSENTEEISM}

Ignoring the measurement issues, this section develops a model which allows for the possibility of structural overtime. The model serves as a benchmark for further discussion. There are two lines of research that are combined in my model. First, there are papers that focus on the employment effects of work-sharing policies if overtime is allowed for, as in Calmfors and Hoel (1988), Hart (1984b) or Hunt (1999). Second, Ehrenberg (1970) is the classic reference for the impact of absenteeism on overtime. ${ }^{6}$ Although their focus is different, the basic set-up of these models is rather similar. Overtime is determined by firms to minimise costs and workers are always prepared to work overtime.

Compared to the first class of models, the main contribution of this section is to include absenteeism in the analysis. Moreover, I take a long-run perspective, allowing the capital stock to adjust. This is also the main difference with Ehrenberg (1970). Such a long-run perspective may seem odd in an analysis of overtime, but the model presented here is one of structural overtime, typically based on relative cost considerations. The next section will introduce short-run demand fluctuations.

6 Brown and Sessions (1996) provide a survey of the economics of absenteeism, most of which is related to labour supply considerations. 
Chapter 2 stressed the importance of incorporating the impact of hours worked on capital services. Calmfors and Hoel (1988) is one of the few papers analysing overtime that includes this possibility. Nevertheless, they keep the capital stock fixed. As a consequence optimal working time is no longer independent of scale, but varies with output. ${ }^{7}$ To focus on the structural determinants I take a long-run perspective in this section and allow the capital stock to adjust. As a consequence optimal hours are independent of scale, which allows me to consider a cost minimising framework. ${ }^{8}$

\subsubsection{The model}

The production function is a variant of the production function of Chapter 2. First of all, I confine myself to the case where capital services and labour services are affected in the same manner by the duration of operations. ${ }^{9}$ Second, following Hart and McGregor (1988), I allow for a distinction between normal and actual hours in efficiency hours. The idea is that overtime hours may be more or less productive than normal hours. A temporary increase in hours worked - more overtime - may have different effects on hourly productivity than a permanent reduction in normal hours. An increase in overtime may, for example, induce workers to provide more effort. ${ }^{10}$ Alternatively, workers may have different work attitudes towards standard hours and non-standard hours. To incorporate this, efficiency hours are modelled as $e\left(H^{c}\right) \tilde{H}^{\gamma}$, where $H^{c}$ is the exogenous standard working time, $H$ is actual hours worked and $\tilde{H} \equiv H / H^{c}$ denotes relative hours. This specification may be viewed as a $\log$-linear Taylor approximation of efficiency hours $e(H)$ around normal hours $H^{c}$. In that case the parameter $\gamma$ corresponds to the elasticity of efficiency hours at standard hours $\eta^{e}$, and may vary with the length of the standard workweek. Figure 3.4 illustrates this interpretation, where an increase in overtime is more productive than the same increase in standard hours.

Although the previous section illustrates that it is important to distinguish between overtime incidence and overtime hours per operative, this is beyond the scope of this chapter. Kalwij and Gregory (2000) and Trejo (1993) include this distinction in their empirical analysis, but I am not aware of any theoretical model dealing with this distinction. Therefore, I follow the literature

7 See also Chapter 2, the exception is a Cobb-Douglas production function.

8 See also Chapter 2, the exception is a Cobb-Douglas production function.

9 So $K=1$ in terms of Chapter 2.

10 Recently, Basu, Frernald et al. (2001) and Galeotti, Maccini et al. (2002) have used observed hours to eliminate unobservable effort from their model. Following Basu and Kimball (1997), they used the insight that a cost minimising firm operates on all margins simultaneously, implying a positive relationship between the observable hours and unobservable utilisation variables such as effort. As a result, the observed elasticity also captures variations in effort. 


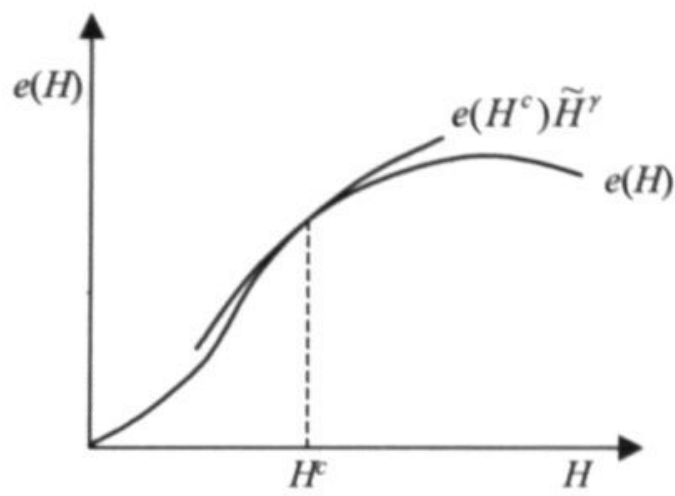

\section{Figure 3.4 Overtime and efficiency hours}

assuming that all workers work the same number of hours. " However, for exogenous reasons such as illness some workers may be absent. Only a fraction $A$ of the workforce $N$ is available for the productive process. Finally, I allow for teamwork effects in the specification of labour services. The key characteristic of teamwork is that the productivity of a worker is enhanced by the working hours of its colleagues, see Alchian and Demsetz (1972). I analyse the corresponding labour services function in Appendix D. Teamwork effects lead to increasing returns of attendance $A .^{12}$

Combining all this, the production function is given by

$$
Q=A^{1 / \tau} N f(k) e\left(H^{\tau}\right) \tilde{H}^{\gamma}, \quad 0<\tau \leq 1,0<\gamma<1
$$

where $Q$ is output, $N$ is the number of workers, $k \equiv K / N$ is the capital-labour ratio, $K$ is the capital stock and $0<A \leq 1$ is the exogenous attendance rate of the workers. Combining capital $K$ and labour $N$, the instantaneous output is $f(k)$ per worker. This function $f(k)$ summarises the technology in terms of the stocks: it has positive but decreasing marginal productivities, so $f^{\prime \prime}(k)<0<f^{\prime}(k)<$ $f(k) / k$, and the corresponding substitution elasticity between capital and labour $\sigma$ is assumed not to exceed one.

Output also depends on the duration of operations and attendance of the workers. The first aspect is captured by efficiency hours $e\left(H^{c}\right) \tilde{H}^{\gamma}$, whereas the second is incorporated by the term

11 In simple models with homogeneous workers this also appears to be the optimal strategy for firms: teamwork effects and increasing overtime premiums provide an incentive to spread overtime hours over the workforce. If workers have heterogenous preferences an offsetting effect will be that overtime premiums also have to increase with overtime incidence, as more workers have to be lured into overtime.

12 Additionally, heterogeneity of hours worked by attending workers reduces labour services when teamwork is important. 
$A^{1 / \tau}$. The parameter $\tau$ captures teamwork effects: the lower this parameter, the more important teamwork is; teamwork is absent for $\tau=1$. Although in the long run output is proportional to the workforce, teamwork effects may lead to increasing returns of attendance $A$. Notice, however, that the production is of the putty-clay type, as the capital-labour ratio is fixed independent of the attendance rate. So absenteeism also leads to idle capital in the production function (3.3).

The cost structure generalises Calmfors and Hoel (1988) and Ehrenberg (1970), and is also an extension of Chapter 2. Total costs $C$ are given by

$$
C=\left[V+\rho W H^{\tau}(1-A)+A W H^{\tau} o(\tilde{H})\right] N+R K,
$$

with

$$
o(\tilde{H})=\tilde{H}, o(1)=1, o^{\prime}(\tilde{H})>0, o^{\prime}(\tilde{H}) \gtrless 1 \text { for } \tilde{H} \gtrless 1, o^{\prime \prime}(\tilde{H}) \geq 0,
$$

where $R$ is the given user cost of capital, $V$ are the quasi-fixed costs per worker, $W$ is the normal hourly wage cost and $\rho$ is the replacement rate for absent workers. The fixed costs per worker $V$ are independent of attendance and working time. Standard hours are paid according to the basic hourly wage rate $W$. Contrary to Ehrenberg (1970), absent workers get a fraction $\rho$ of the normal compensation $W H^{c}$. This reflects the Dutch institutions, where firms must continue to pay at least $70 \%$ of the salary of sick employees during the first year of sickness (and collective agreements may even stipulate payment of the full salary). These sickness benefits increase the fixed costs per worker.

The compensation schedule $o(\tilde{H})$ summarises the relation between relative hours worked and their remuneration. Deardorff and Stafford (1976) have shown that, if the compensation schedule is to compensate for the disutility of hours worked, the average wage rate should be roughly $\mathrm{U}$ shaped. This condition is met in (3.5), the minimum occurring at standard hours $H^{*}$. Their argument is essentially based on the assumption that the labour market can be characterised as a spot market, where firms always have to provide the outside reservation utility for their workers. The corresponding properties of the compensation schedule are derived in Appendix E: the compensation schedule should be increasing and convex in relative hours.

An alternative and perhaps more reasonable assumption might be that the labour market is characterised by implicit contracts. In Appendix E I also develop the implications of this assumption. Very definite results can not be obtained, although the slope of the compensation schedule is smaller in implicit contract models compared to the spot market model.

The compensation schedule may also reflect institutional aspects, as legislation in many countries imposes premium pay for overtime. These legislated overtime premiums are typically in the order of 25 to $50 \%$, see OECD (1998). The Netherlands is one of the few exceptions, with no legislated overtime premium. Some rough calculations based on observed overtime for Dutch manufacturing 


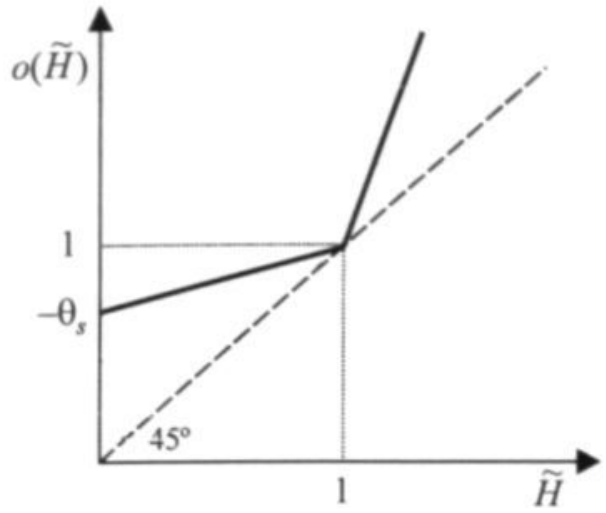

$$
-1<\theta_{s}<0<\theta_{o} ; \mu=0
$$

(a)

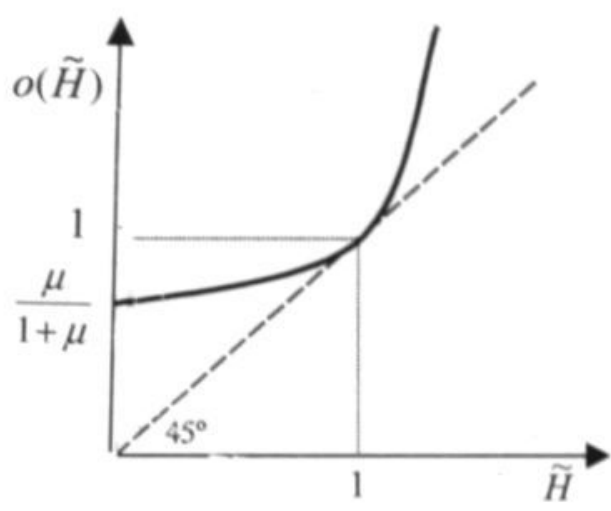

$\mu>0 ; \theta_{s}=\theta_{o}=0$

(b)

\section{Figure 3.5 Overtime schedule}

give an average overtime premium of 0.24 for the period 1985-1997. This is in line with the more elaborated estimates by Hart and Ruffell (1993) for the unregulated British industries. The existence of (legislated) overtime premiums suggests that the compensation schedule may be kinked at standard hours. As a consequence the compensation schedule $o(\tilde{H})$ may not be differentiable for $\tilde{H}$ $=1$, although it remains continuous.

To incorporate these various possibilities I use the following parameterisation of the compensation schedule (3.5)

$$
o(\tilde{H})=\frac{\tilde{H}^{1+\mu}+\mu}{1+\mu}+\max \left[\theta_{s} \frac{\tilde{H}^{1+\mu}-1}{1+\mu}, \theta_{o} \frac{\tilde{H}^{1+\mu}-1}{1+d}\right] . \quad-1 \leq \theta_{s} \leq 0 \leq \theta_{o}, \mu
$$

It encompasses a number of aliternative specifications. For $\mu=0$, it results in a piect-wise linear specification, where $\theta_{o}$ is the overtime premium and $\theta_{s}$ the undertime premium. When $\theta_{s}=0$, undertime payment per hour is just thie normal hourly wage, but when $\theta_{s}=-1$, undertime always leads to full payment of the normal nours. Figure 3.5, panel (a), illustrates the intermediate case, where $-1<\theta_{s}<0$. This could correspord, for example, to the short-time regime mentioned earlier, where firms may reduce their wage bill, although not proportionally.

Figure 3.5, panel (b), illustrates tht smooth case where $\mu>0=\theta_{o}=\theta_{s}$. Apart from the absence of the kink, it looks rather similar: undertime reduces the compensation, although less than proportional, and overtime commanc a a premium. An important difference, however, is that it leads 
to an increasing overtime premium. ${ }^{13}$ Hart and Ruffell (1993) and Hart, Malley et al. (1996) conclude that there is little empirical evidence for increasing overtime premiums as a function of overtime hours. Equation (3.6) combines both panels. Concentrating on overtime, Toedter (1988) for example, considered the case $\theta_{o}=\mu>0$.

Minimising the costs (3.4) at given output with respect to capital $K$, labour $N$ and (relative) hours $\tilde{H}$ gives the production constraint (3.3) and the first-order conditions

$$
\begin{gathered}
\frac{f^{\prime}(k)}{f(k)-k f^{\prime}(k)}=\frac{R}{V+\rho W H^{c}(1-A)+A W H^{c} o(\tilde{H})}, \\
\frac{\gamma f(k)}{f(k)-k f^{\prime}(k)}=\frac{A W H^{c} o^{\prime}(\tilde{H}) \tilde{H}}{V+\rho W H^{c}(1-A)+A W H^{c} o(\tilde{H})} \quad \text { for } \tilde{H} \neq 1, \\
\frac{\left(1+\theta_{\rho}\right) A W H^{c}}{V+\rho W H^{c}(1-A)+A W H^{c}} \leq \frac{\gamma f(k)}{f(k)-k f^{\prime}(k)} \leq \frac{\left(1+\theta_{o}\right) A W H^{c}}{V+\rho W H^{c}(1-A)+A W H^{c}} \text { for } \tilde{H}=1 .(
\end{gathered}
$$

Equation (3.7) equates the marginal rate of substitution between capital and labour to the ratio of their costs. Equation (3.8a) gives an interior solution for hours and basically equates the marginal rate of substitution between hours and workers to the ratio of their marginal costs, compare (2.10) in Chapter 2. Equation (3.8b) allows for a corner solution at standard hours, see Bodo and Giannini (1995) and Calmfors and Hoel (1988).

Let $\eta$ denote the elasticity of $f(k)$ with respect to $k$, then (3.7) implies that $\eta$ is also equal to the share of capital costs in total costs. Moreover, $1-\eta^{\prime}$ corresponds to the elasticity of output with respect to the number of workers. The second-order condition for an interior solution can now be written as

$$
\gamma<\gamma^{*} \equiv \frac{(1+\mu)\left(1-\eta^{\gamma}\right)}{1-(1-\sigma) \eta^{f}},
$$

see Appendix F. It restricts the elasticity of (relative) working time in the production function. For $\mu$ $=0$ it corresponds to the second-order condition for hours demand derived in Section 2.4. When the compensation schedule in strictly convex, $\mu>0$, the elasticity of efficiency hours may be larger, as the increase in productivity is offset by higher marginal costs.

13 The overtime premium $\Theta$ corresponds to $\boldsymbol{\Theta}=\frac{o(\tilde{H})-\tilde{H}}{\tilde{H}-1}$. 


\subsubsection{Interior solution}

First consider the interior solution given by (3.7) and (3.8a) for a given premium rate $\theta .{ }^{14}$ Jointly these equations determine the optimal capital-labour ratio and (relative) hours independent of output. There are basically three (sets of) determinants: first, $r \equiv R /\left(A W H^{*}\right)$ the capital costs relative to normal remuneration of attending workers; second, $v \equiv\left[V+\rho W H^{*}(1-A)\right] /\left(A W H^{*}\right)$ the total fixed costs per worker relative to normal remuneration of attending workers; and third, the parameters of the compensation schedule $\theta$ and $\mu$.

The comparative statics are derived in Appendix F. Focussing on relative working time, the solution is of the type

$$
\tilde{H}_{c}=h(v, r, \theta, \mu),
$$

where the subscript $c$ refers to the solution under certainty and where the signs of the partial derivatives are given below the variables. The impact of the first two variables is the same as for hours demand in Chapter 2 . As expected, fixed labour costs increase the demand for hours, see e.g. Hart (1984b). The impact of capital costs is due to the assumption that working hours also affect capital services, but the effect disappears for the Cobb-Douglas case. The premium $\theta$ reduces relative hours, as it increases the marginal costs of the intensive margin (hours) more than the marginal costs of the extensive margin (workers), see e.g. Calmfors and Hoel (1988) and Trejo (1993). Finally, the impact of $\mu$ depends on the size of relative hours: if overtime prevails, hours are reduced; but when undertime is relevant, hours worked increase. In both cases deviations from standard hours become more expensive.

Using the definitions of $v$ and $r$, the following results can be derived: $\partial \tilde{H} / \partial \rho>0, \partial \tilde{H} / \partial A<0$ and $\partial \tilde{H} / \partial H^{c}<0$. The sickness replacement rate $\rho$ adds to the fixed costs per worker and therefore increases hours. Increased attendance $A$, or in other words lower absenteeism, reduces hours. The impact occurs through a reduction of relative fixed costs $v$, as in Ehrenberg (1970), and a reduction in relative capital costs $r$. A reduction in standards hours $H^{c}$ operates through the same channels: as it reduces normal remuneration, $v$ and $r$ increase and as a consequence relative hours increase.

The impact of reduced standard hours on actual hours is less than proportional, as relative hours increase. In general the sign is ambiguous and depends on the parameter constellation, see Appendix F for details. For $\mu=\rho=0$ and $\theta=\theta_{o}>0$, as in Calmfors and Hoel (1988), Hart (1984b) or Hunt (1999), hours worked increase. A more convex compensation schedule, $\mu>0$ as in Toedter

14 This could be either $\theta_{o}$ or $\theta_{s}$, depending on the prevalent regime. The determination of the regime is discussed in the next sub-section. 
(1988), or a higher sickness replacement rate $\rho$, may lead to a reduction in hours per worker. ${ }^{15}$ For reasonable parameter values, however, the adverse effect through the overtime premium rate $\theta_{o}$ is most likely to dominate.

\subsubsection{Corner solution}

It remains to be determined under what conditions the interior solution (3.10) applies and when the corner solution $\tilde{H}=1$ is relevant. Define $\tilde{H}_{o}=h\left(v, r, \theta_{o}, \mu\right)$ and $\tilde{H}_{s}=h\left(v, r, \theta_{s}, \mu\right)$, as the solutions at given overtime and undertime premium, respectively. Then $\tilde{H}_{o}<\tilde{H}_{s}$ as $\partial \tilde{H} / \partial \theta<0$ and $\theta_{s}<\theta_{o}$. Moreover, $\tilde{H}_{o}\left(\tilde{H}_{s}\right)$ is only relevant as long as $\tilde{H}_{o}>1\left(\tilde{H}_{s}<1\right.$, respectively). This is most easily expressed in terms of the premium $\theta$. Let $\theta_{c}$ correspond to the virtual premium that equates actual and standard hours in (3.10), so $\theta_{c}$ is implicitly defined by $h\left(v, r, \theta_{c} \mu\right)=1$. As the righthand side of equation (3.8a) is zero for $\theta=-1$, the virtual premium $\theta_{c}$ exceeds -1 . Because relative hours are decreasing in the premium rate, overtime (undertime) is only relevant as long as $\theta_{o}$ $<\theta_{c}\left(\theta_{c}<\theta_{s}\right.$, respectively). ${ }^{16}$ For intermediate values of $\theta_{c}$, the corner solution $\tilde{H}=1$ applies. Figure 3.6 illustrates: the regime depends on the value of the virtual premium $\theta_{c}$, relative to the overtime and undertime premiums $\theta_{o}$ and $\theta_{s}$. Indeed, it is easily checked that the condition $\theta_{s} \leq \theta_{c}$ $\leq \theta_{o}$ corresponds to (3.8b). So the full solution for relative hours is given by the following equation

$$
\begin{aligned}
\tilde{H} & =\tilde{H}_{s}=h\left(v, r, \theta_{s}, \mu\right) & & \text { for } \theta_{c}<\theta_{s}, \\
& =1 & & \text { for } \theta_{s} \leq \theta_{c} \leq \theta_{0}, \\
& =\tilde{H}_{o}=h\left(v, r, \theta_{o}, \mu\right) & & \text { for } \theta_{0} \leq \theta_{c} .
\end{aligned}
$$

The likelihood of the corner solution thus depends on the spread of the overtime and undertime premiums. To get a rough idea of the size of $\theta_{c}$, use equation (3.8a). For $\theta=\theta_{c}$, the solution is $\tilde{H}=$ 1. Using the compensation schedule (3.6) and evaluating at $\tilde{H}=1$, condition (3.8a) can be written as $\gamma /\left(1-\eta^{\prime}\right)=\left(1+\theta_{c}\right) /(1+v)$. Using the parameter values of Chapter 2 , we roughly have $\gamma=1-\eta^{\prime}$ $\approx 0.7$ and $V /\left(W H^{*}\right) \approx 0.2 .{ }^{17}$ Dutch absenteeism is currently about $5 \%$, so $A=0.95$. The Dutch sickness replacement rate is at least $70 \%$, so $\rho=0.7$. These values give $\theta_{c}=0.25$, which is about the same as the mean overtime premium mentioned earlier. Small variations in the calibrated parameters may lead to $\theta_{c}<\theta_{o}$. Accordingly, the corner solution is not merely a curiosity, but may

15 Hours worked also fall for $\theta=\theta_{s}<0$, that is when undertime prevails.

16 For the overtime regime $\tilde{H}>1$, or $h\left(v, r, \theta_{o}, \mu\right)>1=h\left(v, r, \theta_{c}, \mu\right)$. As $\partial h / \partial \theta<0$, this implies $\theta_{o}$ $<\theta_{c}$.

17 In Chapter 2 the share of fixed labour costs in total labour costs $\varphi_{V}=V /\left(V+W H^{\star}\right)$ was calibrated at 0.2 , implying $V / W H=0.25$. If correctly measured, $\varphi_{V}$ includes payment for hours not worked, such as sickness. Accordingly, $V / W H^{\leftarrow}$ is set here at 0.2 . 


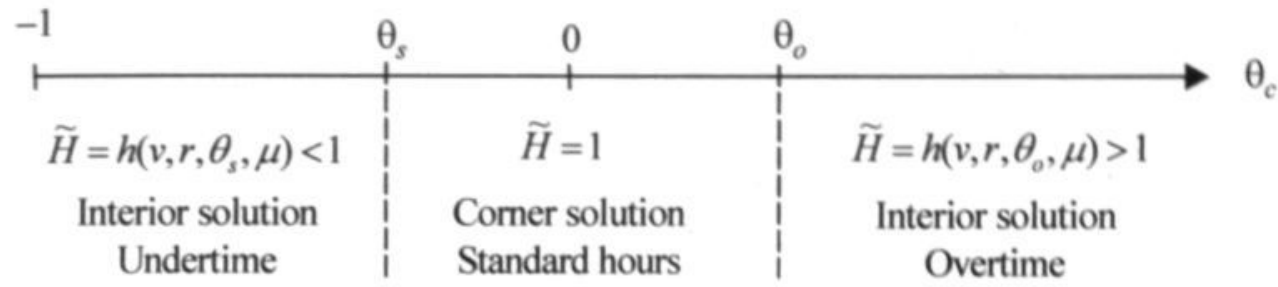

\section{Figure 3.6 Overtime premium and corner solution}

well be relevant for reasonable parameter values.

The virtual premium $\theta_{c}$ is positively related to $v$ and $r$. As a consequence, it depends negatively on standard hours $H^{\mp}$ and the attendance rate $A$. Thus reduced standard hours and higher absenteeism increase the likelihood of structural overtime.

\subsection{UNCERTAINTY}

Ehrenberg (1970, p. 357) concluded that "it is not always the stochastic nature of absenteeism which is responsible for increased overtime hours". In this section I come to a different conclusion, and I will show that stochastic demand and stochastic absenteeism can indeed lead to increased overtime per worker. This corrects two flaws in Ehrenberg's analysis: first, he looked at hours conditional upon average absenteeism; second, he ignored the possibility of undertime at low absenteeism rates.

The only difference with the previous section is that demand and attendance are assumed to be stochastic. Notice that Ehrenberg only considered the latter. Let $q>0$ denote the stochastic demand, with probability density function $g(q)$ and expected value $Q=E(q)$. Similarly, let $0<a \leq 1$ denote the random attendance rate, with probability density function $p(a)$ and expected value $A=$ $E(a)<1$. For simplicity, attendance and demand are assumed to be independently distributed.

The timing in this stochastic framework is as follows: the firm chooses the capital stock and the number of workers before the realisations are observed; then the realisations of the stochastic variables are observed and hours worked are to satisfy the production function. Accordingly, the corner solution of the certainty case is unlikely to be observed: even if firms would aim at normal hours on average, hours actually worked depend on the state of the world.

Using equation (3.3) hours worked are given by $q=a^{1 / \tau} N f(k) e\left(H^{\tau}\right) \tilde{H}^{\gamma}$. Define $y \equiv q a^{1 / \tau}$ and $y_{u} \equiv N f(k) e\left(H^{*}\right)$, then the production function can be written succinctly as

$$
y=y_{u} \tilde{H}^{\gamma} .
$$


The problem for the firm is to minimise its expected costs with respect to capital $K$ and labour $N$. Using the expression for the costs in (3.4) and using the definitions of $k$ and $y_{w}$ expected costs can be expressed as

$$
E(C)=\left[V+\rho W H^{*}(1-A)+W H^{*} E(a o(\tilde{H}))+R k\right] \frac{y_{u}}{f(k) e\left(H^{c}\right)} .
$$

Minimising with respect to the transformed variables $k$ and $y_{\llcorner}$the first-order conditions under uncertainty can be rearranged as

$$
\begin{aligned}
& \frac{f^{\prime}(k)}{f(k)-k f^{\prime}(k)}=\frac{R}{V+\rho W H^{c}(1-A)+W H^{c} E[a o(\tilde{H})]}, \\
& \frac{\gamma f(k)}{f(k)-k f^{\prime}(k)}=\frac{W H^{c} E\left[a o^{\prime}(\tilde{H}) \tilde{H}\right]}{V+\rho W H^{c}(1-A)+W H^{c} E[a o(\tilde{H})]} .
\end{aligned}
$$

The second-order condition is again $\gamma<\gamma^{*}$. The interpretation of (3.13) and (3.14) is similar to the first-order conditions (3.7) and (3.8a) under certainty: marginal rates of substitution are equated to the ratio of expected marginal costs. Equation (3.13) considers capital and labour, whereas (3.14) describes the choice between the intensive and extensive margins of labour.

In the next paragraphs I will argue that the solution for expected hours is given by

$$
E(\tilde{H})=\delta h\left(v+\Delta_{u}, r_{v} \theta_{u}, \mu\right) .
$$

The parameters $\theta_{u}, \Delta_{u}$ and $\delta$, identify the impact of uncertainty on expected relative hours.

In Appendix $\mathrm{F}$ it is shown that the expected values can be expressed as

$$
E[a o(\tilde{H})]=\frac{1+\theta_{u}}{1+\mu} E\left[a\left(y / y_{u}\right)^{(1+\mu) / \gamma}\right]+\frac{\mu-\theta_{u}}{1+\mu} A+\Delta_{u} A
$$

and

$$
E\left[a o^{\prime}(\tilde{H}) \tilde{H}\right]=\left(1+\theta_{\varkappa}\right) E\left[a\left(y / y_{u}\right)^{(1+\mu) / \gamma}\right],
$$

where $\Delta_{u} \geq 0$ and the virtual premium $\theta_{u}$ is a weighted average of the overtime and undertime premiums $\theta_{s}$ and $\theta_{o}$, satisfying $\theta_{s} \leq \theta_{u} \leq \theta_{o}$. Strict inequalities apply for $\theta_{s}<\theta_{o}$.

Given these expressions for the expectations, the first-order conditions (3.13) and (3.14) jointly determine $k$ and $y_{w}$. Using the compensation schedule (3.6) and comparing with the first-order 
conditions (3.7) and (3.8a) under certainty, the equations have the same structure, but with $\theta_{w}$ as the relevant premium, $\left\{E\left[a\left(y / y_{\nu}\right)^{(1+\mu) / \gamma}\right] / A\right\}^{1 /(1+\mu)}$ as the argument of the compensation schedule $o(\cdot)$ and $v+\Delta_{u}$ as the fixed costs per worker. As a consequence, the interior solution (3.10) of the certainty case can also be used to solve (3.13) and (3.14). More specifically, the solution is characterised by

$$
\left\{E\left[a\left(y / y_{u}\right)^{(1+\mu) / \gamma}\right] / A\right\}^{1 /(1+\mu)}=h\left(v+\Delta_{u}, r, \theta_{w}, \mu\right) .
$$

As $\theta_{u}$ and $\Delta_{u}$ depend on $y_{u}$, this is an implicit equation for $y_{w}$.

Using the production function (3.12) expected hours also depend on $y_{w}$ as $E(\tilde{H})=E\left[\left(y / y_{w}\right)^{1 / \gamma}\right]$. Ehrenberg (1970), on the other hand, considered the solution $\tilde{H}_{u}=\left[Q A^{-1 / \tau} / y_{u}\right]^{1 / \gamma}=\left[E(y) / y_{u}\right]^{1 / \gamma}$, i.e. hours worked conditional on the expected values. Due to the decreasing returns to hours $(\gamma<$ 1), $y^{1 / \gamma}$ is a convex function. Jensen's inequality then implies $E(\tilde{H})>\tilde{H}_{u}$, and Ehrenberg underestimated expected hours under uncertainty.

Combining the expression for expected hours with the implicit solution (3.18) for $y_{w}$ the solution under uncertainty can finally be written as equation (3.15), where ${ }^{18}$

$$
\delta \equiv \frac{A^{1 /(1+\mu)} E\left(y^{1 / \gamma}\right)}{E\left(a y^{(1+\mu) / \gamma}\right)^{1 /(1+\mu)}} .
$$

The parameters $\theta_{u}, \Delta_{u}$ and $\delta$, identify the impact of uncertainty on expected relative hours, but each is related to a different channel.

The virtual premium rate $\theta_{u}$ is due to the kink in the compensation schedule. Due to stochastic fluctuations in demand or attendance, sometimes overtime will prevail and sometimes undertime. As the undertime premium is lower than the overtime premium, the average premium is reduced to $\theta_{u}$. The result is an increase in relative hours.

The kink in the compensation schedule also leads to $\Delta_{u}>0$. The consequence is that, for a given premium rate $\theta_{w}$ the expected marginal costs of the extensive margin - the number of workers - is increased relative to the expected marginal costs of the intensive margin - the number of hours. This leads to a substitution effect towards more hours and less workers.

The two effects of the kink in the compensation schedule thus work in the same direction. In Appendix $\mathrm{F}$ it is shown that $\tilde{H}_{o} \leq h\left(v+\Delta_{w} r, \theta_{w}, \mu\right) \leq \tilde{H}_{s}$, so relative hours increase compared to

18 Evaluating at the expected values, as in Ehrenberg's analysis, the result would be $\tilde{H}_{u}=$ $\delta_{u} h\left(v+\Delta_{u}, r, \theta_{u}, \mu\right)$, with $\delta_{u} \equiv \frac{Q^{1 / \gamma} A^{-(1+\mu-\gamma \tau)[\gamma \tau(1+\mu)]}}{E\left(a y^{(1+\mu) \gamma}\right)^{1 /(1+\mu)}}<\min (1, \delta)$. 
the certainty overtime case $\tilde{H}_{o}$, but decrease relative to undertime $\tilde{H}_{s}$. These two effects are absent in Ehrenberg (1970), as he ignored the possibility of undertime, implicitly assuming $\theta_{s}=\theta_{o}>0$.

The parameter $\delta$ captures the effects of uncertainty that do not operate through the overtime premium. Demand uncertainty tends to reduce expected hours $(\delta \leq 1)$, at least when the compensation schedule is strictly convex $(\mu>0) .{ }^{19}$ To reduce the risk of increasingly high marginal overtime costs in a boom, employment is expanded beyond the certainty level. This reduces expected hours relative to the solution $h\left(v+\Delta_{v} r, \theta_{w}, \mu\right)$. However, as the empirical evidence in favour of an increasing overtime premium is thin, this effect is likely to be small.

Next, consider the impact of a stochastic attendance rate $a$, but a certain level of demand $q=Q$. This is the case considered by Ehrenberg (1970). Using Jensen's inequality twice, the result is $1<\delta$, see Appendix F. Beside the effect mentioned for demand uncertainty, there is another effect, as the attendance rate directly influences the relative marginal costs of the intensive and extensive margins. As elaborated in Ehrenberg (1970), the corresponding substitution effect increases the number of workers and reduces hours. Simultaneously, however, expected hours increase as they are a convex function of attendance, due to diminishing returns to hours and teamwork effects. The net effect is uncertain. Ehrenberg showed that the first effect dominates at expected attendance $\left(\delta_{w}<1\right)$. The results here illustrate that the latter effect dominates for expected hours $(\delta>1)$, however.

Summarising, random fluctuations in absenteeism (and demand) increase overtime above the certainty absentee level $\tilde{H}_{o}$. So if structural overtime is observed in the certainty case $\left(\theta_{c}>\theta_{o}\right)$, expected hours under random absenteeism will even be higher. If the corner solution without overtime prevails under certainty $\left(\theta_{s} \leq \theta_{c} \leq \theta_{o}\right)$, the comparison is less clear cut, however. There are opposing effects: through the impact of $\delta$ and $\Delta_{u}$ expected overtime increases, but the expected premium $\theta_{u}$ reduces expected overtime. As long as $\theta_{c} \geq \theta_{u}$ expected overtime is unambiguously positive, but for lower values of $\theta_{c}$ the impact is uncertain. This is also the case if structural undertime would prevail under certainty $\left(\theta_{c}<\theta_{s}\right)$ : the increase in premium from $\theta_{s}$ to $\theta_{u}$ reduces expected hours; this is partially compensated by the higher fixed costs $\Delta_{u}$; but again, $\delta$ increases expected hours. However, at expected demand and absenteeism hours worked decrease (as $\delta_{u}<$ 1).

\subsection{EMPIRICAL ANALYSIS}

To conclude, this section gives an empirical analysis of the determinants of observed relative hours in Dutch manufacturing. The annual data cover the period 1960-1994 and are the same as used in Figures 3.2 and 3.3. Details are provided in Appendix G.

19 Suppose, for example, that demand $q$ is lognormally distributed with variance $\sigma^{2}$. Then $\delta=$ $e^{-0.5 \mu \sigma^{2} / \gamma^{2}}$. 
The idea is to estimate a reduced form equation for relative hours. In such a reduced form, the estimated parameters cannot directly be linked to underlying structural parameters of, for example, the production function or the compensation schedule. Therefore, I do not use a non-linear method to correct for measurement errors in observed hours. ${ }^{20}$ Observed overtime data are corrected for short-time hours, however.

The models of the previous sections identify the main determinants of relative hours. The structural effects occur through $v, r$ and $\theta$. Beside absenteeism $z=1-A$ and standard hours $H$, quasi-fixed costs are the most important determinant of the relative labour $\cos t s v$. I experimented with three crude indicators. Surveys on the structure of labour costs provide information on the mark-up on hourly wages to arrive at total labour costs per hour. As this mark-up also includes social security premiums, I also used the mark-up elements related only to hours not worked. Finally, in the same line but from another source, I used the share of holidays in potential working days. Unfortunately, neither variable was found to have any significant impact on relative hours. ${ }^{21}$ To the best of my knowledge, there is no time series evidence available for the overtime premium. Probably it is best considered as being rather constant over time. Finally, to account for the variable $r$, I tried to include the price of investment goods, relative to the wage costs per worker, and the real interest rate, but without any success. So, given the usual difficulties in measuring user costs of capital, these variables were further ignored in the analysis.

The model under uncertainty stressed the role of fluctuations in demand and attendance. The first is captured by (variations in) the utilisation rate $Q$, the second by (variations in) the rate of absenteeism. As argued above, the latter may also capture structural effects.

From the interrelated factor demand literature, see Nadiri and Rosen (1969) and Hart and Sharot (1978), it is well known that hours may respond to slow adjustment of employment. To allow for such an effect, I tried to include a labour market tightness variable in the overtime equation. Figure 3.2 indeed showed a positive correlation between vacancy duration and relative hours. Although there was some weak evidence that vacancy rates or vacancy durations affect overtime, the effect was never significant. Apparently the correlation in Figure 3.2 is due to the cyclical behaviour of both variables, represented by the utilisation rate in the estimated equation.

20 However, if measurement errors are important as suggested in Section 3.2, the estimated elasticities underestimate the corresponding elasticities of actual hours.

21 In de Regt (1988) I found some influence for the total mark-up. The sign, however, varied according to the specification. 
Table 3.3 Unit root tests overtime equation, 1962-1994

\begin{tabular}{lllll}
\hline Variable $x$ & \multicolumn{4}{c}{ ADF $^{*}$} \\
\cline { 2 - 5 } & \multicolumn{3}{c}{$x$} & \multicolumn{2}{c}{$\Delta x$} \\
\hline$h$ & -0.63 & {$[\mathrm{t}, 0]$} & $-7.35^{* *}$ & {$[\mathrm{c}, 0]$} \\
$h^{*}$ & -0.60 & {$[\mathrm{t}, 0]$} & $-7.27 * *$ & {$[\mathrm{c}, 0]$} \\
$\hat{h}=h-h^{*}$ & -2.40 & {$[\mathrm{c}, 0]$} & $-6.92 * *$ & {$[\mathrm{n}, 0]$} \\
$q$ & -2.17 & {$[\mathrm{c}, 0]$} & $-4.76^{* *}$ & {$[\mathrm{n}, 0]$} \\
$z$ & -1.01 & {$[\mathrm{c}, 1]$} & $-3.75^{* *}$ & {$[\mathrm{n}, 2]$} \\
\hline
\end{tabular}

As Bodo and Giannini (1995) I used a log-linear specification, except for the rate of absenteeism $z$. As a consequence, the endogenous variable $\hat{h}$, using small letters to denote natural logarithms, is approximately equal to relative overtime. ${ }^{22}$ Therefore, I label it as an overtime equation.

To allow for dynamics and slow adjustment, first lag's of each variable were included. ${ }^{23}$ The resulting equation can be written as an error-correction specification, identifying the short-run dynamics and the long-run solution. Such an error-correction mechanism is only warranted if the variables are non-stationary and cointegrated, see Engle and Granger (1987). Table 3.3 gives the time series properties of the data, using augmented Dickey-Fuller tests. All variables appear to be non-stationary, including relative hours, the utilisation rate and absenteeism. First-differencing yields stationary variables, however, so the variables seem to be I(1).

To cope with the potential endogeneity of the current explanatory variables, the equation was estimated by instrumental variables. ${ }^{24}$ For the utilisation rate, it is clear that high overtime may lead to high measured utilisation. As variations in the utilisation rate are meant to capture demand fluctuations, the change in world trade is used as an instrument. For absenteeism, Brown and Sessions (1996) have documented that structural overtime may lead to increased absenteeism. Recently, Yaniv (1995) has incorporated this in a theoretical labour demand model via burn-out problems. To deal with potential endogeneity of the current increase in absenteeism, it is instrumented by its own lag.

$22 \mathrm{As}, \hat{h}=\ln H / H^{c}=\ln \left[1+\frac{\left(H-H^{9}\right)}{H^{c}}\right]=\frac{\left(H-H^{9}\right)}{H^{c}}$.

23 Second lag's were not significant, neither jointly nor separately.

24 The OLS estimates do not differ much, however. 
Table 3.4 presents the final estimation results. Insignificant variables have all been omitted. This also applies for standard hours. There was no evidence whatsoever that relative hours are influenced by standard hours. The p-values of omitting this variable (current, lagged or its first difference) were never below 0.5 , independently of the additional variables included. The typical estimate for lagged standard hours was a highly insignificant small positive coefficient of about 0.01 , whereas the theory would predict a negative impact. This suggests that at a structural level, the corner solution is most relevant. Corroborating evidence is the fact that no influence could be found for any of the indicators of quasi-fixed labour costs.

The only significant determinants of relative overtime appear to be the utilisation rate and absenteeism. In the short run, both have a positive impact on overtime. This is consistent with the short-run production function (3.12). An unexpected result may be the rather small elasticity of changes in the utilisation rate, both compared to the Italian estimate of 0.38 by Bodo and Giannini (1995) and compared to the large impact of absenteeism. Besides measurement errors in observed hours, this may be due to the measurement of utilisation: rather large variations in demand may lead to relatively small changes in the utilisation rate.

Turning to the long-run impact of utilisation and absenteeism, column (1) of Table 3.4 suggests at first sight that the lagged levels of these variables are not significant. Jointly they are significant, however. In the columns (2) and (3) one of them is omitted and then the other turns out to be significant. Encompassing tests in PcGive comparing the specifications (3) and (2) do not reject one model in favour of the other. For example, both models are acceptable against the joint model (1), although the p-value for model (3) is much lower than for model (2) (0.167 and 0.770 , respectively), reflecting the lower residual sum of squares in(2). The misspecification tests reported in the table neither allow for discrimination between the two models, although first-order autocorrelation could be a more serious problem in column (2). To provide some weak evidence on the cointegration of the variables, I also computed Dickey-Fuller tests on the equilibrium correction mechanism. Except for column (2), which is only significant at the $10 \%$ level, they confirm that the variables are cointegrated.

First, consider specification (2), removing the utilisation rate from the long-run solution. As in specification (1), absenteeism turns out to have the wrong sign in the long run. Both from a production function perspective and from the structural model, absenteeism and overtime are expected to be positively correlated. A possible explanation for the observed negative sign could be another measurement error in overtime hours: if actual hours are calculated as total worker-hours divided by the number of workers, instead of dividing it by the workers in attendance, measured overtime would be negatively related to absenteeism. This should then also be the case in the short run, however, raising doubts about this explanation. 
Table 3.4 Overtime equation, 1962-1994

(IV, dependent variable $\Delta \hat{h}_{t}$ )

\begin{tabular}{lccc}
\hline Specification & $(1)$ & $(2)$ & $(3)$ \\
\hline \multirow{4}{*}{ constant } & 0.023 & 0.020 & 0.027 \\
& $(0.008)$ & $(0.005)$ & $(0.008)$ \\
$\Delta q{ }^{b}$ & 0.093 & 0.097 & 0.130 \\
& $(0.041)$ & $(0.029)$ & $(0.030)$ \\
$\Delta z_{,}{ }^{b}$ & 0.679 & 0.674 & 0.457 \\
& $(0.275)$ & $(0.201)$ & $(0.225)$ \\
$\hat{h}_{t-1}$ & -0.389 & -0.331 & -0.519 \\
& $(0.154)$ & $(0.090)$ & $(0.124)$ \\
$q_{t-1}$ & 0.014 & & 0.068 \\
& $(0.047)$ & & $(0.027)$ \\
$z_{t-1}$ & -0.119 & -0.136 & \\
& $(0.084)$ & $(0.047)$ & \\
\hline
\end{tabular}

\begin{tabular}{lccc}
\hline \multicolumn{4}{c}{ Test $_{\text {statistics }}$} \\
DW & 2.27 & 2.40 & 2.20 \\
$\hat{\sigma}(\mathrm{x} 100)$ & 0.321 & 0.317 & 0.320 \\
RSS $(\times 1000)$ & 0.278 & 0.281 & 0.287 \\
LMA & $\mathrm{F}(1,26)=2.35$ & $\mathrm{~F}(1,27)=3.29$ & $\mathrm{~F}(1,27)=1.42$ \\
ARCH & $\mathrm{F}(1,25)=0.14$ & $\mathrm{~F}(1,26)=0.00$ & $\mathrm{~F}(1,26)=0.35$ \\
HET & $\mathrm{F}(10,16)=0.14$ & $\mathrm{~F}(8,19)=0.54$ & $\mathrm{~F}(8,19)=0.45$ \\
NORM & $\chi^{2}(2)=0.45$ & $\chi^{2}(2)=0.52$ & $\chi^{2}(2)=1.74$ \\
CDF & $-3.06^{*}$ & -2.83 & $-3.95^{* *}$ \\
\hline
\end{tabular}

a. Standard errors between parentheses.

b. Potential endogenous variable; the instruments used are $\Delta \tilde{h}_{t-1}, \Delta z_{t-1}$, $\Delta x_{t}$ and $\Delta x_{t-1}$, where $\Delta x$ is the growth rate of world trade.

c. DW is the Durbin-Watson statistic; ô is the equation standard error; RSS is the residual sum of squares; LMA is a Lagrange multiplier test for first-order residual autocorrelation; ARCH is a LM-test for firstorder autoregressive conditional heteroscedasticity; HET is a White test for heteroscedasticity; NORM is PcGive's normality test of the residuals. CDF is an Dickey-Fuller test without trend for nonstationarity of the cointegrating vector. Significance levels test statistics: * at $5 \%$ and $* *$ at $1 \%$. 
In view of the wrong sign and the lower significance of the CDF statistic of column (2), my preferred specification is (3), removing absenteeism from the long-run solution. The long-run elasticity of relative hours with respect to the utilisation rate is $0.13(=0.068 / 0.519)$ and thus rather similar to the short-run impact. For the Italian case Bodo and Giannini (1995) also found a permanent effect of utilisation on relative hours, but with a higher elasticity of 0.28 . Although plausible at first sight, it could be argued that this long-run relation is not in line with the prediction of the theoretical model, where hours are independent of scale. Hence a permanent increase in demand would be accompanied by an increase in employment (the number of workers) and the capital stock, but not in hours. Insofar as variations in the utilisation rate reflect such increases in demand, no corresponding increase in relative hours should thus be expected. On the other hand, adjustment of the capital stock may take quite a long time, and in the mean time short-run demand for hours would depend on demand shocks.

All in all, the number of explanatory variables is rather limited, only absenteeism and demand appear in Table 3.4. So the link with the theoretical model is at best rather week. The observation that hours worked are proportional to standard hours and that mainly temporary factors such as variations in absenteeism and demand determine the pattern of overtime, can be seen as evidence that the corner solution prevails in many situations. Alternatively, one could argue that this is a result of other omitted variables, like relative prices. Further research in this respect is needed.

\subsection{Conclusion}

The objective of this chapter was to investigate the impact of weekly standard working time on weekly actual hours per worker. The theoretical analysis under certainty showed that if overtime is worked, actual hours respond less than proportionally. By definition they are proportional in a corner solution, and work-sharing policies reduce the probability of such a corner solution. From an empirical point of view, the relevance of corner solutions is illustrated by the low incidence of overtime. Moreover, I have argued that due to measurement errors, observed overtime data may well overstate actual overtime. Models starting from the assumption that overtime is the dominant regime, may thus give misleading predictions.

Instead of being induced by structural cost minimising factors, overtime may also result from variations in demand and attendance. Indeed the theoretical analysis illustrated that the stochastic nature of attendance, and to a lesser extent the stochastic nature of demand, increases average (overtime) hours.

The empirical analysis confirmed the importance of the utilisation rate and absenteeism for the determination of relative overtime. No evidence was found for other structural determinants, such as the structure of labour costs and standard hours. In other words, at least in Dutch manufacturing, 
actual hours appear to be fully proportional to standard hours. As a consequence, it is reasonable to ignore overtime in the remaining chapters of this thesis.

Further research is needed, however. From a theoretical point of view, it seems important to incorporate limited overtime incidence in labour demand models. Similarly, the distinction between overtime incidence and overtime hours is important for empirical analysis. So there is a need for more comprehensive data. This may also shed more light on the relation between overtime and absenteeism. 


\section{Shiftwork, Operating Time and Working Time}

\subsection{INTRODUCTION}

The maintained hypothesis of the previous two chapters was that the capital operating time correspondes to the working time of workers. Hence any reduction of working time is matched by a corresponding decrease in the operating time of machinery, worsening the capacity constraints of firms. In an international comparative study Anxo and Taddei (1995) conclude, however, that for the last thirty years the capital operating time in manufacturing industry remained more or less constant despite the reduction in hours of work. For the USA, Foss (1997) found that manufacturing plants where operating $25 \%$ more hours per week in 1976 than in 1929 and increased by another $4 \%$ until 1988. The main factor behind the diverging behaviour of working and operating times is the increased incidence of shiftwork. For Europe, Evans, Lippoldt et al. (2001) present some evidence for an increase in shiftwork during the 1980s and the 1990s.

For the Dutch manufacturing sector a similar pattern can be observed. Table 4.1 provides the incidence of shiftwork for selected years since the sixties: it increased from $10 \%$ in the sixties to almost $18 \%$ in the eighties, although it seems to have levelled off a bit during the nineties. The increased shiftwork incidence occurred both for the discontinuous 2-shift system and for the continuous 4 - or 5 -shift system. The semi-continuous 3 -shift system remained roughly constant, however.

In general there is almost no direct evidence available on the capital operating time. Bosworth and Cette (1995) discuss the measurement issues of the operating time. Although they suggest that it may be prudent to work with more than one statistical measure, they conclude that shiftwork based indicators seem to offer the broadest scope. Table 4.2 illustrates the effect of the increased shiftwork incidence on the weekly capital operating time, using an arithmetic average over the various shifts. ${ }^{1}$

1 The calculated operating time corresponds to the U(3)-indicator defined by Bosworth and Cette (1995). 
Table 4.1 Shiftwork incidence, Dutch manufacturing

\begin{tabular}{lcccc}
\hline & 2-shift & 3-shift & 4/5-shift & Total \\
\hline 1963 & 4.5 & 4.5 & 1.3 & 10.2 \\
1966 & 4.1 & 4.4 & 1.9 & 10.4 \\
1969 & 4.5 & 4.6 & 2.3 & 11.4 \\
1972 & 4.2 & 3.8 & 2.3 & 10.3 \\
1980 & 7.4 & 5.7 & 4.3 & 17.4 \\
1985 & 7.2 & 5.7 & 5.2 & 18.1 \\
1990 & 7.1 & 4.9 & 5.6 & 17.5 \\
1992 & 7.0 & 4.9 & 5.5 & 17.4 \\
1995 & & & & 16.3 \\
1997 & & & & 16.9 \\
\hline
\end{tabular}

Source: CBS, Sociale Maandstatistiek, march 1976, CBS, Supplement Sociaal Economische Maandstatistiek, january 1985, CBS, Statistiek Werkzame Personen, various issues and CBS, private communication.

Table 4.2 Weekly working time and operating time, Dutch manufacturing

\begin{tabular}{cccc}
\hline & $\begin{array}{c}\text { normal working } \\
\text { time } \\
H\end{array}$ & $\begin{array}{c}\text { operating } \\
\text { time } \\
\text { a }\end{array}$ & $\begin{array}{c}\text { shiftwork } \\
\text { intensity } \\
S=U / H\end{array}$ \\
\hline 1963 & 44.5 & 52.0 & 1.17 \\
1966 & 44.5 & 52.6 & 1.18 \\
1969 & 43.3 & 52.1 & 1.20 \\
1972 & 42.0 & 49.9 & 1.19 \\
1980 & 40.0 & 53.0 & 1.33 \\
1985 & 39.5 & 53.5 & 1.36 \\
1990 & 38.9 & 52.7 & 1.35 \\
1992 & 38.9 & 52.5 & 1.35 \\
\hline
\end{tabular}

a Computed as $U=H\left(1-S_{2}-S_{3}-S_{4}\right)+2 H S_{2}+3 H S_{3}+168 S_{4}$, where $S_{i}$ is the incidence of the $i$-th shift. 


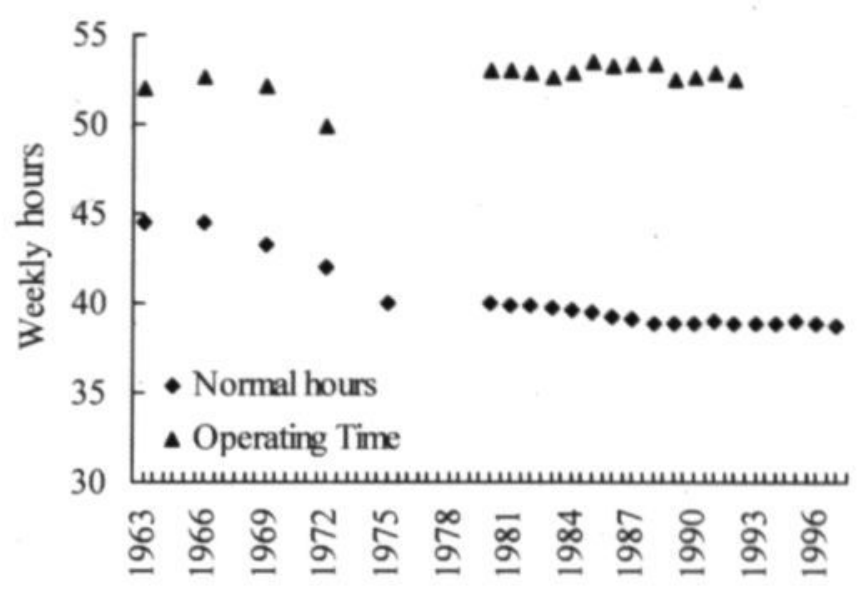

Figure 4.1 Operating time and working time in Dutch manufacturing

Even though the normal working time declined with more than five hours per week, the operating time remained more or less constant at 52 hours a week. As a consequence, shiftwork intensity defined as the ratio between operating time and normal working time - increased from around 1.2 to 1.35. Figure 4.1 provides a graphical illustration of these trends in operating and working times. This provides corroborating evidence for the near stationarity of operating times found by Anxo and Taddei (1995).

Compared to the results presented in Anxo and Taddei (1995), the Dutch manufacturing operating time is at the lower end of the spectrum. For France and Germany the weekly operating time seems to be around 60 hours, whereas they report values of around 80 hours for the United States. The levels of the operating times presented should be viewed with care, however, see Bosworth and Cette (1995). For example, the results presented in Table 4.2 may be biased for at least two reasons. On the one hand, it is assumed in the calculation that th: working time is independent of the shiftwork system. However, scattered evidence suggests that workers working in shifts have shorter workweeks, compared to their colleagues working only regular hours. This provides an upward bias of the operating time. On the other hand, the shiftwork incidence data of Table 4.1 may not cover all situations where operating time exceeds the normal working time of workers. For example, part-time employment might be used to lengthen the operating time beyond the working time of regular workers. The use of flexible labour might work in the same direction. ${ }^{2}$ More important perhaps, is the use of partial shifts. Consider, for example, a firm where workers

2 Evans, Lippoldt et al. (2001), for example, provide some evidence that the incidence of so-called 'unsocial working hours' has increased during the $1990 \mathrm{~s}$. 
work 36 hours in a compressed workweek, divided in 4 days of nine hours. The operating time can easily be equal to $36,45,54$ or even 63 hours a week, simply by extending the number of days in operation and varying the days in attendance over the workforce. For instance, suppose that capital stock is operated for 6 days a week: the weekly operating time equals 54 hours a week, and every day only $2 / 3(=36 / 54)$ of the total number of workers is present. This type of job rotation or partial shifts is unlikely to be covered by shiftwork incidence data, and hence the operating time of Table 4.2 may be biased downward. ${ }^{3}$

The above observations on the stationarity of operating times and increasing shiftwork lead to the following two questions: what incentives do firms have to change the operating time as a response to changes in the working hours of their workers; and what is the consequence of the adjustment of the operating time on the demand for labour. These two questions form the core of the current chapter. They have been discussed before by Calmfors and Hoel (1989), but in a framework with a given capital stock. When discussing shiftwork, however, it seems important to incorporate capital adjustment. Shiftwork and the optimal choice of the capital stock are closely related.

Surveys of the literature on capital utilisation and the duration of operations are given by Bosworth and Heathfield (1995) and Oi (1981). A main theme of that literature is that higher utilisation increases output, but simultaneously raises some of the factor prices. ${ }^{4}$ Optimal utilisation rates balance these two opposing forces. This may involve several dimensions. For example, Betancourt and Clague (1981), Mayshar and Halevy (1997) and Winston (1974) analyse the (discrete) choice of the number of shifts due to shiftwork premiums. Lucas (1970) and Winston and McCoy (1974) focus on the timing of operations due to rhythmically varying labour costs, eveningor night-shifts being more expensive than work during the day. Recently it has been acknowledged that there may be multiple rhythmically varying prices, the tariff structure of electricity prices being another example, see Bosworth and Pugh (1985). Another dimension of utilisation is the speed or intensity of use of capital. Madan (1987) provides an example where the speed influences wear and tear, and thus raises capital costs.

In the present chapter I consider only the duration of operations, and ignore any problem arising from timing during the day or week. Beside a simplification of the analysis, the main reason is that the duration depends on the average costs of operating, whereas the timing during the day or week depends on the rhythmic variations around this mean. A further simplification is that working hours of labour are assumed to be given exogenously. So, contrary to the previous chapter, firms can not use

3 Indeed, Mayshar and Halevy (1997) provide evidence, based on a survey conducted in 1989 for the Commission of the European Union, that weekly plant operation in the Netherlands was 74 hours, compared to an EU average of 66. Correspondingly, their shiftwork intensity of 1.90 for the Netherlands ( 1.69 for the EU) is higher than the numbers reported in Table 4.2.

4 Another theme is the cyclical behaviour of capital operating hours and the implications for labour productivity, see Dupaigne (1998) and Shapiro (1993) for recent contributions. 
overtime. Nevertheless they can adjust the operating time of machinery by an appropriate choice of shiftwork.

The rest of the chapter is organised as follows. Section 4.2 presents the specification of the model. Section 4.3 analyses the short-run behaviour of cost minimising firms, choosing between employment and shiftwork. Section 4.4 turns to the long-run cost minimisation problem, where the capital stock is adjusted as well. The next section 4.5 briefly discusses the sensitivity of the numerical results. Section 4.6 then turns to the problem of profit maximisation in a monopolistic competitive market. Finally, Section 4.7 concludes with a brief discussion.

\subsection{THE MODEL}

The model considers a cost minimising firm producing its output $Q$, with capital and labour as its production factors. Obviously it is important to distinguish between the stocks of capital $K$ and labour $N$ and their services rendered. As argued in Chapter 2, this is done by the incorporation of the duration of operations, see also Georgescu-Roegen (1970). With shiftwork, however, the capital operating time $U$ no longer corresponds to the working time $H$ of workers. A straightforward extension of the production function (2.5) in Chapter 2 is the summation over all $S$ shifts:

$$
Q=\sum_{s=1}^{S} e_{s}\left(H_{s}\right) F\left(K_{s}, A N_{s}\right)
$$

where the subscript $s$ refers to the $\operatorname{shift}(s=1, \ldots, S)$ considered, $K_{s}$ is the capital stock in use during a shift, $N_{s}$ is the number of workers being present, in other words the crew size, and $A$ is an index of labour augmenting technological progress.

Essentially the production function (4.1) is additive and separable over time, as in Lucas (1970), Mayshar and Halevy (1997) and Winston and McCoy (1974). The technology is characterised by the instantaneous production function $F(\cdot)$, only involving the stocks of capital and labour. This function is assumed to be linear homogeneous in its arguments. The instantaneous production can be replicated over time, but is subject to efficiency gains or losses of working time, see Chapter 2. Therefore output in each shift is multiplied by efficiency hours $e_{s}\left(H_{s}\right)$, instead of working time $H_{s}$. These efficiency hours might depend on the shift, as for example night shifts can be less productive. Finally, equation (4.1) is also additive over the number of shifts. Shifts can thus be replicated, although this may affect efficiency hours. 
To further simplify the analysis, I focus on symmetric shifts. This implies that within each shift the full capital stock $K$ is used, that the crewsize $N_{s}$ is constant and that each shift has the same duration $H$, thus ${ }^{5}$

$$
\begin{aligned}
& K_{s}=K \\
& N_{s}=N / S \\
& H_{s}=H .
\end{aligned}
$$

With respect to efficiency hours it is assumed that shiftwork may shift the whole efficiency hours curve, but for symmetry reasons, independently of the shift under consideration. Using an iso-elastic specification, this yields

$$
e_{s}(H)=e(H, S)=e(H) S^{\mu} \text {. }
$$

On the one hand, when $\mu \geq 0$ shiftwork negatively affects efficiency hours, for example because shiftwork implies work at rather unsocial hours, reducing productivity. On the other hand, some production processes might need longer operation times than the working time of workers. In that case shiftwork enhances productivity of hours per shift. Therefore the shiftwork productivity parameter $\mu$ can not be signed a priori.

Upon substitution of the above symmetry assumptions in (4.1), the production function can be written as

$$
Q=S e(H, S) F(K, A N / S)=A N e(H) S^{-\mu} f(k),
$$

where

$$
k \equiv S K /(A N)
$$

is the capital-intensity of the production process. In equation (4.4) the instantaneous production function is written in its intensive form $f(k) \equiv F(k, 1)$ to reduce notation.

It is tempting to treat the number of shifts $S$ as an integer, but that needs not to be so, as the introductory examples on partial shifts or compressed workweeks illustrate. Therefore, ignoring any possible discontinuities, I shall simply treat $S$ as a continuous variable. This is admittedly not the most accurate or realistic description, but focusses attention on the underlying incentives. Ignoring maintenance time, the operating time cannot fall below hours worked, so $S=1$ is the logical lower

5 Mayshar and Halevy (1997) allow the second shift to be operated by less workers and during a shorter period than the first shift. This could be optimal when the costs for the second shift exceed the costs for the first shift. For example, when hourly wages for the first shift are lower than for the second shift. Even though the number of shifts may affect the hourly wage in my model, the implicit assumption is that wages do not vary between shifts. In other words, a night-shift commands the same wage as a day-shift. 
bound. Finally, the total available time per day, week or month $T$, sets an upper bound to the operating time and thus, given the working hours $H$, to the number of shifts. Hence, shiftwork should satisfy the condition

$$
H \leq U=S H \leq T \text {. }
$$

Increasing the amount of shiftwork, keeping the capital stock and employment constant, raises the operating time, reduces the crew size, see equation (4.2) and might affect efficiency hours, see equation (4.3). Due to the declining marginal productivity of labour, the increase of the operating time dominates the reduction in crew size for output. So the elasticity of output with respect to shiftwork in the production function (4.4) is equal to $\eta^{-}-\mu$, where $\eta^{\prime}=k f^{\prime}(k) / f(k)$ corresponds to the elasticity of the instantaneous production $f(k)$ with respect to the capital-intensity, but also to the elasticity of output with respect to the capital stock. ${ }^{6}$

Obviously, there are also costs to the use of shiftwork. I consider the following specification of labour costs per worker $V+W H o(S)$, where $W$ is the normal hourly wage rate and $V$ are the quasifixed costs per worker, see Chapter 2 for a discussion of the latter. Typically, a larger amount of shiftwork involves less convenient working hours, or more irregular schedules. The disutility of shiftwork is likely to be compensated by increased hourly wages; this is modelled by the rising shiftwork schedule $o(S)$, with $0<o^{\prime}(S)$. For simplicity I use the same iso-elastic specification as Calmfors and Hoel (1989), $o(S)=S^{\theta}$ with $0<\theta<1$. It implies that a rise in the number of shifts leads to a less than proportional increase in remuneration. Calmfors and Hoel (1989) argue that this is consistent with the 'empirics' - this is confirmed in Anxo and Taddei (1995).

Beside labour costs, shiftwork might also affect capital costs. A first possibility is that increased utilisation, in our case longer operating times, increases the wear and tear of capital, see Basu and Kimball (1997), Madan (1987) and Oi (1981). Secondly, Hart (1984b) suggested that there may be hourly operating costs that vary only with working time of workers, but not with the number of workers. His examples related to the working environment, such as lighting, heating and canteen facilities. On closer inspection, these costs seem rather related to the operating time, and not to the average working time. Moreover, even if they do not vary directly with the number of workers, they are likely to vary with the scale of operations. This scale dependence can perhaps be captured by the capital stock. To include this possibility, the capital costs per unit of capital are specified as

6 As far as possible, this chapter uses the same notation for elasticities as in Chapter 2. Accordingly the elasticity of efficiency hours $e(H)$ with respect to hours is denoted by $\eta^{e}$. Moreover, the elasticity of substitution of the instantaneous production function is $\sigma$. In line with the observations in Chapter 2, I assume that $\sigma \leq 1$. 
$R+Z U$, where $R$ is the usual user cost and $Z$ is the variable hourly operating costs per unit of capital. The latter may well depend on energy prices. Suppose for example that every machine hour needs a fixed amount of energy, then $Z U K$ simply reflects these energy costs. ${ }^{7}$

Combining capital and labour costs, the firm's total cost $C$ is expressed as

$$
C=\left(V+W H S^{\theta}\right) N+(R+Z U) K .
$$

The firm tries to minimise its costs given the output constraint (4.4).

\subsection{SHORT-RUN COST MINIMISATION}

First consider the short run, where the capital stock is fixed, but the firm can still lengthen its operating time by using more shifts. This short-run model thus focuses on the choice between employment and shiftwork. This corresponds to the case considered by Calmfors and Hoel (1989). The formal cost minimisation problem can be written as

$$
\min _{N, S} \mathrm{C}=\left(V+W H S^{\theta}\right) N+(R+Z U) K
$$

subject to (4.4) and (4.6),

so besides the output constraint (4.4), we have to take account of the logical boundaries of the shiftwork variable in equation (4.6); Table 4.1 suggests that the majority of firms decides not to use any shiftwork $(S=1)$; whereas a minority chooses to operate on a continuous basis $(S=T / H)$.

The first-order conditions for a solution are given by

$$
\frac{k f^{\prime}(k)-\mu f(k)}{f(k)-k f^{\prime}(k)} \frac{N}{S}=\frac{\theta W H S^{\theta-1} N+Z H K-\lambda_{S}+\lambda_{U} H}{V+W H S^{\theta}}
$$

and the two complementary slackness conditions

7 More generally, instead of including hourly operating costs, we could include energy as a separate production factor in the production function. Contrary to capital $K$ and labour $N$, however, energy should be viewed as a flow variable. 


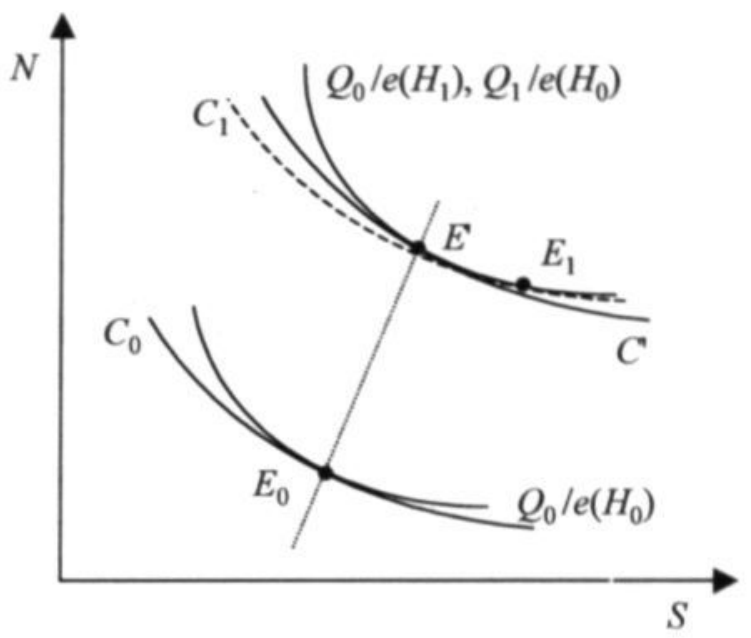

Figure 4.2 Employment and shiftwork

$$
\begin{array}{ll}
\lambda_{S}(S-1)=0, & \lambda_{S} \geq 0, \\
\lambda_{U}(T-S H)=0, & \lambda_{U} \geq 0 .
\end{array}
$$

The non-negative multipliers $\lambda_{S}$ and $\lambda_{U}$ are associated with the two inequalities of (4.6).

\subsubsection{Interior solution}

Consider the interior solution $\left(\lambda_{S}=\lambda_{U}=0\right)$ first. This implies shiftwork $(S>1)$, but not around-theclock $(S<T / H)$. The first-order condition (4.8) reduces to

$$
\frac{k f^{\prime}(k)-\mu f(k)}{f(k)-k f^{\prime}(k)} \frac{N}{S}=\frac{\theta W H S^{\theta-1} N+Z H K}{V+W H S^{\theta}} .
$$

The left-hand side represents the marginal rate of substitution between employment and shifts, the right-hand side is the corresponding ratio of factor costs. The marginal costs of shifts in the numerator consist of two parts, the first part representing the higher shift premium to be paid and the second part corresponding to the additional hourly operating costs. The marginal costs of employment obviously includes the fixed costs $V$.

Since working time is given exogenously in the present analysis, the optimisation problem is the same as minimising the costs per efficiency hour given the output per efficiency hour. This is illustrated in Figure 4.2 for an interior solution, see Calmfors and Hoel (1989) for a rat'her similar graph. The $C_{0}$-curve is a downward sloping convex isocost curve. It will be steeper the higher the 
Table 4.3 Parameter values

\begin{tabular}{ll}
\hline$\eta^{\prime}=0.7$ & $\varphi_{V}=0.175$ \\
$\eta^{\prime}=0.3$ & $\varphi_{z}=0.05$ \\
$\sigma=0.5$ & $\theta=0.32$ \\
$\mu=0.1$ & \\
\hline
\end{tabular}

shiftwork premium $\theta$, the higher the hourly operating $\operatorname{costs} Z$ or the lower quasi-fixed labour costs $V$. The $Q_{0} / e\left(H_{0}\right)$-curve is the isoquant per efficiency hour. It is downward sloping as long as the adverse productivity effects of shiftwork are sufficiently small $\left(\mu<\eta^{\gamma}\right)$. This is assumed to hold, as in the opposite case there wouldn't be any shiftwork, the left-hand-side of $(4.8)$ being negative. In the optimum $E_{0}$ the slopes of both curves should be equal, as stated in equation (4.10).

Obviously this is only the least-cost combination if the isoquant is more convex than the isocost curve. This is guaranteed by the second-order condition. Appendix H provides a general expression: it amounts to an upperbound $\sigma_{N S}$ for the elasticity of substitution $\sigma$ of the instantaneous production function. ${ }^{8}$ It can be shown that the upperbound is always larger than one, hence the second-order condition is assumed to be fulfilled. ${ }^{9}$

The comparative statics of the model are also derived in Appendix H. It includes rather involved expressions, therefore I will concentrate on some numerical results. The parameter values of the model have largely been chosen in line with Chapter 2 and are summarised in Table 4.3. Only the share of fixed costs $\varphi_{V} \equiv V /(V+W H o(S))$ is reduced from 0.2 to 0.175 , as, due to the shiftwork premium, wage costs should account for a larger part of labour costs. Compared to Chapter 2 , three additional parameters are introduced in the model. First, it is assumed that there is a small adverse productivity impact of shiftwork $(\mu=0.1)$. Second, the hourly operating costs are assumed to be relatively small but non-zero, as the share of operating costs in capital costs $\varphi_{Z} \equiv Z U /(R+Z U)$ is set equal to 0.05 . I am not aware of any evidence for both parameters. Finally, to allow for an interior solution, the elasticity of the shiftwork premium is set in accordance with the first-order condition (4.10), implying a value of $\theta=0.32$. This is somewhat higher than the value of 0.2 calibrated by Calmfors and Hoel (1989) for Sweden. ${ }^{10}$ The current value implies that workers working two, three or four shifts obtain a 25,42 and 56 per cent shift premium, respectively. This is within the range mentioned by Mayshar and Halevy (1997).

8 For large values of the shiftwork premium $\theta$, the critical value $\sigma_{N S}$ may be infinite.

9 With the parameter values of Table 4.3 below the second-order condition is $\sigma<\sigma_{N S}=1.113$.

10 The other parameters used by Calmfors and Hoel (1989) are $\eta^{e}=1, \sigma=0.5, \varphi_{V}=0.1$ and $\varphi_{z}=\mu$ $=0$. They set $\eta^{\prime}$ at the rather low value of 0.153 to satisfy the first-order condition (4.10). Including non-zero values for $\mu$ and $\varphi_{D}$, the capital share $\gamma^{\prime}$ can be set more realistically in the present analysis. 
Table 4.4 Numerical elasticities, interior solution

\begin{tabular}{ccccccccc}
\hline & $Q$ & $A$ & $K$ & $R$ & $Z$ & $V$ & $W$ & $H$ \\
\hline \multicolumn{7}{c}{ Short-run cost minimisation } \\
\hline$N$ & 1.12 & -0.99 & -0.12 & 0. & 0.01 & -0.03 & 0.02 & -0.75 \\
$S$ & 1.09 & -0.04 & -1.09 & 0. & -0.04 & 0.09 & -0.05 & -0.86 \\
\hline \multicolumn{7}{c}{ Long-run cost minimisation } \\
\hline$K$ & 1. & -0.69 & -0.69 & 0.00 & 0.03 & 0.65 & -0.04 \\
$N$ & 1. & -0.91 & 0.08 & 0.01 & -0.03 & -0.06 & -0.75 \\
$S$ & 0. & 0.71 & 0.75 & -0.04 & 0.06 & -0.77 & -0.81 \\
$k=S K / T N$ & 0. & -0.07 & -0.02 & -0.05 & 0.12 & -0.05 & -0.10 \\
$c=C / Q$ & 0. & -0.70 & 0.29 & 0.02 & 0.12 & 0.58 & -0.11 \\
\hline
\end{tabular}

Table 4.4 provides the numerical comparative static short-run elasticities for the interior solution. The key results are in the last column and relate to a policy of reduced working time. To get a feeling for the model, however, I first briefly discuss the other columns of the table.

- An increase in output Q shifts the isoquant in Figure 4.2 out towards $Q_{1} / e\left(H_{0}\right)$, and increases both employment $N$ and shiftwork $S$ along the expansion path $E_{0} E .{ }^{11}$ Employment increases more than proportionally due to the declining marginal productivity, although the crew size $N / S$ increases only slightly.

- Labour augmenting technical progress $A$, shifts the isoquant in Figure 4.2 inward, making it steeper at the same time. As a consequence employment decreases almost proportional in the short run and there is only a small reduction in shiftwork.

- Obviously capital costs $R$ do not matter in the short run, but hourly operating costs $Z$ raise the marginal costs of shifts and induce a substitution effect towards more employment.

- An increase in the capital stock $K$ shifts the isoquant inward, but makes it flatter. Moreover, through the hourly operating costs, the isocost curve becomes steeper. All three effects reduce shiftwork, whereas for employment the latter two effects tend to increase it.

- An increase in the quasi-fixed costs $V$ raises the marginal costs of workers relative to shifts. Hence there is a substitution effect towards more shifts, the elasticities being rather modest, however.

11 The slope of the expansion path in Figure 4.2 changes if the elasticity of substitution exceeds 1 . So, in the short run, shiftwork increases with output as long as $\sigma<1$, but decreases for $\sigma>1$. A similar result was found in Chapter 3 in relation to overtime hours. 
- An increase in the hourly wage $W$ operates in the opposite direction, reducing the number of shifts. At least if the share of operating costs in capital costs is low enough.

A reduction of working time $H$ combines the effects of an outward shift of the isoquant in Figure 4.2 and a reduction in the wage rate. ${ }^{12}$ For a given output level, output per efficiency hour increases towards $Q_{d} e\left(H_{1}\right)$, leading to $E^{\prime}$ with more employment and more shifts. The lower remuneration, due to the given hourly wages, tilt the isocost line towards the dotted $C_{1}$, shifting the new equilibrium towards $E_{1}$. Both effects lead to more shiftwork, but work in opposite directions for employment. In Table 4.4 employment increases, and shiftwork increases less than proportionally. As a consequence, the operating time $U$ decreases slightly.

Calmfors and Hoel (1989) have provided a rather similar analysis, but with a different set of parameters (see footnote 10). The major difference is their higher elasticity of efficiency hours, as they do not consider the difference between efficiency hours and working time. This leads to a stronger shift of the isoquant, and hence leads to a stronger impact of reduced hours on both employment and shiftwork. Table 4.6 in Section 4.5 below, illustrating the sensitivity of my results, illustrates that our short-run working time elasticities would be $\varepsilon_{N M X}=-1.09$ and $\varepsilon_{\operatorname{SMX}}=-1.19$ in that case. Reduced hours would now tend to increase the operating time $U$.

\subsubsection{Corner solutions}

Table 4.1 illustrated that the majority of firms face a corner solution without shiftwork. In that case allocation $E_{0}$ in Figure 4.2 would imply a non-feasible solution $S<1$, and the solution would be on the isoquant at $S=1$. The corresponding isocost curve is steeper than the isoquant at this corner solution, see equation (4.8) with $\lambda_{s}>0$. Such a corner solution might, for example, be due to a relatively high shiftwork premium $\theta$, large adverse productivity effects of shiftwork $\mu$ or important hourly operating costs $\varphi_{Z}$.

A small working time reduction again shifts the isoquant outwards. Given the absence of shiftwork higher employment is needed to accommodate the reduction in efficiency hours. Compared to the interior solution, the short-run employment elasticity with respect to working time increases in absolute value from $\varepsilon_{N H K}=-0.75$ to -1.00 , see Table 4.5 . For a sufficiently large reduction in hours worked, the new equilibrium might be an interior solution involving some shiftwork, however. Hence the incidence of shiftwork is likely to increase with shorter working times.

12 Formally the relation between the various elasticities is the $\varepsilon_{x H K}=-\eta^{e} \varepsilon_{x Q K}+\varepsilon_{x w K}$ for $X=N, S$, where $\varepsilon_{m K K}$ is the elasticity of the endogenous variable $X$ with respect to the exogenous variable $Y$ conditional on the variable $K$. 

Table 4.5 Elasticities with respect to working
time and corner solutions

\begin{tabular}{cccc}
\hline & $\begin{array}{c}\text { No } \\
\text { shiftwork } \\
(\theta=0.4)\end{array}$ & $\begin{array}{c}\text { Interior } \\
\text { solution } \\
(\theta=0.32)\end{array}$ & $\begin{array}{c}\text { Continuous } \\
\text { operation } \\
(\theta=0.2)\end{array}$ \\
\hline \multicolumn{4}{c}{ Short-run cost minimisation } \\
\hline$N$ & -1.00 & -0.75 & -0.71 \\
$S$ & 0.00 & -0.86 & -1.00 \\
\hline$K$ & Long-run cost minimisation \\
\hline$N$ & -0.43 & -0.04 & 0.05 \\
$S$ & -0.82 & -0.75 & -0.73 \\
$k$ & 0.00 & -0.81 & -1.00 \\
$c$ & 0.39 & -0.10 & -0.22 \\
\hline
\end{tabular}

On the other end of the spectrum, Table 4.1 illustrated that continuous operation prevails for some $5 \%$ of employment. This can be the case for a sufficiently low shiftwork premium $\theta$, or for strongly positive productivity effects of shiftwork $(\mu<0)$, etc. In this situation, a reduction of working time leads - by definition - to a fully proportional increase in the number of shifts. As this is stronger than the impact in the interior solution, see Table 4.5, employment rises slightly less.

\subsection{LONG-RUN COST MINIMISATION}

In the short-run model firms can vary the amount of shiftwork without adjusting the capital stock. However, I would argue that decisions to implement shiftwork are closely related to investment decisions; implementing shiftwork is typically a long-run decision, with a need to adapt the organization and the capital stock. Hence a natural extension of the previous analysis, and of Calmfors and Hoel (1989), is to allow the capital stock to adjust simultaneously. Indeed most papers on shiftwork include the determination of investment or the capital stock. But these papers do not tend to emphasize the impact of hours worked on shiftwork. This section thus adds another variable to the standard determinants of shiftwork.

The long-run cost minimisation problem faced by the firm becomes

$$
\begin{gathered}
\min _{K, N, S} C=\left(V+W H S^{\theta}\right) N+(R+Z U) K \\
\text { subject to (4.4) and (4.6). }
\end{gathered}
$$


The first-order conditions reduce to the production function (4.4), the choice between shifts and employment in (4.8), the complementary slackness conditions (4.9) and

$$
\frac{S f^{\prime}(k)}{A\left[f(k)-k f^{\prime}(k)\right]}=\frac{R+Z U}{V+W H S^{\theta}}
$$

This equation describes the traditional choice between capital and labour, where the marginal rate of substitution equals the price ratio. This introduces a second margin of substitution into the model.

The second-order condition for an interior solution again sets an upperbound $\sigma_{s}$ to the elasticity of substitution of the instantaneous production function, see Appendix $\mathrm{H}$ for details. As $\sigma_{s}>1$, this condition is assumed to hold. The parameter values of Table 4.3 imply $\sigma_{S}=1.08<\sigma_{N S}$.

\subsubsection{Interior solution}

The first-order conditions (4.10) and (4.11) jointly determine the capital-intensity $k$ and shiftwork $S$. This is due to the assumption that the instantaneous production function $\mathrm{F}(\cdot)$ is homothetic. Figure 4.3 provides an illustration of the first-order conditions. Reinterpreting equation (4.11), the capitalintensity is chosen such that the marginal rate of substitution per shift is equal to the factor cost ratio per shift. With more shifts, the capital costs per shift decline, hence there is a substitution effect towards a higher capital-intensity. This is the curve labelled $k$ in the figure; its slope is steeper the larger the elasticity of substitution $\sigma$. Indeed, with fixed factor proportions, $\sigma=0$, the capitalintensity would be fixed by technological requirements, leading to a horizontal line.

The choice between employment and shiftwork in (4.10) also implies a relation between the capital-intensity and the amount of shiftwork. A higher capital-intensity essentially leads to a flatter isoquant in Figure 4.2, at least for $\sigma<1$. Moreover, it increases the importance of hourly operating costs, making the isocost line steeper. Both factors tend to reduce shiftwork. In Figure 4.3 this is represented by the downward sloping curve labelled $S .{ }^{13}$

The equilibrium $E_{0}$ is given by the intersection of both curves. When the equilibrium $E_{0}$ would violate one of the time restrictions on shiftwork in (4.6), a corner solution would prevail; the solution is then given by the intersection of the $k$-curve and the vertical line $S=1$ (no shiftwork) or $S=T / H$ (continuous operation).

13 This curve is downward sloping for $\sigma<(1-\mu) /\left(1-\mu-\varphi_{2}\right)$, the right-hand side being larger than one when hourly operating costs are included in the model. In the absence of hourly operating costs, a Cobb-Douglas production function would imply a vertical $S$-curve. The curve will be upward sloping for values of $\sigma$ exceeding the above critical level. In that case, the second-order condition guarantees that the $S$-curve is steeper than the $k$-curve. 


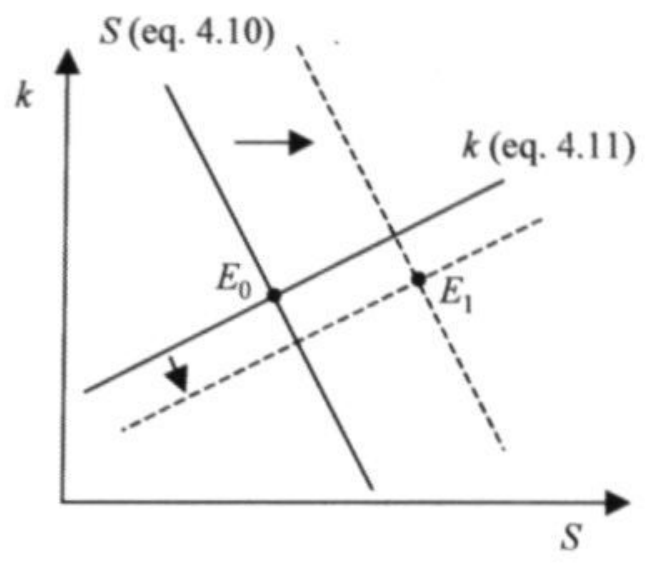

Figure 4.3 Capital-intensity and shiftwork

Comparative static results for the interior solution are derived in Appendix $\mathrm{H}$. Here I focus on the numerical elasticities, again based on the parameter values of Table 4.3. The resulting long-run elasticities for the interior solution were already included in Table 4.4. The table also presents the impact on unit $\operatorname{costs} c=C / Q$. Before discussing working time reduction, consider briefly the other determinants.

- As the production function is linear homogeneous in the capital stock and employment, an increase in output leads to a full proportional increase of both stocks, leaving the capital-intensity, shiftwork and unit costs unaffected.

- An increase in the user cost of capital $R$ leads towards a substitution effect away from the capital stock, see equation (4.11). In Figure 4.3 the $k$-curve would shift downward, increasing shiftwork and reducing the capital-intensity. In terms of capital services the increase in shiftwork (intensive margin) offsets the reduction in the capital stock (extensive margin). Employment is only marginally increased. Obviously, unit costs increase, the elasticity being equal to the shate of capital corrected for the share of hourly operating costs.

- An increase in the operating costs $Z$ also induces substitution away from capital services. In Figure 4.3 the $k$-curve would shift downward, and the $S$-curve would shift to the left. The latter negative effect dominates for shiftwork.

- For a large part, labour augmenting technical progress $A$ has a similar impact as an increase in the user cost of capital. Equation (4.11) illustrates that it is more or less comparable to an increase in the capital costs, leading to a reduction in capital (services). However, employment is reduced almost proportionally due to its augmented productivity in the production function (4.4). As a result unit costs decrease. 
- An increase in quasi-fixed labour costs $V$, leads to a small additional substitution effect towards capital, beside the short-run substitution away from labour.

- As wage costs form the major part of labour costs, an increase in the hourly wage leads to larger elasticities. The rising costs of shifts due to higher wages reduces shiftwork both in (4.10) and (4.11). In Figure 4.3 both curves would shift to the left. ${ }^{14}$ For the capital-intensity both effects operate in the opposite direction, but the negative effect via the $S$-curve can be shown to dominate. The impact on employment is mildly negative and the capital stock increases more to offset part of the reduction in capital services due to reduced shiftwork.

Working time reduction again combines the effects of reduced wage costs and an increase of output per efficiency hour. ${ }^{15}$ For shiftwork and the capital-intensity, only the former effect matters, as is illustrated in Figure 4.3. With constant hourly wages, reduced working time leads to lower remuneration rates, hence both the $S$ - and $k$-curves shift to the right, the new equilibrium being $E_{1}$. As a result shiftwork increases unambiguously and the capital-intensity can also be shown to rise. With $\varepsilon_{S H}=-0.81$ the operating time is reduced slightly. As a consequence of the lower remuneration at constant hourly wages, employment expands and the capital stock is reduced, compare the column $W$ in Table 4.4. Moreover, additional capital and employment are needed to increase output per efficiency hour. Both effects work in the same direction for employment, but in opposite directions for the capital stock. Given our parameter values, the scale effect weakly dominates for capital. As the impact on the capital stock is rather small, the long-run effect on employment is of the same magnitude as the short-run impact.

Table 4.4 finally illustrates that unit costs increase as a consequence of reduced hours. This is due to the choice of the elasticity of efficiency hours $\eta^{e}$, which implicitly defines the initial working time. As in Chapter 2 scale invariant long-run hours demand can be determined minimising long-run unit costs with respect to hours. The resulting first-order condition is

$$
\frac{e^{\prime}(H)}{e(H)} \frac{f(k)}{f(k)-k f^{\prime}(k)} N=\frac{W S^{\theta-1} N+Z S K}{V+W H S^{\theta}},
$$

or, in short-hand, $\eta^{e}=\left(1-\varphi_{v}\right)\left(1-\eta^{\prime}\right)+\varphi_{z} \eta^{\prime}$, using equation (4.11). Given the parameter values of Table 4.3, the right-hand side of this short-hand expression is equal to 0.59 , which is lower than the 0.7 for $\eta^{e}$. This means that hours initially worked fall short of hours demanded by firms. As reduced hours increase the gap between the two, unit costs will increase.

14 The shift from $E_{0}$ to $E_{1}$ in the figure corresponds to a wage reduction.

15 The relation between the various elasticities is $\varepsilon_{x \rightarrow Q}=-\eta^{e} \varepsilon_{x Q}+\varepsilon_{x m Q}$ for $X=K, N, S$, and $k$. 


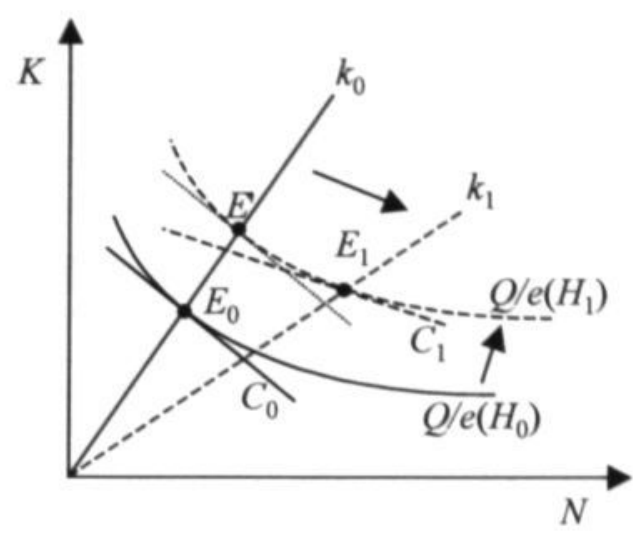

Figure 4.4 Capital-labour substitution

\subsubsection{Corner solutions}

The results of Table 4.4 only hold for the interior solution with positive shiftwork. Table 4.5 provides the same results with respect to reduced hours for the two possible corner solutions. In the absence of shiftwork, substitution will only occur between the capital stock and labour, see equation (4.11). As Figure 4.4 - a copy of panel (a) of Figure 2.2 - illustrates, the increased output per efficiency hour (the shift from equilibrium $E_{0}$ to $E$ ) and the lower remuneration rate (the shift from $E$ to $E_{1}$ ) lead to increased employment. For the capital stock both effects operate in opposite directions, but the shift in the isoquant dominates in Table 4.5. Obviously the capital-intensity falls from $k_{0}$ to $k_{1}$, due to the lower labour costs. In the interior solution of Table 4.4, this was more than offset by the increase in shiftwork. This also reduces the employment effects in the interior solution, relative to the corner solution without shiftwork.

For firms using continuous operation, shiftwork increases proportionally with the reduction in hours worked. As the interior solution leads to a smaller increase in the number of shifts, the employment effects are slightly lower. The difference is small, however.

\subsection{SENSITIVITY ANALYSIS}

The results presented in the last two sections depend for a large part on the parameter values chosen in Table 4.3. This section briefly considers how sensitive the resulting elasticities of working time reduction are with respect to changes in these parameter values. Table 4.6 summarises the results; the table contains the benchmark case in the first column.

- The first variant to consider is a higher elasticity of efficiency hours $\eta^{e}$. This case corresponds more closely to the parameter choice of Calmfors and Hoel (1989). As there are no longer any 
Table 4.6 Sensitivity analysis elasticities with respect to working time

\begin{tabular}{cccccccc}
\hline & $\eta^{e}=1$ & $\sigma=0.75$ & $\begin{array}{c}\eta^{\prime}=0.25 \\
(\theta=0.22)\end{array}$ & $\begin{array}{c}\varphi_{V}=0.25 \\
(\theta=0.35)\end{array}$ & $\begin{array}{c}\varphi_{z}=0 . \\
(\theta=0.35)\end{array}$ & $\begin{array}{c}\mu=0 . \\
(\theta=0.49)\end{array}$ \\
\hline \multicolumn{7}{c}{ Short-run cost minimisation } \\
\hline$N$ & -0.75 & -1.09 & -0.72 & -0.76 & -0.75 & -0.76 & -0.66 \\
$S$ & -0.86 & -1.19 & -0.99 & -0.86 & -0.88 & -0.85 & -0.78 \\
\hline \multicolumn{7}{c}{ Long-run cost minimisation } \\
\hline$K$ & -0.04 & -0.34 & -0.05 & 0.00 & -0.07 & -0.06 & -0.03 \\
$N$ & -0.75 & -1.05 & -0.71 & -0.76 & -0.74 & -0.75 & -0.66 \\
$S$ & -0.81 & -0.81 & -0.94 & -0.86 & -0.81 & -0.79 & -0.75 \\
$k$ & -0.10 & -0.10 & -0.28 & -0.10 & -0.14 & -0.09 & -0.12 \\
$c$ & -0.11 & -0.41 & -0.11 & -0.07 & -0.16 & -0.12 & -0.11 \\
\hline
\end{tabular}

When changing parameter values, the elasticity of shiftwork in labour $\operatorname{costs} \theta$ is adjusted simultaneously, in order to fulfil the first-order condition (4.10).

hourly productivity gains, the isoquant shifts further outward in Figures 4.2 and 4.4. Accordingly the impact is stronger: in the short run for employment and shiftwork; in the long run only for the two stock variables, as shiftwork, capital-intensity and unit costs are independent of scale.

- Further variations of the elasticity of efficiency hours - and thus in initial working hours, as the two are inversely related - allow to identify a number of critical values within this cost minimising framework:

- for worker-hours $E=N H$ to be constant, the hours elasticity $\eta^{e}$ should be 0.92 in the short run and 0.95 in the long run;

- in the short run operating time $U$ will be constant for $\eta^{e}=0.83$; in the long run the decline in operating time is independent of $\eta^{e}$;

- in the long run the capital stock would be constant for $\eta^{e}=0.66$;

- finally, long-run unit costs remain unaffected for $\eta^{e}=0.59$.

Thus for relatively long initial hours, i.e. $\eta^{e}<0.59$, working time reduction leads to a fall in unit costs, a decrease in the capital stock, a fall in operating time and a decrease in worker-hours. But for initial short hours, i.e. $\eta^{e}>0.95$, the opposite effects occur. Figure 4.5 illustrates that the effects of reduced hours vary with the initial length of the workweek.

- A higher elasticity of substitution $\sigma$ of the instantaneous production function, reduces the curvature of the isoquants in Figures 4.2 and 4.4. A reduction in working time then leads to stronger substitution effects towards shiftwork, reducing the impact on employment. In the long run the operating time decreases, unless $\sigma>0.80$. The impact on employment becomes zero for $\sigma>1.044$ in the short run and $\sigma>1.045$ in the long run. For a Cobb-Douglas production 


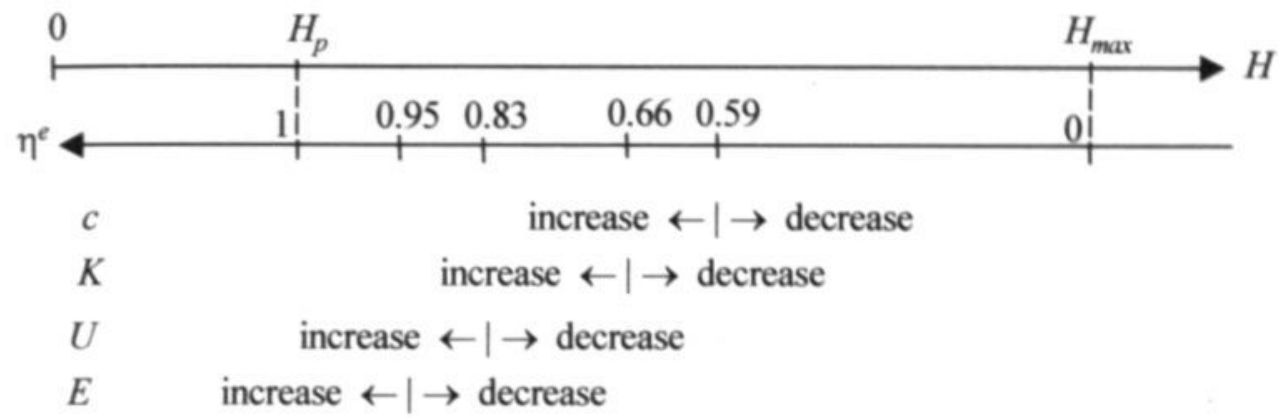

\section{Figure 4.5 Initial working time and working time reduction}

function, the long-run elasticities are $\varepsilon_{N H Q}=-0.43$ and $\varepsilon_{S H}=-1.89$ (the latter being independent of scale).

- The sensitivity with respect to the other parameters appears to be rather minor.

All in all, the sensitivity analysis suggests that the results are fairly robust, but that the initial length of working time is an important determinant of the size of the effects.

\subsection{COMPETITIVENESS}

The above results refer to a cost minimisation framework, thus at given output. The results indicate that unit costs may increase as a result of a reduction in the working time. As a consequence, profit maximisation can lead to adverse scale effects. This is analysed by Calmfors and Hoel (1989) for their short-run model in the context of perfect competition in the goods market. Their results indicate that the negative scale effect of the supply decision is likely to dominate the picture for the demand for labour.

This approach can not be followed in the long-run model of this chapter, however, as with constant returns, the scale of operations of individual firms is indeterminate under perfect competition. This can be remedied by the introduction of a downward sloping demand curve for goods. Therefore, briefly consider a goods market characterised by monopolistic competition. Suppose the demand for firm $i$ is given by the downward sloping demand curve

$$
Q_{i}=d\left(P_{i} / P\right) D(P), \quad \quad d^{\prime}(\cdot)<0, D^{\prime}(\cdot) \leq 0
$$

where $P_{i}$ is the price of firm $i, P$ is the average price on the market and $D$ is a shift parameter of the demand curve, for example related to aggregate demand, but which might well decline with the market price $P$. Let $\tau$ and $\eta$ denote the absolute value of the elasticities of the functions $d(\cdot)$ and $D(\cdot)$, respectively, then it is sensible to assume that $\tau>\eta \geq 0$. 
It is now straightforward to extend the long-run analysis of Section 4.4. Long-run profit maximisation with constant returns to scale leads to the well known condition for the Lerner index:

$$
\frac{P_{i}-c}{P_{i}}=\frac{1}{\tau} .
$$

The Lerner- index should be equal to the inverse of the absolute elasticity of firm demand. As a consequence, the price is a mark-up on unit costs and an increase in unit costs $c$ leads to a proportional increase in the price, at least if the elasticity of demand is constant. ${ }^{16}$

Suppose that the working time is reduced. Table 4.4 provided the numerical cost minimising elasticities $\boldsymbol{\varepsilon}_{X M Q}$ for $X=K, N$ and $\boldsymbol{\varepsilon}_{X H}$ for $X=S, k$ and $c .{ }^{17}$ In the profit maximising framework, the impact on unit $\operatorname{costs} \boldsymbol{\varepsilon}_{c H}$ triggers an additional scale effect of size $\tau \varepsilon_{c H}$ for capital and employment. The total effect for these stock variables thus becomes ${ }^{18}$

$$
\boldsymbol{\varepsilon}_{X H}=\boldsymbol{\varepsilon}_{X H Q}-\tau \boldsymbol{\varepsilon}_{c H} . \quad \text { for } X=K, N
$$

As the demand elasticity $\tau$ is probably relatively large, the scale effect might well dominate for these stock variables. Given the numerical elasticities of Table 4.4, reduced hours increase employment as long as $\tau<7.0$, whereas for larger values the negative scale effect dominates. Considering the parameter values underlying the sensitivity analysis of Table 4.6, the critical value varies between 2.6 (for $\eta^{e}=1$ ) and $11.1\left(\eta^{\prime}=0.25\right) .{ }^{19}$ So whether employment will fall in the case of profit maximisation, as suggested by Calmfors and Hoel (1989), depends most importantly on the firm specific demand elasticity.

The average observed profit share (in value added) from the Dutch National Accounts was 0.062 over the period 1960-1997. Using this value for the Lerner index in (4.14), a very rough indicator of the firm specific demand elasticity would be around 16. In Chapter $2 \mathrm{I}$ used the lower value $\tau=5$. Comparing these values with the above critical level, it should be no surprise if the scale effect would indeed dominate.

16 In the symmetric market equilibrium $P=P_{0}$, see below, so $\tau$ is the elasticity of $d(\cdot)$ evaluated at the relative price of 1 , which is independent of $c$.

17 In the long run shiftwork $S$, the capital-intensity $k$ or unit costs $c$, are independent of scale. Therefore, these elasticities need not to be taken conditional on $Q$.

18 Nothing changes for shiftwork $S$ and the capital-intensity $k$, as they are independent of scale. Calmfors and Hoel (1989) conclude that shiftwork might even fall in the case of profit maximisation. However, this is an artifact of their assumption of a given capital stock.

19 Using the parameter values of Calmfors and Hoel (1989), the critical value for $\tau$ is 4.2 . 
However, this is only a partial result ignoring the repercussion of reduced hours on the competitors. In a partial market equilibrium framework, competitors face the same increase in unit costs. Hence their prices will increase in line, as $P=P_{i}$. The scale effect then only operates through the aggregate demand $D(P)$, which is less elastic. As a consequence, the total effect in a symmetric equilibrium of the goods market reduces to

$$
\varepsilon_{X H}=\varepsilon_{X H Q}-\eta \varepsilon_{c H}, \quad X=K, N
$$

instead of (4.15). Estimates of market demand elasticities are typically much lower than firm specific elasticities. Therefore, the scale effect is less likely to dominate in a market equilibrium context.

\subsection{Conclusion}

This chapter considered in more detail the employment effects of reduced working time on employment and shiftwork. The additional intensive margin of adjusting shiftwork reduces the impact on employment, but in a cost minimising framework employment is still likely to increase, although the size of the effect depends on the initial length of the workweek. Moreover, it is shown that there are incentives to increase shiftwork, although probably somewhat less than proportional. As a consequence, the capital operating time will probably fall only slightly. This conclusion appears to be roughly in line with the observed near stationarity of operating times despite the reduction in working times. This chapter also identified other determinants of shiftwork and operating time, including factor costs and labour augmenting technical progress.

The analysis also illustrated that unit costs tend to increase as a consequence of working time reductions. In a profit maximising framework this loss in competitiveness will lead to adverse employment effects, although without altering the results with respect to shiftwork and operating time. In a closed economy all competitors will face the same increase in unit costs, hence the scale effect may be modest. In the exposed sectors of an open economy more important scale effects will arise. However, the claim by Calmfors and Hoel (1989) that there is a general presumption that employment will fall, can not be substantiated once the capital stock is allowed to be determined endogenously. 



\section{Wage Bargaining, Working Time and Unemployment}

\subsection{INTRODUCTION}

Work-sharing is a recurring theme in the European unemployment debate. Every now and then at times of high unemployment, the suggestion is made to reduce working times as to redistribute the available work. A recent example is France, where in 1997 the then newly elected socialist Jospin government suggested to reduce weekly hours to 35 at the beginning of the new millennium. Around the same time a similar discussion occurred in Italy. In France a law has been enacted to implement this reduction in 2000 . Early adopting firms got deductions on their social premiums to provide incentives. In the early eighties a similar attempt by Mitterand was considered a failure, see Hunt (1998).

In Germany and the Netherlands, similar discussions were observed in the eighties. In these countries, however, the work-sharing debate must be considered in the context of labour relations. Unions, instead of governments, pressed for reduced hours. After the first two oil shocks in the seventies, the Dutch economy was in disarray. ${ }^{1}$ Unemployment increased rapidly, reaching its highest level of about $10 \%$ in 1983 . The government and the social partners felt the urge for changes. This lead to consultations and in October 1982 the famous Wassenaar Agreement was struck. One of the main recommendations for unions was to moderate wage claims in exchange for increases in employment and reductions in working time. Except as employer in the public sector, the government was not directly involved in the agreement, but would facilitate the wage moderation by general tax reductions. Since then annual full-time working time has fallen by roughly 100 hours, partly as a reduction in weekly hours from 40 to 38 hours ( 36 in the public sector) and partly by an increase in holidays. Moreover wages have been moderated and the wedge has been reduced. In the second half of the nineties, this sustained policy was considered a success and was referred to as the Dutch miracle.

The economic literature has been rather sceptical towards the merits of work-sharing policies. The major argument is the so-called lump-of-labour fallacy, see Layard, Nickell et al. (1991, Ch.

1 The German case is discussed in Hunt (1998). 
10). This critique refutes the idea that there is a fixed amount of work that can be redistributed at will. On the contrary, employment is determined by demand and supply factors. The impact of working time may occur through various channels, see Freeman (1998) and Hunt (1998) for recent discussions. ${ }^{2}$ The main ones are:

- Labour productivity per hour may change, although the direction is ambiguous. First, the share of non-productive hours increases, reducing hourly productivity, but second, reduced fatigue works in the opposite direction, Booth and Ravallion (1993).

- Wage costs per hour increase through the existence of fixed costs per employee. Beside the direct negative effect on the demand for labour (worker-hours), this provides an incentive to use more overtime and to substitute away from workers, Hart (1984b) and Hunt (1999).

- Capital utilisation will decrease, at least to the degree that the operating time of the capital stock is linked to the working time of workers, see Calmfors and Hoel (1989). This leads to an increase in production costs and a reduction of labour demand.

- Hourly wage rates may increase in an attempt to protect real incomes. This may occur due to union wage setting, as in Calmfors (1985), or to efficiency wage considerations, as in Hoel and Vale (1986).

- Labour supply, i.e. participation in the labour market, may change, although the direction is ambiguous and depends on desired hours, Hunt (1998).

Taking these factors together, the general equilibrium effects of work-sharing on unemployment are puzzling. Layard, Nickell et al. (1991, Ch. 10) claim that equilibrium unemployment is unaffected by work-sharing. However, as their model does not incorporate working time and leisure as separate elements, this conclusion seems doubtful. In the efficiency wage model of Hoel and Vale (1986) the unemployment rate will increase if working time is reduced, but they also ignore the utility of leisure. Cahuc and Granier (1997) do take this into account, and conclude that equilibrium unemployment is unaffected by work-sharing policies. The current chapter elaborates on these issues. The conclusion is that there is a $U$-shaped relation between equilibrium unemployment and working time. Recently, FitzRoy, Funke et al. (2002), Marimon and Zilibotti (2000), Moselle (1996) and Rocheteau (2002) obtained similar results, but in different settings. FitzRoy, Funke et al. (2002) use a monopoly union model with simple Cobb-Douglas utility and production functions. Moselle (1996) considers a moral hazard efficiency wage model. Marimon and Zilibotti (2000) use an equilibrium matching model and Rocheteau (2002) combines the equilibrium matching approach with moral hazard issues. This chapter uses the union bargaining framework, considering three different settings: monopoly union, right-to-manage and efficient bargaining. Moreover, the chapter generalises the specification of utility and production functions, as contrary to most other papers, the

2 Further references can be found in the surveys by Corneo (1994) and Houpis (1993). 
utility function is left unspecified and the production function incorporates the impact of working time on capital services.

The chapter can be considered as an elaboration of the seminal paper by Calmfors (1985). That paper considers a partial equilibrium monopoly union model. I extend the model in a number of directions to incorporate most of the above issues and to derive general equilibrium results. As in Calmfors (1985) I do not include overtime into the analysis, but assume that cuts in standard hours translate almost one for one into reductions of actual hours. Hunt (1999) confirms this for Germany and I found a similar result for the Netherlands in Chapter 3, see also Hunt (1998). In the labour demand model I do incorporate a dependence of capital services on the working time of workers, reducing the scope of work-sharing policies. This is reinforced by a focus on long-run adjustment, where the capital stock is allowed to adjust.

With respect to the wage bargaining, I extend the monopoly union results of Calmfors (1985) towards right-to-manage and efficient bargaining models. As working time is assumed to be given exogenously, wage bargaining can be described in terms of hourly wages or in terms of total remuneration. It turns out that the latter is easier, but I also describe the impact on hourly wages to compare with Calmfors' results. For hourly wages, the results of my partial equilibrium analysis are fairly in line with his results, but I hope to suggest a more intuitive interpretation. Even though hourly wages may increase as a consequence of working time reduction, the results indicate that annual incomes are likely to fall. The partial equilibrium employment effects are ambiguous and depend on the initial working time: for long hours employment increases, but for short hours employment falls. In the general equilibrium, I find similar results, leading to the U-shaped relation between unemployment and working time.

The chapter is organized as follows. Section 5.2 introduces the partial equilibrium monopoly union model and describes the impact of reduced working time within this model. Section 5.3 discusses the impact of working time reductions on wage setting in the right-to-manage union model and section 5.4 considers the efficient bargaining framework. Section 5.5 then considers the labour market equilibrium of the right-to-manage model. Section 5.6 concludes.

\subsection{THE MONOPOLY UNION MODEL}

\subsubsection{Firms}

The model of the firm has been extensively discussed in Chapter 2, so I can be rather brief here. Firms are operating in a monopolistically competitive output market. A typical firm in the industry faces a downward sloping iso-elastic demand curve of the type $Q=P^{-\tau} D$, where $Q$ is the output of the firm, $P$ is its price, $D$ is a demand shift variable and $\tau>1$ is the elasticity of demand. The demand shifter $D$ may well depend on the aggregate price level, but for the present analysis it can, 
without loss of generality, be set equal to unity. So the revenue of the firm is given by $Q^{v}$, where $v \equiv$ $1-1 / \tau \in(0,1)$ measures the competitiveness of the output market.

Firms produce their output with capital and labour as their only two production factors. Beside the stocks of these inputs, capital $K$ and employment $N$, the duration of operation matters. Ignoring shiftwork, the operating time of the capital stock is equal to the working time $H$ of labour. To incorporate warming-up times and fatigue effects, working time in labour services is replaced by efficiency hours $e(H)$. For the sake of analytical convenience, I also replace working time in capital services by efficiency hours. ${ }^{3}$ In line with the discussion in Section 2.2.1, efficiency hours are increasing in working time, though probably at a decreasing rate, so $e^{\prime \prime}(H)<0<e^{\prime}(H)$, at least in the relevant range of working hours. More specifically, the elasticity of efficiency hours with respect to working time $\eta^{\prime}$ is non-increasing in working time.

Combining these assumptions with a linear homogeneous production function $F(\cdot)$ in capital and labour services, see also equation (2.5), output is given by

$$
Q=F(K e(H), N e(H))=e(H) N f(k),
$$

where $k \equiv K / N$ is the capital-labour ratio, measured in bodies, and $f(k) \equiv F(k, 1)$ is the per capita instantaneous production function, satisfying $f^{\prime \prime}(k)<0<f^{\prime}(k)<f(k) / k$. So the elasticity $\eta^{\prime} \equiv$ $k f^{\prime}(k) / f(k)$ of the per capita instantaneous production function satisfies $\eta \in(0,1)$. The substitution elasticity between capital and labour (bodies) is $\sigma$, and in line with most evidence, see Hamermesh (1993, Ch. 3), I assume $\sigma \leq 1$.

In this chapter working time is still considered fixed exogenously for the firms. It is best interpreted as standard hours either set by the government or, more realistically, determined in the bargaining between firms and unions. As elaborated in Chapter 6, there are many different solutions to this hours bargaining problem. The maintained hypothesis here is that hours are determined before the wage bargaining. In this way I'm able to describe the response to changes in hours for any outcome of the hours bargaining process. Moreover, I assume that firms do not use overtime. Although the impact of reductions in working time on employment may depend on the use of overtime, see e.g., Freeman (1998) and Hart (1984b), the evidence seems to suggest that actual hours vary proportionally with standard hours, see Hunt (1998) and Chapter 3.

With this set-up, labour costs consist of two parts: first, the hourly wage costs $W$ and second, quasi-fixed labour costs $V$. The latter are independent of the number of hours and may consist of

3 This amounts to the case $K=1$ in Chapter 2. As argued in Chapter 2, the crucial assumption is that working time affects capital services. Allowing for different efficiency hours in capital and labour services, see de Regt (1988), complicates the algebra but does not yield qualitatively different results. 
discounted hiring costs, holiday and sick payments, etc. In the search models of Marimon and Zilibotti (2000) and Rocheteau (2002) these hiring costs depend on labour market tightness. This is ignored here. Given the absence of overtime hours, total remuneration per worker corresponds to $Y$ $=W H$. As the firm also incurs fixed costs, labour costs per worker are $V+Y$. The share of fixed costs in labour costs is denoted $\varphi_{V} \equiv V /(V+Y)$. Finally, the user costs of capital are exogenously given by $R$. It is thus assumed that operating time of capital does not influence these costs, see Chapter 4 for a discussion. Given the above assumptions, the profit of an individual firm can be written as $\Pi=Q^{v}-(V+W H) N-R K$.

In Chapter 2 I have shown that it is important to include the optimal determination of the capital stock when considering the impact of reduced hours on the demand for labour. The reason is that working time affects capital services in my specification of the production function. Hence working time reductions make capital less productive and may reduce capital formation. Taking the capital stock fixed, as in Calmfors (1985), may thus overstate the potential for work-sharing policies. Therefore, I concentrate on the opposite extreme where the capital stock may be adjusted freely. The qualitative outcomes for the short-run model with fixed capital stock are rather similar, however, and the short-run impact will be included in the numerical illustration.

Maximising the profit with respect to the capital stock $K$ and number of workers $N$ gives the firstorder conditions, compare equations (2.15) and (2.16),

$$
\begin{gathered}
v e(H)^{v} N^{v-1} f(k)^{v-1} f^{\prime}(k)=R, \\
v e(H)^{v} N^{v-1} f(k)^{v-1}\left[f(k)-k f^{\prime}(k)\right]=V+Y .
\end{gathered}
$$

The marginal revenue of the input variables should correspond to their marginal costs. The secondorder conditions for profit maximisation, $v<1$ and $\sigma>0$, are satisfied. Log-differentiating both equations, one can easily show that the elasticity of labour demand with respect to remuneration is $\varepsilon_{N Y}=-\left(1-\varphi_{V}\right)\left[\tau\left(1-\eta^{\prime}\right)+\sigma \eta^{\prime}\right]<0$.

Dividing the first-order conditions, the capital-labour ratio is determined independently of the scale as

$$
\frac{f^{\prime}(k)}{f(k)-k f^{\prime}(k)}=\frac{R}{V+Y}
$$

which is a special case of equation (2.7). The optimal capital-labour ratio only depends on working time through its impact on total remuneration $Y$. 
The impact of a working time reduction on labour demand was extensively discussed in Chapter 2 , recall Figure 2.5 for a graphical illustration. It is useful to distinguish between the case where remuneration $Y$ is fixed or where the hourly wage $W$ is fixed. In the first case we have the conditional elasticity $\varepsilon_{N H Y}=(\tau-1) \eta^{e}>0$, whereas in the second case the conditional elasticity becomes $\varepsilon_{N H W}$ $=\boldsymbol{\varepsilon}_{N M Y}+\boldsymbol{\varepsilon}_{N Y}$, which can be either positive or negative. ${ }^{4}$

- A reduction in hours at given remuneration $Y$ is tantamount to neutral technological regress, and consequently reduces employment. Although more workers are needed to produce the same amount of output, the higher unit costs at fixed remuneration $Y$ imply that output is reduced in a monopolistic competitive environment. The second-order condition $(\tau>1)$ guarantees that this output effect dominates.

- At given hourly wages $W$, however, a simultaneous decrease in remuneration occurs, which leads to a positive impact on employment through the labour demand elasticity $\boldsymbol{\varepsilon}_{N Y}$.

- Whether employment increases or falls depends on the length of working time, see Chapter 2. The productivity effect $\varepsilon_{N M y}$ dominates for short hours, whereas the cost effect $\varepsilon_{N T}$ dominates for long hours.

More formally, let $H_{n}$ be implicitly defined by $\varepsilon_{N H W}=0$, as in Chapter 2 . In Appendix I it is shown that the critical level $H_{n}$ is a decreasing function of the wage. Moreover, $\varepsilon_{N H W} \gtrless 0$ for $H \lessgtr H_{n}$. In other words, at given hourly wage $W$, the number of workers is maximised at $H_{n}$ and employment is positively (negatively) related to hours worked for shorter (longer) working times.

The same two effects can also be identified for profits $\Pi$; again the productivity effect dominates for relative short hours, whereas the cost effect dominates for relatively long hours. A work-sharing policy will thus reduce profits for relatively short hours, but will increase profits for long hours. Using the envelope theorem, the corresponding elasticities can be shown to be $\varepsilon_{\Pi H Y}=(\tau-1) \eta^{e}>0$ for the productivity effect and $\varepsilon_{\Pi Y}=-(\tau-1)\left(1-\varphi_{V}\right)\left(1-\eta^{\prime}\right)<0$ for the cost effect. The critical level for which both effects cancel is given by hours demand $H^{d}>H_{n}$, see Appendix I.

Finally, these two opposing effects can also be used to define the warranted change in remuneration as to keep employment, or profits, constant in case of a working time reduction. This will provide useful reference points for the discussion. The corresponding iso-employment working time elasticity of remuneration (iso-employment elasticity for short) is given by $\lambda_{N} \equiv-\varepsilon_{N H Y} / \varepsilon_{N Y}>$ 0 , whereas the iso-profit working time elasticity of remuneration (iso-profit elasticity for short) is defined as $\lambda_{\Pi I} \equiv-\varepsilon_{\Pi M Y} / \varepsilon_{\Pi Y}>\lambda_{N}$. The properties of these elasticities are derived in Appendix I. Figure 5.1 illustrates that the iso-employment and iso-profit elasticities are declining in hours. Moreover, the iso-profit elasticity $\lambda_{\Pi}$ exceeds the iso-employment elasticity $\lambda_{N}$, although in more

4 Remember that $\varepsilon_{z x}$ denotes the elasticity of the endogenous variable $Z$ with respect to the exogenous variable $X$, whereas $\varepsilon_{\mathrm{zxY} Y}$ denotes the same elasticity, but conditional on variable $Y$. 


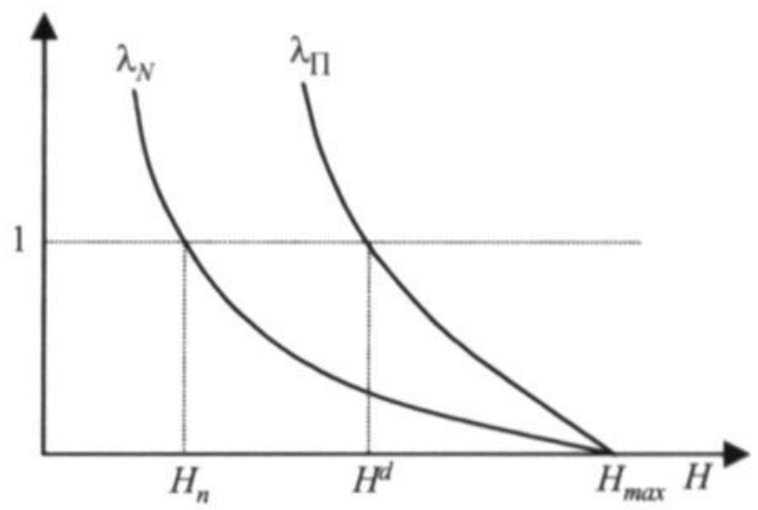

Figure 5.1 Iso-employment and iso-profit elasticities

competitive markets the iso-employment elasticity is closer to the iso-profit elasticity. The declining nature of both curves illustrates that at shorter initial hours work-sharing policies should be accompanied by stronger decreases in remuneration to keep employment, or profits, constant. When the iso-employment (iso-profit) elasticity exceeds one, hourly wages should even fall to keep employment (profits) constant. The corresponding level of hours is $H_{n}$, and $H^{d}$ for profits. Thus, in the range $\left(H_{n}, H^{d}\right)$ a working time reduction at unchanged hourly wages, leading to a proportional fall in remuneration, leads to more employment but lower profits. This will be important in the general equilibrium analysis of Section 5.5.

\subsubsection{Worker utility}

All agents in the economy have an identical utility function in terms of consumption and leisure. In our static set-up, there is no saving, and consumption is equal to income. Hence $Y$ stands both for total remuneration and for consumption. Agents can be in three different states: they can be employed, unemployed or not participating. This section only considers workers employed in a specific firm. If not employed in this firm, their outside option is given as $U^{a}$ in utility terms. This outside option will be specified in the labour market equilibrium analysis of section 5.5, but is exogenous in the partial equilibrium framework.

Workers can only be employed full-time at a fixed working time $H$, earning $Y$. Their utility is then given by $U(Y, H)$, with partial derivatives $U_{H}<0<U_{Y}$, as agents enjoy consumption and leisure. It will be useful to parameterise the utility function and to put in some more structure than in Calmfors (1985). The rate of relative risk aversion for consumption is $\alpha_{Y} \equiv-Y U_{Y Y} / U_{Y} \geq 0$. The 'parameter' $\xi \equiv-Y U_{Y H} / U_{H}$ plays an important role in the sequel. ${ }^{5}$ The sign of $\xi$ determines whether

5 Notice that $\xi$ is not a constant parameter, but typically depends on income and hours worked, except for Cobb-Douglas preferences. 
consumption and leisure are Edgeworth substitutes $(\xi>0)$ or complements $(\xi<0)$. Marimon and Zilibotti (2000) use two different specifications for the utility function: a CES-specification and socalled GHH-preferences. The latter is a generalised version of the quasi-linear utility introduced in the real business cycle literature by Greenwood, Hercowitz et al. (1988). ${ }^{6}$ Consumption and leisure can be shown to be substitutes $(\xi>0)$ for the GHH-preferences, but complements $(\xi<0)$ for the CES-preferences. As I argue in Chapter 6, I have no strong feelings about the sign of $\xi$. Finally, as usual, leisure is assumed to be a normal good, implying $\xi<\boldsymbol{\alpha}_{Y}$.

To derive more specific results later on, I need to assume that consumption and leisure are not too strong Edgeworth complements. A sufficient - but not necessary - condition will be that

$$
U_{Y H} \geq \frac{U_{Y} U_{H}}{U},
$$

or $\xi \geq-Y U_{Y} / U$. It is easily checked that this condition holds for a Cobb-Douglas utility function. For a CES-utility function, however, the sufficient condition (5.5) is violated if the elasticity of substitution between consumption and leisure, say $\zeta$, is below one. Marimon and Zilibotti (2000) consider values of $\zeta$ ranging between 0.2 and 2 . Based on micro-econometric evidence on Dutch labour supply, Bovenberg, Graafland et al. (2000) set $\zeta=4.0$ in their applied general equilibrium model for the Netherlands.

If workers would be free to choose hours worked, their hours supply $H^{\boldsymbol{F}}$ would be determined by the usual equality between the wage and the marginal rate of substitution. This can be written as $\omega \equiv$ $-\left(H U_{H}\right) /\left(Y U_{Y}\right)=1$, where $\omega$ represents the marginal rate of $\log$-substitution. Notice that $\omega \lessgtr 1$ for $H \lessgtr H$, indicating that $\omega$ increases with working time. ${ }^{7}$ The impact of income (or the hourly wage rate) on the marginal rate of $\log$-substitution $\omega$ is ambiguous, however. Let $\omega_{Y}$ denote the relative change in $\omega$ due to changes in income, so $\omega_{Y} \equiv \frac{\partial \ln \omega}{\partial \ln Y}=\alpha_{Y}-1-\xi$. The sign of the hours supply is given by the sign of $-\omega_{\gamma}$. In view of the secular trend towards shorter working times, it seems reasonable to focus on cases where $\omega_{Y} \geq 0$.

Straightforward calculations show that for CES-preferences $\omega_{Y}=1 / \zeta-1$, so $\omega_{Y} \geq 0$ implies $\zeta s$ 1, with the equality for Cobb-Douglas preferences. GHH-preferences lead to $\omega_{Y}=-1$. Accordingly, CES-preferences with $\zeta>1$ and GHH-preferences appear to have some counterfactual feature, as they cannot explain the secular downward trend in hours worked. As noted by Marimon and Zilibotti (2000), this unattractive property can be remedied if the disutility of working increases with labour productivity, e.g., through technical progress in home production or

6 The GHH-preferences are specified as $U=\gamma\left(Y-X H^{x} / \chi\right)^{1 / \gamma}$, with $\gamma>1, \chi>1$ and $X>0$.

7 As is guaranteed - at least locally around supply $H$ - by the second-order condition of utility meximisation. 
consumption externalities as 'keeping up with the Joneses'. A shortcut could be to make the disutility of hours proportional to income - or income of a reference group - but that basically brings us back to multiplicative separable preferences, such as the Cobb-Douglas. ${ }^{8}$

The two left panels of Figure 5.2 below illustrate the properties of the utility function of an employed worker. The figure uses natural logarithms, so slopes correspond to elasticities. The upper-left panel uses total remuneration (or income) $Y$ as the relevant variable. To be willing to work in the firm under consideration, the utility level has at least to be equal to the outside option $U^{p}$, as is for example the case for the indifference curve $U^{m}$. Along an indifference curve, there is a positive relation between income $Y$ and working time $H{ }^{9}$ The slope corresponds to the marginal rate of logsubstitution $\omega$. Starting from the outside option $U^{u}$ with marginal rate of $\log$-substitution $\omega^{a}$, an increase of income from $Y^{a}$ to $Y^{m}$ raises utility and increases the slope to $\omega^{m}>\omega^{a}$, at least as long as $\omega_{Y}>0$.

The lower-left panel of Figure 5.2 illustrates the same properties, but with the hourly wage $W$ as the dependent variable. The main difference is that the indifference curves are $\mathrm{U}$-shaped and have a minimum at hours supply $H^{5}$. Assuming that $\omega_{Y}>0$, hours supply is backward bending. The figure considers the case of underemployed workers, so $H<H^{E}$ or $\omega<1$.

\subsubsection{Monopoly union wage setting}

Employment at each firm in the economy is unionised. Firms retain their right-to-manage power and determine employment (and capital) after the wage has been set unilaterally by the union. This corresponds to Calmfors (1985). The assumption that capital is determined after the wage setting, implies that firms cannot pre-commit on the capital stock. Manning (1994) has shown that the timing of the capital stock decisions might change the comparative statics of the model. To simplify the model, I abstract from strategic behaviour in the determination of capital, however. As labour demand is more elastic in this case, this will reduce wage claims.

The specification of the union utility function is an awkward business, see Pencavel (1991, Ch. 3) for a discussion. Obviously, union utility incorporates, among others, employment possibilities, income and leisure. For the present purpose, I assume that the utility $\Gamma$ of a typical union is given by the Stone-Geary function

$$
\Gamma=N^{\theta}\left[U(Y, H)-U^{a}\right] . \quad \theta>0
$$

8 Such a procedure may reconcile the cross-sectional evidence of weekly increasing labour supply with the time-series evidence of a secular decline in hours worked.

9 As $\omega_{H} \equiv \frac{\partial \ln \omega}{\partial \ln H}>0$, the indifference curve can be shown to be convex. 
The union wants to increase the utility of its employed members above the given outside option $U^{u}$, but also cares about employment $N$. The parameter $\theta$ is an indicator of the weight put on employment. For $\theta=1$, this specification generates the same outcomes as the expected or utilitarian utility function used by Booth and Ravallion (1993), Calmfors (1985), FitzRoy, Funke et al. (2002) and Houpis (1993).

At given working time, maximising union utility with respect to the hourly wage $W$ is equivalent to maximising it with respect to total remuneration $Y$. Maximising the (log of the) union utility function (5.6), subject to the labour demand in (5.3) and (5.4), with respect to remuneration $Y$ gives

$$
\frac{1}{\boldsymbol{\varepsilon}_{N Y}}=-\frac{\theta\left[U(Y, H)-U^{a}\right]}{Y U_{Y}(Y, H)} .
$$

The left-hand side is the slope of the logarithmic labour demand curve, which corresponds to the inverse of the labour demand elasticity. The right-hand side is the slope of the union indifference curve in the log-income and log-employment space. It corresponds to minus the ratio of the utility ent per unit income $\left(U-U^{u}\right) / Y$ of additional workers, weighted by the value $\theta$ unions attach to employment relative to the marginal utility $U_{Y}$ of income of employed workers.

The monopoly solution is illustrated in Figure 5.2. The upper-right panel illustrates that union indifference curves are downward sloping in terms of income and hours worked. It has an asymptote for $Y^{u}$, implicitly defined by $U^{u}=U\left(Y^{u}, H\right)$, as the utility for employed workers should not fall below the outside option. The logarithmic labour demand function is depicted as $\ln N^{d}$ in the right-hand panels of the figure. Given the use of logarithms, the slope of the labour demand curve is the reciprocal of the elasticity $\varepsilon_{N Y}$. Moreover, as argued in Chapter 2, the logarithmic labour demand is concave. ${ }^{10}$ At the equilibrium $M$, as identified by equation (5.7), the union indifference curve $\Gamma^{m}$ is tangent to the labour demand curve. The second-order condition for monopoly union wage setting ensures that the union indifference curve is less concave than the labour demand curve. From the left panels, observe that employed workers have utility $U^{m}>U^{u}$. In a competitive labour market with fixed working time the resulting allocation would be $A$, because workers would be forced to accept their outside option.

10 Basically, the absolute value of the labour demand elasticity $\varepsilon_{N Y}$ increases with the level $c^{f}$ remuneration $Y$ : first, with higher remuneration the share of quasi-fixed costs in labour costs $\varphi_{V}$ falls; second, higher remuneration may change the optimal share of capital costs $\eta^{f}$ in total costs. See also Appendix I. 

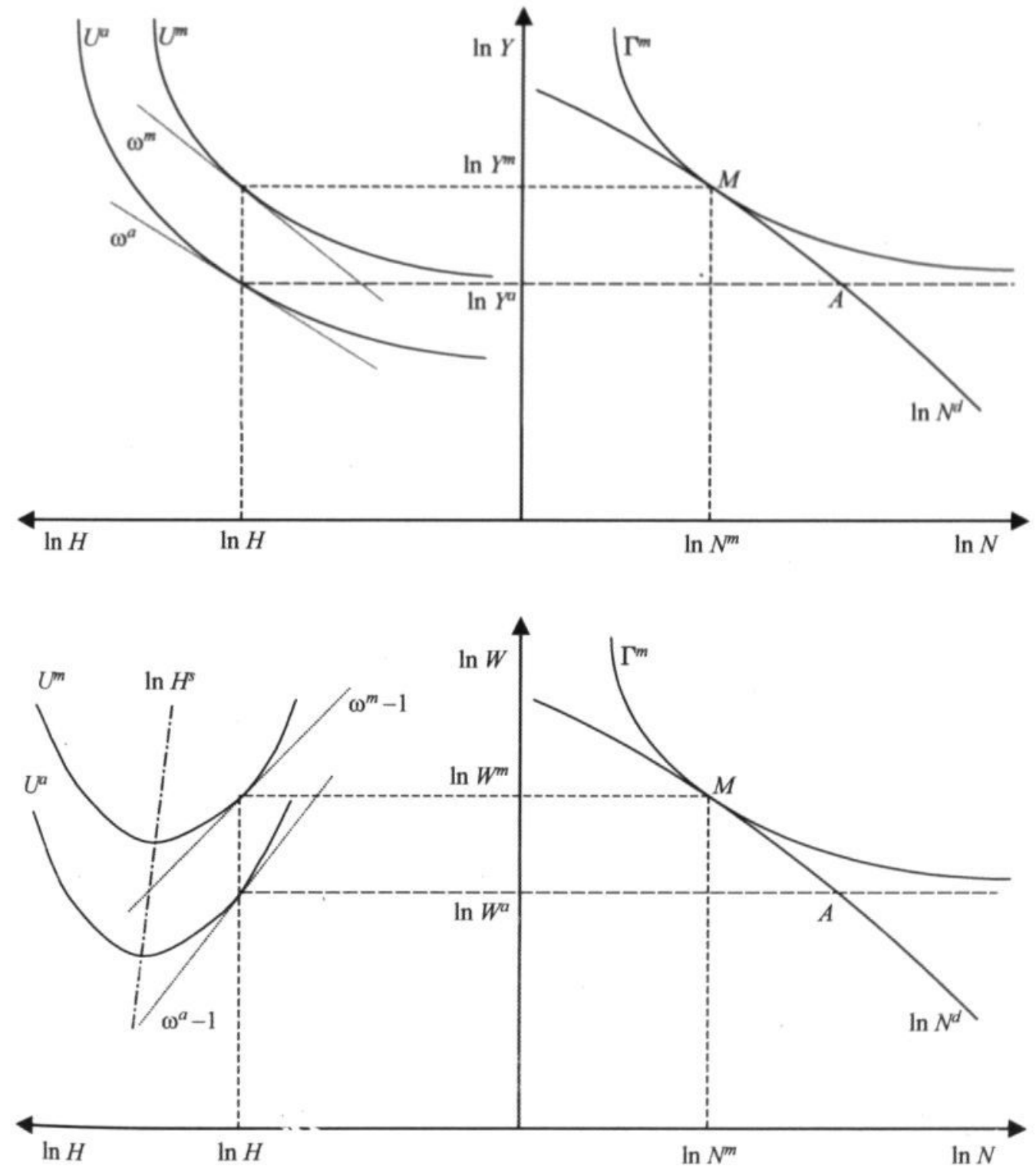

Figure 5.2 The monopoly union model 
The same partial equilibrium is again illustrated in the lower panels, but with the hourly wage on the vertical axis. The asymptote is given by $W^{a}=Y^{a} / H$, but the remaining part of the figure is similar.

\subsubsection{Working time reduction}

First, consider the impact of reduced working time on individual and union preferences at given monopoly union remuneration $Y^{m}$. This is illustrated in Figure 5.3, which corresponds to the upper panel of Figure 5:2, where hours are reduced from $H_{0}$ to $H_{1}$. From the left-hand panel it is obvious that employed workers increase their utility from $U^{m}$ to $U_{1}$. The increased individual utility implies that the union can obtain its old utility level $\Gamma^{\mathrm{m}}$ with lower employment $N_{1}$. Hence the union indifference curve in the right-hand panel shifts left towards the dotted curve $\Gamma_{1}\left(H_{0}\right)$. With the old working time, this combination of $Y^{m}$ and $N_{1}$ would yield union utility $\Gamma_{1}\left(H_{0}\right)<\Gamma^{m}$.

More important, the union indifference curve rotates, compare the curves $\Gamma_{1}\left(H_{0}\right)$ and $\Gamma^{m}\left(H_{1}\right){ }^{\prime \prime}$ Differentiating the left-hand side of the first-order condition (5.7) with respect to hours, it can be shown that the union indifference curves become steeper if (and only if)

$$
U_{Y H}-\frac{U_{Y} U_{H}}{U-U^{a}}>0 .
$$

The left-hand side cannot be signed unambiguously: it is positive if consumption and leisure are Edgeworth substitutes $(\xi>0)$, but could be negative if consumption and leisure are Edgeworth complements $(\xi<0)$. Condition $(5.5)$, however, is a sufficient condition for the expression to be positive. For this type of preferences the union indifference curves in Figure 5.3 become steeper, as $\Gamma_{1}\left(H_{0}\right)$ and $\Gamma^{m}\left(H_{1}\right) .^{12}$

Combining the effects of the changes in labour demand and union utility in Figures 2.5 and 5.3 , we can derive the impact on remuneration. Merging the two figures gives a rather blurred picture, however, yielding no further insight. But as the monopoly remuneration is determined by tangency between labour demand and union utility, recall equation (5.7), it is only the change in the slopes of labour demand and union utility that matter, and not the change in their positions. At given remuneration the labour demand elasticity is unaffected by a work-sharing policy, but the indifference curve becomes steeper, at least if (5.8) is fulfilled. Hence there is an incentive to reduce

11 Moreover, their limit remuneration $Y^{a}$ falls to $Y_{1}^{a}$ due to the increased leisure. Due to the fall in limit remuneration the union indifference curve also shifts downward, see $\Gamma^{m}\left(H_{1}\right)$.

12 The sufficient condition (5.5) does not hold for CES-preferences with an elasticity of substitution $\zeta$ $<1$. However, I conjecture that the necessary condition $(5.8)$ holds as long as the elasticity of substitution is not too small. Indeed, for CES-preferences this condition can be written as $\zeta>$ $1-U^{\mu} / U$ and wage setting guarantees that the utility $U$ exceeds the outside option $U^{u}$. 


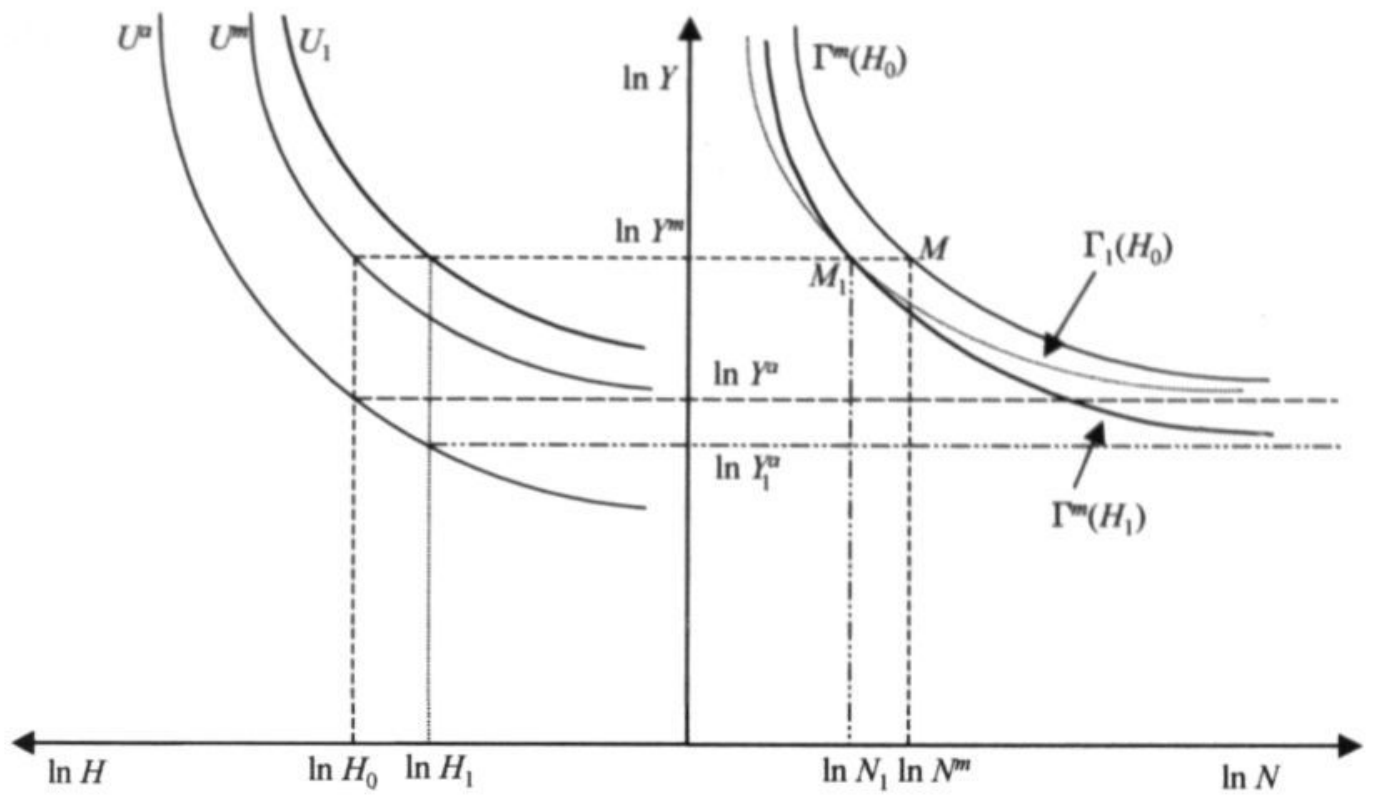

Figure 5.3 Union utility, remuneration and working time reduction

remuneration. In the next section this is elaborated for the more general right-to-manage bargaining framework.

\subsection{RIGHT-TO-MANAGE BARGAINING}

\subsubsection{Wage bargaining}

The monopoly union model is a special case of the right-to-manage bargaining framework and it is easy to extend the analysis in this direction. The wage bargaining game is not modelled explicitly. As usual in the literature on wage formation, see e.g., Layard, Nickell et al. (1991), I assume that the outcome of the bargaining process can be found by maximising an asymmetric Nash function. Muthoo (1999) provides a critique on this approach. The Nash-maximand is given by

$$
\mathbf{\Omega}=(\Gamma-\underline{\Gamma})(\underline{I}-\underline{\Pi})^{\beta}, \quad \beta \geq 0
$$

where $\beta$ measures the bargaining power of firms, insofar not reflected in their fallback options $\underline{\Gamma}$ and II. For $\beta=0$ the model reduces to the above monopoly union model, whereas for $\beta \rightarrow \infty$ firms have all the bargaining power and will set the wage equal to the outside option. In the long-run model, both threat-points are set equal to zero, hence the Nash-maximand reduces to $\Omega=\Gamma \Pi^{\beta}$. 
For the union this implies that workers are able to obtain the outside utility $U^{u}$ during a strike, for the firm this is consistent with the (admittedly unrealistic) hypothesis that the capital stock can be adjusted freely after completion of the wage bargain. ${ }^{13}$

The outcome of the wage bargain is most easily obtained differentiating the log of the Nashmaximand with respect to remuneration. After rearranging, this yields the first-order condition

$$
\frac{Y U_{Y}(Y, H)}{U(Y, H)-U^{a}}=\mu_{Y} \equiv-\theta \varepsilon_{N Y}-\beta \varepsilon_{\Pi Y} .
$$

This is a straightforward generalisation of equation (5.7) for the monopoly union. The left-hand side is the increase in utility rent for employed workers. The first term on the right-hand side is due to the right-to-manage assumption and measures the employment costs of increasing remuneration. The second term is due to the bargaining power of firms and captures employer resistance due to lower profits. Taken together, $\mu_{Y}$ thus captures wage resistance.

As usual in right-to-manage models, the outcome will be on the labour demand curve somewhere between $M$ and $A$ in terms of the right panels of Figure 5.2. As $\beta$ increases, wage resistance increases and we move downwards along the labour demand curve. The competitive outcome $A$, where $U=U^{u}$, results in the limiting case where the firm has all bargaining power $(\beta \rightarrow \infty)$.

Wage resistance $\mu_{Y}$ plays an important role in the model. So consider its determinants. Using the model of the firm, wage resistance can be written as

$$
\mu_{Y}=\left(1-\varphi_{V}\right) \theta\left[\tau_{\beta}\left(1-\eta^{f}\right)+\sigma \eta^{f}\right]>0,
$$

where $\tau_{\beta} \equiv \tau+\beta(\tau-1) / \theta \geq \tau>1$. One easily checks that wage resistance satisfies

$$
\mu_{Y}=\mu\left(\varphi_{\eta}, \theta, \beta, \tau, \sigma, k\right),
$$

where the signs below the variables denote the sign of the corresponding partial derivative. The signs of the partial derivatives are as expected. Wage resistance is high in more competitive markets ( $\tau$ high); when labour is easily substituted by capital ( $\sigma$ high); when the labour share is high ( $\eta^{\prime}$ low); when employment is highly valued ( $\theta$ high); or when firm bargaining power $\beta$ is high. Higher quasifixed costs $V$ reduce employer resistance, as it makes remuneration $Y$ a smaller part of labour costs. For the capital-intensity $k$, which operates through the capital share $\gamma$, the sign depends on the

13 In the short-run model the fallback option of the firm should be specified as $\underline{\Pi}=-R K$. 
elasticity of substitution, being positive for $\sigma<1$ and equal to zero for the Cobb-Douglas case $(\sigma=$ 1). For the total impact of $Y$ on wage resistance, notice that

$$
\gamma_{Y} \equiv \frac{Y}{\mu_{Y}} \frac{d \mu_{Y}}{d Y}=\varphi_{V}+\left(1-\varphi_{V}\right) \frac{(1-\sigma)\left(\tau_{\beta}-\sigma\right) \eta^{f}\left(1-\eta^{f}\right)}{\tau_{\beta}\left(1-\eta^{f}\right)+\sigma \eta^{f}}>0 .
$$

So wage resistance increases with remuneration $Y$, although less than proportionally as $\gamma_{Y} \in$ $\left[\varphi_{r}, 1\right) .{ }^{14}$ Finally, notice that wage resistance does not depend on working time, except for its impact on total remuneration. This is the main reason why it is easier to work in terms of remuneration instead of hourly wages.

The second-order condition of the wage bargain corresponds to

$$
\Lambda_{Y} \equiv \omega_{Y}+\gamma_{Y}+\xi+\mu_{Y}>0
$$

which is assumed to hold. Sufficient, but not necessary, conditions are $\omega_{Y} \geq 0$ and assumption (5.8), as (5.8) and (5.10) jointly imply $\xi+\mu_{Y}>0$.

\subsubsection{Working time reduction}

The partial equilibrium bargaining model can be used to derive the impact of an exogenous reduction in working time on remuneration, hourly wages, employment and welfare. It turns out that it is most convenient to start with the impact on remuneration, instead of the hourly wages used by Calmfors (1985). Hourly wages can then be derived recursively. This provides more intuition in the underlying mechanisms.

\subsubsection{Remuneration and hourly wages}

To derive the impact of a reduction in working time on income, totally differentiate the first-order condition (5.10) to obtain the partial equilibrium remuneration elasticity

$$
\varepsilon_{Y H \mid U^{a}}=\frac{H}{\Lambda_{Y} U_{Y}}\left(U_{Y H^{-}}-\frac{U_{Y} U_{H}}{U-U^{a}}\right)=\omega \frac{\xi+\mu_{Y}}{\omega_{Y}+\gamma_{Y}+\xi+\mu_{Y}}>0 .
$$

14 Comparing wage resistance $\mu_{Y}$ with the labour demand elasticity $\varepsilon_{N Y}$, the only differences are the use of $\tau_{\beta}$ instead of $\tau$ and the multiplicative constant $-\theta$. Hence we can use the properties of $\varepsilon_{N Y}$, see Chapter 2 and Appendix I. 
The second-order condition guarantees that the denominator is positive. Hence the sign is determined by the expression in (5.8). Thus, given the outside option $U^{p}$, the right-to-manage union model indicates that working time reduction leads to wage moderation, in the sense that remuneration per worker will fall. Through the value of leisure, no full wage compensation is needed. This is true as long as consumption and leisure are not too strong Edgeworth complements $\left(\xi+\mu_{Y}\right.$ $>0$ ). An obvious counterexample is a Leontief utility function, where consumption (or income) and leisure are to be used in fixed proportions. A reduction in working time increases leisure and hence income should be increased too. Remembering that the sufficient condition (5.5) holds for the CobbDouglas case, but not for CES-preferences with elasticity of substitution $\zeta<1$, this example illustrates that the necessary condition (5.8) holds up to some critical level of the substitution elasticity $\zeta$. Below that level, working time reductions do not lead to wage moderation. On the contrary, total remuneration might even increase. I further restrict myself to the case where (5.8) is satisfied, so $\xi+\mu_{Y}>0$.

An increase in $\omega_{Y}$ reduces the remuneration elasticity in (5.13). Recall that the slope of the hours supply curve $H^{5}$ is given by minus the sign of $\omega_{\gamma}$. If it is upward sloping, a decrease in working time can be accommodated by a decrease in the hourly wage, to stay in line with hours supply. The opposite holds for a backward sloping curve. Hence higher values of $\omega_{Y}$ - making hours supply more backward sloping - make unions bargain more aggressively in case of a reduction in workiıg time. An increase in $\gamma_{Y}$ has a similar impact. The higher $\gamma_{Y}$, the more concave the labour demand curve is. A working time reduction at given hourly wages makes labour demand more inelastic, increasing wage claims. ${ }^{15}$

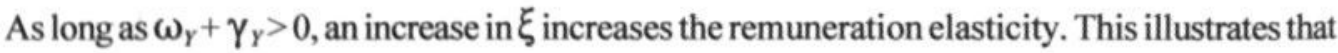
bargaining is less aggressive - a larger reduction in income being accepted - when consumption and leisure are Edgeworth substitutes, as argued by Marimon and Zilibotti (2000) when comparing their GHH- and CES-preferences. Finally, an increase in wage resistance $\mu_{Y}$ also leads to more wage moderation. Hence right-to-manage bargaining models lead to more wage moderation than the monopoly union model. In the limiting case of $\beta \rightarrow \infty$, wage determination will follow the outside option $U^{n}$, and the remuneration elasticity is equal to the marginal rate of $\log$-substitution $\omega$. As $\omega$ increases with working time this suggests that the amount of wage moderation is reduced as working time falls. This is also illustrated in Figure 5.4, which compares $\omega$ and $\varepsilon_{Y H U^{a}}$, see equation (5.13). Both are increasing in working time. ${ }^{16}$ In general the marginal rate of log-substitution exceeds the remuneration elasticity, but to a lesser extend when wage resistance $\mu_{Y}$ is high.

15 These two effects are absent in FitzRoy, Funke et al. (2002), as they consider Cobb-Douglas preferences and production functions and they do not consider quasi-fixed labour costs. Hence $\omega_{Y}$ $=\gamma_{Y}=0$.

16 For CES-preferences, for example, $\omega$ tends to infinite as hours approach the available time per period. Therefore curves are drawn convex. 
The second-order condition guarantees that the denominator is positive. Hence the sign is determined by the expression in (5.8). Thus, given the outside option $U^{\boldsymbol{p}}$, the right-to-manage union model indicates that working time reduction leads to wage moderation, in the sense that remuneration per worker will fall. Through the value of leisure, no full wage compensation is needed. This is true as long as consumption and leisure are not too strong Edgeworth complements $\left(\xi+\mu_{Y}\right.$ $>0$ ). An obvious counterexample is a Leontief utility function, where consumption (or income) and leisure are to be used in fixed proportions. A reduction in working time increases leisure and hence income should be increased too. Remembering that the sufficient condition (5.5) holds for the CobbDouglas case, but not for CES-preferences with elasticity of substitution $\zeta<1$, this example illustrates that the necessary condition (5.8) holds up to some critical level of the substitution elasticity $\zeta$. Below that level, working time reductions do not lead to wage moderation. On the contrary, total remuneration might even increase. I further restrict myself to the case where (5.8) is satisfied, so $\xi+\mu_{Y}>0$.

An increase in $\omega_{Y}$ reduces the remuneration elasticity in (5.13). Recall that the slope of the hours supply curve $H^{5}$ is given by minus the sign of $\omega_{\gamma}$. If it is upward sloping, a decrease in working time can be accommodated by a decrease in the hourly wage, to stay in line with hours supply. The opposite holds for a backward sloping curve. Hence higher values of $\omega_{Y}$ - making hours supply more backward sloping - make unions bargain more aggressively in case of a reduction in working time. An increase in $\gamma_{Y}$ has a similar impact. The higher $\gamma_{Y}$, the more concave the labour demand curve is. A working time reduction at given hourly wages makes labour demand more inelastic, increasing wage claims. ${ }^{15}$

As long as $\omega_{Y}+\gamma_{Y}>0$, an increase in $\xi_{\text {increases the remuneration elasticity. This illustrates that }}$ bargaining is less aggressive - a larger reduction in income being accepted - when consumption and leisure are Edgeworth substitutes, as argued by Marimon and Zilibotti (2000) when comparing their GHH- and CES-preferences. Finally, an increase in wage resistance $\mu_{Y}$ also leads to more wage moderation. Hence right-to-manage bargaining models lead to more wage moderation than the monopoly union model. In the limiting case of $\beta \rightarrow \infty$, wage determination will follow the outside option $U^{n}$, and the remuneration elasticity is equal to the marginal rate of $\log$-substitution $\omega$. As $\omega$ increases with working time this suggests that the amount of wage moderation is reduced as working time falls. This is also illustrated in Figure 5.4, which compares $\omega$ and $\varepsilon_{Y H \mid U^{\bullet}}$, see equation (5.13). Both are increasing in working time. ${ }^{16}$ In general the marginal rate of log-substitution exceeds the remuneration elasticity, but to a lesser extend when wage resistance $\mu_{Y}$ is high.

15 These two effects are absent in FitzRoy, Funke et al. (2002), as they consider Cobb-Douglas preferences and production functions and they do not consider quasi-fixed labour costs. Hence $\omega_{Y}$ $=\gamma_{Y}=0$.

16 For CES-preferences, for example, $\omega$ tends to infinite as hours approach the available time per period. Therefore curves are drawn convex. 


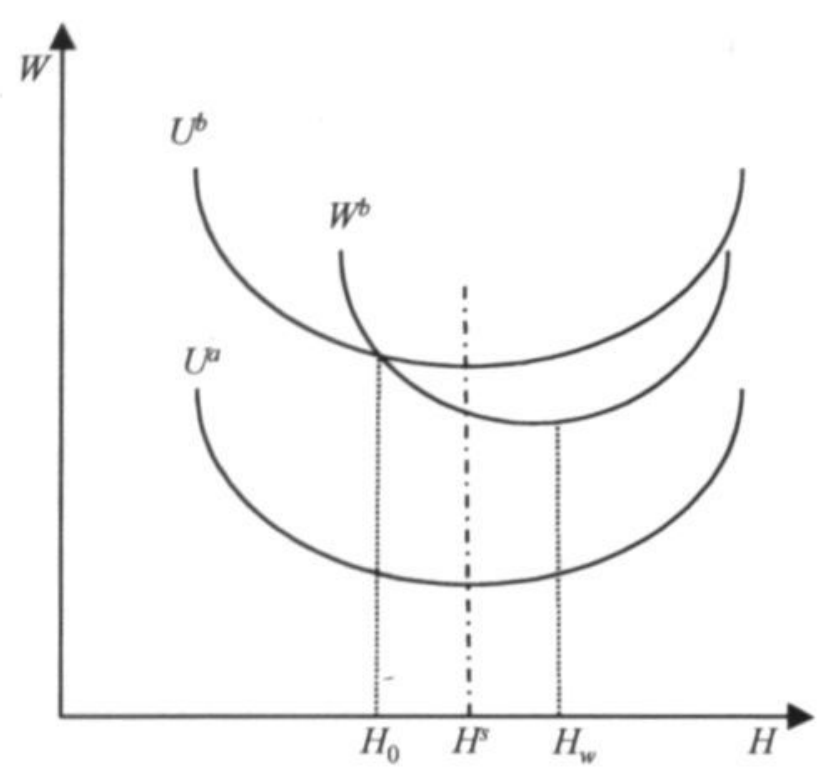

Figure 5.5 Hourly wages and working time

although that figure used a logarithmic scale. Wages will be higher if the union bargains about the wage, this yields the curve labelled $W^{b}$. It gives all bargained hourly wages as a function of working time, but given the outside option. When hours worked correspond to $H_{0}$, worker utility increases to $U^{b}$. The curve $W^{b}$ is $U$-shaped as long as the final term in the numerator of $(5.14)$ dominates. ${ }^{19}$ The second term $\gamma_{\gamma}$ tilts the whole curve clock-wise, the minimum $H_{w}$ being to the right of hours sipply. The first term in (5.14) would tilt the $W^{b}$ - curve in the opposite direction of the slope of the labour supply curve. Thus a backward sloping supply curve shifts the minimum further to the right, and reduces the likelihood of a positive elasticity $\boldsymbol{\varepsilon}_{W H \mid U^{a}}$.

The U-shape of the $W^{b}$ - curve underscores the conclusion of the previous paragraph that wage moderation - in terms of remuneration - will fall as working time is reduced. Wage moderation of hourly wages is much less likely to occur, however, and depends on the initial length of the working week. For initial hours below $H_{w}$, hourly wages will increase.

\subsubsection{Employment and welfare}

Having determined the partial equilibrium impact of working time reduction on wages, consider the effects on employment and welfare. For employment two effects work in opposite directions: the productivity effect reduces employment; but wage moderation leads to an increase in employment. The total impact is given by $\frac{d \ln N}{d \ln H}=\varepsilon_{N Y}\left(\varepsilon_{Y H U^{a}}-\lambda_{N}\right)$. Therefore, employment increases as long as the remuneration elasticity exceeds the iso-employment elasticity $\lambda_{N}$. As the former elasticity is

19 Calmfors (1985, Fig. 2) also draws a U-shaped pattern for hourly wages. 
increasing in hours and the latter decreasing, recall Figures 5.2 and 5.4, there is a critical value $H_{u}$ above which a reduction in working time increases employment. For shorter working times employment will decrease. ${ }^{20} \mathrm{So}$, at the firm level, there is an inverted U-shape between working time and employment.

For output $Q$ there is an additional negative direct impact on productivity. So output is more likely to decrease. It can be shown to have exactly the same sign distribution as profits $\Pi$. For profits the total effect of working time is given by $\frac{d \ln \Pi}{d \ln H}=\varepsilon_{\Pi Y}\left(\varepsilon_{r m U^{\bullet}}-\lambda_{\Pi}\right)$. So reduced working time increases profits only if the remuneration elasticity exceeds the iso-profit elasticity $\lambda_{\mathrm{n}}$. Again this gives an inverted $U$-shape between profits (or output) and working time. The critical value for profits is $H_{\pi}>H_{w}$. Figure 5.6 - which combines Figures 5.2 and 5.4 - illustrates the determination of these critical levels. There is an interval of working hours $\left(H_{w}, H_{\pi}\right)$ where a reduction in working time leads to increased employment, but to reduced output and profits. Given that employers typically resist work-sharing policies, it seems that currently working time is at least lower than $H_{\pi}$.

A reduction in working time has two opposite effects on the utility $U$ of employed workers. First, leisure is increased, but second, as a result of wage moderation, remuneration falls. Totally differentiating the utility rent of employed workers gives, using (5.13),

$$
\frac{d \ln \left(U-U^{a}\right)}{d \ln H}=\mu_{Y}\left(\varepsilon_{Y H \mid U^{a}}-\omega\right)=-\omega \mu_{Y}\left(\omega_{Y}+\gamma_{Y}\right) / \Lambda_{Y} .
$$

As long as $\omega_{Y}+\gamma_{Y}>0$, as was assumed to hold, employed workers always gain. In other words, the wage moderation will not fully offset the gain in leisure. This could also be seen in Figure 5.5 , as at initial hours $H_{0}$, the $W^{b}$-curve is steeper then the indifference curve $U^{b}$. A movement to the left along the bargained $W^{b}$-curve then leads to an increase in utility.

Finally, consider union utility $\Gamma$. Combining the effects on employment and individual utility, the impact on union utility can be written as

$$
\frac{d \ln \Gamma}{d \ln H}=\theta \varepsilon_{N Y}\left(\varepsilon_{Y H \mid U^{a}}-\lambda_{N}\right)+\mu_{Y}\left(\varepsilon_{Y H \mid U^{a}}-\omega\right)
$$

The first part on the right-hand side measures the impact on employment and is negative for $H>H_{u}$. The second part measures the impact on the utility rent and is negative. For $H<H_{u}$ both effects

20 In a short-run labour services model Booth and Ravallion (1993) conclude that a sufficient, but not necessary, condition for a cut in hours to increase employment is that absolute wage elasticity is less than the share of variable labour costs in the wage bill. This can also be interpreted as a lowerbound on working time. 


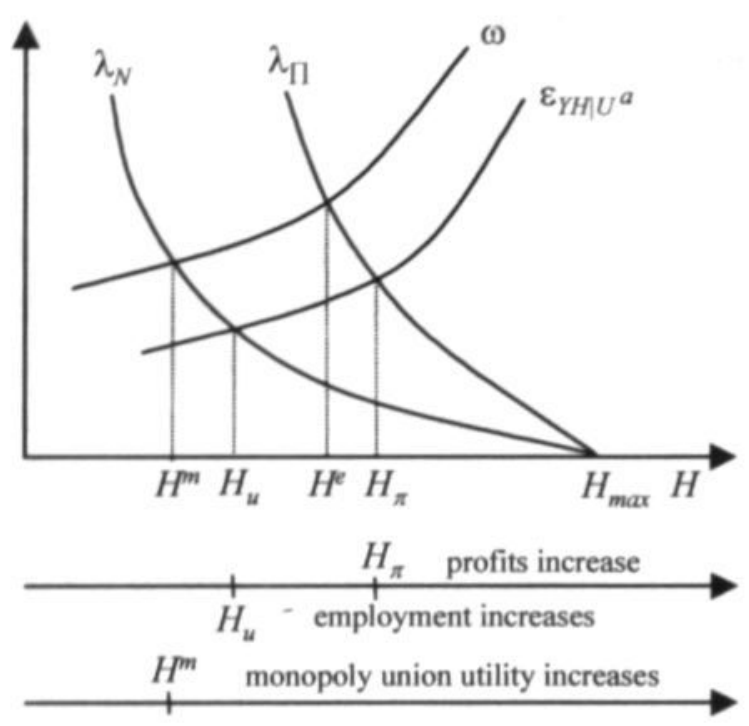

Figure 5.6 Critical working times and worksharing

work in opposite directions. For the monopoly union the above expression simplifies to $\frac{d \ln \Gamma^{\mathbf{m}}}{d \ln H}=$ $-\theta \varepsilon_{N Y}\left(\lambda_{N}-\omega\right)$. Hence the union gains as long as the marginal rate of log-substitution $\omega$ exceeds the iso-employment elasticity $\lambda_{N}$. In Figure 5.6 this corresponds to $H>H^{m}$. It can be shown, see Chapter 6, that $H^{m}$ corresponds to the optimal hours as set by a monopoly union. As in general $\frac{d \ln \Gamma}{d \ln H} \leq-\theta \varepsilon_{N Y}\left(\lambda_{N}-\omega\right)=\frac{d \ln \Gamma^{*}}{d \ln H}$, the critical level of hours is even lower in a bargaining framework. So there is a rather large interval where unions gain from a work-sharing policy. This might explain why unions favour work-sharing policies, even when there may be adverse employment effects. Employed workers always gain.

The discussion illustrates that the consequences of reduced working time depend on the initial length of the working week. Adverse effects are likely to occur at relatively short hours, whereas gains can be obtained for longer hours. This brings the issue of the determination of working time to the fore. This is elaborated in more detail in Chapter 6. Here I only look briefly at three benchmark cases used in the literature.

- Calmfors (1985), considers the case where the union sets the working time, so $H=H^{m}$. As illustrated in Figure 5.6, work-sharing policies then lead to negative employment and profitability effects.

- Contensou and Vranceanu (1998) and Moselle (1996) consider the opposite case where hours are set unilaterally by the firm, given the utility constraint of the workers. This gives the constrained Pareto-efficient solution that the slope of the indifference curve is equal to the slope of the iso-profit line, see FitzRoy, Funke et al. (2002). In my notation this implies $\omega=\lambda_{\mathrm{II}}$, or $H$ $=H^{\boldsymbol{F}}$ in Figure 5.6. Work-sharing policies then lead to reduced profitability (as $H^{\boldsymbol{F}}<H_{\pi}$ ), but the impact on employment is ambiguous. In the graph $H_{w}<H^{*}$, so employment increases, but 
more aggressive bargaining (lower $\xi_{\text {or }} \mu_{Y}$ ) shifts the remuneration elasticity $\varepsilon_{Y \eta U^{*}}$ downward, increasing the likelihood of adverse employment effects (when $H^{*}<H_{u}$ ). ${ }^{21}$

- Finally, Marimon and Zilibotti (2000) and Rocheteau (2002) consider the case where hours are set by simultaneous bargaining about wages and hours. In our set-up this means that hours are determined along the $\omega$-curve between $\lambda_{N}$ and $\lambda_{\mathrm{l}}$, the exact position depending on the bargaining power $\beta .^{22}$ The corresponding bargained hours, say $H^{\dagger}$, will thus be somewhere between $H^{m}$ and $H^{*}$. Again work-sharing will reduce profitability, but the impact on employment is ambiguous. More bargaining power for firms increases bargained hours $H^{b}$ and reduces the critical value $H_{u}$ (as the remuneration elasticity shifts upward toward $\omega$ ). This increases the likelihood of positive employment effects.

\subsubsection{A numerical example}

To illustrate the working of the model, this subsection provides a numerical illustration of the main effects of a work-sharing policy in the model. The intention is not to provide very realistic outcomes, but to illustrate the main channels operating within the model. Therefore, I use a rather crude calibration of the parameters of the model.

First, consider the model of the firm. Here I use the same parameters as in Chapter 2: so the share of capital costs $\eta$ is set at 0.3 ; quasi-fixed labour costs account for $20 \%$ of labour costs; and I adopted $\sigma=0.5$ for the elasticity of substitution. Estimates of the elasticity of output with respect to hours are rather imprecise, see Freeman (1998) and Hamermesh (1993). Contrary to Chapter 2, I used $\eta^{e}=0.6$ as the benchmark, indicating that work-sharing leads to some hourly productivity gains. As $\eta^{e}=0.6>0.56=\left(1-\varphi_{V}\right)\left(1-\eta^{\prime}\right)$, firms would like to have longer hours. For the firm specific elasticity of goods demand $\tau$, I used 5.0 as the benchmark.

These five parameters determine the labour demand elasticities $\boldsymbol{\varepsilon}_{N H Y}$ and $\boldsymbol{\varepsilon}_{N Y}$ of the partial equilibrium in Table 5.1, see also Chapter 2. As $\varepsilon_{N H Y}+\varepsilon_{N Y}<0$, the calibration implies that worksharing increases employment at unchanged hourly wages.

Second, consider the labour supply parameters. For the rate of relative risk-aversion with respect to income $\alpha_{Y}$, Pissarides (1998) uses 0.8 whereas Teulings and Hartog (1998) suggest a value of roughly 1.25 . I took the intermediate value of $\alpha_{Y}=1$. With respect to $\xi$ I am not aware of any sensible estimates. As a benchmark I just assumed that consumption and leisure are neither Edgeworth complements nor substitutes, leading to $\xi=0$. These joint assumptions on the utility function imply that $\omega_{Y}=0$, so hours supply $H^{3}$ is inelastic. Evidence on workers being over- or

21 This mechanism also explains the different employment effects for the CES- and GHHpreferences in Marimon and Zilibotti (2000). CES-preferences entail more aggressive wage bargaining through a lower $\xi$ and hence are less likely to have positive employment effects.

22 See Chapter 6 for details. 
Table 5.1 Numerical working time elasticities: partial equilibrium

\begin{tabular}{|c|c|c|c|c|c|c|}
\hline & $\boldsymbol{\varepsilon}_{N H Y}$ & $\varepsilon_{N \gamma}$ & $\varepsilon_{Y H}$ & $\frac{d \ln N}{d \ln H}$ & $\omega^{*}$ & $\begin{array}{c}\eta^{e} / \omega \\
d N=0\end{array}$ \\
\hline \multicolumn{7}{|c|}{ Monopoly union $(\beta=0)$} \\
\hline Short-run labour demand & 0.329 & -0.548 & 0.554 & 0.025 & 1.624 & 0.616 \\
\hline Long-run labour demand & 2.400 & -2.920 & 0.815 & 0.019 & 1.104 & 0.661 \\
\hline \multicolumn{7}{|c|}{ Right-to-manage bargaining } \\
\hline Short-run labour demand & 0.329 & -0.548 & 0.707 & -0.059 & 1.273 & 0.786 \\
\hline Long-run labour demand & 2.400 & -2.920 & 0.849 & -0.079 & 1.060 & 0.689 \\
\hline \multicolumn{7}{|c|}{ Efficient bargaining } \\
\hline Long-run labour demand & 2.400 & -2.988 & 0.851 & -0.143 & 1.058 & 0.706 \\
\hline
\end{tabular}

The parameter values for the partial equilibrium are $\varphi_{V}=0.2, \eta^{\prime}=0.6, \gamma^{\prime}=0.3, \sigma=0.5, \tau=5, \theta=1$, $\beta=1, \alpha_{y}=1, \xi=0$ and $\omega=0.9$.

underemployed is mixed, see for example OECD (1998). I assumed that workers work less than their desired hours, so the marginal rate of $\log$-substitution $\omega$ is below one. I adopted $\omega=0.9$.

Third, consider the bargaining parameters. The results in Pencavel (1991) indicate that unions care about employment, but estimates vary considerably. I mimicked the results of an utilitarian union utility function, as I set the employment elasticity in union utility $\theta$ equal to one. Finally, evidence of bargaining power of firms $\beta$ is scarce. As in Marimon and Zilibotti (2000) I assumed that both parties have the same power, accordingly I took $\beta=1$, but I also considered the case of a monopoly union $(\beta=0)$.

The partial equilibrium results in Table 5.1 indicate that work-sharing will lead to wage moderation, as the elasticity of remuneration with respect to working time $\varepsilon_{Y H}$ is positive. However, hourly wages increase as $\boldsymbol{\varepsilon}_{Y H}$ is smaller than one. Wage moderation is stronger in the right-tomanage bargaining model than in the monopoly union. Wage moderation is also stronger in the longrun labour demand models, compared to the short-run labour demand model. In both cases this is due to the difference in wage resistance $\mu_{Y}$ (not included in the table): bargaining power increases wage resistance, as does the absolute value of the labour demand elasticity $\boldsymbol{\varepsilon}_{N \gamma}$.

The column labelled $\omega^{\prime \prime}$ indicates what the marginal rate of log-substitution should be for full wage moderation. This corresponds to minimum $H_{w}$ of the U-shape bargained wage curve in Figure 5.5. The results indicate that workers should be overemployed $(\omega>1)$ for this to occur. 
The impact of the work-sharing on employment $N$ differs between the monopoly union model and the right-to-manage model. In the former employment is reduced, whereas in the latter employment is increased. The monopoly union model is less favourable, because of its weaker wage moderation. In both cases the resulting elasticities are rather small, however.

The final column considers the critical value of $\eta \% \omega$ where employment does not change as a result of work-sharing. This corresponds to $H_{u}$ in Figure 5.6. Notice that the ratio $\eta^{e} / \omega$ is decreasing in working time, so relative low figures in this column correspond to relative long initial hours. In the benchmark $\eta \% \omega=2 / 3$. In the right-to-manage models the critical values are higher than the benchmark, hence employment increases. With a lower initial working time, however, employment could fall, as in the monopoly union model. This illustrates the inverted U-shape for employment.

Experimenting with different parameter values gives different numbers, but the broad picture remains: there is some wage moderation; long-run labour demand models and right-to-manage bargaining lead to stronger wage moderation; and employment effects tend to be rather limited, the sign depending on the initial level of working time.

\subsection{EFFICIENT BARGAINING}

The next question is whether the qualitative results change if we allow for bargaining over employment. So I turn to the class of efficient union bargaining models. Booth and Schiantarelli (1987) also analyse a cut in working time within such a set-up. They conclude that the employment outcome is ambiguous, but likely to be negative, and they do not discuss the impact on remuneration. Moreover, their model ignores capital as a separate production. Johnson (1990) does include capital, but then ignores the impact of working time on capital services.

The solution of the efficient bargaining model can be derived by maximising the (logarithm of the) Nash-maximand (5.9) with respect to capital, employment and remuneration. The first-order conditions for a maximum are, respectively

$$
\begin{gathered}
0=\frac{\partial \ln \Omega}{\partial K}=\frac{\beta}{\Pi}\left\{v e(H)^{v} N^{v-1} f(k)^{v-1} f^{\prime}(k)-R\right\}, \\
0=\frac{\partial \ln \Omega}{\partial N}=\frac{\theta}{N}+\frac{\beta}{\Pi}\left\{v e(H)^{v} N^{v-1} f(k)^{v-1}\left[f(k)-k f^{\prime}(k)\right]-(V+Y)\right\}, \\
0=\frac{\partial \ln \Omega}{\partial Y}=\frac{U_{Y}(Y, H)}{U(Y, H)-U^{a}}-\frac{\beta N}{\Pi} .
\end{gathered}
$$


Rearranging equations (5.15) and (5.16) the optimal capital labour ratio is now determined as

$$
\frac{v(\theta+\beta) f^{\prime}(k)}{(\theta+\beta v) f(k)-v(\theta+\beta) k f^{\prime}(k)}=\frac{R}{V+Y} .
$$

Comparing this expression with equation (5.4) for the right-to-manage model, one can show that the optimal capital-labour ratio $k^{E B}$ in the efficient bargaining model is lower than in the right-to-manage model. As in Johnson (1990), efficient bargaining leads to overmanning of the capital stock. As before, the capital-labour ration is scale independent and does not depend directly on the working time. Given $k^{E B}$, equation (5.15) can be used to derive the employment level $N^{E B}$. So the model can be interpreted as follows: unions and firms bargain over the manning ratios, but given this choice of technology the firm chooses its scale in an optimal way, see Johnson (1990).

Differentiating (5.15) and (5.18) the wage elasticity of labour demand for the efficient bargaining model is given by

$$
\varepsilon_{N Y}^{E B}=-\left(1-\varphi_{V}\right)\left[\tau\left(1-\eta^{f}\right)+\eta^{f}\right]<0 .
$$

It is tempting to write $\varepsilon_{N Y}^{E B}=\delta \varepsilon_{N Y}$, where

$$
\delta \equiv \frac{\tau_{\beta}\left(1-\eta^{f}\right)+\eta^{f}}{\tau_{\beta}\left(1-\eta^{f}\right)+\sigma \eta^{f}} \geq 1 \text { for } \sigma \leq 1,
$$

but this ignores the fact that, due to the lower capital-labour ratio in the efficient bargaining model, the elasticity $\eta^{\prime}$ may be higher in the efficient bargaining model. ${ }^{23}$ For a Cobb-Douglas production function, however, the wage elasticity of labour demand is always the same in both models.

On the other hand, the working time elasticity of labour demand at given remuneration is the same in both models, as $\boldsymbol{\varepsilon}_{N H \mid Y}^{E B}=(\tau-1) \eta^{e}=\varepsilon_{N H Y}$. The reason is that a working time reduction can be compared to neutral technical regress and the firm is free to choose its optimal scale - and thus employment - in both models.

Using equations (5.15) and (5.18), the first-order condition (5.17) for the wage can be rewritten as

23 Moreover, $\eta$ is no longer equal to the capital share in total costs, see Johnson (1990). Due to the inefficient high manning ratio, the capital share falls to $\frac{v(\theta+\beta)}{\theta+v \beta} \eta^{f}<\eta^{\prime}$. 


$$
\frac{Y U_{Y}(Y, H)}{U(Y, H)-U^{a}}=\mu^{E B} \equiv\left(1-\varphi_{\nu}\right) \theta\left[\tau_{\beta}\left(1-\eta^{f}\right)+\eta^{f}\right] .
$$

This expression has the same structure as the wage setting equation (5.10) for the right-to-manage model. The only difference is that wage resistance $\mu^{E B}$ is defined in a slightly different way for the efficient bargaining model, compare with equation (5.11). Due to the possible difference in the elasticity $\eta^{\prime}$ between both models, it is hard to compare the levels of $\mu^{E B}$ and $\mu_{r}$, although they are the same for a Cobb-Douglas production function. As in the right-to-manage model, wage resistance is increasing in $\theta, \beta, v$ and $\sigma$, non-decreasing in the capital-labour ratio (at least for $\sigma \leq$ 1) and decreasing in the share of quasi-fixed labour costs.

To derive the comparative statics of the efficient bargaining model with respect to working time reduction, differentiate (5.19) to obtain ${ }^{24}$

$$
\varepsilon_{Y H \mid U^{*}}^{E B}=\omega \frac{\xi+\mu^{E B}}{\omega_{Y}+\gamma_{Y}+\xi+\mu^{E B}}>0
$$

The second-order condition for maximisation of the Nash-maximand guarantees that the denominator is positive.

Comparing (5.20) with (5.13) shows that the partial equilibrium elasticity of remuneration with respect to working time has the same structure in the efficient bargaining model and the right-tomanage model. Both elasticities are positive, at least given condition (5.8). Hence the conclusion that a working time reduction will be followed by wage moderation is independent of the bargaining framework.

The numerical example in Table 5.1 indeed illustrates that the results for the efficient bargaining model are rather similar to the right-to-manage model. The impact on remuneration is almost unchanged, but due to the slightly higher labour demand elasticity, the impact on employment is somewhat more favourable.

\subsection{LABOUR MARKET EQUILIBRIUM}

The wage bargaining process presented above takes the outside option as given. In the labour market equilibrium, wages in all sectors or firms are set in a similar vein. As a result the outside option $U^{u}$ becomes endogenous. Layard and Nickell (1990) have shown that the labour market

24 The expression derived for $\gamma_{Y}$ in the right-to-manage model remains valid in the efficient bargaining model, although one should use the appropriate value for the elasticity $\eta$. 
equilibrium results might differ substantially from the partial equilibrium analysis. This is the issue of this section, where I use the right-to-manage model of section 5.3. Similar results hold for the efficient bargaining model of the previous section.

Layard, Nickell et al. (1991, Ch. 10) claim that equilibrium unemployment is unaffected by worksharing. However, their model does not incorporate working time and leisure as separate elements. Cahuc and Granier (1997) do take this into account, and conclude that equilibrium unemployment is unaffected by work-sharing policies, at least in the absence of unemployment benefits. Including these benefits, unemployment may be affected, although the sign depends on the determination of benefits. Work-sharing leads to higher unemployment if the benefit level is given, but lowers unemployment at a given replacement rate. Their model, however, does not incorporate the impact of working time on capital services.

\subsubsection{Wage determination}

When participating in the labour market, agents are either employed or unemployed. Considering a symmetric equilibrium, all firms provide the same utility level $U(Y, H)$ for their workers. When being unemployed, workers get an unemployment benefit $B$, but have more leisure time. ${ }^{25}$ The corresponding utility is given by $\tilde{U}^{\mathbb{t}}=\tilde{U}(\bar{B}, 0)<U(Y, H)$. The outside option corresponds to the expected utility when participating in the labour market and is thus given by a weighted average of the utility when working and the utility when unemployed

$$
U^{u}=(1-u) U(Y, H)+u U(B, 0),
$$

where $u$ is the unemployment rate. ${ }^{26}$

In the partial equilibrium, wage setting depends on the outside option $U^{u}$. In a symmetric equilibrium, the latter depends on unemployment as in equation (5.21). Substituting this in the partial equilibrium condition (5.10) gives the equilibrium wage setting curve

$$
\frac{Y U_{Y}(Y, H)}{U(Y, H)-U(B, 0)}=\mu_{Y} u .
$$

It has the same structure as (5.10), but with outside option $U^{n}$ replaced by the utility $U^{\phi}$ of the unemployed and with wage resistance $\mu_{Y}$ multiplied by the unemployment rate $u$. As a consequence

25 I don't discuss the issue of financing the benefits. This is incorporated in FitzRoy, Funke et al. (2002).

26 In the intertemporal search models of Marimon and Zilibotti (2000) and Rocheteau (2002) the weight on the instantaneous utility $U(B, 0)$ of the unemployed is higher, as employed workers also face the probability of being fired. For our purposes, this is just a reinterpretation of the variable $u$. 
of this analogy in structure, the comparative statics are roughly similar. For example, higher benefits $B$ increase remuneration, whereas wages decline with higher unemployment or higher wage resistance. These are standard predictions of aggregate wage setting behaviour, see Layard, Nickell et al. (1991).

With respect to the impact of working time on remuneration, the equilibrium elasticity can be written as

$$
\varepsilon_{Y H}=\omega \frac{\xi+\mu_{Y} u}{\omega_{Y}+\gamma_{Y}+\xi+\mu_{Y} u}
$$

Compared to the partial equilibrium elasticity $\varepsilon_{Y H U^{*}}$ in (5.13), the numerator and the denominator have both decreased. The second-order condition (5.12) no longer guarantees that the denominator is positive, although it is along the aggregate wage setting curve. ${ }^{27}$ The numerator of $(5.23)$ is once again ambiguouis, and may be negative if consumption and leisure are strong Edgeworth complements $\left(\xi<-\mu_{\gamma} \mathrm{u}\right)$. A sufficient, but not necessary, condition to exclude this possibility was given by the class of utility functions in (5.5). So, for this class of utility functions the analysis predicts that, in terms of annual remuneration, working time reduction will lead to wage moderation in the symmetric equilibrium.

Comparing wage moderation at the partial and the labour market equilibrium, notice that $\boldsymbol{\varepsilon}_{Y H \eta U^{*}}$ $>\varepsilon_{Y H}$ if and only if $\omega_{Y}+\gamma_{Y}>0$. This corresponds to the condition for employed workers to gain from a cut in working time. The reason is the following: if workers gain due to a cut in working time, the outside option will increase in the labour market equilibrium; this in turn increases wage claims and thus reduces wage moderation in the labour market equilibrium. In terms of Figure 5.6, this means that the remuneration elasticity shifts downward in the labour market equilibrium, see Figure 5.7. As a consequence the interval with adverse effects of work-sharing on employment and profits becomes larger.

\subsubsection{Unemployment}

To determine the effect of working time on unemployment, wage setting behaviour should be combined with the market demand for labour. Two complications arise compared to the labour

27 The semi-elasticity of remuneration with respect to unemployment is $\varepsilon_{\gamma_{u}}=\frac{d \ln Y}{d u}=$ $\frac{-1}{u} \frac{1}{\omega_{Y}+\gamma_{Y}+\xi+\mu_{Y} u}<0$, with the same expression in the denominator. The denominator is positive for $u$ $=1$, as guaranteed by the second-order condition of the wage bargain. Decreasing unemployment increases wages more at lower unemployment rates. For $u=u_{\min } \equiv \max \left[0,-\left(\omega_{Y}+\gamma_{Y}+\xi\right) / \mu_{Y}\right]$ the increase is infinite. Hence aggregate wage setting implies a lowerbound on the feasible unemployment rate given by $u_{\min }$. This in turn guarantees that the denominator in (5.23) is positive. Finally notice that the asymptote $u_{\min }$ is positive for low levels of risk aversion, that is for $\alpha_{Y}<$ $1-\gamma_{\gamma}$. 


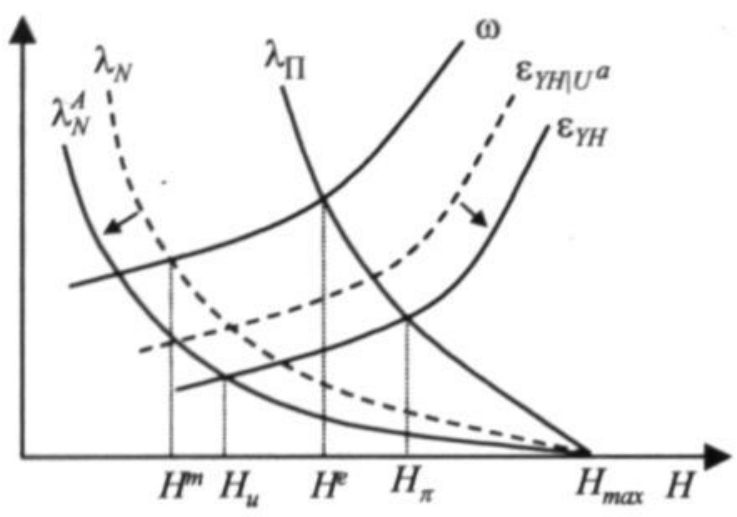

Figure 5.7 Critical working times

demand of individual firms. First, we should take into account that the aggregate price level may change, second, entry may blur the picture. In this subsection I deal with the first problem, entry is covered in the next section.

Consider aggregate prices. Given the assumption of constant returns to scale, each firm sets its price $P$ as a mark-up on unit $\operatorname{costs} c$, as long-run profit maximisation implies $P=c / v$. As a consequence, the elasticity of price with respect to remuneration is equal to the share of variable labour costs in total costs, so $\varepsilon_{P Y}=\left(1-\varphi_{V}\right)\left(1-\eta^{\prime}\right)$, and the elasticity of price with respect to working time is $\varepsilon_{P H Y}=-\eta^{e}$. The total impact of a change in hours on the market price is thus given by $\frac{d \ln P}{d \ln H}=\varepsilon_{P Y} \varepsilon_{Y H}+\varepsilon_{P H Y}=\varepsilon_{P Y}\left(\varepsilon_{Y H}-\lambda_{\Pi 1}\right)$. Accordingly, reduced hours will increase the market price as long as $\varepsilon_{Y H}<\lambda_{\Pi}$, or $H<H_{\pi}$ in Figure 5.7.

In a symmetric equilibrium, all firms set the same price, reducing the sensitivity of the individual firm demand with respect to price. ${ }^{28}$ Let the elasticity of the demand shifter $D$ with respect to the market price level be $\tau_{A}$, then it can be shown that the elasticities of aggregate labour demand are given by similar expressions as $\varepsilon_{N Y}$ and $\varepsilon_{N H Y}$, but with $\tau$ replaced by $\tau_{\mathcal{A}}$. As the aggregate demand is most likely less elastic than firm demand, this makes aggregate labour demand less elastic and less responsive to changes in working time. In terms of the iso-employment elasticity $\lambda_{N}$, the aggregate version shifts $\lambda_{N}^{A}$ towards the origin in Figure 5.7, reducing the interval of adverse employment effects. The intuition is simply that all firms face the same change in unit costs, so in equilibrium there is a smaller loss in competitiveness. Compared to the partial equilibrium version, the remuneration elasticity $\varepsilon_{Y H}$ and the iso-employment elasticity $\lambda_{N}^{A}$ both shift down, making the shift of $H_{u}$ ambiguous.

The aggregate model consists of the wage setting equation (5.22) and the aggregate labour demand curve. Given a fixed labour supply $S$ and together with the definition of unemployment, $u \approx$

28 The elasticity $\tau$ is best interpreted as the elasticity of firm demand with respect to their relative price. In a symmetric equilibrium the relative price is unity. 


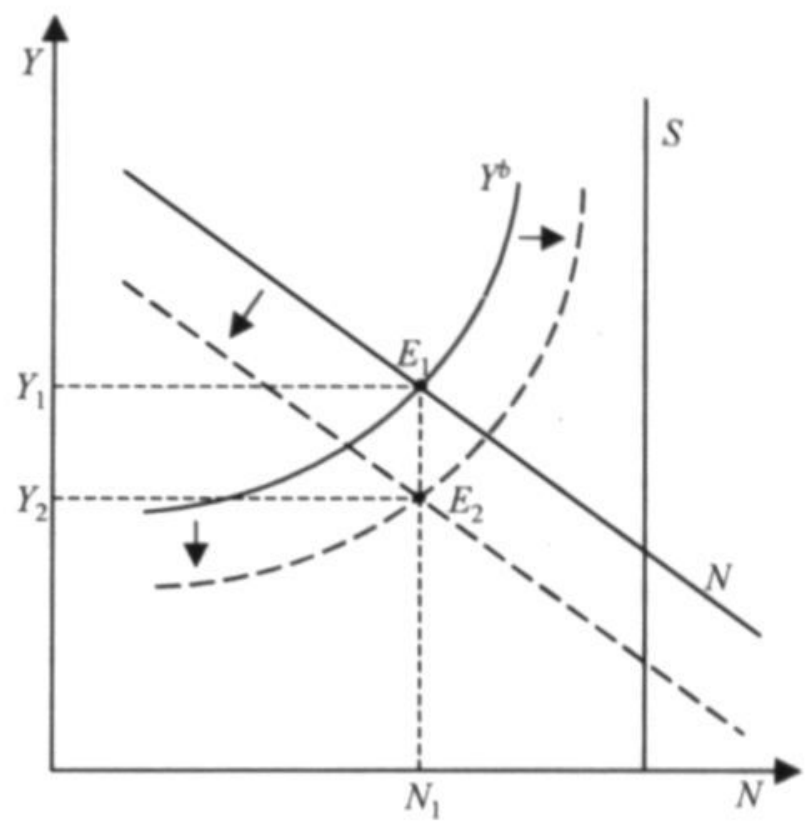

Figure 5.8 Unemployment and work-sharing

$\ln S-\ln N$, the model determines (real) remuneration $Y$, employment $N$ and the unemployment rate $u$. The model is illustrated in Figure 5.8. Wage setting is illustrated by the upward sloping $Y^{b}$, whereas market demand for labour is given by the downward sloping curve $N$. The intersection of both curves gives the equilibrium remuneration $Y_{1}$ and the corresponding employment level $N_{1}<S$. Union wage setting leads to equilibrium unemployment.

The vertical axis gives (real) annual remuneration and not hourly wages. As working time reduction leads to wage moderation, the wage setting curve $Y^{b}$ shifts downward. Moreover, labour demand also declines. Both effects reduce the equilibrium remuneration, but the impact on (un-)employment is ambiguous. As a benchmark, the figure considers the case where employment is unaffected. This corresponds to initial hours $H_{u}$ in Figure 5.7.

Indeed, solving for the comparative statics, the equilibrium effects on remuneration and unemployment are

$$
\frac{d \ln Y}{d \ln H}=\frac{\varepsilon_{Y H}-\varepsilon_{N H Y Y} \varepsilon_{Y u}}{\Lambda_{Y u}}>0 \text { and } \frac{d u}{d \ln H}=\frac{-\varepsilon_{N Y}\left(\varepsilon_{Y H}-\lambda_{N}^{A}\right)}{\Lambda_{Y u}} \text {, }
$$

where $\varepsilon_{Y_{u}}<0$ is the semi-elasticity of remuneration with respect to unemployment and $\Lambda_{Y_{u}} \equiv$ $1+\varepsilon_{N Y} \varepsilon_{Y u}>1$. The unemployment rate will fall - or employment will increase - when wage 
moderation dominates, that is for $\varepsilon_{Y H}>\lambda_{N}^{A}$, or $H>H_{w}$. In any case there exists a U-pattern between the equilibrium unemployment rate and working time, and $H_{u}$ is the working time that minimises the unemployment rate.

\subsubsection{Extensions}

In the next subsections I introduce three simple extensions of the model. First, I consider the impact of a fixed replacement rate, instead of fixed benefits. This institutional change affects the slope of the wage setting curve in Figure 5.8. Second, I allow for endogenous participation decisions, leading to an upward sloping labour supply curve. Finally, I introduce free entry into the model, leading to a horizontal price setting curve, instead of the downward sloping labour demand. These variations do not affect the general conclusion that there is a U-pattern between the equilibrium unemployment rate and working time, but they do affect the value of hours $H_{u}$ that minimise the unemployment rate.

\subsubsection{Replacement rate}

The above labour market equilibrium results take the benefit level $B$ of the unemployed as given. In the longer nun. however, it magv he more realistic to sonsider a fixed cepnlacement.cate $\Omega=B / Y<.1$. As working time reduction leads to wage moderation, this suggests that benefits will be reduced. In practice, this may seem an unrealistic assumption. But in an environment with productivity growth, as in Chapter 6, the only implication is that benefits and remuneration grow at different rates in the face of working time reduction.

Taking the fixed replacement rate into account, remuneration is given by

$$
\frac{Y U_{Y}(Y, H)}{U(Y, H)-U(\rho Y, 0)}=\mu_{Y} u .
$$

In standard wage bargaining models, a constant replacement rate typically implies a vertical wage setting curve, see e.g., Layard, Nickell et al. (1991). This is not the case here. The first reason is that the wage elasticity of employment - or more general wage resistance $\mu_{Y}$ - changes with the level of remuneration. The only exception is a Cobb-Douglas production function without quasi-fixed labour costs. The second reason is that the left-hand side may also depend on remuneration, the exception being a Cobb-Douglas utility function. So only with the often used Cobb-Douglas specifications and without quasi-fixed costs as in Cahuc and Granier (1997) and FitzRoy, Funke et al. (2002), equation (5.24) defines a unique equilibrium unemployment rate. For such a specification, it can be shown that, due to the disutility of working time, equilibrium unemployment will be reduced as a consequence of a cut in working time. 
In general, however, equation (5.24) defines a wage setting curve where remuneration falls if unemployment increases. The slope is steeper than with fixed benefits. This curve may shift due toa change in the replacement rate and due to changes in working times. In terms of elasticities, the impact of the latter can be written as

$$
\varepsilon_{Y H p}=\boldsymbol{\omega} \frac{\left(\xi+\mu_{Y} u\right)}{\omega_{Y}+\gamma_{Y}+\xi+\mu_{Y}\left(1-\rho_{U}\right) u}>\varepsilon_{Y H},
$$

where $\rho_{U} \equiv \rho \frac{U_{Y}(\rho Y, 0)}{U_{Y}(Y, H)}>0$ is related to the replacement rate $\rho$. Compared to (5.23), only the denominator becomes smaller, increasing the impact of reduced working time. This reflects the fact that, at given replacement ratio, benefits will fall as a consequence of the wage moderation. The sign remains unaffected, however, and the previous analysis applies only with a reinterpretation of the elasticities of the wage setting curve. As wage moderation is increased, the critical value $H_{w}$ is reduced, see Figure 5.7, and a working time reduction is more likely to increase employment, than with fixed unemployment benefits.

\subsubsection{Labour supply}

When deciding to participate in the labour market, agents compare the expected utility of participation $U^{a}$ with their endowment in utility $U^{E}$. I follow the specification in Cahuc and Granier (1997), assuming that these utility endowments may differ between agents. This may, for example, result from differences in wealth or in family composition. Let $s\left(U^{*}\right)$, with $s^{\prime}(\cdot)>0$, denote the cumulative density of utility endowments in the economy. Individuals will only participate when $U^{u}>$ $U^{*}$. Normalising without loss of generality the number of agents to one, labour supply $S$ - i.e. the number of participants and not their desired hours $H^{s}$ - is given by $S=s\left(U^{u}\right)$. This is a nondecreasing function of the expected utility level $U^{u}$.

For the properties of the labour supply equation, (log-)differentiate labour supply, using (5.21). Rearranging, using (5.22) and the definition of $\omega$, this yields

$$
d \ln S=\varepsilon_{S}\left[(1-u)(d \ln Y-\omega d \ln H)-\frac{1}{\mu_{Y} u} d u+\rho_{U} u d \ln B\right],
$$

where $\varepsilon_{S} \equiv \eta^{s} Y U_{Y} / U^{a}>0$ and $\eta^{s}>0$ is the elasticity of the density function $s(\cdot)$. So labour supply is an increasing function of remuneration and benefits. The negative impact of unemployment illustrates the discouraged worker effect in the model. 
At given remuneration, a reduction in working time increases labour supply, as leisure is valuable. ${ }^{29}$ Another mechanism working in the same direction, but not present in this chapter, is the effect on the non-wage incomes of partners. If working time reduction leads to wage moderation, family incomes are reduced. Such a negative income effect may trigger additional participation of partners, increasing labour supply.

This shift of the labour supply curve induces another shift of the wage setting curve, which is defined relatively to the labour supply curve. So remuneration will fall even more. This in turn increases employment. The effect on the unemployment rate remains ambiguous, however, as both labour supply and labour demand increase. The critical value of initial hours $H_{u}$ where work-sharing starts to have adverse unemployment effects is most likely to increase. Indeed, including endogenous labour supply, the impact of work-sharing on unemployment is given by

$$
\frac{d u}{d \ln H}=\frac{-\varepsilon_{N Y}\left(\varepsilon_{Y H}-\lambda_{N}\right)+\varepsilon_{S}(1-u)\left(\varepsilon_{Y H}-\omega\right)}{\Lambda_{Y u}+\varepsilon_{S}\left[1 /\left(\mu_{Y} u\right)-(1-u) \varepsilon_{Y u}\right]} .
$$

The denominator is positive and the second term in the numerator is negative as long as $\omega_{\gamma}+\gamma_{\gamma}>$ 0 . If this is the case, as assumed throughout, the labour supply effect dominates and $H_{u}$ increases compared to the case of inelastic participation.

\subsubsection{General equilibrium}

As can be seen from Figure 5.7, work-sharing policies lead to reduced profitability as long as $H<$ $H_{\pi}$, because wage moderation $\varepsilon_{Y H}$ falls below the rate $\lambda_{\Pi I}$ needed to keep profits constant. This will have adverse effects in the long run, for example, through exit of firms. However, entry and exit is difficult to model with constant returns to scale. A shortcut, leading to similar results, is to replace market labour demand in the general equilibrium by price setting behaviour, see e.g., Blanchard (2000). With constant returns to scale this gives a fully elastic price setting curve, shifting downwards as a consequence of working time reductions. ${ }^{30}$

To keep profitability constant, the long-run impact of reduced working time on remuneration is given by the iso-profit elasticity, or $\frac{d \ln Y}{d \ln H}=\lambda_{\Pi}>0$. Combining this with the wage equation (5.22), the general equilibrium impact on unemployment is given by ${ }^{31}$

29 At given hourly wages, however, a cut in hours has an ambiguous effect on labour supply, depending on whether workers are over- or underemployed. For overemployed workers $(\omega>1)$ the cost of participation declines, leading to an increase in labour supply. The opposite holds when workers would be underemployed.

30 The impact of working time on price setting is larger than on (market) labour demand, as $\lambda_{\mathrm{II}}>\lambda_{N}$.

31 Keeping the replacement rate constant, instead of the benefits, as in (5.24), the effect on the unemployment rate becomes $\frac{d \mathrm{w}}{d \ln H}=-\frac{\left(\boldsymbol{e}_{n+p_{n}}-\lambda_{\mathrm{n}}\right)}{\boldsymbol{e}_{\mathrm{nap}}}$. This yields similar conclusions. 


$$
\frac{d u}{d \ln H}=-\frac{\left(\varepsilon_{Y H}-\lambda_{\Pi I}\right)}{\varepsilon_{Y u}} .
$$

The sign of this expression is determined by the relative sizes of the iso-employment elasticity $\lambda_{n}$ and the remuneration elasticity $\varepsilon_{\eta m}$. Using Figure 5.7, it is clear that work-sharing policies only lead to reduced unemployment if $H>H_{\pi}>H_{w}$. So, the general equilibrium results, thus including entry and exit, are more likely to give adverse effects compared to the labour market equilibrium.

Moreover, if, as argued before, bargained hours are determined in the interval $\left[H^{m}, H^{\top}\right]$ any work-sharing policy starting from bargained hours will in the long run lead to higher unemployment (and lower remuneration).

\subsubsection{A numerical illustration}

Table 5.2 concludes the section with a numerical illustration of the equilibrium effects. As a reference, the first row repeats the values found in Table 5.1 for the partial equilibrium right-tomanege model. Moreover, one additional column is added, $\frac{d \ln Y}{d \ln H}$, to illustrate the interaction effects on remuneration. Contrary to the right-to-manege model, the final impact of reduced hours on remuneration will differ from the remuneration elasticity $\varepsilon_{Y H}$.

To find the equilibrium results, I need to calibrate four more parameters. The price elasticity of aggregate demand $\tau_{A}$ is set at 1.5 as in Chapter 2. Participation in the labour market is considered to be fully inelastic, so $\varepsilon_{S}=0$. The parameter $\rho_{U}$ is related to the replacement rate $B / Y$, but may be higher due to risk aversion. Ignoring the latter aspect, I used $\rho_{U}=0.6$ as in Pissarides (1998), but lower than in Bovenberg, Graafland et al. (2000). Although unemployment is determined within the model, I also needed an initial value as I only consider relative changes. This benchmark value for unemployment $u$ was set at 0.075 , as work-sharing is typically suggested at times of high unemployment.

For given benefits, wage moderation is lower in the general equilibrium than in the partial equilibrium. The reason is that in the partial equilibrium employed workers gain from work-sharing, hence the outside option increases in equilibrium. This reduces wage moderation. Due to the lower price elasticity of goods demand in the aggregate, aggregate labour demand reacts less. Combining the shifts in labour demand and wage setting, see Figure 5.8, remuneration falls and employment is slightly increased in the labour demand model. The $\omega$-column illustrates that full wage moderation only occurs at rather long working times. The last column demonstrates that employment is more likely to increase, compared to the partial equilibrium.

The opposite holds for the general equilibrium model, where remuneration is adjusted as to keep profitability constant. Here price setting is independent of the scale of production(or employment). As initial working time $H$ is lower than the demand $H^{d}$ of firms, remuneration declines more than proportionally in the equilibrium. Nevertheless, employment falls. The last column illustrates that 
Table 5.2 Numerical working time elasticities: market equilibrium

\begin{tabular}{|c|c|c|c|c|c|c|c|}
\hline & $\boldsymbol{\varepsilon}_{\text {NHY }}$ & $\boldsymbol{\varepsilon}_{N Y}$ & $\varepsilon_{Y H}$ & $\frac{d \ln Y}{d \ln H}$ & $\frac{d \ln N}{d \ln H}$ & $\omega^{*}$ & $\begin{array}{c}\eta^{e} / \omega \\
d N=0\end{array}$ \\
\hline \multicolumn{8}{|l|}{ Partial equilibrium } \\
\hline Long-run labour demand & 2.400 & -2.920 & 0.849 & 0.849 & -0.079 & 1.060 & 0.689 \\
\hline \multicolumn{8}{|l|}{ Equilibrium } \\
\hline \multicolumn{8}{|c|}{ Benefits given } \\
\hline Labour market equilibrium & 0.600 & -1.240 & 0.499 & 0.322 & -0.009 & 1.803 & 1.065 \\
\hline General equilibrium & $\infty$ & $\infty$ & 0.499 & 1.071 & 0.030 & 1.803 & 0.311 \\
\hline \multicolumn{8}{|c|}{ Replacement rate given } \\
\hline Labour market equilibrium & 0.600 & -1.240 & 0.748 & 0.328 & -0.015 & 1.203 & 1.596 \\
\hline General equilibrium & $\infty$ & $\infty$ & 0.748 & 1.071 & 0.014 & 1.203 & 0.466 \\
\hline
\end{tabular}

a. Besides the parameters from Table 5.1, the additional parameters for the market equilibrium are $\tau_{A}=1.5, \varepsilon_{s}=0, \rho_{v}$ $=0.6$ and $u=0.075$.

initial working time should be rather long to get positive employment effects of work-sharing.

If the replacement rate is given, the employment effects become somewhat more favourable. Due to wage moderation, benefits also decline reinforcing the positive impact on employment. Notice, however, that the utility of the unemployed falls. Employment still declines in the price setting model, although the critical value for initial hours is reduced considerably.

\subsection{Conclusion}

Working time reduction is a recurrent theme in the European discussion on unemployment. Proponents typically stress the work-sharing aspects, whereas opponents stress the impact on costs and competitiveness. This raises the issue of wage determination in the wake of working time reduction. In this chapter I have incorporated these issues in an equilibrium labour market framework. The main conclusions of the analysis are:

- working time reduction is likely to lead to wage moderation in terms of annual remuneration;

- wage moderation holds for any type of union bargaining framework;

- wage moderation is stronger if consumption and leisure are Edgeworth substitutes in utility;

- wage moderation is stronger in right-to-manage models compared to monopoly unions; 
- wage moderation is stronger at longer working times;

- there is a U-shaped relation between working times and hourly wages; and, as a consequence,

- there is a U-shaped relation between working times and the equilibrium unemployment rate. So working time reduction can indeed reduce unemployment, but only for sufficiently long working times. Moreover, a numerical example suggests that the (un-)employment effects are rather limited. The key then is to determine at what level of working time the impact changes sign. This is on the agenda for future research. From an empirical point of view, the question is whether one can estimate wage setting curves and labour demand or price setting curves with the predicted impact of working times. From a theoretical point of view, the main question is how, and at what level, working times are determined. This is the topic of the next chapter. 



\section{Bargaining over Hours or Effort}

\subsection{INTRODUCTION}

During the $20^{\text {th }}$ century the industrialised world has witnessed a strong decrease in annual hours worked per person in employment. In the beginning of that century the annual working time was around 2700 hours, see Maddison (1982), whereas in 1995 full-time annual hours of industrialised countries varied somewhere between 1700 and 1900 hours, see Hunt (1998). Around 1700 hours is typical for northern continental European countries like Germany and the Netherlands, whereas American workers tend to work around 1900 hours a year. A similar difference is observed for normal weekly hours: the 40-hours week is the norm in the USA, but in continental Europe 36 or 38 hours seem to be the rule. The remaining difference is explained by longer vacations in Europe compared to the USA.

The standard explanation for these reductions in annual or weekly hours is based on productivity gains: productivity gains lead to higher hourly wages in the labour market and with a backward bending labour supply curve this in turn leads to reductions in hours worked. The 1000 hours reduction in a century corresponds roughly to a $0.5 \%$ decrease per annum. With a not unrealistic increase in productivity and hourly real wages of $2 \%$ per year, this would imply a labour supply elasticity of -0.25 . Although perhaps a bit high in absolute value, this seems within the bounds of empirical estimates of male labour supply elasticities.

The decline of 800 to 1000 hours during the century, did not occur at the same time on both sides of the Atlantic, however. The 40-hour week was introduced in the 1940s in the USA. Since then annual full-time hours have remained rather constant. In continental Europe, on the other hand, the 40-hours week was only introduced in the 1960s or 1970s, but annual and weekly hours further decreased during the 1980s and 1990s. This difference in development is sometimes attributed to the role of labour unions in Europe. In the high unemployment era after the oil-shocks of the seventies, European unions have been pushing towards reductions in working time to redistribute work amongst people. This is the so-called work-sharing strategy, see Hunt (1998). The merits of such a strategy have been questioned in the literature, see e.g., Freeman (1998) or Hunt (1998).

In the previous chapter I have shown that the impact of working time redistribution depends on the length of the original working week. A natural extension is to consider the determinants of working time in a union bargaining framework. This seems to be a rather underresearched area, but 
notable exceptions are Calmfors (1985) and, more recently, Marimon and Zilibotti (2000). This chapter tries to fill the gap and provides an overview of various hours bargaining models. To explain the impressive reduction in working hours of the last century, the final question will be how productivity growth affects bargained hours. It will be shown that declining hours can be consistent with inelastic, or even upward sloping, labour supply.

The plan of the chapter is as follows. Section 6.2 sets the scene by considering a taxonomy of hours determination models. This leads to a natural distinction between hours models and effort models. In Section $6.3 \mathrm{I}$ introduce the partial equilibrium model, which closely follows the model of Chapter 5, and I compare the traditional labour supply model of hours determination with three alternatives: labour demand, union hours and bargained hours. Section 6.4 then considers effort bargaining and Section 6.5 briefly summarises the wage bargaining model of Chapter 5 . Section 6.6 considers the simultaneous hours and wage bargain. In Section $6.7 \mathrm{I}$ briefly consider a sequential bargain, where hours are determined before the wage bargain. In Section $6.8 \mathrm{I}$ turn to the impact of productivity growth on bargained hours. For this we need a general equilibrium framework. Section 6.9 concludes the chapter.

\subsection{A TAXONOMY OF HOURS AND EFFORT BARGAINING}

Let me first provide a framework for hours or effort determination within a union bargaining framework. The industrial relations literature ascribes an important role to trade unions in the setting of hours worked or effort. This is, for example, confirmed by the observation that a large majority of British unions negotiate about hours of work, see Clark and Oswald (1993). Andrews and Simmons (1995) and Oswald (1993) also stress that working conditions, including working time issues, are on the bargaining agenda. The call for work-sharing by continental European unions in the 1980 s and $1990 \mathrm{~s}$ is another piece of corroborating evidence.

The term 'effort' has become widespread in recent years, yet its meaning varies considerably. Andrews and Simmons (1995) clarify the definition and meaning and give examples, see also Oi (2001). It is best perceived as being multi-dimensional - think of working conditions - but for modelling purposes it is mostly treated as being one-dimensional. Two key characteristics are that effort increases labour productivity, but is disliked by individuals. This suggests an analogy with hours of work, which has the same two characteristics. There is one crucial difference, however, as "labour costs are different, because firms pay directly for hours but not for effort" (Andrews and Simmons (1995, p. 314)). In other words, whereas an additional hour increases the wage bill with the hourly wage costs $W$, effort can in principle be increased without a corresponding rise in remuneration $Y$. 
This property of effort has an important impact on the functioning of labour markets. If effort is unobservable, this has led to various efficiency wage theories, mostly of the shirking type introduced by Shapiro and Stiglitz (1984). In this chapter, however, the focus is on observable effort which is bargained over with unions. ' In doing so, I will concentrate on working time $H$. Nevertheless, the distinction between hours and effort models is still relevant: in the former, working time is determined at given hourly wage $W$, whereas in the latter, working time is determined at given annual or weekly remuneration $Y$. In a sense it is the timing of decisions which matter for the distinction between hours models and effort models: in effort models annual remuneration is fixed before annual working time, whereas in hours models the choice of hours will affect annual remuneration, as only the hourly wage is fixed in advance. When hours, or effort, is determined before the wage bargain, the distinction is meaningless.

Table 6.1 illustrates the difference between the two types of models within a wage bargaining framework. In all cases, the maintained hypothesis of the table is that wages $W$ (or remuneration $Y$ ) are bargained between unions and firms. Moreover, as the number of workers $N$ is typically not directly bargained about, see Clark and Oswald (1993), Layard, Nickell et al. (1991) and Oswald (1993), I also assume throughout that wage bargaining is of the right-to-manage type, as introduced by Nickell and Andrews (1983), where the firm determines the number of workers.

First, consider the various hours models. The best known is the labour supply model, where working time $H^{s}$ is determined by workers given the prevailing hourly wage. Alternatively, we can define hours demand $H^{d}$ as the working time firms would like to implement at given hourly wage, see Dobbs (1992). Contensou and Vranceanu (1998) use a model where firms set hours, but at given reservation utility of its employees, instead of a given wage. Alternatively we could let agents determine hours, given the profit level of firms. Combining all points where the iso-profit curves and indifference curves are tangent, we get a contract curve in terms of hourly wages and hours. This is labelled efficient hours $H^{e}$ in the table. It is included as a benchmark case.

As unions also care about employment, their desired hours $H^{m}$ do not necessarily correspond to labour supply. But if unions do not have all the bargaining power, bargained hours $H^{w}$ will be different and also incorporate the preferences of firms.

Although union bargaining models were high on the research agenda, see e.g., Layard, Nickell et al. (1991), only little effort has been devoted to the determinants of normal hours of work within

1 Bulkley and Myles (1996) consider unobservable effort in a bargaining framework, see the comment by Goerke (1998), however. 


\section{Table 6.1 A taxonomy of some hours and effort models}

\begin{tabular}{|c|c|c|c|c|c|}
\hline & & $\begin{array}{r}\text { Variables } \\
\text { firms }\end{array}$ & agents & $\begin{array}{l}\text { aterally by } \\
\text { unions }\end{array}$ & $\begin{array}{c}\text { Variables determined } \\
\text { by bargaining }\end{array}$ \\
\hline \multicolumn{6}{|c|}{ Hours models } \\
\hline hours supply & $H^{\prime}$ & $N$ & $H$ & & $W$ \\
\hline hours demand & $\dot{H^{i}}$ & $N, H$ & & & $W$ \\
\hline union hours & $H^{m}$ & $N$ & & $H$ & $W$ \\
\hline bargained hours & $H^{*}$ & $N$ & & & $W, H$ \\
\hline \multicolumn{6}{|c|}{ Efficient hours/effort } \\
\hline efficient hours & $H^{*}$ & $N$ & & & $H$ \\
\hline \multicolumn{6}{|c|}{ Effort models } \\
\hline union effort & $H^{r}$ & $N$ & & $H$ & $Y$ \\
\hline bargained effort & $H^{\nu}$ & $N$ & & & $Y, H$ \\
\hline
\end{tabular}

such a framework. ${ }^{2}$ Notable exceptions are Calmfors (1985), Earle and Pencavel (1990) and Pencavel (1991). Calmfors (1985) considers the optimal working time $H^{m}$ for the trade union and Earle and Pencavel (1990) provide a taxonomy of the bargaining structure, of which Pencavel (1991) considers two special cases. More recently, Marimon and Zilibotti (2000) and Rocheteau (2000) consider bargained hours $H^{w}$ as their benchmark.

In effort models, annual (or weekly) remuneration $Y$, instead of hourly wages $W$, is determined in the wage bargain. At given remuneration firms have an incentive to maximise working time $H$, whereas employed individuals would tend to minimise it. These conflicting interest can be solved in a union bargaining framework, leading to $H^{u}$ in a monopoly union setting and to $H^{v}$ if the bargaining power of the union is limited.

A number of papers has been devoted to the determination of effort within union bargaining models. A major conclusion of the literature is that union power tends to reduce effort, suggesting $H^{\prime}$ $>H^{u}$, see e.g., Bulkley (1992), Bulkley and Myles (1997), Johnson (1990), Rosen (1989) and Sampson (1993).

2 Booth and Schiantarelli (1987) and Houpis (1993) do consider the determination of actual (or overtime) hours within a wage bargaining context. Overtime is typically determined by firms in the last stage of the model, after the wage bargain. Cahuc and Granier (1997) show that firms would like to precommit on actual hours in such models. These models take normal hours, which is the focus of this chapter, as parametric, however. 


\section{Table 6.2 Hours and effort bargaining models}

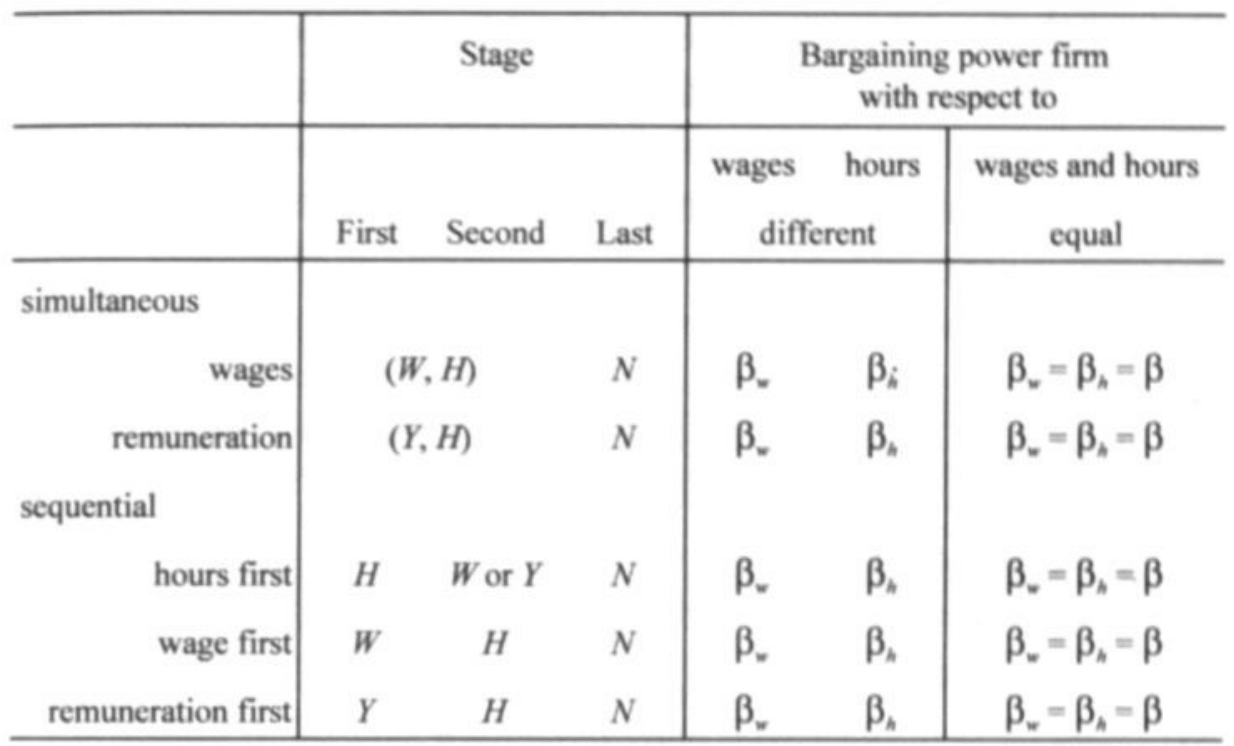

The bargaining outcomes also critically depend on the timing and structure of the bargaining process, see Manning (1987). Whereas the papers above consider simultaneous bargaining over remuneration and effort, Andrews and Simmons (1995), Nickell, Wadhwani et al. (1992) and Rosen (1989) compare this with recursive bargaining, where effort is determined before remuneration. On the other hand, Table 6.1 assumes that hours are (or effort is) determined after the wage bargain. This may lead to strategic behaviour in the wage bargaining phase, where the bargaining parties take the subsequent impact on working time into account.

Moreover, when including more than one issue on the bargaining agenda, the bargaining power of the union and the firm might differ between the issues. Let the parameter $\beta_{x} \geq 0$ denote the bargaining power of the firm with respect to issue $X: \beta_{x}=0$ corresponds to the monopoly union model and $\beta_{x} \rightarrow \infty$ to the firm having all bargaining power on this issue. In the symmetric case the bargaining power is the same, say $\beta$, on all issues.

Table 6.2 lists the possible alternatives, at least restricting our attention to right-to-manage models with respect to employment $N$ in the last stage. ${ }^{3}$ This yields 9 different models. By and large three groups with respect to the timing can be distinguished:

- With simultaneous bargaining, hours and wages are determined jointly in the first stage. With equal bargaining power on both issues, but not with different bargaining power, this is observationally equivalent to a simultaneous effort and remuneration bargain.

3 Earle and Pencavel (1990) and Pencavel (1991) also include efficient bargaining with respect to employment as an alternative. 
- Casual observation of industrial relations suggests that normal working times are only adjusted once in a while, whereas wages are bargained in each round. ${ }^{4}$ Similarly, Andrews and Simmons (1995) argue that work practices seem to be less sensitive to economic changes than wages and employment. This suggests that we should consider hours or effort to be set prior to wages. This leads to the sequential hours, or effort, first bargains, but these two are observationally equivalent. In the first stage normal hours are (or effort is) determined and in the second stage wages (and hence remuneration).

- Hours-first bargains suggest that hours or effort are not adjusted that often, but it could be argued that hours or effort may be changed rather quickly at the discretion of firms or individuals. This would suggest the opposite sequence, where hours are determined after wages or remuneration. This leads to the wage- and remuneration-first models of Table 6.2. The bargained hours model of Table 6.1 corresponds to a wage-first bargain, whereas the bargained effort model corresponds to remuneration-first bargain. ${ }^{5}$ This sequence of events, where working time is adjusted after the wage bargain, should not be confused with overtime models, however. The reason is that in wage-first (remuneration-first) models employment is determined after the hours (effort) determination, whereas the overtime decision is typically taken at given employment levels. Thus, incorporating overtime would lead to a fourth stage, after employment determination, where actual hours are determined, see Pencavel (1991). Overtime is ignored in this chapter.

Summarising, Tables 6.1 and 6.2 illustrate that there is a wealth of economic models to analyse hours worked, and most of them have indeed been used in the literature. The relevance of each seems to depend on the institutional detail. In this chapter I take it for granted that unions are involved in the determination of hours. This still ieaves the nine models of Table 6.2. The simultaneous bargaining model with equal bargaining power will be used as a benchmark, but I will briefly discuss the impact of differences in bargaining power and consider the hours-first sequential model as an alternative. The sequential wage- or remuneration-first models seem less relevant to me, as they imply that hours will be adjusted after each wage bargain, and that does not seem to be the normal practice. ${ }^{6}$

4 There may be many reasons for this, including coordination problems, externalities and heterogeneity of preferences. This is all ignored here.

5 Manipulating the firm's second stage bargaining power $\beta_{h}$, all outcomes of Table 6.1 can be obtained, except for the labour supply model $H^{P}$ and efficient hours $H$. Consider the wage-first model, for example, then $\beta_{h}=0$ gives $H^{\mathrm{m}}$, whereas $\beta_{h} \rightarrow \infty$ gives $H^{I}$.

Unless bargained hours would be inelastic. 


\section{3}

\section{HOURS DETERMINATION}

To introduce the partial equilibrium model and the corresponding notation, the hours models of Table 6.1 are introduced first. As a by-product, the analysis provides a comparison of the various hours models in the literature. The model is essentially the same as in the previous chapter, the only difference is that I explicitly include productivity parameters, to analyse the impact of productivity growth on hours (and wages) later on.

\subsubsection{Individuals}

Individuals derive utility from consumption $Y$ and leisure $L$. Given a fixed time constraint, leisure is the complement of hours worked $H$. So the utility function can be written as $U(Y, H)$, with partial derivatives satisfying $U_{H}<0<U_{r}$. There is no non-wage income and the price of consumption goods is normalised to one, so consumption is equal to income, which is given by the budget constraint $Y=W H$, where $W$ is the real hourly wage.

Hours supply $H$ is obtained by maximising utility at a given hourly wage. Hence the marginal rate of substitution is equated to the wage. It seems reasonable to assume that consumption and leisure are both normal goods, but the sign of the derivative $\partial H / \partial W$ of the hours supply curve is ambiguous. The bulk of the evidence indicates that labour supply elasticities (if positive) are rather small. To explain the decredse in working time during the last century with an hours supply model it should be negative.

For future reference I use the same notation as in Chapter 5: first, the marginal rate of substitution between log-leisure and log-consumption is denoted as $\omega \equiv-\left(H U_{H}\right) /\left(Y U_{Y}\right)>0$; second, the rate of relative risk aversion with respect to consumption is $\alpha_{Y} \equiv-Y U_{Y Y} / U_{Y} \geq 0$; third, the rate of relative risk aversion with respect to hours worked is $\alpha_{H} \equiv H U_{H H} / U_{H} \geq 0$; and finally, $\xi \equiv-Y U_{Y H} / U_{H}$ reveals the substitutability between consumption and leisure. Using this notation, hours supply $H^{*}$ is implicitly given by $\omega=1 .^{7}$ The signs of the $\alpha$ 's indicate that individuals are risk averse - or at least not risk seeking - with respect to consumption and leisure. ${ }^{8}$ Finally, the usual assumption that consumption and leisure are both normal goods implies that $\xi<\min \left(\alpha_{\gamma}, \alpha_{H} / \omega\right)$. As in Manning (2001), I need to assume in the sequel that this condition holds everywhere, i.e. for all hours and not only for hours supply $H^{5}$.

The cross-partial $U_{Y H}$, and hence $\xi$, cannot be signed a priori. In the often used Cobb-Douglas type multiplicative separable utility function, e.g., Johnson (1990) and Nickell, Wadhwani et al. (1992),

7 The second-order condition, $\alpha_{Y}-2 \xi+\alpha_{H}>0$, is assumed to hold. This is clearly the case if consumption and leisure are normal goods.

8 The coefficient of relative risk-aversion with respect to leisure is given by $-L U_{L L} / U_{L}=\alpha_{H} L / H \geq 0$. 


$$
U(Y, H)=a(Y) d(H),
$$

with $a^{\prime}>0 \geq a^{\prime \prime}$ and $d^{\prime}<0, \xi$ is negative, implying that consumption and leisure are Edgeworth complements. Machin and Manning (1992, p. 293) find this a plausible assumption, as it implies that 'workers who work hard are too tired to enjoy their income'. Andrews and Simmons (1995), on the other hand, argue that this sign is counterintuitive, as it implies that the marginal utility of income declines as hours (or effort in their model) increase. Non-negative cross-partials are obtained, for example, in utility functions of the type

$$
U(Y, H)=v(a(Y)-g(H)),
$$

with $a^{\prime}>0 \geq a^{\prime \prime}, v^{\prime}>0 \geq v^{\prime \prime}, g^{\prime}>0, g^{\prime \prime} \geq 0$ and $g^{\prime \prime}>a^{\prime \prime}$. This class of utility functions is often used in papers on effort, see e.g., Andrews and Simmons (1995), Bulkley (1992), Rosen (1989) and Sampson (1993), although in most papers at least one of these three functions is an identity. The so-called GHH-preferences of Marimon and Zilibotti (2000) also belong to this class, as they use iso-elastic specifications for $v(\cdot)$ and $g(\cdot)$, and set $a(Y)=Y$.

I have no strong feelings about the sign of the cross-partial. Maybe it also depends on the length of the workweek: for long hours tiredness may dominate ( $\xi$ being negative), but that is less likely for shorter workweeks ( $\xi$ positive). I am not aware of a simple utility function satisfying this property. However, to derive more specific results, I need to assume that consumption and leisure are not too strong Edgeworth complements. As in Chapter 5 , a sufficient, but not necessary, condition will be that

$$
U_{Y H} \geq \frac{U_{Y} U_{H}}{U}
$$

This gives a negative lowerbound for the parameter $\xi$. It is easily checked that (6.3) is satisfied for both of the above utility functions.

Finally, two important expressions are the elasticities of the marginal rate of $\log$-substitution $\omega$ with respect to consumption and hours. They are given by $\omega_{Y} \equiv \frac{\partial \ln \omega}{\partial \ln Y}=\alpha_{Y}-1-\xi$ and $\omega_{H} \equiv$ $\frac{\partial \ln \omega}{\partial \ln H}=1+\alpha_{H}-\omega \xi$, respectively. When consumption is a normal good, as is assumed, $\omega_{H}>1$, and $\omega$ is changing more than proportionally in hours at given income levels. ${ }^{10}$ On the other hand, $\omega_{\gamma}$ can not be signed a priori. Leisure being a normal good implies $\omega_{Y}>-1$. For a Cobb-Douglas

9 The only exception I am aware of is Andrews and Simmons (1995), who use three iso-elastic functions.

10 As a corollary, $\omega$ is positively correlated to $H$ at given hourly wage. Indeed in that case $\left.\frac{d \ln \omega}{d \ln H}\right|_{\mathbb{T}}=$ $\omega_{\mu}+\omega_{Y}>0$. The second-order condition for utility maximisation implies that the last expression is positive. 
utility we have $\omega_{\gamma}=0$, and the marginal rate of $\log$-substitution $\omega$ is independent of consumption. For the class of utility functions (6.2), we have $\omega_{Y}=\alpha_{a}-1$, where $\alpha_{\alpha}$ is the rate of relative risk aversion of $a(Y)$. So in general, $\omega$ can either be increasing or decreasirg in consumption. Notice, however, that the sign of the derivative $\partial H / \partial W$ of the hours supply cur $*$ s $s$ given by minus the sign of $\omega_{Y}($ evaluated at $\omega=1)$. "So to explain the decrease in working time during the last century by hours supply we would need $\omega_{Y}>0$.

\subsubsection{Firms}

Conventional analysis of a firm's choice between workers and hours focusses on the determination of overtime at given standard hours, see e.g., Rosen (1968), Ehrenberg (1971), Hamermesh (1993) or Hart (1987). This short-run decision is not what this chapter is about, but see Chapter 3. Here the focus is on the long-run demand for hours. So I assume that there is no overtime and focus on the desired (standard) hours from the viewpoint of the firm, as in Dobbs (1992). Given the long-run perspective it is important to incorporate the impact of hours on capital services, see Chapter 2.

The model of the firm is the same as in Chapters 5, except that exogenous technical progress is introduced in this version. The instantaneous production function $F\left(A_{K} K, A_{N} N\right)$ relates output at any moment of time to the stock of capital $K$ and labour $N$, i.e. the number of machines and workers. The variables $A_{K}$ and $A_{N}$ capture capital or labour augmenting technological progress, respectively. The production function is assumed to have constant returns to scale, so it can be written in intensive form as $F\left(A_{K} K, A_{N} N\right)=A_{N} N f(k)$, where the capital-intensity $k \equiv A_{K} K / A_{N} N$ is now the capitallabour ratio expressed in efficiency units. To capture positive but decreasing marginal productivity, the function $f(k)$ satisfies $f^{\prime \prime}(k)<0<f^{\prime}(k)<f(k) / k$. As before, the elasticity of $f(k)$ will be denoted as $\eta$ and $\sigma>0$ is the elasticity of substitution between the stocks of capital and labour. In view of the available evidence, I concentrate on the case where $\sigma \leq 1$.

Beside the scale of operations - as determined by the stocks of capital and labour - output can be increased lengthening the duration of operations. Including efficiency hours $e(H)$ to capture things like warming-up times and fatigue effects, output is $Q=e(H) A_{N} N f(k)$. Let $\eta^{e}$ denote the elasticity of efficiency hours and define $H_{p}$ and $H_{\max }$ implicitly by $\eta^{e}=1$ and $\eta^{e}=0$, respectively. In line with Chapman (1909) and Walker (2000), hourly productivity reaches a maximum at $H_{p}$, whereas output per worker, and hence efficiency hours, is maximised at $H_{\max }>H_{p}$. The relevant range of hours for firms is then $\left[H_{p}, H_{m a x}\right]$. Within this range, efficiency hours are increasing in hours worked, so $e^{\prime}>0$, whereas the elasticity $\eta^{e}$ is declining. To capture the last property, let $\gamma_{H} \equiv-\frac{d \ln \eta}{d \ln H}>0$.

11 More specifically, the elasticity of hours supply is given by $\varepsilon_{H}{ }_{W}=-\frac{\omega_{Y}}{\omega_{Y}+\omega_{H}}$. 
On the cost side, wage costs per worker correspond to $\mathrm{V}+\mathrm{WH}$, where fixed costs per worker $V$ are independent of hours worked and hourly wage costs are $W$. Each worker's remuneration corresponds to $W H$, which is equal to his of her income $Y$. With respect to capital costs, the exogenous user cost of capital, $R$, is independent of the duration of operations.

In the output market, firms are operating in a market of monopolistic competition. A typical firm faces a downward sloping iso-elastic demand curve of the type $Q=D P^{-\tau}$, where $P$ is its price, $D$ is an exogenous demand shifter and $\tau>1$ is the elasticity of demand. Substituting out the price, the revenue of the firm is thus $D^{1-v} Q^{v}$, where $0<v \equiv 1-1 / \tau<1$ measures the competitiveness of the output market, with $v$ close to 1 the market being very competitive. Combining all this, the profit of a firm is given by

$$
\Pi=D^{1-v} Q^{v}-(V+W H) N-R K .
$$

Maximising the profit with respect to the capital stock $K$ and number of workers $N$, the firstorder conditions can be rewritten as ${ }^{12}$

$$
\frac{A_{K} f^{\prime}(k)}{A_{N}\left[f(k)-k f^{\prime}(k)\right]}=\frac{R}{V+Y}
$$

and

$$
v D^{1-v} e(H)^{v} A_{N}^{v} N^{v-1} f(k)^{v-1}\left[f(k)-k f^{\prime}(k)\right]=V+Y .
$$

Equation (6.4) equates the marginal rate of technical substitution between the stocks of capital and labour to their ratio of marginal costs. It determines the optimal capital-intensity $k$, which is inversely related to relative costs, corrected for non-neutral productivity changes, but independent of the scale $D$. Equation (6.5), equating the marginal revenue product to unit labour costs, determines the demand for workers. As in Chapter 5, the elasticity of labour demand with respect to remuneration is $\varepsilon_{N Y}=-\left(1-\varphi_{V}\right)\left[\tau\left(1-\eta^{\prime}\right)+\sigma \eta^{\prime}\right]<0$, where $\varphi_{V} \equiv V /(V+Y) \in(0,1)$ is the share of fixed costs $V$ in labour costs.

For the impact of hours worked on labour demand $N$, it is important to distinguish between the case where remuneration $Y$ is fixed (effort) or where the wage $W$ is fixed (hours). In the first case we have the conditional elasticity $\varepsilon_{N H Y}=(\tau-1) \eta^{e}>0$, whereas in the second case $\varepsilon_{N H W}=\varepsilon_{N H Y}{ }^{+}$ $\varepsilon_{N Y}$. An increase in effort is tantamount to neutral technological progress $\left(d \ln A_{N}=d \ln A_{K}>0\right)$, and

12 The second-order conditions for profit maximisation are the same as in Chapter 5, and are satisfied for $v<1$ and $\sigma>0$. 
increases employment. Although less workers are needed to produce the same amount of output, the lower costs imply that output is expanded in a monopolistic competitive environment. The second-order condition $(\tau>1)$ guarantees that the output effect dominates. At given hourly wages, however, a simultaneous increase in remuneration occurs, which reduces the positive impact on employment. Whether employment increases or falls depends on the length of working time, see Chapter 5. Let $H_{n}$ be implicitly defined by $\varepsilon_{N M W}=0$, then the number of workers is maximised at $H_{n}$ and employment is positively (negatively) related to hours worked for shorter (longer) initial working times. In Appendix I it was shown that the critical level $H_{n}$ is a decreasing function of the wage,

Next consider the impact of hours worked on profits II. Using the envelope theorem, it is easily shown that $\varepsilon_{\mathrm{\Pi I} Y Y}=(\tau-1) \eta^{e}=\varepsilon_{N H Y}>0$ and $\varepsilon_{\Pi H W}=\varepsilon_{\mathrm{\Pi} H Y}+\varepsilon_{\mathrm{I} r}$, where $\varepsilon_{N Y}<\varepsilon_{\mathrm{II} Y}=$ $-\left(1-\varphi_{V}\right)(\tau-1)\left(1-\eta^{\prime}\right)<0$, as in Chapter 5. Obviously, profits and effort are positively related, but for hours, thus at given wage, the negative impact of increased remuneration has to be added. The sign then once again depends on the length of working time.

If the firm can unilaterally set hours, it will determine optimal hours $H^{f}$ as to maximise profits. This gives the first-order condition

$$
v e^{\prime}(H) D^{1-v} e(H)^{v-1} A_{N}^{v} N^{v-1} f(k)^{v}=W .
$$

Dividing equation (6.6) by (6.5), the marginal rate of substitution between hours and workers should be equal to the ratio of marginal costs. This implies

$$
\frac{e^{\prime}(H)}{e(H)} \frac{f(k)}{f(k)-k f^{\prime}(k)}=\frac{W}{V+Y}
$$

or $\eta^{e}=\left(1-\varphi_{V}\right)\left(1-\eta^{\prime}\right)<1$ in short-hand. ${ }^{13}$ In the optimum the elasticity of efficiency hours (or output) with respect to hours should be equal to the elasticity of output with respect to employment $1-\eta^{f}$, corrected for the share of remuneration in labour costs $1-\varphi_{V}$. As a consequence, $\eta^{e}<1$ and $H_{p}<H^{d}<H_{\max }$

Jointly, the equations (6.4) and (6.7) define the capital-intensity and hours that minimise unit costs. The comparative statics of hours demand $H^{d}$ can easily be derived. This was discussed at length in Chapter 2. For simplicity the signs are summarised in Table 6.3 below. Hours demand is declining in the hourly wage $W$ and increasing in the fixed costs $V$. Moreover, as long as $\sigma<1$, it is

13 As a consequence, we have $\varepsilon_{\Pi H W}=\varepsilon_{\Pi h Y}+\varepsilon_{\Pi Y}=0$ in the optimum, as was to be expected from the first-order condition. 
increasing in the user cost of capital $R$. Long-run hours demand is independent of scale $D$. For the same reason it is independent of competitiveness $v$. Neither will neutral technical progress affect hours demand. Biased technological progress, however, changes the marginal rate of technical substitution between capital and labour, see equation (6.4). Therefore, it has the same effect as a change in the user cost of capital.

Table 6.3 also incorporates the comparative statics of the critical hours $H_{n}$, see again Chapter 2 for a more extensive discussion. It has the same properties as hours demand $H^{d}$, except for the impact of competitiveness $v$ : in more competitive markets ( $v$ closer to one) the critical level of hours is higher, and both coincide under perfect competition. ${ }^{14}$

\subsubsection{Efficient hours}

Combining the ingredients of the above two models, consider the determination of hours in competitive markets. Many economists commonly assume that hours are determined by the labour supply curve. As illustrated in the previous section, however, firms typically have their own preferences for hours worked. So in general, hours supply and hours demand need not to correspond and the question is how to equate demand and supply. At first sight, the hourly wage rate seems to be a relevant price variable. However, the wage rate can not equate the labour market at the extensive (workers) and at the intensive margin (hours). The only exception is the unlikely case when the production functions can be expressed in terms over employee-hours, $E=\mathrm{NH}$, and when there are no fixed labour costs, $V=0$. Only then the firm is willing to leave the choice of working time to the workers, as it can get the optimal employee-hours adjusting the number of workers, see Lewis (1969) and Manning (2001). To equate the extensive and intensive margins of the labour market in more general models, one typically needs a non-linear pricing schedule where average hourly wages depend on hours worked. The simplest example is the two-tier price mechanism with a constant hourly wage and a fixed fee or benefits. ${ }^{15}$ The hourly wage rate equates demand and supply at the intensive margin and the fee or benefit equates demand and supply at the extensive margin.

I will not elaborate on this, but just consider the properties of the corresponding contract curve for hours and hourly wages. This corresponds to the case analysed by Contensou and Vranceanu (1998), who consider the competitive solution under utility competition. That is, the firm maximises its profits under a participation constraint for its workers, as they should obtain at least their

14 In general we have $H_{n}<H^{d}$, see also Cahuc and Granier (1997), and lim , $_{-1} H_{n}=H^{d}$, see Appendix I.

15 This could be one possible interpretation of the labour cost structure introduced in the previous subsection, where $W$ is the hourly wage and $V$ the fixed fee. However, this is not the interpretation used in this chapter. Moreover, notice that the two-tier schedule only works with homogeneous agents. 


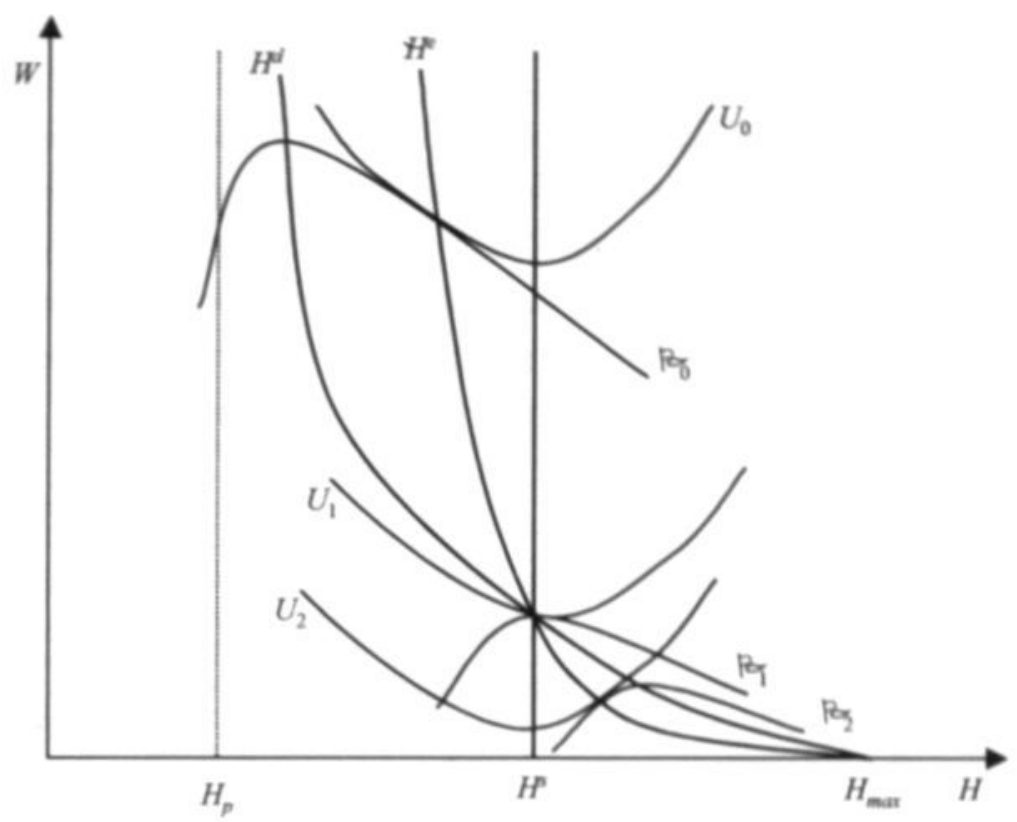

Figure 6.1 Efficient hours

reservation utility $U^{a}$. Maximising profits $\Pi$, subject to the constraint $U(Y, H) \geq U^{a}$, with respect to capital $K$, employment $N$, working time $H$ and remuneration $Y$, the first-order conditions can be written as (6.4), (6.5) and

$$
\frac{e^{\prime}(H)}{e(H)} \frac{f(k)}{f(k)-k f^{\prime}(k)}=-\frac{U_{H}}{U_{Y}} \frac{1}{V+Y}
$$

This equation replaces hours demand (6.7) and determines the contract curve between hours and wages. ${ }^{16}$ In short-hand this equation can be rewritten as $\eta^{e}=\left(1-\varphi_{V}\right)\left(1-\eta^{\prime}\right) \omega$ or $\lambda_{\Pi}=\omega$, where $\lambda_{\Pi} \equiv \frac{\eta^{e}}{(1-\Phi)\left(1-\eta^{\Im}\right)}$ is the iso-profit elasticity of remuneration with respect to hours. The latter condition just states the tangency between the iso-profit curve and the indifference curve and hence defines the contract curve. The solution is illustrated in Figure 6.1. In the graph hours supply $H^{F}$ is assumed to be fully inelastic. The minimum of the U-shaped indifference curves $U_{i}$ is at hours supply. Hours demand $H^{d}$ is downward sloping and corresponds to the maximum of the iso-profit lines $\Pi_{i}$. Hours demand exceeds productive hours $H_{p}$, but is lower than maximum hours $H_{\max }$. Efficient hours $H^{F}$ correspond to the tangency between the indifference curves and the iso-profit lines. The exact

16 Notice that when the marginal rate of substitution is equal to the wage rate, that is at hours supply, both equations are the same. 
position on the contract curve depends on the reservation utility, or more general, on the bargaining power of firms and workers.

Figure 6.1 also illustrates that efficient hours can be seen as a kind of weighted average of the hours demand and hours supply. Indeed, its properties combine the properties of hours supply and hours demand in Table 6.3. The comparative static properties are easily derived differentiating equations (6.4) and (6.8). The corresponding wage elasticity of efficient hours is a weighted average of the hours demand elasticity and the hours supply elasticity. As hours demand is decreasing, efficient hours are more likely to decrease with wages than hours supply. ${ }^{17}$

\subsubsection{Union hours}

Another possibility of hours determination is that hours are set by unions, instead of firms or individuals. The main difference with individual hours supply, is that unions take into account the impact on employment. To illustrate this, let the utility $\Gamma$ of a typical union be given by the StoneGeary function

$$
\Gamma=N^{\theta}\left[U(C, H)-U^{\alpha}\right] . \quad \theta>0
$$

The union wants to increase the utility of its employed members above the given outside option $U^{n}$, but also cares about employment $N$. The parameter $\theta$ is an indicator of the weight put on employment. Johnson (1990) uses a similar specification. For $\theta=1$, this specification generates the same outcomes as the expected or utilitarian utility function used by e.g., Andrews and Simmons (1995), Bulkley (1992), Calmfors (1985), Rosen (1989) or Sampson (1993) in their analysis of hours or effort bargains.

I consider a right-to-manage framework, where the firms unilaterally determine capital and labour, after hours have been set. The same model was used in Chapter 5 to analyse wage determination. For the moment, however, hourly wages are exogenously given and the union sets hours of work. Maximising union utility $\Gamma$ with respect to hours, given the long-run labour demand curve, gives the first-order condition

$$
\frac{Y U_{Y}+H U_{H}}{U-U^{a}}=-\theta \varepsilon_{N H W W}=-\theta\left(\varepsilon_{N H Y Y}+\varepsilon_{N Y}\right) .
$$

The utility gain of an additional hour for employed workers at the left-hand side, should be balanced against the loss of employment at the right-hand side. From section 6.3 .2 we know that $\varepsilon_{N H W} \gtrless 0$

$17 \gamma_{\mathrm{n}} \epsilon\left[\varphi_{n}, 1\right)$ is the relative change of the profit elasticity $\varepsilon_{\mathrm{II}}$, see Chapter 5 and Appendix I. 


\section{Table 6.3 Comparative statics working time}

\begin{tabular}{|c|c|c|c|c|c|c|c|}
\hline & $W / Y$ & $\theta$ & $\beta_{h}$ & $v$ & $U^{P}$ & $V$ & $R A_{N} / A_{K}{ }^{*}$ \\
\hline \multicolumn{8}{|c|}{ Hours models } \\
\hline$H$ & $-\operatorname{sign} \omega_{Y}$ & 0 & 0 & 0 & 0 & 0 & 0 \\
\hline$H^{\prime}$ & - & 0 & 0 & 0 & 0 & + & +10 \\
\hline$H_{n}$ & - & 0 & 0 & + & 0 & + & +10 \\
\hline$H$ & $-\operatorname{sign}\left(\omega_{Y}+\gamma_{\Pi}\right)$ & 0 & 0 & 0 & 0 & + & +10 \\
\hline Ir & $?$ & $\pm H \lessgtr H_{*}$ & 0 & $\pm H \lessgtr H$ & $\pm H r \lessgtr H$ & + & +10 \\
\hline Hr & $?$ & $\pm H^{r} \lessgtr H_{*}$ & $\pm H \lessgtr H$ & $\pm H \lessgtr H$ & $\pm H \lessgtr H$ & + & +10 \\
\hline \multicolumn{8}{|c|}{ Effort models } \\
\hline$H$ & + & + & + & + & - & 0 & 0 \\
\hline$H^{*}$ & $-\operatorname{sign}\left(\omega_{\gamma}+\gamma_{r}\right)$ & - & + & + & 0 & + & +10 \\
\hline
\end{tabular}

a. For $\sigma \leq 1$.

for $H \lessgtr H_{n}$, whereas the left-hand side is positive for $H<H^{f}$ (and negative for $H>H^{p}$ ). So union hours $H^{m}$ fall short of hours supply $H^{5}$, as long as they exceed the critical level $H_{n}$.

This is illustrated in Figure 6.2, where union hours $H^{m}$ are a weighted average of $H_{n}$ and $H^{P}$. For simplicity, the latter is assumed to be inelastic in the figure. The difference between both panels is the level of the outside option $U^{a}$. The only relevant part is when union hours are above this outside option. The figure illustrates that for wages high enough, unions prefer shorter working times than the individual employed workers. The reason is that when acting collectively through a trade union, workers take into account that reduced working time decreases the risk of unemployment, see Calmfors (1985). Empirical evidence on this issue is scarce, see Pencavel (1991, Ch. 2), but Perloff and Sickles (1987), for example, provide evidence for a negative union hours mark-up in the US construction industry.

Table 6.3 contains the properties of union hours $H^{m}$. As can be expected from the above figure, it combines the properties of hours supply $H^{5}$ and the critical level $H_{m}$, although the weight of each may also change due to exogenous shocks. The impact of hourly wages $W$ is ambiguous. It can be shown to consist of three similar effects as bargained hours below, but as long as $H^{m}<H^{s}$ union hours are more likely to be downward sloping than labour supply. An increase in other factor costs, like $V$ or $R$, increases $H_{n}$ and hence increases union hours. An increase in the outside option $U^{n}$ makes unemployment less costly and shifts the weight towards $H$. Accordingly union hours increase if they 

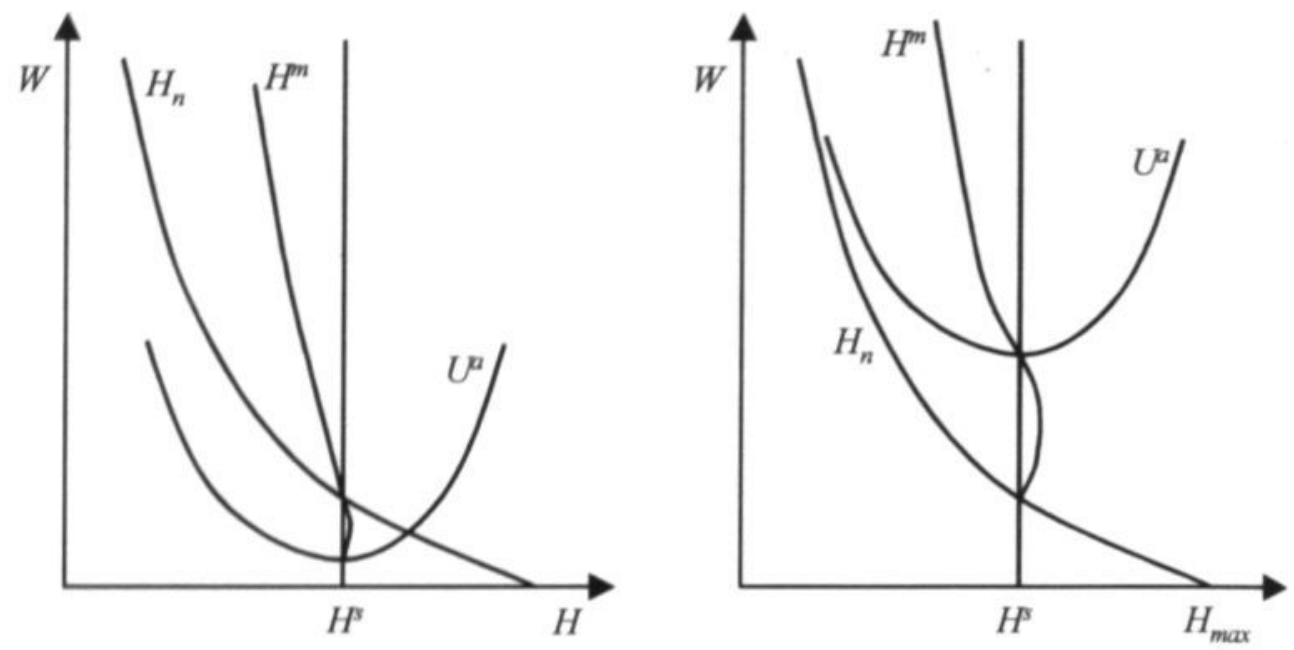

\section{Figure 6.2 Union hours}

fall short of hours supply. Increasing the weight $\theta$ of employment in union utility shifts the weight more to $H_{n}$, and union hours decrease if they exceed this critical level. Finally, an increase in competitiveness $v$ increases $H_{n}$ but also shifts the weight towards this critical level. The two effects operate in opposite directions, but the increase in $H_{n}$ dominates as long as $H^{m}<H^{d}$.

These results may provide a rationale for the work-sharing strategy followed by European unions in the 1980s. The increase in unemployment reduced the outside option for its members. This led to a higher weight on the employment effects in hours determination. As long as employment is negatively correlated with hours, thus for $H>H_{n}$, unions had an incentive to reduce hours. Furthermore, notice that $H_{n}$ is higher in more competitive output markets. So the incentive for worksharing strategies was smaller in countries with more competitive markets, Beside the weaker position of unions, this may explain why work-sharing is less an issue in the USA than in Europe.

\subsubsection{Bargaining over hours}

Instead of assuming that unions determine hours worked, it may be more realistic to consider the case where unions and firms bargain over working time. I assume that the outcome of the bargaining process can be found by maximising an asymmetric Nash function $\Omega^{h}=\Gamma \Pi^{\beta_{h}}$, where $\beta_{h}$ measures the bargaining power of firms with respect to hours worked. As I focus on longer run issues, it seems reasonable to set the threat-points equal to zero: for the union this implies that workers are able to obtain the outside utility $U^{n}$ during a strike; for the firm this is consistent with the hypothesis that the capital stock can be adjusted freely after completion of the bargain.

Maximising the Nash-maximand with respect to hours, given the long-run labour demand curve, gives the condition (see Appendix $\mathrm{J}$ for the second-order condition) 


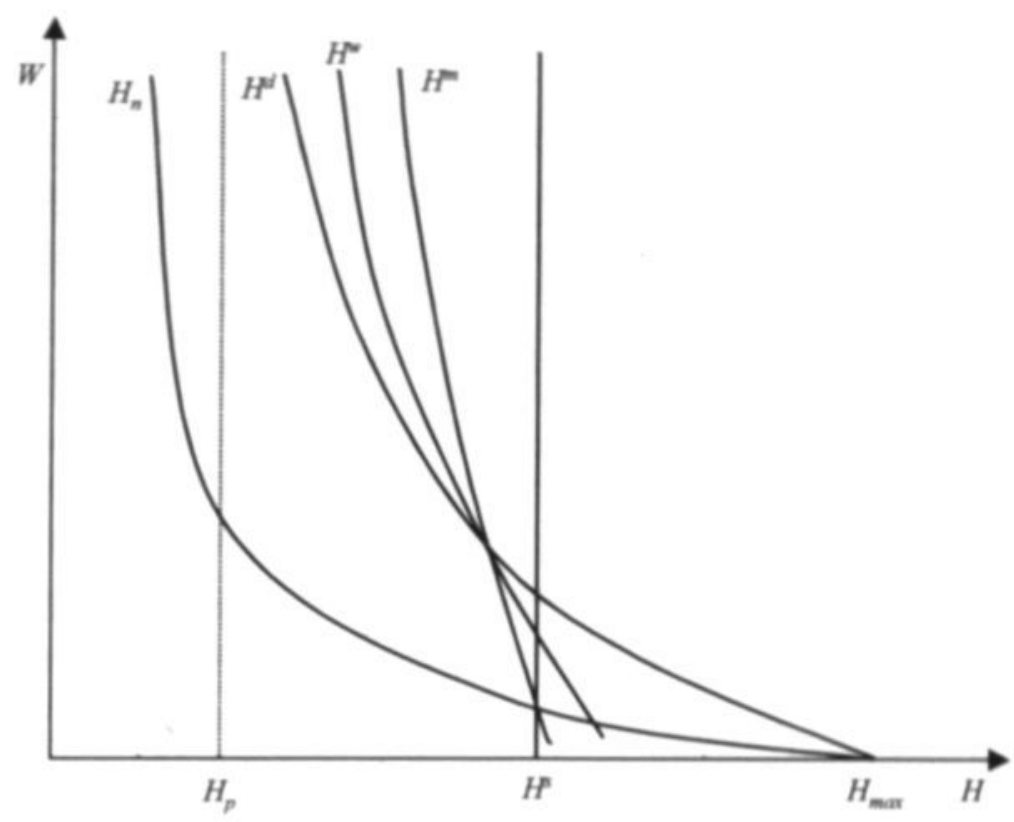

Figure 6.3 Bargained hours

$$
\frac{Y U_{Y}+H U_{H}}{U-U^{a}}=-\theta \varepsilon_{N H \mid W}-\beta_{h} \varepsilon_{\mathrm{II} H \mid W}
$$

This is a straightforward generalisation of the monopoly union condition (6.10). The right-hand side now also takes into account the impact of an additional hour on profits. As profits increase (decrease) with hours as long as hours worked are less than (exceed) hours demand $H^{d}$, bargained hours $H^{w}$ will be longer than union hours $H^{m}$. if the latter fall short of hours demand $H^{d}$.

In Figure 6.3 this implies that bargained hours can be viewed as a weighted average of union hours $H^{m}$ and hours demand $H^{d}$. The weight on the latter increases with bargaining power $\beta_{h}$. Hence an increase in bargaining power will increase bargained hours as long as $H^{w}<H^{d}$, see Table 6.3. For the other variables the comparative static results are the same as for union hours. The impact of wages on bargained hours will be discussed in some detail in section 6.6.2. Finally, the figure illustrates that, depending on the going wage rate, workers can be over- or underemployed in the bargaining set-up. Underemployment will most likely occur at relatively high wages. Therefore, it is important to consider the determination of wages, but before doing so in Section 6.5, there is a brief digression on effort bargains. 


\subsection{BARGAINING OVER EFFORT}

The crucial difference between effort and hours, at least for the present analysis, is that for the former remuneration is given, whereas for the latter hourly wages are fixed. If firms could unilaterally determine effort, they would like to increase it as much as possible, that is, they would choose $H_{\max }$. However, as effort decreases the utility of its workers, effort can only be increased until the outside option becomes binding. The corresponding iso-utility curve implicitly defines effort as an increasing function of remuneration, with elasticity $1 / \omega$.

On the other hand, if employed individuals could determine effort, they would like to reduce their effort to zero. However, this would reduce the revenues of the firm to zero and profits would become negative. As this is not sustainable, effort can only be reduced until profits are zero. The corresponding iso-profit line would implicitly define an upward sloping effort curve, with elasticity $1 / \lambda_{\Pi}$

Unions would also take into account the employment effects of effort, and therefore set effort $H^{n}$ higher than individuals, as higher effort increases employment. In a bargaining framework, effort will increase even further to accommodate the firm's pressure, so $H^{\boldsymbol{y}}>H^{\mathrm{F}}$. To illustrate this, maximise the Nash-maximand $\Omega^{h}$ with respect to $H$ at given remuneration $Y$ and given the long-run labour demand curve. The first-order condition implies

$$
\frac{H U_{H}}{U-U^{a}}=-\mu_{H} \equiv-\theta \varepsilon_{N H Y}-\beta_{h} \varepsilon_{\mathrm{II} H Y} .
$$

The disutility of effort to employed workers should be offset by the gains to the union and the firm in terms of employment and profits, respectively. Let me call $\mu_{H}>0$ effort inclination, as it measures the joint inclination of unions and firms to increase effort. Effort inclination declines with effort as returns to effort decline with effort levels $\left(\frac{d \ln \mu_{H}}{d \ln H}=\frac{d \ln \eta^{*}}{d \ln H}=-\gamma_{H}<0\right)$.

The second-order condition corresponds to $\Lambda_{H} \equiv \alpha_{H}+\mu_{H}+\gamma_{H}+1>0$, see Appendix J. This is satisfied in the present set-up. As consumption is a normal good, one can even show that $\Lambda_{H}>$ $\omega \Lambda_{0}$, where $\Lambda_{0} \equiv \xi+\lambda_{Y}$ and $\lambda_{Y} \equiv \frac{Y U_{Y}}{U-U^{*}}>0$. Assumption (6.3) guarantees that $\Lambda_{0}>0$.

Table 6.3 also includes the comparative statics of the resulting bargained effort $H$. Effort is an increasing function of remuneration $Y$. Higher remuneration increases the utility of employed workers and, at given effort inclination $\mu_{H}$, workers are willing to supply more effort. The corresponding elasticity is $\varepsilon_{H^{y}}=\Lambda_{0} / \Lambda_{H}>0$. The elasticity is smaller than one as long as $\omega>\omega^{h} \equiv$ $1-\left(\omega_{H}+\gamma_{H}\right) / \Lambda_{0}$, with $\omega^{h}<1 .{ }^{18}$ An increase in the outside option $U^{n}$ is followed by a reduction

18 Using this expression the effort elasticity can be written as $\varepsilon_{H} \gamma_{\gamma}=1 /\left(1-\omega^{h}+\omega\right)$. 
in effort, to increase the utility of workers. So effort bargaining is not consistent with a work-sharing strategy, as higher unemployment now leads to more effort. Finally, effort is increasing in effort inclination. This can be due to a higher employment weight $\theta$, more bargaining power $\beta_{h}$, see also Bulkley (1992) and Bulkley and Myles (1997), or increased competitiveness v. Factor costs do not influence effort inclination, and therefore have no impact on bargained effort.

These comparative static results seem consistent with the observed stylised facts as summarised by Andrews and Simmons (1995): a removal of restrictive practices, interpreted as an increase in bargaining power for firms, leads to more effort and there is a positive relation between effort and remuneration. ${ }^{19}$

\subsection{WAGE BARGAINING}

To compare effort and hours bargains, we need to determine the relevant wage. As a benchmark, consider the case of bargaining over remuneration at given hours or effort. Moreover, the bargaining power with respect to wages $\beta_{w}$ is not necessarily equal to the bargaining power with respect to hours $\beta_{h}$. This wage bargain is exactly the same as in Chapter 5 , where the focus was on the effect of working time on wages and remuneration. This sections summarises the most relevant results.

The model is most easily presented in terms of remuneration. Maximising the Nash-maximand $\Omega^{w}$ $=\Gamma \Pi^{\beta}$ w with respect to the remuneration, taking account of the right-to-manage assumption, gives the first-order condition

$$
\frac{Y U_{Y}}{U-U^{a}}=\mu_{Y} \equiv-\theta \varepsilon_{N Y}-\beta_{w} \varepsilon_{I I Y} .
$$

The left-hand side is the elasticity of the utility rent of workers with respect to remuneration, $\lambda_{Y}$. It corresponds to the ratio of marginal utility of consumption and the average utility rent of employed workers. The right-hand side $\mu_{Y}$ is what was called wage resistance in Chapter 5 . It measures the resistance of unions and firms to raise wages, due to its costs in terms of employment and profits, respectively.

The second-order condition for the wage bargain is given by $\Lambda_{Y} \equiv \alpha_{Y}+\mu_{Y}+\gamma_{Y}-1>0$, where $0<\gamma_{Y} \equiv \frac{d \ln \mu_{Y}}{d \ln Y}<1$, see Chapter 5 or Appendix J. So the sum of the coefficient of relative risk aversion $\alpha_{Y}$ and wage resistance $\mu_{Y}$ should be sufficiently large, as is assumed to hold.

19 Andrews and Simmons (1995) interpret the latter observation in terms of the contract curve between effort and remuneration, whereas the last row of Table 6.3 refers to bargained hours at given remuneration. 


\section{Table 6.4 Comparative statics remuneration}

\begin{tabular}{c|ccccccc}
\hline & $H$ & $\theta$ & $\beta_{v}$ & $v$ & $U^{p}$ & $V$ & $R A_{N} / A_{K}{ }^{2}$ \\
\hline$Y^{b}$ & + & - & - & - & + & + & $+/ 0$ \\
\hline
\end{tabular}

a. For $\sigma \leq 1$.

The properties of the bargained remuneration are summarised in Table 6.4. Most of them are as usual. An increase in the outside option $U^{n}$ increases remuneration, whereas an increase in wage resistance reduces wages. This may be due to a higher weight of employment for unions $(\theta)$, more bargaining power of firms $\left(\beta_{w}\right)$ or a more competitive goods market $(v)$. An increase in quasi fixed labour costs $V$ reduces wage resistance, see Chapter 5 , and therefore increases the bargained remuneration. The same applies for the user costs of capital $R$, at least if the elasticity of substitution $\sigma$ is smaller than one. Biased technical progress $\left(A_{N} / A_{K}\right)$ has the same effect. Finally, an increase in hours is matched by an increase in remuneration, to compensate for the disutility of longer hours. The corresponding elasticity is $\varepsilon_{Y^{b} H}=\omega \Lambda_{0} / \Lambda_{Y}>0$.

In Chapter $5 \mathrm{I}$ argued that the impact of hours on hourly wages is U-shaped. Hourly wages and hours are negatively correlated if (and only if) $\Lambda_{Y}>\omega \Lambda_{0}$. This can be rewritten in terms of the marginal rate of log-substitution as $\omega<\omega^{w} \equiv 1+\left(\omega_{Y}+\gamma_{Y}\right) / \Lambda_{0}$, see Appendix J. ${ }^{20}$ Given the positive correlation between hours and $\omega$, this gave the U-shape. The minimum is obtained for $\omega=$ $\omega^{\prime \prime}$ and this exceeds hours supply $\left(\omega=1<\omega^{\prime \prime}\right)$ as long as $\omega_{Y}+\gamma_{Y}>0$. The latter expression plays an important role in the sequel. The model of the firm guarantees that $\gamma_{Y}>\varphi_{V} \geq 0$, so that wage resistance increases with remuneration, see Chapters 2 and 5 . As stated earlier, the sign of $\omega_{\gamma}$ determines whether labour supply is backward bending $\left(\omega_{Y}>0\right)$ or not. Given the small estimates of labour supply elasticities, we might conclude that $\omega_{\gamma}$ is unlikely to be very negative. Taking together, these observations suggest that it may be reasonable to focus attention on the case where $\omega_{Y}+\gamma_{Y}>$ 0 , or in a different notation $\omega^{w}>1$. The implication is that, unless workers are sufficiently overemployed $\left(\omega>\omega^{w}>1\right)$, hourly wages will increase with working time reduction, although less than proportional.

20 Using this expression the remuneration elasticity can be written as $\varepsilon_{y^{b} H}=\omega / \omega^{*}$. 


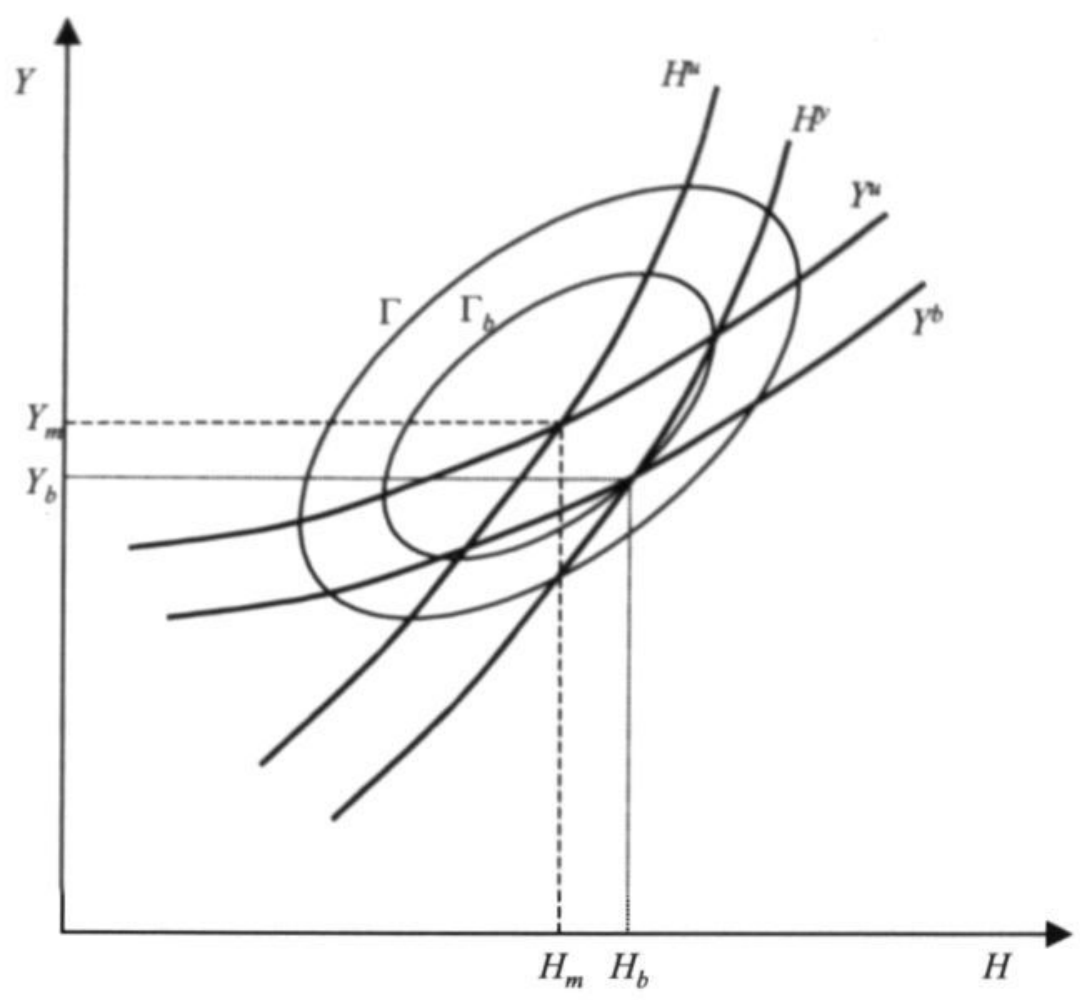

Figure 6.4 Bargained effort

\subsection{SIMULTANEOUS WAGE AND HOURS BARGAINING}

The most straightforward way to combine wage and hours determination, is the case of simultaneous bargaining over wages and hours with equal firm bargaining power $\beta$ on both issues, recall Table 6.2. This is equivalent to a simultaneous bargain over remuneration and effort, which is more easily analysed.

\subsubsection{Remuneration and effort}

The first-order conditions for the latter model are given by the equations (6.12) and (6.13), with $\beta_{h}$ $=\beta_{w}=\beta$. The joint determination of effort and remuneration is illustrated in Figure 6.4. For simplicity, consider first the monopoly union model. The curve labelled $Y^{u}$ corresponds to monopoly union wage determination, as given by equation (6.13), but with $\beta_{w}=0$. The curve labelled $H^{u}$ determines effort for the monopoly union and is given by equation (6.12), but with $\beta_{h}=0$. Both equations are upward sloping, see the Tables 6.3 and 6.4 , and the second-order condition guarantees that the effort-curve is steeper. ${ }^{21}$ Union utility is maximised at the intersection of both

21 The corresponding second-order conditions are $\Lambda_{Y}>0$ and $\Lambda \equiv \Lambda_{Y} \Lambda_{H}-\omega \Lambda_{0}{ }^{2}>0$. The first guarantees that $\omega^{*}>0$ and the second is always satisfied for $\omega^{*} \geq 1$. For $\omega^{*}<1$, the second 


\section{Table 6.5 Comparative statics simultaneous bargaining}

\begin{tabular}{c|ccccc}
\hline & $\theta$ & $\beta, v^{a}$ & $U^{*}$ & $V$ & $R A_{N} / A_{K}{ }^{b}$ \\
\hline$H_{b}$ & $\pm \omega^{*} \gtrless \delta_{N}$ & $\pm \omega^{*} \gtrless \delta_{\mathrm{II}}$ & $\mp \omega^{*} \gtrless 1$ & + & $+/ 0$ \\
$Y_{b}$ & - & $-c$ & + & + & $+/ 0$ \\
$W_{b}$ & $-d$ & - & + & $\pm \omega \gtrless \omega^{h}$ & $\pm \omega \gtrless \omega^{h}$ \\
\hline
\end{tabular}

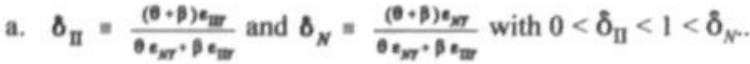
b. For $\boldsymbol{\sigma} \leq 1$.
c. Unless $\omega>\delta_{\mathrm{II}}\left(1-\omega^{h}\right)\left(1-\delta_{\mathrm{n}}\right)$.
d. Unless $\omega<\left(\delta_{N} \omega^{h}-\omega^{t}\right) /\left(\delta_{N}-1\right)$.
e. Unless $\omega>\left(\omega^{*}-\delta_{n} \omega^{h}\right)\left(1-\delta_{\eta}\right)$.

curves, yielding the monopoly union allocation $\left(H_{m}, Y_{m}\right)$. The figure also gives two union indifference curves $\Gamma$. As in Rosen (1989) they are ellipsoids. At the intersection with the $H^{u}\left(Y^{n}\right)$ curve the indifference curves are horizontal (vertical, respectively). The larger the ellipsoid, the lower the union utility.

Allowing for bargaining power of the firm, both curves shift to the right, see again Tables 6.3 and 6.4: more bargaining power for the firm in the effort bargain would increase effort and remuneration along the monopoly wage schedule $Y^{u}$; whereas more bargaining power for the firm in the wage bargain would reduce effort and remuneration along the monopoly effort curve $H^{u}$. With equal bargaining power $\beta$, wage determination (6.13) yields the curve labelled $Y^{b}$ and effort bargaining (6.12) the curve $H^{\prime}$. The bargaining equilibrium is $\left(H_{b}, Y_{b}\right)$, with corresponding union utility $\Gamma_{b}$. Bargaining with equal bargaining power on both issues reduces remuneration $\left(Y_{b}<Y_{m}\right)$, but the impact on effort is ambiguous. The figure assumes that effort is increased $\left(H_{b}>H_{m}\right)$. A sufficient condition for this to occur is $\omega^{\omega}>1$.

The comparative statics of the equilibrium of the simultaneous bargaining solution are summarised in Table 6.5, see Appendix J for the underlying calculations. An increase in quasi-fixed labour costs $V$, or an increase in capital costs $R$, reduces wage resistance and hence shifts the wage setting curve $Y^{b}$ (and $Y^{m}$ ) upward. As a consequence, both hours and remuneration increase. The impact on hourly wages is ambiguous, however. Wages increase if (and only if) $\omega>\omega^{h}$. So unless hours are relatively short, hourly wages increase as well.

The other variables shift both curves in Figure 6.4 in the same direction, recall Tables 6.3 and 6.4 , leading to possibly ambiguous results. For the outside option $U^{n}$, the curves shift upward. For remuneration, the shift of the wage setting curve dominates, but for hours the impact is ambiguous. Hours decrease as long as $\omega^{*}>1$. In any case, hourly wages will increase.

condition sets an upperbound to the marginal rate of $\log$-substitution $\omega$, see Appendix $\mathrm{J}$. 

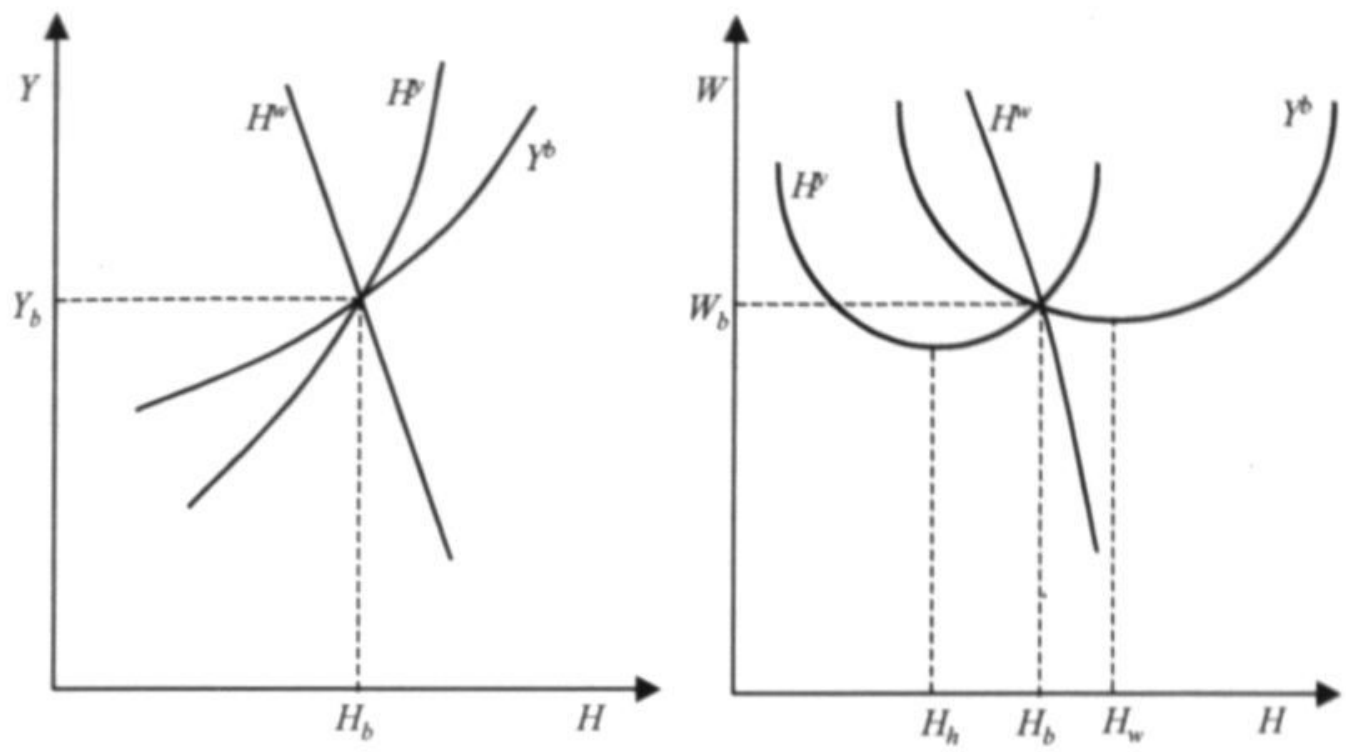

\section{Figure 6.5 Simultaneous bargaining}

For the remaining parameters both curves shift downward, as has been illustrated for bargaining power $\beta$ in Figure 6.4. Hourly wages tend to move in the same direction as remuneration. An increase in competitiveness $v$ (or in bargaining power $\beta$ ) has ambiguous effects for remuneration and effort, although we can exclude the possibility that remuneration increases while effort declines. The most likely outcome is that remuneration falls and effort increases. Hourly wages tend to decrease with competitiveness. Finally, an increase in the union employment weight $\theta$ reduces remuneration and hourly wages. The impact on hours depends on the size of $\omega^{w}$, however.

\subsubsection{Hours and effort bargains compared}

Figure 6.5 compares hours bargaining with effort bargaining. As in the previous figure effort determination $H^{v}$ and wage bargaining $Y^{b}$ correspond to the equations (6.12) and (6.13), respectively. The figure adds hours determination $H^{w}$ as given by equation (6.11). Obviously, the three curves cross in the equilibrium, as condition (6.11) is implied by (6.12) and (6.13). The lefthand panel expresses all curves in terms of remuneration, the right-hand panel uses the hourly wage rate on the vertical axis. First, consider the left-hand panel. Compared to Figure 6.4, only bargained hours $H^{w}$ are added, but expressed as a function of remuneration $Y$ and not of hourly wages $W$. Contrary to the other two clir.es, the slope of the bargained hours curve is undetermined. It is 
downward sloping if (and only if) $\boldsymbol{\omega}^{h}<\boldsymbol{\omega}<\boldsymbol{\omega}^{\boldsymbol{w}}$, as is assumed in the graph. ${ }^{22}$ The figure illustrates that for remuneration rates above (below) the equilibrium level $Y_{b}$ effort bargains lead in general to longer (shorter) hours than hours bargains.

Second, consider the right-hand panel of Figure 6.5, which makes the same comparison, but now in terms of hourly wage rates $W$ instead of remuneration $Y$. As argued before, wage bargaining (6.13) leads to a $U$-shaped wage setting curve $Y^{b}$, the minimum corresponding to $\omega=\omega^{\omega}$. Effort bargaining (6.12) also leads to a $U$-shaped effort curve $H^{\nu}$ in terms of hourly wages. The minimum of this curve corresponds to $\omega=\omega^{h}<\omega^{w}$. Next consider the impact of hourly wages on bargained hours $H^{m}$. It can be shown, using the expressions in Appendix $\mathrm{J}$, that the sign of the elasticity is given by the sign of the following expression

$$
\operatorname{sign} \boldsymbol{\varepsilon}_{H^{*} \boldsymbol{W}}=-\operatorname{sign}\left\{\omega_{Y}+(1-\omega) \Lambda_{0}+\gamma_{\mathrm{Y}} \mu_{Y} / \lambda_{Y}\right\} .
$$

The first term $\omega_{Y}$ is the ambiguous slope of hours supply $H^{F}$, the second part $(1-\omega)$ is the disequilibrium of bargained hours $H^{*}$ compared to supply $H^{F}$, and the third term with $\gamma_{\gamma}$ reflects the change in wage resistance $\mu_{r}$. This final term captures the negative slope of both hours demand $H^{t}$ and the critical level $H_{n}$. This decomposition indicates that bargaining hours are likely to be downward sloping, unless bargaining hours exceed hours supply and hours supply is rather elastic.

In Chapter 5 it has been shown that a similar decomposition holds for bargained wages at given hours. The only difference is that wage bargaining ensures $\lambda_{Y}=\mu_{Y}$. So in the equilibrium, the sign of the slopes of bargained hours and bargained wages are the same. As long as $\omega<\omega^{w}$ in the equilibrium, both will be downward sloping as suggested in Calmfors (1985) and as illustrated in the right-hand panel of Figure 6.5.

Finally, the figure illustrates that for wage rates above (below) the equilibrium level $W_{b}$ effort bargains tend to lead to longer (shorter) hours than hours bargains.

\subsubsection{A labour contract}

Although simultaneous bargaining gives a unique equilibrium pair of hours and wages - or equivalently effort and remuneration - the results can also be used to define a trade-off between hours and wages (or effort and remuneration). Dividing equations (6.12) and (6.13) yields the following expression for the marginal rate of log-substitution $\omega$

$$
\omega=-\frac{H U_{H}}{Y U_{Y}}=\frac{\mu_{H}}{\mu_{Y}} .
$$

22 In the equilibrium the hours elasticity is given by $\varepsilon_{H^{*} \gamma}=-\left(\omega^{*}-\omega\right) /\left[\omega\left(\omega-\omega^{h}\right)\right]$. For $\omega<\omega^{h}$ tie curve will be upward sloping and steeper than the bargained effort $H$, and for $\omega>\omega^{*}$ it wil' be upward sloping but less steep than the bargained wage curve $Y^{t}$. 
I will call this the labour contract, as it gives all combinations of hours and wages, or effort and remuneration, consistent with the bargaining framework, but independent of the outside option $U^{m}$. The latter only affects the remuneration determined in enuation (6.13).

This trade-off between hours and wages is somewhat re. .' $w$ to the efficient hours $H$ discussed in section 6.3.3. Efficient contracts between workers and firms imply that the marginal rate of logsubstitution between hours and remuneration $\omega$ equals the iso-profit function elasticity $\lambda_{\mathrm{nl}}$, see equation (6.8). This would also be the outcome of (6.14) if the union does not care about employment $(\theta=0)$ and the bargaining power on both issues is the same $\left(\beta_{w}=\beta_{h}\right)$ or if the firm would have all the bargaining power on both issues $\left(\beta_{w}=\beta_{h}=\beta \rightarrow \infty\right)$. In general, however, simultaneous union-firm bargaining about wages and hours implies $\omega=\mu_{H} / \mu_{Y}<\lambda_{\mathrm{n}}{ }^{23}$ Let $H^{*}$ denote the solution of (6.14), then this condition illustrates that $H^{\tau}<H$. Due to the right-to-manage assumption, the labour contract implied by union bargaining reduces hours or effort below the efficient level.

Table 6.3 included the properties of the labour contract $H$. The impact of higher wages of hours (or remuneration of effort) is ambiguous. Hours decline as long as $\omega_{\gamma}+\gamma_{\gamma}>0$, or $\omega^{*}>1$. So, compared to hours supply, the labour contract is more likely to be downward sloping, as wage resistance $\mu_{Y}$ is increasing in remuneration $\left(\gamma_{Y}>0\right)$. On the other hand, the labour contract is somewhat less likely to be downward sloping than efficient hours $H^{e}{ }^{24}$ Increas $;$;. factors costs $V$ and $R$ increase hours through their negative impact on wage resistance $\mu_{\gamma}$. Tte same applies for labour saving technical progress. An increase in competitiveness $v$, an increase in bargaining power $\beta_{h}$ and a decrease in the value of employment $\theta$ all increase $\mu_{H} / \mu_{\gamma^{*}}{ }^{25}$ Hence in the labour contract hours would increase after such shocks.

\subsubsection{Work-sharing}

Figure 6.6 illustrates the relations between the key parameters of the simultaneous bargaining model as a function of effort or hours. It is an extension of Figure 5.6 in Chapter 5. Due to concavity of efficiency hours, the iso-profit elasticity $\lambda_{\Pi}$ is decreasing in hours. The demand for hours $H^{t}$ is given by $\lambda_{\Pi \text { II }}=1$, see equation (6.7). Let $\lambda_{N} \equiv-\varepsilon_{N H \mid r} / \varepsilon_{N Y}$ denote the iso-employment elasticity of labour demand. As was shown in Chapter 5 , this parameter is also decreasing in hours, with $\lambda_{N}<\lambda_{\Pi}$. The critical employment level $H_{n}$ is given by $\lambda_{N}=1$, so $H_{n}<H^{d}$. The right-hand side of the labour

23 Notice that (6.14) does not correspond to the contract curve between unions and firms, except for $\theta=0$. The union-firm contract curve depends on the outside option, as the right-to-manage assumption with respect to employment implies that for the union the marginal rate of substitution between effort and remuneration depends on the outside option.

24 As $\gamma_{\Pi}>\gamma_{\gamma}$.

25 Although not included in the table, an increase in bargaining power $\beta_{w}$ works in the opposite direction of a change in $\beta_{h}$. With equal bargaining power on both issues, the impact of $\beta_{h}$ dominates. 


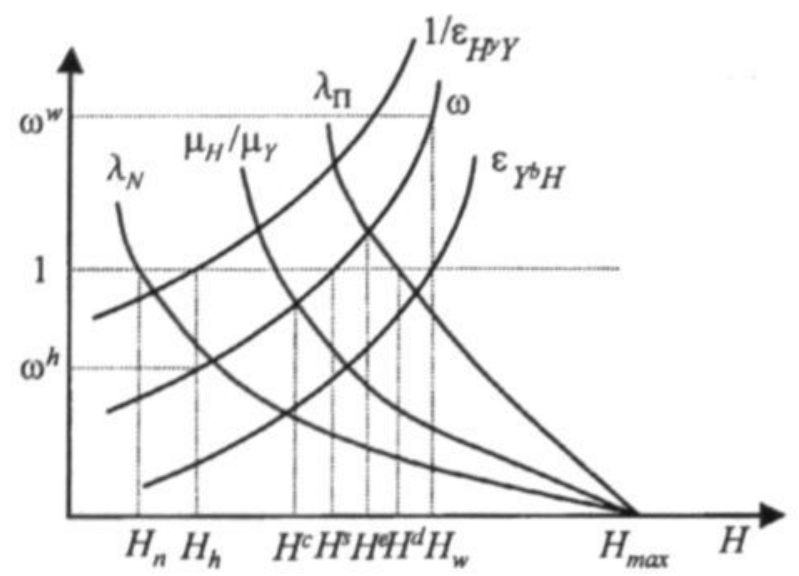

Figure 6.6 Models compared

contract (6.14) $\mu_{H} / \mu_{Y}$ is a weighted harmonic mean of $\lambda_{N}$ and $\lambda_{\Pi \text { II }}$. It is equal to $\lambda_{N}$ for a monopoly union and equal to $\lambda_{\Pi 1}$ when firms have all the bargaining power on both issues. Moreover, the more unions value employment the closer $\mu_{H} / \mu_{Y}$ is to $\lambda_{N}$.

The marginal rate of log-substitution $\omega$ is increasing in hours. Hours supply $H^{\S}$ is determined by $\omega=1$. The labour contract (6.14) is given by the intersection of $\omega$ and $\mu_{H} / \mu_{r}$, yielding hours $H^{\text {c }}$. As efficient hours $H^{*}$ are given by the intersection of $\omega$ and $\lambda_{\text {II }}$, see equation (6.8), efficient hours exceed the hours from the labour contract. As $H^{*}<H^{*}$ in the figure, workers are underemployed, although this is not necessarily the case. ${ }^{26}$

The hours elasticity of remuneration $\varepsilon_{Y^{b} H}=\omega / \omega^{w}$ is increasing in effort. This reflects the Ushape of bargained wages with respect to hours. Hourly wages are independent of hours for $\omega=$ $\omega^{w}$, which corresponds to $\varepsilon_{\gamma^{\Delta} H}=1$. Figure 6.6 considers the most likely case where $\omega^{w}>1$, or equivalently $\omega_{Y}+\gamma_{Y}>0$. Accordingly, $\varepsilon_{Y^{b} H}$ is lower than $\omega$. The second-order conditions guarantee that the inverse of the remuneration elasticity of effort $\varepsilon_{H^{y} Y}$ exceeds $\max \left(\omega, \varepsilon_{Y^{b} H}\right)$. The critical value $\omega^{h}$ corresponds to the value of $\omega$ where $\boldsymbol{\varepsilon}_{H^{y} y^{y}}=1$.

In Chapter 5 it was argued that a work-sharing policy can increase employment as long as initial hours are not too long, the critical level being given by the intersection of $\lambda_{N}$ and $\varepsilon_{Y^{b} H}$. A simultaneous bargain would lead to $H$ as initial hours. Accordingly, with the parameter constellation underlying the figure, a work-sharing policy would lead to negative employment effects. However, changing the union employment weight $\theta$, or bargaining power $\beta_{h}$ or $\beta_{w}$ the relative positions could change, leading to positive employment effects of work-sharing. Similarly, the ch sice of the utility

26 The figure also assumes that $H^{P}<H^{f}$. This needs not to be the case as can be seen by shifting the unit line upwards. 
function may affect the relative position. For example, Marimon and Zilibotti (2000) using essentially a simultaneous bargaining model, find different results for their CES- and GHH-utility functions. In terms of Figure 6.6, the choice of the utility function influences the position and slope of the $\omega$-curve, and thus of the corresponding elasticities $\varepsilon_{Y^{b} H}$ and $\varepsilon_{H^{\gamma}{ }_{Y}}$. As a consequence, different utility functions may well lead to disparate conclusions with respect to the effectiveness of work-sharing policies.

\subsection{SEQUENTLAL BARGAINING: HoURS FIRST}

Although it seems reasonable to assume that hours or effort are on the bargaining agenda of unions and firms, it is not necessarily the case that unions have the same bargaining power for working conditions as for wages. Moreover, the bargaining sequence may be important, recall Table 6.2. To me, the most relevant model seems the sequence where hours are determined prior to the wages, the so-called hours-first bargains.

Compared to the sequential wage and employment bargaining model of Manning (1987), the main difference is that sequential bargaining is now about hours and wages - or effort and remuneration - and that the firm retains the right-to-manage with respect the employment, i.e. the number of workers, in the final stage. Working backwards, the second-stage remuneration is found maximising the corresponding Nash-maximand $\Omega^{w}=\Gamma \Pi^{\beta_{w}}$, subject to the factor demand equations (6.4) and (6.5). This just gives the wage bargain (6.13), with the corresponding remuneration elasticity $\varepsilon_{Y^{b} H}$. Then in the first-stage, hours are (or effort is) found by maximising the Nash-maximand $\Omega^{h}=\Gamma \Pi^{\beta_{h}}$, subject to factor demand and the wage bargain (6.13). The firstorder condition for hours can be written as

$$
\frac{H U_{H}}{U-U^{a}}=-\mu_{H}-\left(\beta_{h}-\beta_{w}\right) \varepsilon_{I I Y} \varepsilon_{Y^{b} H^{*}}
$$

The last term on the right-hand side is the strategic effect of the sequential bargain: during the first stage, the bargaining parties take into account the subsequent positive effect of hours on remuneration. As long as the bargaining power on both issues is equal, that is for $\beta_{h}=\beta_{w}=\beta$, the last term vanishes and there is no difference between the sequential bargain (6.15) and the simultaneous bargain (6.12).

Figure 6.7 illustrates the outcome of the sequential hours-first bargain with different bargaining power. It considers two extreme cases: the first case assumes that the union has all the bargaining power $\left(\beta_{h}=0<\beta_{w}\right)$ during the hours bargain; the second case gives all the first stage bargaining power to the firm $\left(\beta_{h} \rightarrow \infty\right)$. The wage curves $Y^{u}$ and $Y^{t}$ and the effort curves $H^{u}$ and $H^{p}$ are the same as used in Figure 6.4. A simultaneous bargain with equal bargaining power $\beta$ on both issues 


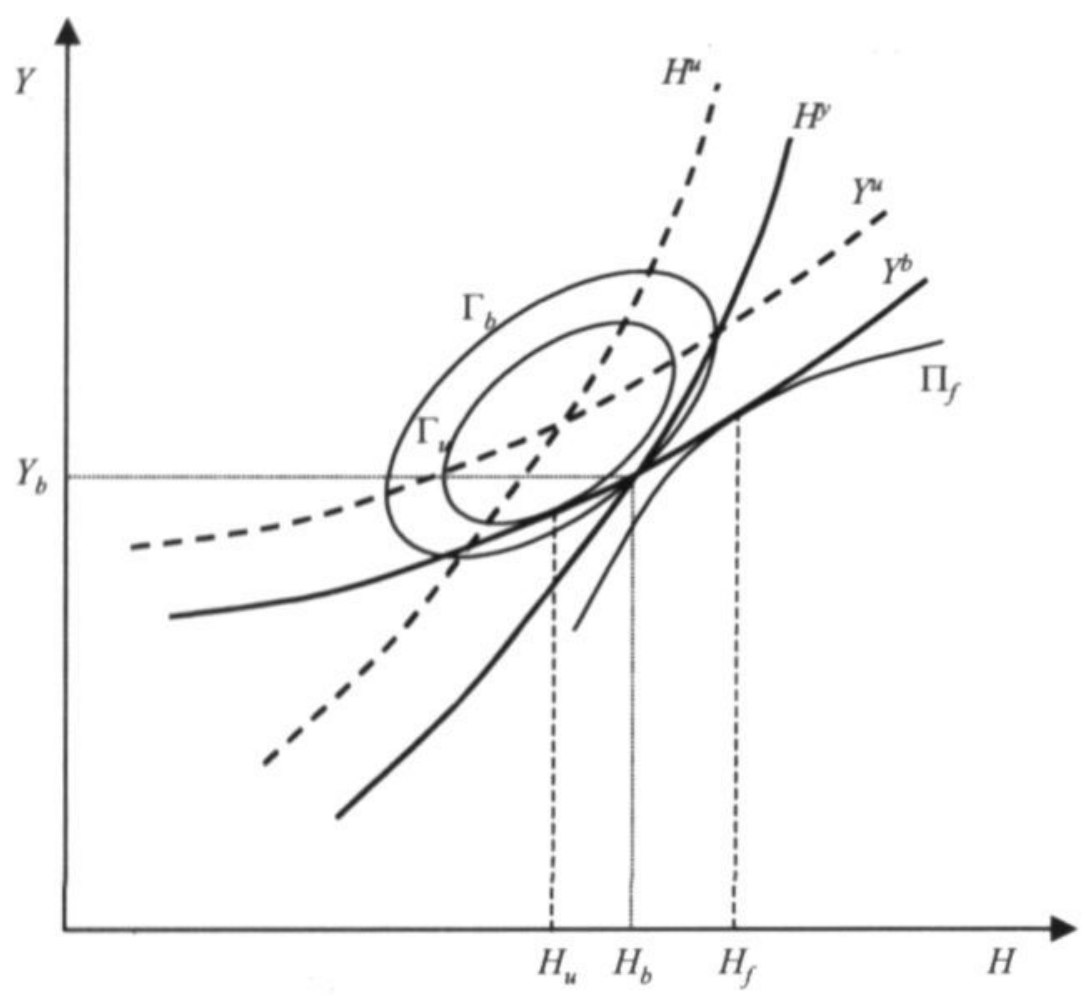

Figure 6.7 Sequential bargaining

would yield the bargained outcome $\left(H_{b}, Y_{b}\right)$, at the intersection of the $Y^{b}$ and $H^{y}$ curves. In this simultaneous bargaining equilibrium, the slope of the union indifference curve $\Gamma_{b}$ is equal to the slope of the firm's iso-profit line (in log's the latter is equal to the iso-profit elasticity $\lambda_{\Pi \text { ) }}$. The reason is that the outcome of the simultaneous bargain lies on the union-firm contract curve in terms of hours and remuneration. The slope (in log's) of the second-stage bargained wage $Y^{b}$ is the elasticity $\varepsilon_{Y^{b} H}$.

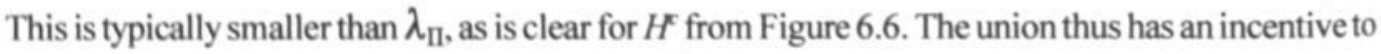
reduce hours towards $H_{w}$, where union's utility $\Gamma_{w}$ is tangent to wage setting $Y^{b}$. As a consequence remuneration is also lowered in the second stage. 
So, according to equation (6.15), unions have an incentive to reduce effort in a sequential bargain, as long as $\varepsilon_{\mathrm{Y}^{*} \mathrm{H}}<\lambda_{\mathrm{II} \cdot}{ }^{27}$ This is consistent with the results in Andrews and Simmons (1995) for their specific utility function.

Nickell, Wadhwani et al. (1992) and Rosen (1989) compare the simultaneous bargain with the situation where the firm has all the power to determine effort in the first stage. This corresponds to the limiting case of $\beta_{h} \rightarrow \infty$. This is illustrated in Figure 6.7. The firm having all bargaining power during the first stage, the iso-profit curve should now be tangent to wage determination $Y^{t}$. As the iso-profit line is steeper in $\left(H_{b}, Y_{b}\right)$ than the wage curve, this implies that firms would like to set higher effort. The highest profit $\Pi_{f}$ is reached at $H_{f}$ where the slopes are equal, implying $\boldsymbol{\varepsilon}_{\gamma^{b} H}=$ $\lambda_{\mathrm{n}}$. Compared to the simultaneous bargain, workers will be partly compensated by an increase in their remuneration.

A important result of the simultaneous bargain was that it implied a trade-off between remuneration and hours independent of the outside option, the so-called labour contract of equation (6.14). A similar result holds for the sequential bargaining model of this section: dividing the first stage condition (6.15) by the second stage condition (6.13), the resulting labour contract becomes

$$
\omega=-\frac{\mu_{H}+\left(\beta_{h}-\beta_{w}\right) \varepsilon_{\Pi Y} \varepsilon_{Y^{b} H}}{\mu_{Y}} .
$$

This equation has a rather similar structure as (6.14), only the right-hand side is adjusted to incorporate the strategic effects of sequential bargaining. The occurrence of the remuneration elasticity $\varepsilon_{Y^{b} H}$ in the strategic effect complicates the comparative statics of the labour contract, so when studying the impact of productivity growth we return to the simultaneous bargain.

27 At first sight, equation (6.15) might suggest a different outcome as the last term is negative for $\beta_{h}=$ 0 . However, hours bargaining power $\beta_{h}$ also affects effort inclination $\mu_{H}$. So using (6.15), one compares the sequential model with a simultaneous bargaining model with unequal bargaining power, as given by the intersection of the $H^{\prime \prime}$-curve with the $Y^{b}$-curve. Compared to that situation, the sequential bargaining model leads to an increase in effort. However, rewriting (6.15) as

$$
\frac{H U_{H}}{U-U^{a}}=-\theta \varepsilon_{\mathrm{II} H Y}-\beta_{w} \varepsilon_{\mathrm{II} H Y}-\left(\beta_{h}-\beta_{w}\right) \varepsilon_{\mathrm{II} Y}\left(\varepsilon_{Y^{b} H}-\lambda_{\Pi \mathrm{II}}\right)
$$

the last term is positive for $\beta_{h}=0$, showing that hours indeed decrease relative to the simultaneous bargain with equal bargaining power $\beta_{w}$ on both issues. 


\subsection{PRODUCTIVITY AND HOURS IN GENERAL EQUILIBRIUM}

Finally, let us investigate the impact of technical progress on hours (and remuneration) in the simultaneous bargaining model. The partial equilibrium effects can be read from Table 6.5. Neutral technical progress leaves $A_{N} / A_{K}$ unchanged and has no direct impact on the bargaining outcome. ${ }^{28}$ Labour saving technical progress, on the other hand, reduces wage resistance, and therefore shifts the bargained wage $Y^{t}$ in Figure 6.5 upward, see Table 6.4. The bargained effort curve $H^{P}$ is not affected by biased technical progress, see Table 6.3, but bargained hours $H^{*}$ would increase. As a result, see Table 6.5, remuneration and hours increase in the partial equilibrium. This increase in hours is rather incompatible with the observed secular decline in working times. A simple explanation can be found in the general equilibrium, where the outside option $U^{n}$ is no longer exogenous.

As in Chapter 5 , consider a symmetric equilibrium where all firms have the same working time $H$ and remuneration $Y$. Let $u$ denote the unemployment rate of the economy and let $B$ be the exogenous unemployment benefit for the unemployed. For simplicity I ignore taxation issues to finance these benefits. The unemployed thus have a utility level $U^{\phi} \equiv U(B, 0)$ and the outside option for each union is given by the expected utility

$$
U^{n}=(1-u) U(Y, H)+u U(B, 0) .
$$

Substituting this in the partial equilibrium effort bargaining equation (6.12) and wage bargaining equation (6.13), respectively, gives their general equilibrium counterparts as

$$
-\frac{H U_{H}}{U-U^{b}}=\mu_{H} u
$$

and

$$
\frac{Y U_{Y}}{U-U^{b}}=\mu_{Y} u .
$$

These equations have a similar structure as their partial equilibrium counterparts; only the outside option $U^{n}$ is replaced by the utility of the unemployed $U^{b}$ and wage resistance $\mu_{Y}$ and effort inclination $\mu_{H}$ are multiplied with the unemployment rate.

These two equations can be used to derive the effect of an increase in unemployment $u$ on wages and hours. This leads to the same type of effects as a fall in the outside option in the partial

28 This could change if unions would claim their fair share of profits. 
equilibrium model of Table 6.5. So, remuneration falls and the impact on hours is ambiguous, but they increase as long as $\omega_{Y}+\gamma_{Y}>0$. However, unemployment is endogenous in the general equilibrium and is determined by the interaction of wage setting and labour demand or price setting, as in Layard, Nickell et al. (1991). With the focus on the long-run development of hours, the equilibrium is best characterised by the price setting behaviour, see Blanchard (2000).

Given the assumption of constant returns to scale, each firm sets its price $P$ as a mark-up on unit $\operatorname{costs} X$, as long-run profit maximisation implies $P=X / \mathrm{v}$. Let $V, Y$ and $R$ now reflect real prices, then this price setting behaviour implies

$$
v=\frac{(V+Y)+R A_{N} / A_{K} k}{A_{N} e(H) f(k)},
$$

where the right-hand side corresponds to real unit costs $X / P$. Implicitly this equation determines real remuneration $Y$ as a function of working time, technology parameters and other (real) factor prices.

Equations (6.4), (6.18), (6.19) and (6.20) jointly determine the general equilibrium, with $Y, H, k$ and $u$ as the endogenous variables. The model can be solved recursively, however. Dividing equation (6.18) by (6.19), shows that the labour contract (6.14) also holds in the aggregate. As it is independent of the unemployment rate $u$, equations (6.4), (6.14) and (6.20) can be used to determine general equilibrium remuneration $Y$, hours $H$ and capital-intensity $k$. The unemployment rate then follows recursively from (6.19). As equations (6.4), (6.14) and (6.20) do not include the unemployment benefit $B$, remuneration and hours will in the long run be independent of these benefits. On the other hand, the unemployment rate is positively correlated to unemployment benefits according to (6.19).

Figure 6.8 illustrates the long-run general equilibrium for remuneration and hours. The upward sloping line corresponds to price setting (6.20), including cost minimisation (6.4). The downward sloping line is the labour contract (6.14). The price setting curve is upward sloping because an increase in hours is tantamount to neutral technical progress, at least as long as hours do not exceed the level $H_{\max }$. This allows the firm to set lower prices and hence real wage costs $Y$ increase. In more competitive goods markets the price setting line is higher. The slope of the bargained labour contract (6.14) is ambiguous, but it was shown to be downward sloping as long as $\omega^{w}>1$, or $\omega_{Y}+\gamma_{Y}>0$, recall Table 6.3.

Neutral technical progress does not influence the labour contract, but shifts the price setting curve (6.20) upward. As a result, remuneration increases unambiguously and the impact on hours depends on the slope of the labour contract. With the downward sloping curve in Figure 6.8 hours will be reduced. Labour saving technical progress has a similar impact on price setting, shifting it upward, 


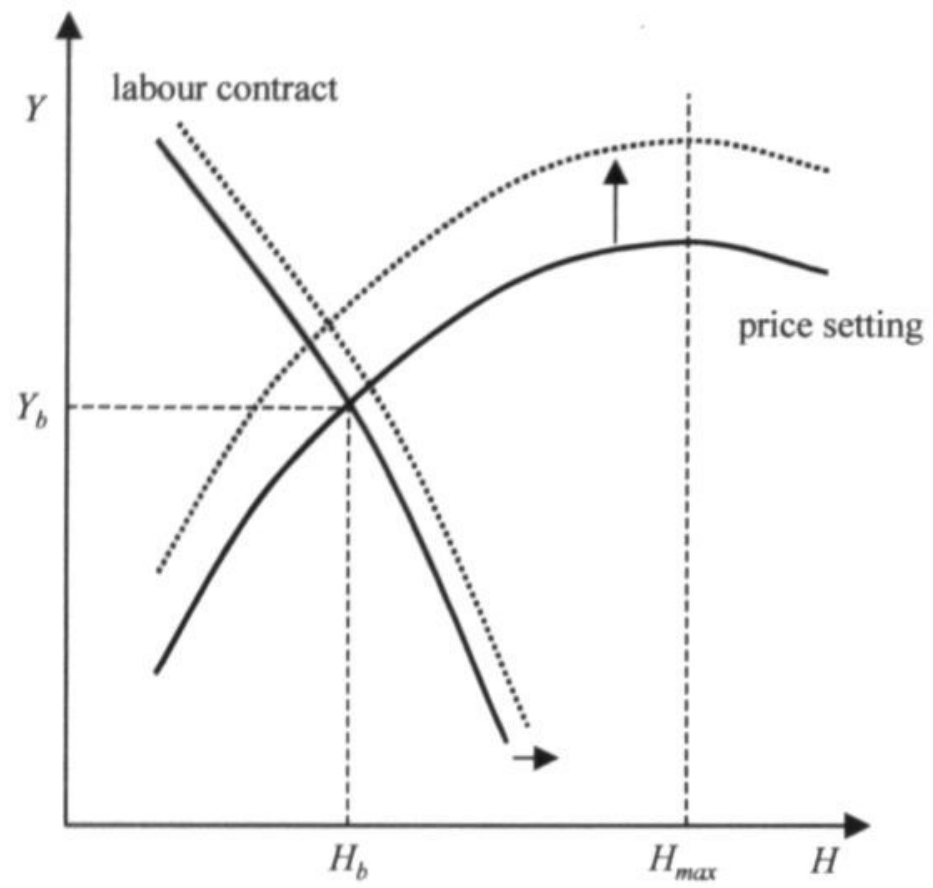

Figure 6.8 General equilibrium hours and technical progress

although to a lesser extend. In this case, however, the labour contract may also shift. If the elasticity of substitution $\sigma$ between capital and labour is smaller than one, labour saving technical progress reduces wage resistance $\mu_{\gamma}$. As a consequence, the labour contract (6.14) shifts to the right. This reinforces the increase in remuneration, but has an offsetting effect on hours. ${ }^{29}$ In Appendix $\mathrm{K}$ it is shown that the shift in price setting dominates, as in Figure 6.8, if (and only if) $\omega_{Y}+\varphi_{V}>0$.

In the standard hours supply model, productivity growth translates into wage growth, which in turn affects labour supply. To explain the observed secular decline of hours during the last century, labour supply should be backward bending $\left(\omega_{Y}>0\right)$. Within an hours bargaining framework, the slope of the hours supply curve is no longer the sole determinant, and factor demand elements play a role. Due to quasi-fixed labour costs, we are more likely to observe a decline in working time as a consequence of productivity growth. Thus, even if the hours supply curve would be moderately upward sloping, labour saving productivity growth will reduce hours in a bargaining framework.

29 With an upward sloping labour contract, hours unambiguously increase, as both effects work in the same direction. 


\subsection{SUMMARY AND CONCLUSION}

This chapter provides a unifying framework for working time determination within union bargaining models. Many models can be found in the literature, and their relevance depend on the institutional context. The taxonomy of models yields a natural division between hours and effort models, although the two are observationally equivalent for some - and perhaps the most relevant - bargaining setups. So the results of the more abundant effort bargaining models may be used for the inference on working time determination in a union bargaining framework.

Combining wage bargaining and hours or effort bargaining, the labour supply curve of standard models is basically replaced by a labour contract, identifying the bargaining trade-off between wages and hours (or remuneration and effort). This curve is more likely to be backward bending than the ordinary labour supply curve, for example due to the existence of quasi-fixed labour costs. Moreover, the labour contract summarises in a neat way the institutional context of hours determination. For example, increased union bargaining power and a less competitive goods market shift the labour contract towards lower hours. These kind of factors may explain part of the hours differential between Europe and the USA. It would be interesting to test these predictions in a crosscountry analysis.

The bargaining framework has finally been used to investigate the impact of technical progress on hours and remuneration. The results indicate that it is important to consider general equilibrium effects: whereas in the partial equilibrium hours tend to increase, the opposite may be true in the general equilibrium, even when hours supply is inelastic. 



\section{Hourly Wages and Working Time in the Dutch Market Sector 1962-1995}

\subsection{INTRODUCTION}

During the $20^{\text {th }}$ century there was an impressive decline in annual working hours in capitalist countries. Nowadays full-time workers tend to work about 800 to 1000 hours less per year than their grandparents a few generations earlier. In some countries the bulk of the decline occurred during the first half of the century, in other countries the decline started later. In 1936, under Blum's Front Populaire, France was the first country to introduce the 40 -hour week, for example. The New Deal policy of the 1930s in the United States also involved a reduction of working hours. These are two early examples of a so-called work-sharing strategy, i.e. 'redistributing work amongst people so as to reduce involuntary unemployment', Drèze (1986, p. 562).

After the Second World War during the period of reconstruction, working hours remained rather high in many European countries, whereas the 40-hour week was introduced in the USA. During the high growth period of the 1960s and early 1970s, however, working times were substantially reduced in (continental) European countries. So before the oil shocks of the 1970s, standard working times were fairly harmonized in Western industrialized countries, just as in the beginning of the century. The large reductions of working time during this post-war period, are probably examples of the process of allocating the gains of productivity growth between wage increases and increases in leisure time. I will call this phenomenon productivity-sharing, as opposed to the worksharing argument presented above.

Since the oil shocks of the 1970 s, full-time hours remained rather stable in the USA and the UK, but they dropped further in continental Europe. In this chapter I confine myself to the decline in fulltime hours in the Netherlands. An important question is whether this decline was due to worksharing or to productivity-sharing. In other words, was it a defensive strategy intended to reduce unemployment or was it just the consumption of a part of the productivity gains in increased leisure?

Consider the French case, for illustration. In 1981 the just elected socialist Mitterand government called for a substantial but gradual reduction of weekly hours from 40 hours to 35 hours in 1985 . In 1982 a first statutory reduction to 39 hours (and one additional week of holiday) was imposed. This 


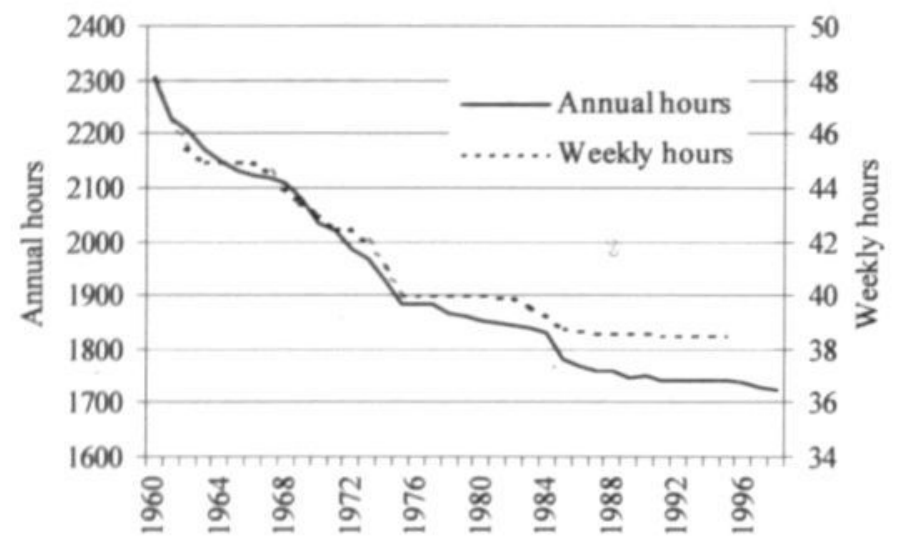

Figure 7.1 Full-time working hours

was a clear example of a work-sharing strategy. After disappointing results in terms of unemployment, see Hunt (1998), the remaining reduction to 36 hours was not implemented. In 1997 the newly elected socialist Jospin government announced a similar policy of mandated (gradual) reduction of weekly hours to 35 hours a week in 2000, in exchange for some labour flexibility and reduced social security contributions. The law ('La Loi Aubry') was enacted in January 2000.

In the Netherlands, a similar debate was initiated in the early $1980 \mathrm{~s}$, although here trade unions, instead of the government, asked for reduced working time. After the famous 1982 Wassenaar Agreement, social partners agreed to moderate wage increases and to reduce working time in due course. In the late 1990s this strategy of wage moderation is commonly believed to have been successful in terms of employment performance. It is not clear, however, whether the observed decline in full-time hours is due to work-sharing or to productivity-sharing: indeed the 1990s is also the period of larger productivity increases, probably due to IT. This chapter tries to identify whether work-sharing or productivity-sharing was the main force behind the observed reduction in working time.

To this end, the chapter presents a small empirical model of the joint behaviour of Dutch hourly wages and standard full-time working hours. I use cointegration techniques to deal with the nonstationarity of the data. For the work-sharing hypothesis, unemployment should have a negative impact on hours worked, whereas for the productivity-sharing hypothesis productivity increases would lead to reduced working times. The chapter does not answer the question whether worksharing has been effective in terms of unemployment reduction. Thus, the focus is on the determinants of full-time normal annual working hours.

The chapter is set out as follows. Section 7.2 provides some background for the Dutch market sector since 1960. Section 7.3 introduces some of the theoretical aspects of the work-sharing versus 


\section{Table 7.1 Key indicators}

\begin{tabular}{lrrrrr}
\hline & $1960-1995$ & $1960-1973$ & $1974-1995$ & $1974-1982$ & $1983-1995$ \\
\hline \multicolumn{5}{c}{ Growth rates } \\
$H$ & -0.8 & -1.2 & -0.6 & -0.7 & -0.5 \\
$W_{c}$ & 4.4 & 7.5 & 2.4 & 4.0 & 1.3 \\
$W_{n}$ & 2.7 & 5.0 & 1.3 & 1.3 & 1.3 \\
$A_{h}$ & 4.0 & 6.2 & 2.6 & 3.2 & 2.2 \\
& & Levels & & & \\
$u$ & 4.4 & 1.1 & 6.5 & 4.0 & 8.2 \\
$\varphi_{N}=W_{c} / A_{h}$ & 73.9 & 69.3 & 76.8 & 81.3 & 73.6 \\
\hline
\end{tabular}

productivity-sharing debate. It provides a simple model for the behaviour of wages and working hours. Section 7.4 presents some properties of the data, showing that cointegrating relations exist. Section 7.5 then presents the estimation results. The implications for the work-sharing or productivity-sharing debate are given in Section 7.6. Conclusions are drawn in the final Section 7.7.

\subsection{THE DUTCH MARKET SECTOR ${ }^{1}$}

Figure 7.1 shows the development of normal full-time working hours in the Dutch market sector. The solid line corresponds to annual hours, whereas the dotted line represents weekly hours. The data do not incorporate overtime hours, neither do they correct for absenteeism. During the fifties, annual working time $(H)$ decreased rather slowly from about 2350 hours to roughly 2300 hours. At that time a normal job was characterized by a workweek of 48 hours and employees had two to three weeks off per year, including public holidays. During the sixties and early seventies, weekly hours decreased gradually to reach the 40 -hour week in 1975. At the same time some additional holidays were introduced, so that in the beginning of the seventies four weeks off became the norm. As a consequence of both developments, annual working time fell below 1900 hours in 1975 . The average decrease in normal hours during this period until the oil shocks amounted to $1.2 \%$ per annum, see Table 7.1, which presents some key indicators by sub-period.

The whole period of the sixties and the first half of the seventies was characterized by low unemployment rates, see Figure 7.2, and strong productivity growth, see Figure 7.3. Before the first

1 For more extensive descriptions of the recent history of the Dutch labour market, see e.g. Broersma, Koeman et al. (2000), Hartog (1999) or van Veen (1997). An account of the development of Dutch working time is given in de Neubourg (1991) and van Doorne-Huiskes and de Lange (1994). 


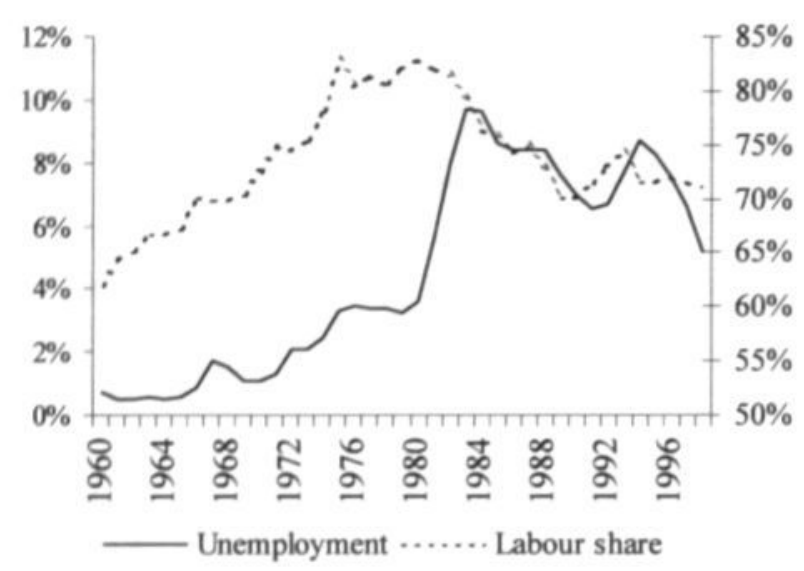

Figure 7.2 Unemployment and labour share

oil crisis, the unemployment rate $(u)$ was on average only $1.1 \%$ over the period $1960-1973$, and hourly productivity $\left(A_{h}\right)$ increased by $6.2 \%$ per year. The net hourly real consumer wage $\left(W_{n}\right)$ lagged slightly behind with a growth rate of $5.0 \%$, whereas gross hourty real producer wages $\left(W_{c}\right)$ increased by $7.5 \%$. The difference was mainly caused by the increasing tax wedge to finance the welfare state arrangements introduced during the sixties. As a consequence, the labour share in value added $\left(\varphi_{N}=W_{c} / A_{h}\right)$ increased substantially from $62 \%$ in 1960 to $82 \%$ in 1975 , see Figure 7.2 .

After the first oil shock in 1974, the Dutch economy was in disarray. Unemployment increased rapidly, reaching its highest level of about $10 \%$ in 1983 . Simultaneously, the growth rate of hourly productivity dropped to only $3.2 \%$ in the period $1974-1982$. Wage increases where roughly in line with productivity, but the labour share remained at a high level. The decrease in working time slowed down: 40-hours a week remained the norm, although the number of holidays increased slightly, reducing the number of weeks worked. In 1982 the labour market situation was considered to be dramatic, this lead to consultations between the government and the social partners. In October 1982 the famous Wassenaar Agreement was struck. One of the main recommendations was to moderate wage claims in exchange for increases in employment and reductions in working time.

With respect to wages, the impact of the Wassenaar Agreement can be seen in Figure 7.2. Real hourly wages increased less than hourly productivity: whereas hourly productivity increased with $2.2 \%$ per year in the period $1983-1995$, real hourly wage costs increased only by $1.3 \%$. As a consequence, the labour share fell with 10 percentage points. In terms of unemployment the results were less impressive, as unemployment remained rather high, see Figure 7.2. However, the small decrease in 1995, has been followed by larger decreases during the second half of the 1990s. 


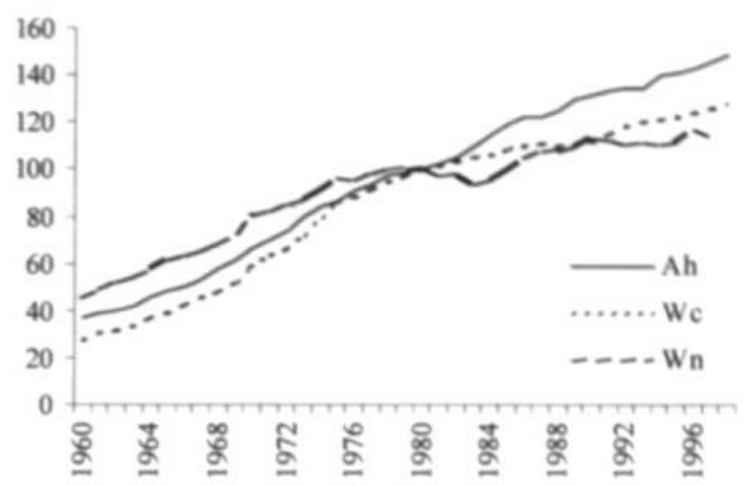

Figure 7.3 Hourly wages and productivity

$(1980-100)$

After the Wassenaar Agreement, annual normal full-time working time fell from 1840 hours in 1982 to 1740 hours in 1992, see Figure 7.1. This decrease is partly due to a reduction of the normal workweek to 38.5 hours in the eighties. The second element is a further increase in the number of days off, amounting to almost seven weeks in 1995.

Summarising the development of working time, annual full-time working hours show a steady decline of $0.8 \%$ per year in the period 1960-1995. Part of this decline occurred during the golden sixties, but another part during the high unemployment era of the eighties. This suggests that both the productivity-sharing - i.e. consuming productivity gains in leisure - and the work-sharing arguments - reducing hours in an attempt to redistribute unemployment - could be relevant.

As a first crude test, Table 7.2 presents Granger causality tests between working time $H$, hourly productivity $A_{h}$ and unemployment $u .^{2}$ The results indicate that working time is Granger caused by productivity, but not by unemployment. Moreover, productivity and unemployment do not seem to be Granger caused by full-time working hours. ${ }^{3}$ These result suggest that the decline in full-time working hours is most likely due to the productivity-sharing hypothesis. To analyse the underlying mechanisms in some more detail, however, I develop and estimate a simple model in the next sections.

2 Except for the unemployment rate, small letters denote natural logarithms of the variables.

3 Similar results were obtained from a reduced form specification, omitting the contemporaneous exogenous variables as explanatory variables under the general specification. 
Table 7.2 Granger causality tests (1962-1995)

\begin{tabular}{lllll}
\hline \multirow{2}{*}{$\begin{array}{l}\text { Endogenous } \\
\text { variable }\end{array}$} & \multicolumn{4}{c}{ Exogenous variables } \\
\cline { 2 - 4 } & \multicolumn{1}{c}{$h$} & \multicolumn{1}{c}{$u$} & joint \\
\hline$h$ & & $0.002^{* *}$ & 0.093 & $0.007^{* *}$ \\
& & {$\left[0.008^{* *}\right]$} & {$[0.444]$} & \\
$a_{h}$ & 0.610 & & 0.244 & 0.333 \\
& {$[0.456]$} & & {$[0.155]$} & \\
$u$ & 0.771 & 0.104 & & 0.253 \\
& {$[0.718]$} & {$[0.072]$} & & \\
\hline
\end{tabular}

p-values Granger causality test in tri-variate model, trend included; p-values bivariate Granger causality tests (trend included) between brackets. Significance levels: * at $5 \%$ and $* *$ at $1 \%$.

\subsection{THEORETICAL BACKGROUND}

From a theoretical point of view, the work-sharing strategy has been severely criticised. The major argument is the so-called lump-of-labour fallacy, see Layard, Nickell et al. (1991, Ch. 10). Krugman (1997) called this the global-glut doctrine. This critique refutes the idea that there is a fixed amount of work that can be redistributed at will. On the contrary, employment - and thus unemployment - is determined by demand and supply factors, or in a more modern context by price and wage setting behaviour. Reductions in working time, may affect both price setting and wage setting, and the final impact on unemployment is uncertain, see Chapter 5 for a theoretical analysis.

The main topic of this chapter is to have a closer look at the origin of the observed reduced hours. The impact on unemployment is not investigated. ${ }^{4}$ As stated in the previous sections, two alternative hypotheses are typically suggested: the work-sharing hypothesis and what I labelled as the productivity-sharing hypothesis. According to the work-sharing hypothesis reductions in hours may be due to high unemployment; whereas the productivity-sharing hypothesis indicates that productivity growth is the driving force. In the latter case, there may be a trade-off in wage determination between increased hourly remuneration and reductions in hours worked. To analyse these types of questions I develop a simple joint model of wage and hours determination capturing both elements.

4 To do so, the model should be augmented with a labour demand or price setting equation, see Chapters 5 and 6 . This falls outside the scope of this chapter. 


\subsubsection{Wage determination}

In modern wage theories, wages are set, in one way or another, as a mark-up on the outside option, see Layard, Nickell et al. (1991) or Chapter 5 for an illustration. In the general equilibrium this leads to a wage curve, where wages depend negatively on the unemployment rate $u$. This curve may shift upward if aspiration levels, such as benefits or productivity, increase. Considering a simple log-linear specification, where except for the unemployment rate $u$ lowercase letters denote log's, this may be summarized for our purposes as

$$
w_{c}=\gamma_{0}-\gamma_{h} h+\gamma_{a} a_{h}+\gamma_{b} b-\gamma_{u} u+\gamma_{s} s+\gamma_{x}{ }^{\prime} x_{w}
$$

where $w_{c}$ is the real hourly wage cost, $h$ is annual full-time hours worked, $a_{h}$ is hourly productivity, $b$ is net real level of unemployment benefits, $u$ is the unemployment rate, $s$ is the wedge between real producer wage costs $w_{c}$ and real net hourly consumer wages $w_{n}$ and finally $x_{w}$ summarizes other wage push variables. In general the $\gamma$-parameters are expected to be positive.

As it stands, equation (7.1) includes the main determinants of Dutch wage equations, see for example Graafland and Huizinga (1999) and Muysken, van Veen et al. (1999). First, capturing the aspiration level of workers, wages increase with productivity and with benefit levels. Typically, it is found that the effect is proportionally, implying $\gamma_{a}=1-\gamma_{b}$. Second, as predicted in theory, higher unemployment reduces wages. Third, tax shifting is an important phenomenon in the Netherlands. ${ }^{5}$

In Chapter 5 I discussed the impact of working hours in a union bargaining framework, see also Calmfors (1985). The conclusion is that the impact of hours worked on hourly wages is indeterminate, various factors operating in different directions. Chapter 5 suggests that the impact is likely to be U-shaped: for short working times reduced working times are likely to increase hourly wages; whereas for longer hours the opposite may be true. The sign conjectured in equation (7.1) illustrates the belief that the first case is nowadays most likely to occur. Moreover, as total remuneration is likely to fall, I expect to have $\gamma_{h}<1$.

Unfortunately, most empirical aggregate wage studies formulate their models in terms of annual wages $\left(w_{c}+h\right)$ and annual productivity $\left(a=a_{h}+h\right)$. This is a special case of equation (7.1), with $\gamma_{h}=1-\gamma_{a}$. The only exception for the Netherlands I am aware of is Dur (2001). He finds an estimate of 0.77 for $\gamma_{h}$ indicating that a reduction in hours worked leads to an increase in hourly wages, although significantly less than proportional. However, as his wage equation contains the capital stock instead of labour productivity as an explanatory variable, it is hard to interpret this result. In their cross-country panel study, Kapteyn, Kalwij et al. (2000) find a value of 1.15 for $\gamma_{h}$,

5 It is sometimes suggested that there is a difference between employer contributions and employee taxes, see Muysken, van Veen et al. (1999). This difference is ignored in the present paper. 
with a standard error of 0.21 , suggesting that hourly wages increase proportionally. However, the productivity variable is GNP per capita (with an elasticity of 0.98 ). Rewriting this in terms of GN per hour worked, as in equation (7.1), the implied coefficient for $\gamma_{h}$ is only $0.17(=1.15-0.98$ suggesting only a minor increase in hourly wages, contrary to their conclusion. ${ }^{6}$

\subsubsection{Hours determination}

Turning to the determinants of hours worked, the bulk of the literature focusses on labour suppl models. Using a log-linear specification this would yield something like

$$
h^{s}=\alpha_{0}-\alpha_{w} w_{n}+\alpha_{x}^{\prime} x_{s}
$$

where $h^{\prime}$ is labour supply and $w_{n}\left(\equiv w_{c}-s\right)$ is the net real consumer wage. The vector $x_{s}$ capture other factors that may affect the individual labour supply decision, such as non-wage incomes, socit norms, etc. To explain the downward trend in hours worked, these type of models have to assum that the labour supply curve is backward bending, implying $\alpha_{w}>0$ in equation (7.2). A probler with this approach is that most (cross-section) estimates of labour supplv elasticities find small bc non-negative wage elasticities, indicating $\alpha_{w}<0$. This is inconsistent with the observed secular decline in hours. Within the labour supply model, there does not seem to be another obvious candidate for explaining this trend in hours worked, as for the bulk of workers non-wage incomes are typically rather low or non-existent. The only alternative would be to recur to an autonomous shift in preferences or social norms.

Another explanation may be that the estimated labour supply elasticities are biased. The reason could be that workers are constrained in their choice of working hours. For example, Dickens and Lundberg (1993), Osberg and Phipps (1993) and Tummers and Woittiez (1991) present evidence for the importance of hours constraints in the labour market. Osberg and Phipps (1993) conclude, for example, that the desired labour supply is slightly backward bending for much of their (Canadian) sample. If suppliers are indeed constrained in their choice of hours, an alternative model for explaining the actual development of working hours is needed. Chapter 6 provided an overview of the alternatives. Within union models the two extreme alternatives are: hours set by monopoly unions and hours set by firms. Intermediate cases allow for bargaining between unions and firms.

To start with the monopoly union case, Calmfors (1985) has shown that unions tend to demand working times $\left(h^{\prime \prime}\right)$ that are shorter than considered optimal from the viewpoint of individuals $\left(h^{\prime}\right)$. The idea is that unions take into account the impact of hours worked on the demand for labour (i.e.

6 Alternatively, their estimates appear to be consistent with a specification of annual wages and annual productivity, without a separate term for hours worked. 
the number of workers). Unions thus have an incentive to cut down hours to reduce the probability of unemployment. However, the loss is less if the outside option for union members is higher. Hence union hours $h^{m}$ increase with the outside option, see Chapter 6 . This implies that union hours will increase with the benefit level and decrease with unemployment. The latter effect corresponds to the work-sharing hypothesis. Generalising the labour supply equation (7.2), union hours can be written as

$$
h^{m}=\alpha_{0}-\alpha_{w} w_{n}+\alpha_{b} b-\alpha_{w} u+\alpha_{x}{ }^{\prime} x_{m}
$$

Unfortunately, the wage elasticity of union hours can not be signed a priori, although it is argued in Chapter 6 that union hours are more likely to fall with net real wages than individual labour supply. The vector $x_{m}$ consists of the labour supply factors $x_{z}$, and also of factors related to the labour demand elasticity of the firm, see Chapter 6 . But as long as the labour demand elasticity is not affected by productivity increases, there is no direct role for the hourly productivity variable $a_{\mathrm{h}}$. Nevertheless, equation (7.3) does incorporate elements of productivity-sharing hypothesis, but in the same indirect way as for the labour supply model: a permanent productivity shock affects the wages determined in (7.1), which in turn influence union hours. Accordingly, $\alpha_{w}>0$ is consistent with the productivity-sharing hypothesis.

A rather different approach would be to assume that working times are determined unilaterally by firms. In labour demand models distinguishing between workers and hours, there is a trade-off between the extensive margin - the number of workers - and the intensive margin - the number of hours worked per worker. As long as fixed costs per worker exist, an increase in hourly wage costs leads to a relative cost increase for the intensive margin, reducing optimal hours $h^{d}$, see e.g. Hart (1984b). In a log-linear specification, this leads to the following simple demand for hours,

$$
h^{d}=\alpha_{0}-\alpha_{w} w_{c}+\alpha_{x}{ }^{\prime} x_{d}
$$

The demand for hours depends negatively on wage $\operatorname{costs} w_{c}$ and not on net real wages $w_{n}$ as in the labour supply model (7.2) or the monopoly union hours equation (7.3). The vector $x_{d}$ captures other factors that may influence the demand for hours, such as factor prices like the user costs of capital, and non-neutral technical progress, see Chapters 2 or 6 for the comparative statics.

Finally, a bargaining model of hours would combine the determinants included in the monopoly union model (7.3) and the labour demand model (7.4), see Chapter 6. In a log-linear specification this yields the generic model

$$
h=\alpha_{0}-\alpha_{w} w_{c}+\alpha_{b} b-\alpha_{u} u+\alpha_{s} s+\alpha_{x}^{\prime} x .
$$




\section{Table 7.3 Reduced form wage and working time elasticities}

\begin{tabular}{llll}
\hline & $\frac{d w_{c}}{d^{\cdot}}$ & $\frac{d h}{d \cdot}$ & $\frac{d\left(w_{c}+h\right)}{d \cdot}$ \\
\hline$\frac{d \cdot}{d a_{h}}$ & $\frac{\gamma_{a}}{1-\alpha_{w} \gamma_{h}}>0$ & $-\frac{\alpha_{w} \gamma_{a}}{1-\alpha_{w} \gamma_{h}}<0$ & $\frac{\left(1-\alpha_{w}\right) \gamma_{a}}{1-\alpha_{w} \gamma_{h}}$ \\
$\frac{d^{\cdot}}{d u}$ & $-\frac{\gamma_{w}-\gamma_{h} \alpha_{w}}{1-\alpha_{w} \gamma_{h}}$ & $-\frac{\alpha_{w}-\alpha_{w} \gamma_{u}}{1-\alpha_{w} \gamma_{h}}$ & $-\frac{\left(1-\alpha_{w}\right) \gamma_{u}+\left(1-\gamma_{h}\right) \alpha_{u}}{1-\alpha_{w} \gamma_{h}}$ \\
\hline
\end{tabular}

By appropriate choice of the $\alpha$-parameters and forcing variables in $x$, this equation encompasses all three previous models. The forcing variables will be ignored in the empirical application. The monopoly union model (7.3) then leads to the restrictions $\alpha_{s}=\alpha_{w}$, as net wages determine hours. Further omitting the outside option $\alpha_{b}=\alpha_{u}=0$ yields the labour supply model (7.2), whereas the joint restrictions $\alpha_{b}=\alpha_{u}=\alpha_{s}=0$ give the labour demand model of equation (7.4). Kapteyn, Kalwij et al. (2000) include the hourly before tax earnings and the employment rate in their cross-country study. This is another mixture of the above models. Their corresponding estimates are $\alpha_{w}=0.16$ and $\alpha_{u}=0.18$.

\subsubsection{Reduced form}

The equations (7.1) and (7.5) jointly determine hourly wages and working time, at given productivity, benefit levels, unemployment and wedge. To focus on the work-sharing versus productivity-sharing hypothesis, consider the reduced form elasticities of working time with respect to productivity and unemployment. They are given in Table 7.3. ${ }^{7}$

An increase in hourly productivity directly affects wage setting (7.1), but does not directly influence working time in (7.5). Given the expected signs of the parameters, $\alpha_{w}>0$ and $\gamma_{h}>0$, the induced increase in wages reduces hours worked, which in turn may lead to an additional pressure on hourly wages. As a result, hourly wages increase more than the initial impact $\gamma_{\alpha}{ }^{8}$ and working hours decline more. Total remuneration $\left(w_{c}+h\right)$ increases, as long as the wage elasticity of hours is inelastic $\left(\alpha_{w}<1\right)$. So the model supports the productivity-sharing hypothesis that increased productivity leads to reductions in working time.

7 The following discussion assumes the benefit level $b$ to be given. An alternative assumption could be that the net replacement rate $\rho \equiv b-\left(w_{n}+h\right)$ is given. This yields more complex expressions, but the qualitative results tend to work in the same direction.

8 At least as long as $\alpha_{w} \gamma_{h}<1$, which needs to hold to solve the model. 
An increase in unemployment has a direct impact both on wage setting and on hours determination: wages are moderated $\left(\gamma_{*}>0\right)$ and hours worked are reduced due to the worksharing motive $\left(\alpha_{\mathrm{w}}>0\right)$. The indirect effects, however, work exactly in the opposite directions. The wage moderation leads to an upward pressure on hours worked (if $\alpha_{w}>0$ ), whereas the initial reduction in hours through the work-sharing motive leads to an upward pressure on hourly wages (if $\gamma_{h}>0$ ). The final impact is ambiguous for both variables. This is an empirical matter.

\subsection{DATA AND ESTIMATION PROCEDURE}

The model was estimated with annual data for 1960-1997 for the Dutch market sector. The last two years have been retained to test for predictive failure. The sources are described in the Data Appendix. The development of the main variables has been outlined in Section 7.2. Table 7.4 gives the time series properties of the data. All but one series appear to have unit roots. Most series are I(1), although real wage costs $w_{c}$ seem to be I(2). ${ }^{9}$ Given the well-documented low power of unit root tests in small samples, however, I have the impression that this is due to the rather short sample period. Moreover, net real wages $w_{n}$ and the wedge $s$ are both I(1), which would imply that their sum $\left(w_{c}\right)$ should also be I(1). Similarly, the labour share $\varphi_{N}$ and labour productivity per hours worked $a_{h}$ are I(1), so their sum - again corresponding to $w_{c}-$ should be I(1). From these observations, I proceed as if real wage costs are I(1). The only series that seems to be stationary is the difference between the replacement rate $\rho$ and the labour share $\varphi_{N}$. As both series individually are I(1), this suggests that both variables are cointegrated. ${ }^{10}$

An alternative to the hypothesis of non-stationarity of our series could be that the series are stationary, but with structural breaks. The obvious candidates for such breaks could be the oil crises of the 1970s and 1980s or the Wassenaar Agreement of 1982. Experimenting with such breaks did not change the conclusion, however, that the variables appear to be non-stationary.

To account for this non-stationarity of the data, the model was estimated in error-correction form. This has the additional advantage of allowing flexible dynamics in the process of wage formation and hours determination, as the theories presented in the previous section give no information about the dynamic adjustment path.

Before analysing the structural error correction model for wages and working time, I applied Johansen's procedure to test for the number of cointegrating relations in the system of six variables.

9 There is some evidence in the literature that nominal wages and prices could be I(2), but typically relative prices, and thus real wages, are found to be I(1), see e.g. Banerjee, Cockerell et al. (2001).

10 The economic logic might be that higher benefits lead to higher taxes, leading in turn to an increase in the labour share, but this is speculative. Alternatively, a high labour share might increase the demands for relatively high benefits. 
Table 7.4 Unit root tests (1962-1995)

\begin{tabular}{|c|c|c|c|c|c|c|c|}
\hline \multirow{3}{*}{$\begin{array}{l}\text { Variable } x \\
h\end{array}$} & \multirow{3}{*}{$\begin{array}{l}\text { Growth rate } \\
-0.007(0.007)\end{array}$} & \multicolumn{6}{|c|}{$\mathrm{ADF}^{b}$} \\
\hline & & \multicolumn{2}{|c|}{$x$} & \multicolumn{2}{|c|}{$\Delta x$} & \multicolumn{2}{|c|}{$\Delta^{2} x$} \\
\hline & & -0.21 & {$[\mathrm{t}, 0]$} & $-4.71^{* *}$ & {$[\mathrm{c}, 0]$} & & \\
\hline $\boldsymbol{w}_{e}$ & $0.041(0.032)$ & -1.39 & {$[\mathrm{t}, 3]$} & -0.86 & [c, 2] & $-7.85^{* *}$ & {$[\mathrm{n}, 1]$} \\
\hline $\boldsymbol{w}_{n}=\boldsymbol{w}_{c}-\boldsymbol{s}$ & $0.024(0.029)$ & -1.64 & {$[\mathrm{t}, 0]$} & $-3.42^{*}$ & {$[c, 0]$} & & \\
\hline$a_{h}$ & $0.038(0.024)$ & -0.29 & {$[\mathrm{t}, 0]$} & $-3.00^{*}$ & {$[\mathrm{c}, 0]$} & $-7.14^{* *}$ & {$[\mathrm{n}, 2]$} \\
\hline$b$ & $0.019(0.041)$ & -1.34 & {$[\mathrm{t}, 0]$} & $-3.49^{*}$ & {$[\mathrm{c}, 0]$} & & \\
\hline$u$ & $0.002(0.007)$ & -0.86 & {$[\mathrm{c}, 2]$} & $-4.47 * *$ & {$[\mathrm{n}, 1]$} & & \\
\hline$s$ & $0.017(0.025)$ & -1.62 & {$[\mathrm{c}, 0]$} & $-3.00^{* *}$ & {$[\mathrm{n}, 0]$} & & \\
\hline $\boldsymbol{\varphi}_{N}=\boldsymbol{w}_{c}-\boldsymbol{a}_{\boldsymbol{h}}$ & $0.003(0.023)$ & -1.94 & {$[\mathrm{c}, 0]$} & $-4.86^{* *}$ & {$[\mathrm{n}, 0]$} & & \\
\hline$\rho=b-w_{n}-h$ & $0.002(0.027)$ & -1.55 & {$[c, 0]$} & $-5.15^{* *}$ & {$[\mathrm{n}, 0]$} & & \\
\hline$\rho^{-} \varphi_{N}$ & $-0.001(0.028)$ & $-4.01 * *$ & {$[\mathrm{c}, 0]$} & & & & \\
\hline
\end{tabular}

a. Standard deviation between parentheses.

b. The characteristics of the (adjusted) Dickey-Fuller test statistic (ADF) are given between brackets $[\mathbf{z}, H]: \mathbf{z}=\{\mathrm{n}, \mathrm{c}, \mathrm{t}\}$ indicates neither constant or trend, constant included or trend and constant included, respectively; $\#$ corresponds to the number of significant lags included. Significant rejection of nonstationarity is indicated by asterisks (* at the $5 \%$-level and $* *$ at the $1 \%$-level).

A VAR of order 2 with constant and trend was specified. "In order to exclude the possibility of a quadratic trend under the hypothesis of one or more unit roots, the linear trend was restricted to appear only in the cointegrating relations. Table 7.5 reports the two usual likelihood ratio statistics for cointegration, see Johansen and Juselius (1990). ${ }^{12}$ Neither test statistic rejects the null hypothesis of three cointegrating relationships, whereas the null hypothesis of at most two relations is rejected: at a $1 \%$ significance level for the trace statistic and at $5 \%$ significance for the $\lambda_{\max }$ statistic. Accordingly there appear to be three cointegrating relations within the system of six variables.

Since the main interest lies in modelling wages and working time - rather than in deriving empirical models for productivity, benefits, unemployment or the wedge - a conditional approach seems appropriate. ${ }^{13}$ Such an approach only yields valid inferences if the conditioning variables are weakly exogenous for the short-run and long-run parameters of the wage and working time model. This will be tested for.

11 With annual data two lag's appear to be reasonable, but because of a lack of degrees of freedom I did not test for the number of significant lag's. But, as the unrestricted reduced form of the conditional model does not seem to be misspecified, see Table 7.6 in the next section, the number of lags included appear to be appropriate.

12 The results were obtained using PcFiml 9.0, see Doornik and Hendry (1997).

13 See Urbain (1995) for a discussion of the relative merits and pitfalls of modelling cointegrated systems in conditional or in full system models. 


\section{Table 7.5 Cointegration tests (1962-1995)}

\begin{tabular}{lcc}
\hline $\mathrm{H}_{0}$ & Trace & $\lambda_{\max }$ \\
\hline $\mathrm{r} \leq 5$ & 5.255 & 5.255 \\
$\mathrm{r} \leq 4$ & 17.13 & 11.87 \\
$\mathrm{r} \leq 3$ & 38.06 & 20.93 \\
$\mathrm{r} \leq 2$ & $73.74 * *$ & $35.68 *$ \\
$\mathrm{r} \leq 1$ & $119.8 * *$ & $46.05 * *$ \\
$\mathrm{r}=0$ & $189.8 * *$ & $69.98 * *$ \\
\hline
\end{tabular}

Likelihood ratio tests defined in Johansen and Juselius (1990). Significance levels: $\bullet$ at $5 \%$ and $* *$ at $1 \%$. Trend included.

Within the conditional model a maximum of two cointegrating relations can be identified, which will be identified as wage setting and hours determination, respectively. As there are three cointegrating relations within the system, no unique long-run relations can be found, however. Table 7.4 suggests that the third cointegrating relation may be that between the replacement rate and the labour share, as their difference is stationary. This involves five of the six variables of the system, with only the unemployment rate not included. This relation could be used to eliminate the benefit level from the long-run cointegrating relations.

\subsection{ESTIMATION RESULTS}

As argued by Spanos (1990), the statistical adequacy of a structural model should be assessed by misspecification tests of the unrestricted reduced form (URF). Therefore, I started with an unrestricted model of $w_{c}$ and $h$, conditional upon $a_{h}, b, u$ and $s$. As with the VAR of the system, the maximal lag length was a priori set to 2 . A constant and a trend were also included. The trend may capture the omitted exogenous variables in the model, especially in the hours equation. It is highly significant in the URF-model, with a p-value of 0.006. I tried to include other explanatory variables, but failed to get rid of the trend. In particular, I used the share of female employment, the incidence of part-time employment and a crude measure for quasi-fixed labour costs. The first two variables were intended to capture changes in preferences, the latter variable should influence the demand for hours. Neither variable had a significant effect.

Table 7.6 provides some statistics for the two reduced form equations. There is clear evidence of first-order auto-correlation in the wage equation. However, transforming the dependent variable from hourly wages $w_{c}$ to annual wages $w_{c}+h$ (see the third column of the table), 
Table 7.6 Diagnostic tests unrestricted reduced form (1962-1995)

\section{Dependent variable (OLS)}

\begin{tabular}{|c|c|c|c|c|}
\hline & $\Delta \boldsymbol{w}_{c}$ & & $\Delta h$ & $\Delta\left(w_{c}+h\right)$ \\
\hline \multicolumn{5}{|c|}{ Test statistics" } \\
\hline$\hat{\sigma}(x 100)$ & 1.000 & & 0.370 & 0.921 \\
\hline RSS (x1000) & 1.599 & & 0.220 & 1.188 \\
\hline PF'97 & $F(2,16)=1.68$ & $\mathrm{~F}(2,16$ & $=0.42$ & $F(2,16)=1.86$ \\
\hline LMA & $\mathrm{F}(1,15)=10.77^{* *}$ & $\mathrm{~F}(1,15$ & $=0.29$ & $F(1,15)=3.90$ \\
\hline $\mathrm{ARCH}$ & $\mathrm{F}(1,14)=0.12$ & $\mathrm{~F}(1,14$ & $=0.31$ & $F(1,14)=0.19$ \\
\hline NORM & $\chi^{2}(2)=0.58$ & $\chi^{2}(2)$ & $=2.02$ & $\chi^{2}(2)=0.82$ \\
\hline RESET & $F(1,15)=0.14$ & $\mathrm{~F}(1,15$ & $=3.24$ & $F(1,15)=1.68$ \\
\hline WNC & 21.85 & & $61.41^{* *}$ & 21.67 \\
\hline $\mathrm{CDF}$ & $-4.39 * *$ & & $-4.05^{* *}$ & $-3.86^{* *}$ \\
\hline \multicolumn{5}{|c|}{ Model test statistics ${ }^{\circ}$} \\
\hline log-likelihood & \multicolumn{2}{|c|}{375.343} & \multicolumn{2}{|c|}{375.343} \\
\hline$\hat{\rho}$ & \multicolumn{2}{|c|}{-0.389} & \multicolumn{2}{|c|}{-0.020} \\
\hline PF'97 & \multicolumn{2}{|c|}{$F(4,16)=1.32$} & \multicolumn{2}{|c|}{$F(4,16)=1.32$} \\
\hline VLMA & \multicolumn{2}{|c|}{$F(4,26)=2.08$} & \multicolumn{2}{|c|}{$F(4,26)=2.08$} \\
\hline VNORM & \multicolumn{2}{|c|}{$\chi^{2}(4)=1.89$} & \multicolumn{2}{|c|}{$\chi^{2}(4)=2.84$} \\
\hline LMC & \multicolumn{2}{|c|}{$F(8,38)=1.85$} & \multicolumn{2}{|c|}{$F(8,38)=1.85$} \\
\hline
\end{tabular}

a. $\hat{0}$ is the equation standard error; RSS is the residual sum of squares; PF97 is a Chow test for parameter constancy up to 1997; LMA is a Lagrange multiplier test for first-order residual autocorrelation; ARCH is a Lagrange multiplier test for first-order autoregressive conditional heteroscedasticity; NORM is WinGive's normality test of the residuals; RESET is Ramsey's specification test; WNC is a Wald statistic for no-cointegration; CDF is a Dickey-Fuller test with constant but no trend for non-stationarity of the cointegrating vector. Significance levels test statistics: * at $5 \%$ and $* *$ at $1 \%$.

b. $\hat{\rho}$ is the correlation between the residuals; VLMA is a test for first-order residual vector autocorrelation; VNORM is WinGive's vector normality test of the residuals; LMC is a LM-test for weak exogeneity of the regressors for the long-run parameters. 
seems to solve this problem. This suggests that the auto-correlation problem is an artifact of the contemporaneous interaction between wage setting and hours determination, ${ }^{14}$ which will be taken into account in the structural model. So no further lags were needed to avoid auto-correlation. None of the other diagnostic tests indicate misspecification at the $5 \%$ significance level.

The table also includes the Lagrange multiplier test (LMC) suggested by Boswijk and Urbain (1997) for weak exogeneity of the regressors for the long-run parameters. It tests the significance of the lagged error-correction errors of the URF in the marginal model of the conditioning variables and is not significant. ${ }^{15}$ Accordingly, the conditional approach can be used to provide valid inference on the long-run parameters.

The next step in the analysis is the specification of a just-identified structural model (JID). As illustrated by Johansen and Juselius (1994), this includes identification of the long-run and the shortrun structure. To start with the latter, the previous table already indicated that the contemporaneous interaction between hourly wage setting and hours determination may be an important issue. There are several possibilities: at one extreme, wages may be set with predetermined working hours, which would imply that current hours $h$, influence current wages $w_{c}$ but not vice versa; at the other extreme, current hours are set with predetermined hourly wages in labour supply models, which would imply that current net real wages $w_{n t}$ influence hours $h_{t}$, but not vice versa. Many intermediate positions are possible, see Chapter 6 . In the just-identified model, I allowed for interactions in both directions, which required other identifying restrictions for the dynamics. As there does not seem to be any theoretical reason to pick a particular (lagged) variable, I used the least significant lagged differenced variables in the URF. As a consequence, the lagged change in hours in the wage equation and the lagged change in unemployment in the hours equation were omitted for identification purposes. Using different short-run identification restrictions yielded the same parsimonious results.

To identify the long-run parameters in the JID, I started with the assumption of a diagonal errorcorrection matrix. This does not provide any structural interpretation, but allows for a simple test of no-cointegration (WNC). This is a Wald-test for the joint occurrence of the lagged levels (the errorcorrection terms) in each individual equation. Under the null-hypothesis of no-cointegration the

14 Moreover, the negative correlation $\hat{\rho}$ between the residuals of the two models almost vanishes when $w_{c}$ is replaced by $w_{c}+h$.

15 The marginal system is modelled as an unrestricted VAR of the four conditioning variables with 2 lags, a constant and a trend. 
distribution of the test is non-standard, but Boswijk (1994) has calculated critical values. ${ }^{16}$

Table 7.7 gives the results for the JID-model, estimated by FIML. For notational economy, the table does not report the short-run dynamics, but only the cointegrating relations and the corresponding diagonal error-correction terms. The standard errors of the cointegrating vectors are calculated using the methods given in Bårdsen (1989). The no-cointegration tests give mixed results. For the hours equation, the WNC statistic is significant at the $1 \%$ level, rejecting the null-hypothesis of no-cointegration. This is confirmed by a Dickey-Fuller statistic (CDF) on the cointegrating vector. For the wage equation, however, the WNC is only significant at the $10 \%$ level. On the other hand, the CDF statistic suggests that the cointegrating vector is stationary. ${ }^{17}$

The ambiguous results for the cointegration of the wage equation may be due to the inclusion of the trend in the equation. Single equation estimates of Dutch wage equations, see for example Broer, Draper et al. (2000) and Muysken, van Veen et al. (1999), suggest that wages are indeed cointegrated with the variables included in here, but that no trend is needed. The parameter estimates of the cointegrating vector for wages in the JID even correspond fairly closely to the results found elsewhere: wages increase with productivity and benefits, their joint impact being proportional; ${ }^{18}$ wages decrease with unemployment, the semi-elasticity being around - 1 ; and tax shifting is rather strong. In view of this, I take the results of Tables 7.6 and 7.7 as evidence for the occurrence of two cointegrating relations in the constrained model.

The next step was to identify structural long-run relations in the constrained model. In line with equations (7.1) and (7.5), the following parameterization was used: ${ }^{19}$

$$
\begin{aligned}
& z_{w}=w_{c}-\left[\gamma_{0}-\gamma_{h} h+\gamma_{a} a_{h}+\gamma_{b} b-\gamma_{u} u+\gamma_{s} s\right], \\
& z_{h}=h-\left[\alpha_{0}-\alpha_{w} w_{c}+\alpha_{b} b-\alpha_{u} u+\alpha_{s} s+\alpha_{t} t\right] .
\end{aligned}
$$

16 Boswijk (1994) calls WNC an instability test, but to avoid confusion I prefer to call it a nocointegration test. The $\xi_{*}^{*}$-statistic was used to account for the trend in the model. With 4 exogenous variables, the $10 \%, 5 \%$ and $1 \%$ critical values are $20.76,23.33$ and 28.51 , respectively.

17 A more or less similar ambiguity of the no-cointegration test statistics can be found in the URF of Table 7.6.

18 When the replacement rate is included instead of the benefit level, as in Broer, Draper et al. (2000), wages are proporcional to productivity.

19 As the system of six variables contains three cointegrating relations, the two cointegrating relations of the constrained structural model are not uniquely identified. 
Table 7.7 Cointegration tests just-identified model (FIML, 1962-1995)

\begin{tabular}{|c|c|c|}
\hline \multicolumn{3}{|c|}{ Dependent variable } \\
\hline & $\Delta\left(w_{c}+h\right)$ & $\Delta h$ \\
\hline \multicolumn{3}{|c|}{ Cointegrating vectors * } \\
\hline $\boldsymbol{w}_{c}$ & 1. & $\begin{array}{c}0.610 \\
(0.588)\end{array}$ \\
\hline$h$ & $\begin{array}{c}0.393 \\
(0.676)\end{array}$ & 1. \\
\hline$a_{h}$ & $\begin{array}{c}-0.824 \\
(0.342)\end{array}$ & $\begin{array}{c}0.119 \\
(0.507)\end{array}$ \\
\hline$b$ & $\begin{array}{c}-0.232 \\
(0.189)\end{array}$ & $\begin{array}{c}-0.546 \\
(0.232)\end{array}$ \\
\hline$u$ & $\begin{array}{c}1.182 \\
(0.619)\end{array}$ & $\begin{array}{c}-0.506 \\
(0.698)\end{array}$ \\
\hline$s$ & $\begin{array}{c}-0.588 \\
(0.117)\end{array}$ & $\begin{array}{c}-0.120 \\
(0.344)\end{array}$ \\
\hline trend $(* 100)$ & $\begin{array}{c}0.576 \\
(0.602)\end{array}$ & $\begin{array}{c}-0.941 \\
(0.536)\end{array}$ \\
\hline \multicolumn{3}{|c|}{ Error correction coefficients ${ }^{\text {a }}$} \\
\hline & $\begin{array}{c}-1.158 \\
(0.380) \\
\end{array}$ & $\begin{array}{c}-0.456 \\
(0.159)\end{array}$ \\
\hline \multicolumn{3}{|c|}{ No-cointegration tests ${ }^{b}$} \\
\hline WNC & 21.10 & $51.21^{* *}$ \\
\hline CDF & $-4.12^{* *}$ & $-3.30^{*}$ \\
\hline \multicolumn{3}{|c|}{ Model test statistics ${ }^{\mathrm{c}}$} \\
\hline$\hat{\sigma}(x 100)$ & 0.933 & 0.367 \\
\hline$\hat{\rho}$ & \multicolumn{2}{|c|}{0.580} \\
\hline log-likelihood & \multicolumn{2}{|c|}{375.343} \\
\hline
\end{tabular}

a. Standard errors between parentheses.

b. WNC is a Wald statistic for no-cointegration; CDF is a Dickey-Fuller test with constant but no trend for nonstationarity of the cointegrating vector. Significance levels test statistics: ${ }^{*}$ at $5 \%$ and ${ }^{* *}$ at $1 \%$.

c. $\hat{\sigma}$ is the equation standard error and $\hat{\rho}$ is the correlation between the residuals. 


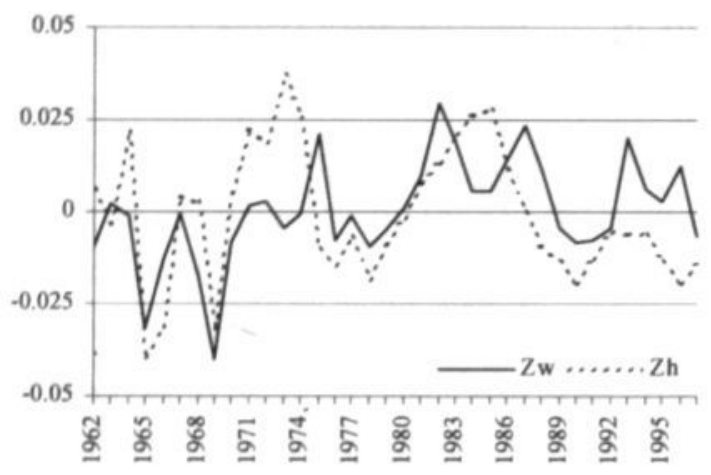

Figure 7.4 Cointegrating vectors

The first cointegrating vector $z_{w}$ is interpreted as wage setting, therefore the coefficient on wages is normalized to one and the identifying restriction is that the trend is excluded. The second cointegrating vector $z_{h}$ is interpreted as hours determination, accordingly the coefficient on hours is normalized to one and, in line with equation (7.5), the identifying restriction is that productivity is excluded. As a consequence, the error-correction matrix is no longer diagonal in the structural model.

Table 7.8 presents the final estimation results of the structural model. It is a parsimonious specification that cannot be rejected against the URF, the p-value of the likelihood ratio test for the 20 parameter restrictions being 0.238 . The no-cointegration tests of the model indicate that there are indeed two different cointegrating vectors. Figure 7.4 plots the two vectors. Both series show deviations of the actual values relative to their long-run targets of at most $4 \%$ in absolute value. Visual inspection suggests that the series are correlated, and indeed their correlation coefficient is 0.48 .

According to the cointegrating relation for wages $z_{w}$, wage costs are proportional to the aspiration levels, given by a weighted average of productivity (64\%) and benefits (the remaining $36 \%$ ). ${ }^{20}$ The long-run semi-elasticity of unemployment on wages is around - 1 and the tax elasticity of wages is 0.6. Given the small standard error of the latter estimate, the tax burden is shared by both sides of the market in the long run. The impact of working time on hourly wages appears to be negative, although not significant ( $\mathrm{p}$-value 0.164 ). The results do reject that the long-run wage equation can be written in annual terms, as the p-value of the restriction $\gamma_{h}=\left(1-\gamma_{a}\right)$ is 0.035 . The suggestion is, in any case, that in the long run reduced working time leads to a small increase in hourly wages, but certainly not sufficient enough to keep annual remuneration constant.

20 The p-value of the likelihood ratio test of the restriction that both coeificients in the cointegrating wage vector sum to one is 0.896 . 
Table 7.8 Parsimonious estimation results (FIML, 1962-1995)

Dependent variable

$\frac{\Delta w_{c}}{\text { Short-run dynamics * }}$

$\begin{array}{lcc}\text { Constant } & -1.234 & 1.069 \\ & (0.627) & (0.533) \\ \Delta w_{a t} & & -0.133 \\ & & (0.035)\end{array}$

$\Delta h,-1$.

(-)

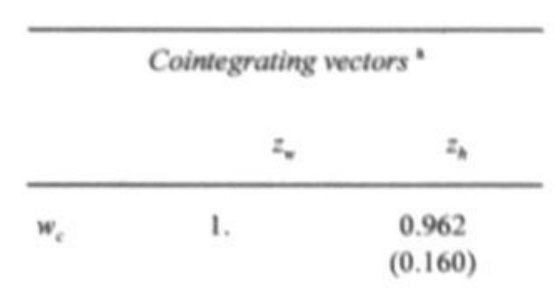

h $0.159 \quad 1$.

. $(0.125)$

$\begin{array}{rr}\Delta h_{h-1} & -0.294 \\ & (0.110)\end{array}$

$\begin{array}{cc}a_{h} & -0.641 \\ & (0.031)\end{array}$

$\Delta a$ 0.480

$b$

$-0.359$

$-0.712$

(-)

\begin{tabular}{lll}
$\Delta b_{,}$ & 0.268 & 0.120 \\
& $(-)$ & $(0.024)$ \\
$\Delta b_{t-1}$ & & 0.120 \\
& & $(-)$ \\
$\Delta s_{t}$ & & 0.133 \\
& $(-)$ & $(-)$ \\
\hline
\end{tabular}

$(-)$

u

1.024

0.

(0.186)

(-)

$s$

$\begin{array}{cc}-0.609 & -0.437 \\ (0.040) & (0.091)\end{array}$

trend $(\bullet 100)$

$-1.201$

(0.294)

Error correction coefficients "

\begin{tabular}{ccc}
$z_{\text {wot-1 }}$ & -0.748 & 0.280 \\
& $\cdot(0.080)$ & $(0.075)$ \\
$z_{h t-1}$ & & -0.485 \\
& & $(0.119)$ \\
\hline
\end{tabular}

\begin{tabular}{|c|c|c|c|c|}
\hline \multicolumn{2}{|c|}{ Model test statistics ${ }^{b}$} & \multicolumn{3}{|c|}{ No-cointegration tests ${ }^{c}$} \\
\hline$\hat{\sigma}(x 100)$ & 0.323 & WNC & $52.17^{* *}$ & $64.62^{* *}$ \\
\hline$\hat{\rho}$ & 0.166 & CDF & $-3.71 * *$ & $-3.37^{*}$ \\
\hline LMO & $\chi^{2}(8)=11.8$ & & & \\
\hline log-likelihood & 363.291 & & & \\
\hline p-value URF & 0.238 & & & \\
\hline
\end{tabular}

\footnotetext{
a. Standard errors between parentheses.

b. $\hat{\sigma}$ is the equation standard error; $\hat{\rho}$ is the correlation between the residuals; LMO is a LMtest for orthogonality of the regressors; the p-value URF is based on a $\chi^{2}$-test against the unrestricted model.
c. WNC is a Wald statistic for no-cointegration and CDF is a Dickey-Fuller test with constant but no trend for non-stationarity of the cointegrating vector. Significance levels test statistics: ${ }^{*}$ at $5 \%$ and ${ }^{* *}$ at $1 \%$.


So working time reduction unambiguously leads to wage moderation in terms of annual remuneration, as suggested in Chapter 5 .

To test the U-shape between hourly wages and hours worked, I also experimented with lagged hours squared as an additional explanatory variable. This did not improve the fit, however.

According to the cointegrating relation for hours $z_{h}$, wages have a strong negative impact on normal hours, the elasticity being almost -1 . However, as the wedge has only a much smaller positive impact, the long-run hours equation can not be written in terms of net wages only. The longrun hours equation thus combines supply and demand factors with roughly equal weights: the elasticity with respect to net wages being -0.44 and with respect to wage costs being -0.52 (= $0.44-0.96)$. Real benefits have a strong positive impact of hours worked in the long run. This is consistent with the role of unions in hours determination, see equation (7.3). However, in that case hours determination should also incorporate the work-sharing argument. But no significant role is found for unemployment in the cointegrating relation for hours in Table 7.8, the p-value of the imposed restriction $\alpha_{u}=0$ is $0.674 .{ }^{21}$ Finally, the cointegrating relation for hours, includes a significant trend. In terms of a labour supply interpretation, this would essentially mean a shift of preferences towards more hours. This seems rather unlikely, although one could argue that the increased opportunities of part-time work allowed the over-employed individuals to switch from fulltime to part-time jobs. To test this hypothesis, I included the incidence of part-time employment or the share of female employment as an explanatory variable, but without success. An alternative interpretation of the trend comes from labour demand. A change in technology or change in relative costs could also shift the demand for hours. I tried to include a rough measure of quasi-fixed labour costs, but again without success. Further research in this direction is needed.

The error-correction matrix is triangular in the structural model. The lagged cointegrating vector for wages $z_{w}$ has an expected negative impact on the growth of wages, but has a positive effect on the growth of working time. The error-correction of hours $z_{h}$ only affects the growth in working time negatively. ${ }^{22}$ The size of the own error-correction coefficients illustrate that wages adjust more quickly to a disequilibrium than hours. This seems in accordance with the notion that bargaining over working time is not always on the agenda. Alternatively, it could be that social norms play an important role in the adjustment of hours worked, see e.g., Bentivogli (1992) and Vendrik (1993).

The sign of $z_{w}$ in the hours equation is slightly puzzling, as it works in the opposite direction of the negative long-run impact of wages on hours. A possible explanation may be the intertemporal substitution hypothesis. When hourly wages temporarily exceed the long-run target, it may pay to increase hours temporarily above its own target level, even though the long-run elasticity of hours

21 Moreover, when included in $z_{h}$, unemployment has the wrong sign.

22 The p-value for the imposed restriction that $z_{h-1}$ does not affect the wage equation is 0.114 . 
with respect to wages is negative. Combining the effects of both error-correction terms in the hours equation, lagged wages have a small negative impact on the growth of working time $(-0.186=$ $\left.0.280-0.485^{*} 0.962\right)$.

Next consider the dynamic adjustment of the parsimonious model. To derive valid inference for the short-run dynamics, weak-exogeneity requires the regressors and the disturbances to be orthogonal, see Boswijk and Urbain (1997). This is tested by adding the residuals of the marginal system of the conditioning variables to the structural model. This variable addition test $(\mathrm{LMO})$ is not significant ( $\mathrm{p}$ value 0.161 ). Thus, the orthogonality restriction cannot be rejected and inferences on short-run dynamics are valid.

The growth of wages is directly affected by the growth in productivity, benefits and the wedge. These estimates corresponded rather closely to the corresponding coefficients in the cointegrating vector for wages multiplied by the error-correction coefficient. Testing for this joint hypothesis gave a p-value of 0.804. Therefore, I imposed this restriction on the short-run dynamics of the wage equation in the parsimonious model of Table 7.8.

Although the cointegrating wage relation is specified in hourly terms, the dependent variable in the dynamic equation is the annual wage. The restriction imposed on the coefficient for the growth in working time is accepted, with a p-value of $0.205 .{ }^{23}$ Notice, however, that the wage equation also includes the growth of annual productivity as an explanatory variable. ${ }^{24}$ Looking at the impact of a reduction in hours, this means that in the short run annual remuneration is only reduced insofar as annual productivity is reduced. In other words, hourly wages tend to increase almost proportionally in the short run. The previously discussed long-run effects showed, however, that in the long run hourly wages increase significantly less than proportional and may even remain constant.

Changes in working hours are endogenous in the model, though, and adjustments in hours take a long time according to the estimates of the hours equation in Table 7.8. Again, this may be explained by social norms and habits. The negative sign of the lagged growth of hours, suggests that the adjustment path is oscillating, but to analyse the dynamic adjustment we should look at the whole system. ${ }^{25}$ The growth in working time reacts negatively to the contemporaneous increase in net real

23 The alternative hypothesis that the coefficient of $\Delta h_{t}$ equals 0 , instead of -1 , is strongly rejected, with a p-value of 0.0003 against a free estimate of that coefficient.

24 Alternatively, I could have included the growth of hourly productivity, instead of annual productivity. This gives rather similar results, the log-likelihood being slightly higher (363.848). On the other hand, the correlation between the residuals of equations increases to 0.347 in this alternative specification.

25 The characteristic roots of the parsimonious system are $0.682,-0.427,0.271$ and 0 . The system is thus stable and oscillates. 


\section{Table 7.9 Long-run reduced form elasticities}

\begin{tabular}{lrrrrr}
\hline & $a_{h}$ & $b$ & $u$ & \multicolumn{1}{c}{$s$} & trend $(* 100)$ \\
\hline \multicolumn{5}{c}{ Benefits given } \\
$w_{c}$ & 0.76 & 0.29 & -1.21 & 0.64 & -0.23 \\
$h$ & -0.73 & 0.43 & 1.16 & -0.18 & 1.42 \\
$w_{c}+h$ & 0.03 & 0.73 & -0.05 & 0.46 & 1.19 \\
\multicolumn{5}{c}{ Replacement rate given } \\
$w_{c}$ & 0.78 & & -1.26 & 0.07 & 1.02 \\
$h$ & -0.68 & & 1.09 & -0.69 & 3.29 \\
$w_{c}+h$ & 0.11 & & -0.17 & -0.62 & 4.31 \\
\hline
\end{tabular}

v /ages, ${ }^{26}$ although the impa $t$ is much smaller than in the long run. So, whereas in the long run labour sup:ly and la'our demar.d factors affect full-time hours, labour supply effects appear to dominate in the short run. Final $y$, to 2 innovation in real benefits increases the growth rate of hours. It is hard to find any interpretation for this result.

\subsection{WORK-S AARING OR PRODUCTIVITY-SHARING}

The estimatirn results can be used to consider the determinants of the Dutch full-time working time in some more detail. Table 7.9 gives the implied long-run reduced form elasticities for wages and hours worked. It is the empirical counterpart of the elasticities presented in Table 7.3. The table also includes the elasticities calculated under the assumption of a given replacement rate $\rho$.

At a given benefit level, the wage elasticities with respect to the exogenous variables are roughly in line with the cointegrating relation $z_{w}$ identified in Table 7.8. The reason is that the estimated coefficient for hours $\gamma_{h}$ in the wage equation (7.1) is rather small, so interaction effects via the hours equation (7.5) are almost negligible. The small negative decline of $0.2 \%$ a year is due to the trend in the hours equation, however.

For full-time hours, the reduced form elasticities at given benefits are a mixture of the effects identified in the hours and wage equations, often with opposite signs. Consistent with the productivity-sharing hypothesis introduced earlier, there is a clear negative impact of productivity. This is due to the negative elasticity of working time with respect to wages, combined with the impact of productivity on wages. Partly offsetting this is the positive effect of the trend in the hours equation. 
An increase in benefits has a similar negative effect via the wage equation as an increase in productivity, but this indirect effect is dominated by the positive direct effect in hours determination. With respect to unemployment, I did not find any evidence for the work-sharing hypothesis in the structural model. Accordingly, there is only an indirect effect via the wage equation, leading to a positive reduced form elasticity. As unemployment reduces wages, there is an upward pressure on hours. For the wedge, the direct and indirect effects work in opposite directions, and the indirect effect via wages appears to dominate. Finally, the positive effect of the trend is determined by its direct impact on hours. As the implied increase in hours reduces hourly wages in the wage equation, this feeds back to even longer hours in the hours equation.

These estimated long-run reduced form elasticities reinforce the conclusion from the Granger causality tests in Table 7.2: the reduction in Dutch full-time hours should be attributed to productivitysharing, whereas work-sharing did not play a significant role.

Combining the elasticities on hourly wages and hours worked, the third row of Table 7.9 gives the impact on annual remuneration. The surprise may be that productivity and unemployment have a rather weak effect, as the elasticities on $w_{c}$ and $h$ roughly cancel each other out.

Turning to the elasticities at a given replacement rate, the results are rather similar. The sign distribution is almost unaffected, except for the effect of the wedge on remuneration and the effect of the trend on wages. The magnitude of the elasticities only change if total remuneration was strongly affected at given benefits.

\subsection{SUMMARY AND CONCLUSIONS}

The starting point for this chapter was the observation that full-time working hours have steadily declined in the Netherlands. The two main hypotheses put forward for this behaviour are worksharing and productivity-sharing. In the former, one would expect hours to decline in times of high unemployment, whereas in the latter productivity induced wage growth is the transmission channel. This chapter developed a simple empirical model to assess the importance of both hypotheses. The joint model for wages and working time is estimated using cointegration techniques to account for the non-stationarity of the data.

I was able to identify two cointegrating relations in the data, which can be interpreted as wage setting and the hours determination, respectively. The wage equation is quite consistent with earlier work on Dutch wage equations, the novelty being that wage models specified in annual terms seem to be misspecified. Indeed, full-time hours only appear to have a weak negative impact on hourly wages in the long run. So a reduction in working hours leads to a significant decline in total remuneration.

The hours equation is not consistent with a simple labour supply model, but also seems to incorporate union (benefits) and labour demand (wage costs) effects. With respect to the 
determinants of working time, the estimates provide clear evidence that the work-sharing hypothesis does not hold. The decline in hours is mainly driven by increases in hourly wages (and hourly wage costs), and thus by productivity-sharing.

Future work in the determination of hours and the interaction with wage determination is needed. If full-time hours are not solely determined by labour supply considerations, as suggested by the present analysis, alternative models are needed to investigate its determinants. From an empirical perspective, this may allow us to dispose of the rather unsatisfactory trend in the current empirical specification. Furthermore, it stresses that labour supply models should take into account hours restrictions. Another strand of research may be to explain the different behaviour of hours in a cross. country study. Unfortunately, the availability of data may be rather restrictive in this respect.

Another extension to the model would be to incorporate labour demand for workers or price setting in the analysis. This would strengthen the relation between the demand side and hours determination. Moreover, it would provide the opportunity to analyse in more detail the relation between working time and employment or unemployment. 


\section{Conclusion}

Every now and then, work-sharing returns to the policy agenda. In times of high unemployment leftwing policy makers and unions tend to ask for a reduction in working time to spread the burden of unemployment. The idea is sympathetic, but professional economists tend to be rather sceptical towards the merits of such a policy. In this thesis I have taken an intermediate position: work-sharing has pitfalls, but may also have some merits.

\subsection{Conclusions}

In the introductory chapter I presented a number of key relations between working time and other variables such as hourly productivity, employment, unemployment, GDP per capita and union involvement. The following conclusions with respect to these relations can be drawn from the thesis:

- Reductions in hours may tend to increase hourly productivity, but increases in hourly productivity - for example through technological progress - provide room for increases in wages and reductions of hours. The choice between the two depends on preferences and institutional factors, such as union power and the bargaining structure. (Chapters 2 and 6)

- When investigating the employment effects of changes in working time, one should take into account that working time will affect capital services. This reduces the scope for working-sharing. In general, however, the employment effects of reduction in hours depend on the initial length of working time. The same holds for unit costs, but there is a range of working times where employment increases, whereas profits fall. (Chapter 2)

- Overtime is unlikely to affect the employment effects of work-sharing, as structural overtime does not seem to be a predominant phenomenon in the Dutch labour market. Overtime is mainly used to cope with demand uncertainty and absenteeism. (Chapter 3)

- Shiftwork limits the employment effects of work-sharing, as shiftwork tends to increase when the workweek is reduced. Moreover, workers will have to work more at unpleasant hours. (Chapter 4)

- The employment effects of work-sharing depend strongly on the impact of reduced hours on hourly wages and annual earnings. A wide range of union models predicts that earnings will fall, whereas there is a U-shaped relation between hourly wages and annual hours. The estimated 
Dutch wage equation suggests that hourly wages were not significantly affected by hours worked during the last decades. (Chapters 5 and 7)

- Incorporating the U-shaped pattern of hourly wages in the labour market equilibrium, equilibriun unemployment exhibits the same pattern. Hence, for relatively long hours work-sharing may reduce unemployment, whereas it may increase unemployment for relatively short workweeks. (Chapter 5)

- The labour supply model does not seem to be the correct model to use when investigating changes in annual hours. Union bargaining models may be more useful, but the appropriate model depends on the institutional background. (Chapters 6 and 7)

- Unions have an incentive to bargain for work-sharing when unemployment is high. More generally, increased bargaining power for unions tends to reduce hours. (Chapter 6)

- The decline in hours during in the period 1960-1995 is not due to work-sharing, but is the result of increased wages, and thus of increased productivity. There is a large unexplained component, however. (Chapter 7)

I did not derive any conclusions with respect to GDP per capita, but this follows from the previous results. Following the decomposition in van Ark and McGuckin (1999), GPD per capita depends proportionally on hourly productivity, hours worked, the employment rate - or one minus the unemployment rate - and the participation rate. So, the direct negative impact of work-sharing on GDP per capita can be partially offset by increases in hourly productivity, increased employment, at least if initial hours are long enough, and increased participation. The size of these effects is an empirical matter.

\subsection{FUTURE WORK}

This study has a number of limitations, one may be that it is mostly theoretical. Some of the predictions of the modeis need to be tested. This is certainly true for the U-shaped relations between hours, on the one hand, and wages or unemployment, on the other hand. But one also needs better empirical models on the determinants of normal working hours. The difficulty in both cases is that standard hours do not show that large variations. A possible solution could be to use cross-country data, but unfortunately the availability of international comparable data on hours worked is limited. Alternatively, one could use pooled time-series and sectoral data, or even better, matched employeremployee data.

A major limitation of the study is that it does not deal with heterogeneity. There are a number of issues at stake here. First, individuals are not homogeneous, but they differ in their skills and productivity. This may have serious impact on the effectiveness of work-sharing policies. When the skills or productivity of unemployed workers do not match the skills and productivity of the 
employed workers, work-sharing has additional detrimental effects on unit costs and may also lead to labour shortages for certain types of labour.

Second, individuals also have different preferences. This might explain the low incidence of overtime: only workers with a low valuation for leisure may be willing to supply overtime hours. This then leads to the issue how to incorporate overtime incidence in labour demand models. Theoretical and empirical work in that direction is needed.

Another implication of heterogeneity in preferences is the occurrence of part-time labour. I fully ignored the issue, even though the Netherlands is the world champion in part-time employment. Incorporating part-time labour raises a number of interesting issues. From the labour demand side, the question is how firms deal with part-time: under what circumstances will they use part-time workers; (how) does part-time work affect the organization of work; will part-time work influence the operating time of firms, etc.? But part-time employment also influences the equilibrium of the labour market: how are wages set in an environment with part-time labour; what is the role of unions in this respect; how is unemployment affected by part-time work?

So, on the research agenda of labour economists there remain a large number of questions dealing with the future of work. 



\section{Appendices}





\section{APPENDIX A COMPARATIVE STATICS LABOUR DEMAND}

This appendix derives the comparative static elasticities of various models in Chapter 2. For future reference in Chapter 6, the production function includes technological shift parameters. Let $A_{N}\left(A_{K}\right)$ denote labour (capital) augmenting technological progress, then the production function ( 2.5$)$ becomes

$$
Q=F\left(A_{k} m(H) K, A_{N} e(H) N\right)=A_{N} e(H) N f(k),
$$

with $k \equiv \frac{A_{x} m(H) K}{A_{N} d(H) N}=e(H)^{\mathrm{x}-1} \frac{A_{K} K}{A_{N} N}$.

\section{A.1 Long-run cost minimisation}

Including the technological parameters, equation (2.7) becomes

$$
\frac{A_{K} e(H)^{k-1}}{A_{N}} \frac{f^{\prime}(k)}{f(k)-k f^{\prime}(k)}=\frac{R}{V+W H} .
$$

To derive the comparative statics totally differentiate (A.1) and (A.2) to obtain

$\left[\begin{array}{cc}-\frac{1}{\sigma} & \frac{1}{\sigma} \\ \eta^{f} & 1-\eta^{f}\end{array}\right]\left[\begin{array}{l}d \ln K \\ d \ln N\end{array}\right]=\left[\begin{array}{ccccccc}0 & -\frac{1-0}{0} & \frac{1-0}{0} & 1 & -\varphi_{V} & -\left(1-\varphi_{V}\right) & -\eta^{e} \frac{(1-\kappa)(1-0)}{0}-\left(1-\varphi_{V}\right) \\ 1 & -\left(1-\eta^{f}\right) & -\eta^{f} & 0 & 0 & 0 & -\eta^{e}\left[1-(1-\kappa) \eta^{\prime}\right.\end{array}\right]\left[\begin{array}{l}d \ln Q \\ d \ln A_{N} \\ d \ln A_{K} \\ d \ln R \\ d \ln V \\ d \ln W \\ d \ln H\end{array}\right]$

or in short-hand notation $B d z=G d x$, where the endogenous variables are $z=(\ln K, \ln N)^{\prime}$ and the exogenous variables are $x=\left(\ln Q, \ln A_{N}, \ln A_{K}, \ln R, \ln V, \ln W, \ln H\right)^{\prime}$. The comparative static effects are easily obtained considering the sign distribution of the matrix $B^{-1} G$, where

$$
B^{-1}=\left[\begin{array}{cc}
-\sigma\left(1-\eta^{f}\right) & 1 \\
\sigma \eta^{f} & 1
\end{array}\right] .
$$




\section{A.2 Demand for hours}

Including the technological parameters does not change the first-order condition (2.10). To derive the properties of optimal hours, differentiate equations (A.2) and (2.10) as a function of $k$ and $H$. This yields

$\left[\begin{array}{c}\frac{-\frac{1}{\sigma}}{1-\eta^{f}} \\ -\frac{1-\sigma}{\sigma} \frac{\kappa \eta^{f}}{1-(1-\kappa) \eta^{f}}-\left(\frac{1}{\eta^{e}}-\frac{1-(1-\kappa) \eta^{f}}{1-\eta^{f}}\right) \eta^{e}\end{array}\right]\left[\begin{array}{c}d \ln k \\ d \ln H\end{array}\right]=\left[\begin{array}{ccc}1 & -\varphi_{V} & -\left(1-\varphi_{V}\right) \\ 0 & -\varphi_{V} & \varphi_{V}\end{array}\right]\left[\begin{array}{c}d \ln R A_{N} / A_{K} \\ d \ln V \\ d \ln W\end{array}\right]$,

where $\eta^{e} \equiv \frac{\eta^{e}}{1+\gamma_{H}}$. The second-order condition for a minimum is

$$
\eta^{e}<\eta_{H} \equiv \frac{\left[1-(1-\kappa) \eta^{f}\right]\left(1-\eta^{f}\right)}{\left[1-(1-\kappa) \eta^{f}\right]^{2}-(1-\sigma) \kappa^{2} \eta^{f}} .
$$

Let $\Lambda_{H} \equiv \frac{1}{\eta^{\prime}}-\frac{1}{\eta_{H}}>0$, then the inverse of the left-hand side matrix in (A.4) is

$$
-\frac{\sigma}{\eta^{e} \Lambda_{H}}\left[\begin{array}{cc}
\left(\frac{1}{\eta^{e}}-\frac{1-(1-\kappa) \eta^{f}}{1-\eta^{f}}\right) \eta^{e} & \frac{\kappa \eta^{e}}{1-\eta^{f}} \\
-\frac{1-\sigma}{\sigma} \frac{\kappa \eta^{f}}{1-(1-\kappa) \eta^{f}} & \frac{1}{\sigma}
\end{array}\right]
$$

which can be used to derive the comparative statics of hours demand $H^{d}$.

\section{A.3 Profit maximisation}

Including the technology parameters, the first-order condition for profit maximisation (2.15) should be replaced by

$$
v P D^{1-v} e(H)^{v} A_{N}^{v} N^{v-1} f(k)^{v-1}\left[f(k)-k f^{\prime}(k)\right]=V+W H .
$$

Differentiating the first-order conditions (A.2) and (A.5) again yields $B d z=G d x$ in short-hand notation, where the exogenous variables are $x=\left(\ln P, \ln D, \ln A_{N}, \ln A_{K}, \ln R, \ln V, \ln W, \ln H\right)^{\prime}$. The matrices $B$ and $G$ are now given by

$$
B=\left[\begin{array}{ll}
-\frac{1}{\sigma} & \frac{1}{\sigma} \\
-\frac{\tau-\sigma}{\sigma \tau} \eta^{f} & \frac{\tau \eta^{f}+\sigma\left(1-\eta^{f}\right)}{\sigma \tau}
\end{array}\right]
$$


and

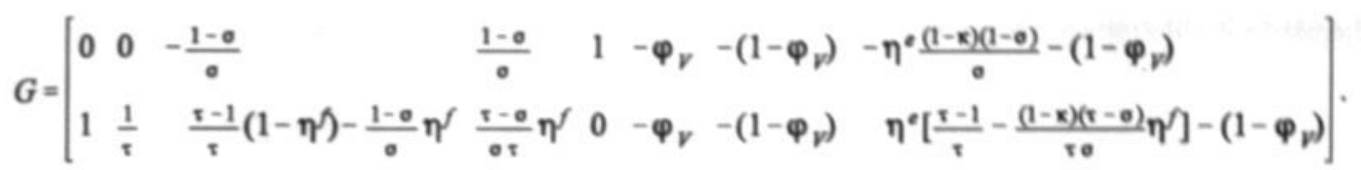

The long-run comparative static effects are obtained considering the sign distribution of the matrix $B^{-1} G$, where

$$
B^{-1}=\left[\begin{array}{ll}
-\left[\tau \eta^{f}+\sigma\left(1-\eta^{\gamma}\right)\right] & \tau \\
-(\tau-\sigma) \eta^{f} & \tau
\end{array}\right] .
$$




\section{APPENDIX B CRITICAL HOURS}

The elasticity of employment with respect to working time is given by $\boldsymbol{\varepsilon}_{N H}=\boldsymbol{\varepsilon}_{N H Y}+\boldsymbol{\varepsilon}_{N Y}$, where

$$
\varepsilon_{N H Y}=\eta^{e}\left[\tau-1-(1-\kappa)(\tau-\sigma) \eta^{\prime}\right] \text { and } \varepsilon_{N Y}=-\left(1-\varphi_{V}\right)\left[\tau\left(1-\eta^{f}\right)+\sigma \eta^{f}\right]<0 \text {. }
$$

As long as $H \leq H_{\max }$ the sign of $\varepsilon_{N H Y}$ depends on $\tau$ and $\kappa$. Define $\tau_{0} \equiv \frac{1-\sigma \eta^{f}}{1-\eta^{f}} \geq 1$, then $\varepsilon_{N H Y Y} \geq 0$ for $\tau$ $z \tau_{0}$. Moreover, for $\tau<\tau_{0}$ the sign depends on the value of $\kappa$. Let $\kappa_{0} \equiv \frac{\left(\tau_{0}-\tau\right)\left(1-\eta^{\gamma}\right)}{(\tau-\sigma) \eta^{f}}<1 / \tau<1$, then $\boldsymbol{\varepsilon}_{N H Y}$ can be written as $\boldsymbol{\varepsilon}_{N H Y}=\left(\boldsymbol{\kappa}-\boldsymbol{\kappa}_{0}\right)(\tau-\boldsymbol{\sigma}) \eta$. So $\varepsilon_{N H Y} \geq 0$ for $\kappa \geq \boldsymbol{\kappa}_{0}$. So $\boldsymbol{\varepsilon}_{N H Y}$ is only negative when $\tau<\tau_{0}$ and $\kappa<\boldsymbol{K}_{0}$. This Appendix further concentrates on the case where $\boldsymbol{\varepsilon}_{N H Y}>0$, corresponding to the intervals $\left\{\tau>\tau_{0}\right\}$ or $\left\{\tau \leq \tau_{0} \wedge \kappa>\kappa_{0}\right\}$.

Taking limits, notice that $\lim _{H \vdash 0} \boldsymbol{\varepsilon}_{N H}=\varepsilon_{N H Y}>0$ as $\varphi_{V}=1$ in that case. Moreover, $\lim _{H \dagger H_{\operatorname{ma}}} \boldsymbol{\varepsilon}_{N H}=\varepsilon_{N Y}<0$, as $\eta^{e}=0$ in that case. So when the elasticity $\varepsilon_{N H}$ is continuous in $H$, there is at least one positive root $H_{n} \in\left(0, H_{\max }\right)$ to the equation $\varepsilon_{N H}=0$. Moreover, $0<H_{n}<H^{d}$ as

$$
\left.\varepsilon_{N H}\right|_{H=H^{d}}=-\frac{1-(1-\kappa \boldsymbol{\sigma}) \eta^{f}}{1-\eta^{f}} \eta^{e}<0 .
$$

To obtain the characteristics of $H_{n}$ (log-)differentiate the following implicit equation for $H_{n}$

$$
\eta^{e}[\tau-1-(1-\kappa)(\tau-\sigma) \eta\}^{\prime}=\left(1-\varphi_{V}\right)\left[\tau\left(1-\eta{ }^{\prime}\right)+\sigma \eta^{\prime}\right]
$$

After rearranging this yields

$$
-\gamma_{H} d \ln H_{n}=\varphi_{V} d \ln Y+\frac{(\tau \kappa-1)(1-\sigma)\left(1-\eta^{f}\right)}{\left[\tau\left(1-\eta^{\dagger}\right)+\sigma \eta^{\dagger}\right]\left(\kappa-\kappa_{0}\right)}\left[\left(1-\varphi_{V}\right) d \ln Y-(1-\kappa) \eta^{e} d \ln H_{n}\right] .
$$

Using the identity $Y=W H$ and noting that $\left(1-\varphi_{V}\right)-\left.(1-\kappa) \eta^{e}\right|_{H=H_{*}}=\frac{(\tau \kappa-1) \eta^{e}}{\tau\left(1-\eta^{f}\right)+\sigma \eta^{f}}$, this can be rewritten as

$$
-\left[\gamma_{H}+\varphi_{V}+\frac{(\tau \kappa-1)^{2}(1-\sigma)\left(1-\eta^{\prime}\right) \eta^{e}}{\left[\tau\left(1-\eta^{\prime}\right)+\sigma \eta^{\prime}\right]^{2}\left(\kappa-\kappa_{0}\right)}\right] d \ln H_{n}=\left[\varphi_{V}+\left(1-\varphi_{V}\right) \frac{(\tau \kappa-1)(1-\sigma)\left(1-\eta^{\prime}\right)}{\left[\tau\left(1-\eta^{\prime}\right)+\sigma \eta^{\prime}\right]\left(\kappa-\kappa_{0}\right)}\right] d \ln W .
$$


As $\sigma \leq 1$ and $\gamma_{H}>0$, the sign of the expression in brackets on the left-hand side is unambiguously positive. The expression in brackets on the right-hand side is positive for $\sigma=1$, or for $\sigma<1$ and $K \geq$ $1 / \tau$, and for $K<K_{0}$, but the sign of the right-hand side is ambiguous for $K_{0}<K<1 / \tau$ and $\sigma<1$. In that case it is positive as long as

$$
\varphi_{V}>\frac{(1-\tau \kappa)(1-\sigma)\left(1-\eta^{\prime}\right)}{\left[\tau\left(1-\eta^{\prime}\right)+\sigma \eta^{\prime}\right]\left(\kappa-\kappa_{0}\right)+(1-\tau \kappa)(1-\sigma)\left(1-\eta^{\prime}\right)},
$$

which essentially gives a lowerbound on the wage $W$.

In conclusion, critical working time $H_{m}$ as implicitly defined by equation (B.1), is decreasing in wages $W$, unless the following conditions hold jointly $\sigma<1, \kappa_{0}<K<1 / \tau$ and $W$ relatively high. The latter case may be relevant for the labour services specification $K=0$.

Finally, consider the two limiting cases. For $W=0$ we have $\varphi_{V}=1$ and equation (B.1) implies $\eta^{*}=0$, so $H_{n}=H_{\operatorname{mar}}$. For $W \rightarrow \infty$ we have $\varphi_{v}=0$ and equation (B.1) implies $\eta^{\prime}=\frac{\tau(1-\eta) \cdot \bullet \eta^{\prime}}{\tau-1-(1-\kappa)(\tau-0) \eta^{\prime}}$. However, the share of capital costs $\eta^{\prime}$ depends negatively on hourly wages (at least for $\sigma<1$ ). For a CES production function we then have $\lim _{W \rightarrow \infty} \eta^{f}=0$, and according to (B.1) this implies that $\lim _{W \rightarrow \infty} \eta^{e}=$ $\tau /(\tau-1)>1$. This ensures that $\lim _{\mathbb{W} \rightarrow \infty} H_{n}<H_{p}$

Figure B.1 captures these characteristics of critical hours $H_{n}$. Panel (a) illustrates the monotonous case, for example for $\kappa=1$, whereas panel (b) may be relevant for the labour services specification $\kappa$ $=0$, as long as $\sigma<1$. If $H_{n}=g(W)$ is a monotonous downward sloping function of wages $W$, as in panel (a), the condition $H \gtrless H_{n}$ can be rewritten as $W \gtrless W_{n}$, where $W_{n}=g^{-1}(H)$ is the inverse downward sloping function of hours $H$. Panel (a) of the figure illustrates the critical values $H_{n}$ and $W_{n}$ for the allocation $E_{0}=\left(H_{0}, W_{0}\right)$. Working time reduction starting from $E_{0}$ increases employment as $H_{0}$ $>H_{n}$ or equivalently $W_{0}>W_{n}$ For panel (b) $W_{n}$ is not uniquely defined for low values of $H$. 


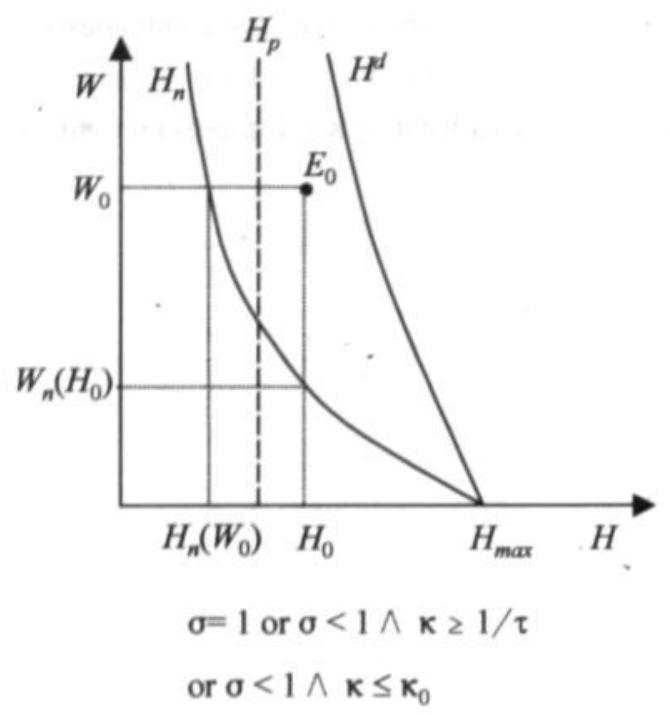

(a)

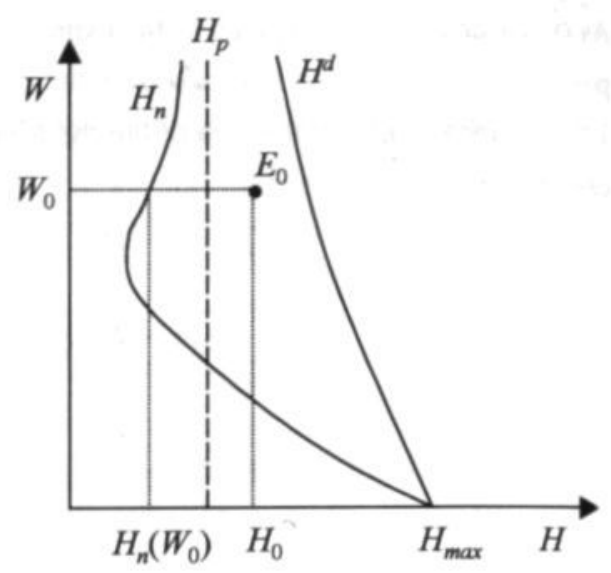

$\boldsymbol{\sigma}<1 \wedge \boldsymbol{\kappa}_{0}<\kappa<1 / \tau$

Figure B.1 Critical hours 


\section{APPENDIX C CES-APPROXIMATIONS}

In this appendix I derive the approximate CES-solutions for the expected value for the minimum and maximum of two lognormally distributed variables $X_{1}$ and $X_{2}$. Let the expected values be $Y_{1}=E\left(X_{i}\right)$, for $i=1,2$ and define $Y=E\left[\min \left(X_{1}, X_{2}\right)\right]$ and $Z=E\left[\max \left(X_{1}, X_{2}\right)\right]$, respectively.

First consider $Y$. In their analysis of disequilibrium models, Kooiman (1986) and Lambert (1988) among others, have shown that the following expression holds for the expected value of the minimum of two lognormally distributed variables

$$
Y=Y_{1} \Phi_{1}+Y_{2} \Phi_{2}<\min \left(Y_{1}, Y_{2}\right)
$$

with

$$
\Phi_{1}=\Phi\left\{-\left(y+1 / 2 \sigma^{2}\right) / \sigma\right\} \text { and } \Phi_{2}=\Phi\left\{\left(y-1 / 2 \sigma^{2}\right) / \sigma\right\} \text {, }
$$

where $\Phi(\cdot)$ denotes the cumulative standard normal distribution function, $y$ is the log-difference of the expected values $y=\ln \left(Y_{1} / Y_{2}\right)$ and $\boldsymbol{\sigma}^{2}$ is the variance of the $\log$-difference $x=\ln \left(X_{1} / X_{2}\right)$.

Lambert (1988) and Sneessens (1983) independently showed that (C.1) can be approximated quite satisfactory by the CES-function

$$
Y \approx\left(Y_{1}^{-1 / \tau}+Y_{2}^{-1 / \tau}\right)^{-\tau} . \quad 0<\tau
$$

Although both authors use different approximation methods, the parameter $\tau$ is a non-linear increasing function of the standard deviation $\sigma$ in either case. I will roughly follow Lambert's derivation, see Lambert (1988, Appendix A) for more details.

Differentiating (C.1), using the properties of the cumulative standard normal distribution function and the definition of $y$, yields $\partial Y / \partial Y_{1}=\Phi_{1}$. Rearranging in log's, this gives ${ }^{1}$

$$
P_{y} \equiv \frac{\partial \ln Y}{\partial \ln Y_{1}}=\frac{Y_{1} \Phi_{1}}{Y_{1} \Phi_{1}+Y_{2} \Phi_{2}}=\frac{1}{1+\frac{Y_{2}}{Y_{1}} \frac{\Phi_{2}}{\Phi_{1}}}=\frac{1}{1+e^{-y} \frac{\Phi_{2}}{\Phi_{1}}} \equiv p(y ; \sigma) .
$$

Thus $P_{y}$ is a decreasing function of $y=\ln \left(Y_{1} / Y_{2}\right)$, with $\sigma$ as the sole parameter. As $\lim _{y \rightarrow-} P_{y}=1$, $\lim _{y \rightarrow \infty} P_{y}=0$ and $P_{y}=1 / 2$ for $y=0$, Lambert approximates the function $p(y ; \sigma)$ by the logistic

$$
p(y ; \sigma) \approx \frac{1}{1+e^{y / \tau}} .
$$

1 In the aggregation by integration approach of micro-markets in Lambert (1988), $P_{y}$ has a clear interpretation: it is the weighted proportion of markets with $X_{1}<X_{2}$; a variable that might correspond to business survey data on proportions of rationed firms. 
The parameter $\tau$ is subsequently determined by equating the derivatives of (C.3) and (C.4), evaluated at $y=0$. This yields

$$
\tau(\sigma)=\frac{\sigma / 2 \Phi(-\sigma / 2)}{\phi(-\sigma / 2)-\sigma / 2 \Phi(-\sigma / 2)},
$$

where $\phi(\cdot)$ is the standard normal density function. As the denominator can be shown to be positive, this equation implies $\tau(\sigma) \geq 0$ for $\sigma \geq 0$ : A first-order Taylor expansion around $\sigma=0$ yields:

$$
\tau \approx 1 / 2 \Phi(0) / \phi(0) \sigma=\sqrt{\pi / 8} \sigma \approx 0.6 \sigma
$$

Finally, to obtain the CES-specification (C.2), the approximation (C.4) of $P_{y}$ has to be integrated over $\ln Y_{1}{ }^{2}{ }^{2}$ The integration constant is found comparing the limiting properties of (C.1) and (C.2), see again Lambert (1988).

Second, consider the expected value of the maximum $Z$. As

$$
\max \left(X_{1}, X_{2}\right)=X_{1}+X_{2}-\min \left(X_{1}, X_{2}\right),
$$

the expected value satisfies $Z=Y_{1}+Y_{2}-Y$, or using (C.1),

$$
Z=Y_{1}\left(1-\Phi_{1}\right)+Y_{2}\left(1-\Phi_{2}\right)
$$

Differentiating the logarithm of (C.6), yields

$$
P_{z} \equiv \frac{\partial \ln Z}{\partial \ln Y_{1}}=\frac{Y_{1}\left(1-\Phi_{1}\right)}{Y_{1}\left(1-\Phi_{1}\right)+Y_{2}\left(1-\Phi_{2}\right)}=\frac{1}{1+\frac{Y_{2}}{Y_{1}} \frac{1-\Phi_{2}}{1-\Phi_{1}}}
$$

Comparing $P_{z}$ with $P_{y}$ in (C.3) and using the property that $1-\Phi(x)=\Phi(-x)$, this implies $P_{z}=p(y ;-\sigma)$. Hence, to obtain a simple approximation, the same procedure as above for $Y$ can be used, only $\sigma$ should be replaced by $-\sigma$. Thus, defining the parameter $\xi=-\tau(-\sigma) \approx 0.6 \sigma \approx \tau$, equation (C.6) can be approximated by the CES-function

$$
Z \approx\left(Y_{1}^{1 / \xi}+Y_{2}^{1 / \hbar}\right)^{\xi} . \quad 0<\xi<1
$$

The upperbound for $\xi$ follows from the non-linear specification in (C.5), as $\lim \tau(-\sigma)=-1$.

2 As is easily checked, log-differentiating (C.2) indeed yields (C.4). 


\section{APPENDIX D A LABOUR AGGREGATOR FUNCTION WITH TEAMWORK}

Consider the following CES aggregator function for labour services $L$

$$
L=N\left[\sum_{n=1}^{N} \frac{1}{N} H_{n}^{\gamma \tau}\right]^{1 / \tau} . \quad 0<\tau \leq 1,0<\gamma \leq 1
$$

Dividing by $N$ the function (D.1) is a generalised average of efficiency hours $e\left(H_{n}\right)=H_{n}^{\gamma}$. Let $\ell=L / N$ denote the average labour services per worker. For $\tau=1, \ell$ is the arithmetic mean, the limit for $\tau \rightarrow 0$ would yield the geometric mean. However, to allow for zero hours, $\tau$ is restricted to be positive.

The partial derivatives of labour services $L$ are

$$
\begin{gathered}
\frac{\partial L}{\partial H_{n}}=\gamma \ell^{1-\tau} H_{n}^{\gamma \tau-1}>0, \\
\frac{\partial^{2} L}{\partial H_{n}^{2}}=-\gamma \ell^{1-2 \tau} H_{n}^{\gamma \tau-2}\left[(1-\gamma \tau) \sum_{m=n}^{N} \frac{1}{N} H_{m}^{\gamma \tau}+(1-\gamma) \frac{1}{N} H_{n}^{\gamma \tau}\right] \leq 0, \\
\frac{\partial^{2} L}{\partial H_{n} \partial H_{m}}=\gamma^{2}(1-\tau) \ell^{1-2 \tau} H_{n}^{\gamma \tau-1} H_{m}^{\gamma \tau-1} \geq 0 . \quad n \neq m
\end{gathered}
$$

Longer hours obviously increase labour services, see (D.2), though according to (D.3) at a decreasing rate due to teamwork $(\tau<1)$ and decreasing returns to hours $(\gamma<1)$. The cross partial derivatives (D.4) illustrate the importance of teamwork: unless individual hours are perfect substitutes $(\tau=1)$, the productivity of worker $n$ is enhanced by the working hours of worker $m$. This is a key characteristic of teamwork, see Alchian and Demsetz (1972).

For large $N$ the generalised average in (D.1) can be approximated by its expectation, yielding the approximate expression

$$
\ell=\frac{L}{N} \approx\left[E\left(H_{n}^{\gamma \tau}\right)\right]^{1 / \tau} \text {. }
$$

As $H_{n}^{\alpha}$ is concave for $\alpha<1$, Jensen's inequality illustrates that $\ell^{\tau} \approx E\left(H_{n}{ }^{\gamma \tau}\right) \leq E\left(H_{n}\right)^{\gamma \tau}$, so $\ell \leq E\left(H_{n}\right)^{\gamma}$. For example, ignoring absenteeism, suppose that working hours are lognormally distributed with mean $\mu$ and variance $\sigma_{H}^{2}$. Expected hours are $H=E\left(H_{n}\right)=\mathrm{e}^{\mu+\frac{1}{2} \sigma_{H}^{2}}$ and $E\left(H_{n}^{\alpha}\right)=\mathrm{e}^{\alpha \mu+\frac{1}{2} \alpha^{2} \sigma_{H}{ }^{2}}=$ $E\left(H_{n}\right)^{\alpha} \mathrm{e}^{-\frac{1}{2} \alpha(1-\alpha) \sigma_{H}^{2}}$. Applying this to (D.5) yields

$$
L=N H^{\gamma} \mathrm{e}^{-\frac{1}{2} \gamma^{2}(1-\tau) \sigma_{H}^{2}}
$$


The variability of hours combined with teamwork effects, reduces labour services below the certainty equivalent level. Moreover, at given expected hours $H$, a higher variance of log hours reduces labour services through teamwork effects.

To allow for absenteeism, assume that attendance $A_{n}$ of each worker is given by a Bernoulli distribution with mean $0<A \leq 1$. While attending, hours worked $H_{n}$ are lognormally distributed as above, whereas hours worked are zero when absent. As a result labour services (D.6) generalise to

$$
L=N A^{\frac{1}{\gamma}} H^{\gamma} \mathrm{e}^{-\frac{1}{2} \gamma^{2}(1-\tau) \sigma_{H}^{2}} .
$$

Increased attendance $A$ raises labour services $L$ more than proportionally, at least if teamwork is relevant $(\tau<1)$. 


\section{APPENDIX E THE COMPENSATION SCHEDULE}

\section{E.1 Spot market}

Let the utility function of a (representative) worker be $U(Y, L)$, where $Y$ is income (and consumption) and $L$ is leisure. The utility function has the usual properties of positive marginal utilities. Due to risk aversion these marginal utilities are declining. Moreover leisure is assumed to be non-inferior. Hence the partial derivatives satisfy

$$
0<U_{n} U_{L} ; U_{r} U_{L L}<0 \text {; and } U_{r L}-\frac{U_{L}}{U_{Y}} U_{r \gamma}>0 \text {. }
$$

Setting the price of consumption equal to 1, the budget constraint is $Y=B+W H$, where $W$ is the hourly wage rate, $H$ hours worked and $B$ non-wage income. With $T$ hours per period available, leisure is simply given by $L=T-H$.

Individual labour supply $H$ is determined by the equality between the hourly wage rate $W$ and the marginal rate of substitution

$$
\frac{U_{L}}{U_{Y}}=W,
$$

with the second-order condition for an interior solution

$$
\Delta_{U} \equiv\left(\frac{U_{L}}{U_{Y}}\right)^{2} U_{Y Y}-2 \frac{U_{L}}{U_{Y}} U_{Y L}+U_{L L}<0 .
$$

First, suppose the compensation schedule $o(\tilde{H})$ is determined in such a way that the utility of workers is always equal to some outside option, the reservation utility $U^{r}$. Thus the compensation schedule $o(\tilde{H})$ is implicitly defined as

$$
U\left(B+W H^{c} o(\tilde{H}), T-H^{c} \tilde{H}\right)=U^{r} .
$$

By appropriate choice of the wage rate $W$, the compensation schedule may be normalised as $o(1)=1$. Hence changes in the outside option $U^{r}$, the non-wage income $B$ or standard hours $H^{*}$ will essentially be reflected in the wage rate $W$.

Taking derivatives of (E.3) with respect to $\tilde{H}$, the compensation schedule satisfies

$$
o^{\prime}(\tilde{H})=\frac{U_{L}}{W U_{Y}}>0
$$




$$
o^{\prime \prime}(\tilde{H})=-\frac{H^{c}}{W U_{Y}} \Delta_{U}>0 .
$$

So the compensation schedule is an increasing and convex function of (relative) working time.

Moreover, the assumption $o^{\prime}(1)=1$ corresponds to the assumption that standard hours $H^{*}$ are equal to the optimal level of hours supplied $H$, since in that case the wage rate equals the marginal rate of substitution, see equation (E.1).

Combining the above expressions for the derivatives, we also obtain

$$
\mu \equiv \frac{\tilde{H} o^{\prime \prime}(\tilde{H})}{o^{\prime}(\tilde{H})}=-\frac{H \Delta_{U}}{U_{L}}=\frac{1}{\epsilon_{H^{\varkappa} W}}>0,
$$

where $\epsilon_{H^{* W}}$ is the wage elasticity of compensated labour supply.

\section{E.2 Implicit contracts}

Second, consider the implicit contract theory with symmetric information and risk-neutral firms. As is well known, see e.g. the surveys by Rosen (1985) and Stiglitz (1986), the optimal contract with symmetric information satisfies two conditions: productive efficiency and efficient risk-sharing. Productive efficiency is obtained by the equality between marginal revenue of hours, say $R_{H}$, and the marginal rate of substitution between leisure and consumption $U_{L} / U_{r}$, whereas efficient risk-sharing equates the marginal utility of consumption $U_{Y}$ in all states of the world. Hence the compensation schedule $o(\tilde{H})$ seems now implicitly defined by

$$
U_{Y}\left(B+W H^{c} o(\tilde{H}), T-H^{c} \tilde{H}\right)=1 / \lambda_{U},
$$

where $\lambda_{U}>0$ is the shadow price of the reservation utility $U$. Without loss of generality, the normalisation $o(1)=1$ may once again be imposed. Taking derivatives of (E.7) with respect to $\tilde{H}$, the compensation schedule now should satisfy

$$
o^{\prime}(\tilde{H})=\frac{U_{Y L}}{W U_{Y Y}} \leq \frac{U_{L}}{W U_{Y}} .
$$

The upperbound is due to the assumption that leisure is non-inferior, and the equality only holds if there is no income effect on leisure. The assumption $o^{\prime}(1)=1$ now indicates that the marginal rate of substitution exceeds the wage rate at standard hours $H$, implying $H \leq H$. Hence the worker isoveremployed at standard hours.

Given the constant marginal utility compensation schedule (E.7), utility $U$ decreases if working time is increased, as 


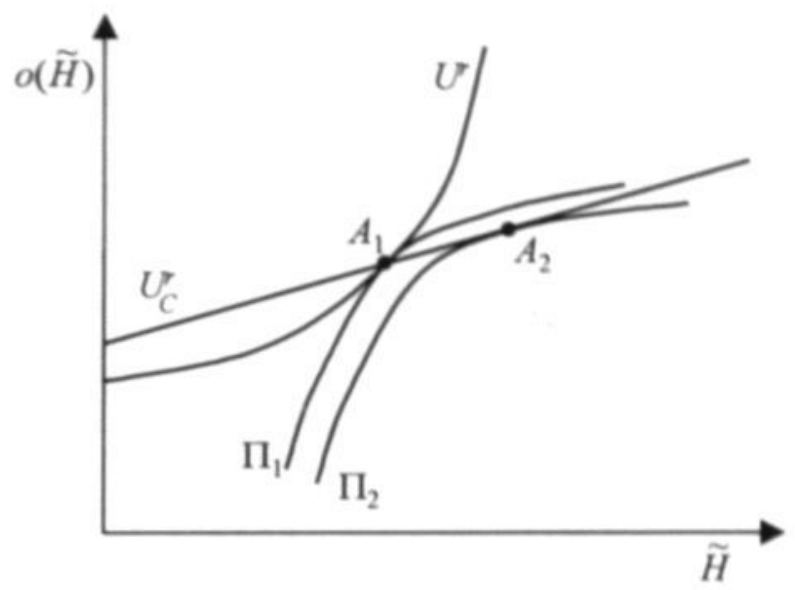

Figure E.1 Constant (marginal) utility compensation schedules

$$
\frac{\mathrm{d} U}{\mathrm{~d} H}=W_{o}^{\prime}(\tilde{H}) U_{Y}-U_{L}=\frac{U_{Y} U_{r L}}{U_{r \gamma}}-U_{L} \leq 0 .
$$

This is the familiar overinsurance result of (symmetric) implicit contract models with normal leisure. Figure E.1 illustrates the problem in the compensation-working time space (normalizing on $\mathrm{WH}^{\mathrm{c}}=1$ ). The curve labelled $U^{r}$ is an indifference curve, and $U_{Y}^{r}$ is a constant marginal utility locus. Increasing working time along $U_{Y}^{r}$ reduces utility $U$ when leisure is a normal good. Therefore, $U_{Y}^{r}$ has a smaller slope than $U^{r}$. More generally, the sign of the slope of the compensation schedule (E.7) depends on $U_{Y L}:$ it is increasing as drawn in the figure if (and only if) consumption and leisure are Edgeworth substitutes (i.e. $\left.U_{Y L}<0\right)$. As the curvature $o^{\prime \prime}(\tilde{H})$ of the compensation schedule depends on the thirdorder derivatives of the utility function, no sensible inference seems possible in this respect.

Figure E.1 also depicts an iso-profit curve $\Pi_{1}$ for a given state of the world (e.g. the demand for goods). The slope of the iso-profit curve is given by the marginal revenue of hours $R_{H l}$. As stated before, productive efficiency requires the iso-profit curve to be tangent to the indifference curve. Therefore, the implicit contract with symmetric information stipulates allocation $A_{1}$. However, given the constant marginal utility compensation schedule (E.7), the firm could increase profits to $\Pi_{2}$ by moving to allocation $A_{2}$, where marginal revenue of hours equals marginal cost. As the iso-profit curve $\Pi_{2}$ corresponds to a better state of the world, the firm has an incentive to lie in bad states. However, this is impossible in the symmetric information case.

The obvious third alternative to consider is implicit contract theory with asymmetric information. The predominant assumption is that the firm has private information on the state of the world. As workers recognise that the firm has an incentive to overstate the state of the world, the first-best contract (E.7) 


\section{APPENDIX F COMPARATIVE STATICS OVERTIME MODELS}

\section{F.1 Certainty}

Using the shorthand $r \equiv R /\left(A W H^{*}\right)$ and $v \equiv[V+\rho W H(1-A)]\left(A W H^{*}\right)$, log-differentiate equations (3.7) and $(3.8 \mathrm{a})$ to obtain

$$
\begin{aligned}
& {\left[\begin{array}{cc}
-\frac{1}{\sigma} & \frac{\gamma}{1-\eta^{f}} \\
-\frac{1-\sigma}{\sigma} \eta^{f} & -\frac{(1+\mu)\left(1-\eta^{f}\right)-\gamma}{1-\eta^{f}}
\end{array}\right]\left[\begin{array}{l}
d \ln k \\
d \ln \tilde{H}
\end{array}\right]=} \\
& {\left[\begin{array}{cccc}
1-\frac{v}{v+o(\tilde{H})} & -\frac{\tilde{H}^{1 \cdot \mu}-1}{(v+o(\tilde{H}))(1+\mu)} & -\frac{\partial o(\tilde{H}) / \partial \mu}{v+o(\tilde{H})} \\
0-\frac{v}{v+o(\tilde{H})} & \frac{1}{1+\theta}-\frac{\tilde{H}^{1 \cdot \mu}-1}{(v+o(\tilde{H}))(1+\mu)} & \mathbf{n} \hat{H}-\frac{\partial o(\tilde{H}) / \partial \mu}{v+o(\tilde{H})}
\end{array}\right]\left[\begin{array}{c}
d \mathbf{l} r \\
d \mathbf{l} v \\
d \boldsymbol{\theta} \\
d \mu
\end{array}\right] .}
\end{aligned}
$$

It is easily checked that $\partial o(\tilde{H}) / \partial \mu \geq 0$, where the equality sign only holds for $\tilde{H}=1$.

The second-order condition for a minimum is that the determinant of the left-hand side matrix is positive, implying

$$
\gamma<\gamma^{*} \equiv \frac{(1+\mu)\left(1-\eta^{f}\right)}{1-(1-\sigma) \eta^{f}}
$$

The inverse of the left-hand side matrix in (F.1) is

$$
\frac{-1}{\left(\gamma^{*}-\gamma\right)\left[1-(1-\sigma) \eta^{f}\right]}\left[\begin{array}{cc}
{\left[(1+\mu)\left(1-\eta^{f}\right)-\gamma\right] \sigma} & \gamma \sigma \\
-(1-\sigma) \eta^{f}\left(1-\eta^{f}\right) & 1-\eta^{f}
\end{array}\right],
$$

which can be used to derive the comparative statics, such as

$$
\begin{gathered}
\frac{\partial \ln \tilde{H}}{\partial \ln v}=\frac{v\left(1-\eta^{f}\right)}{(v+o(\tilde{H}))\left(\gamma^{*}-\gamma\right)}>0, \frac{\partial \ln \tilde{H}}{\partial \ln r}=\frac{(1-\sigma) \eta^{f}(1-\eta f)}{\left(\gamma^{*}-\gamma\right)\left[1-(1-\sigma) \eta^{f}\right]} \geq 0, \\
\frac{\partial \ln \tilde{H}}{\partial \theta}=-\frac{\left(\gamma^{*}-\gamma\right)+\gamma \tilde{H}^{-(1+\mu)}}{\left(\gamma^{*}-\gamma\right)(1+\mu)(1+\theta)}<0 \text { and } \\
\frac{\partial \ln \tilde{H}}{\partial \mu}=\frac{-1}{\left(\gamma^{*}-\gamma\right)(1+\mu)}\left[\left(\gamma^{*}-\gamma\right) \ln \tilde{H}+\gamma \frac{\tilde{H}^{(1+\mu)}-1}{(1+\mu) \tilde{H}^{1+\mu}}\right] \geqslant 0 \text { for } \tilde{H} \lessgtr 1 .
\end{gathered}
$$




\section{APPENDIX F COMPARATIVE STATICS OVERTIME MODELS}

\section{F.1 Certainty}

Using the shorthand $r \equiv R /(A W H)$ and $v \equiv\left[V+\rho W H^{*}(1-A)\right]\left(A W H^{*}\right)$, log-differentiate equations (3.7) and $(3.8 \mathrm{a})$ to obtain

$$
\begin{aligned}
& {\left[\begin{array}{cc}
-\frac{1}{\sigma} & \frac{\gamma}{1-\eta^{f}} \\
-\frac{1-\sigma}{\sigma} \eta^{f} & -\frac{(1+\mu)\left(1-\eta^{f}\right)-\gamma}{1-\eta^{f}}
\end{array}\right]\left[\begin{array}{l}
d \ln k \\
d \ln \tilde{H}
\end{array}\right]=} \\
& {\left[\begin{array}{cccc}
1-\frac{v}{v+o(\tilde{H})} & -\frac{\tilde{H}^{2 * \mu}-1}{(v+o(\tilde{H}))(1+\mu)} & -\frac{\partial o(\tilde{H}) / \partial \mu}{v+o(\tilde{H})} \\
0-\frac{v}{v+o(\tilde{H})} & \frac{1}{1+\theta}-\frac{\tilde{H}^{1 * \mu}-1}{(v+o(\tilde{H}))(1+\mu)} & \mathbf{n} \tilde{H}-\frac{\partial o(\tilde{H}) / \partial \mu}{v+o(\tilde{H})}
\end{array}\right]\left[\begin{array}{c}
d \mathbf{l n} r \\
d \mathbf{l n} v \\
d \theta \\
d \mu
\end{array}\right] .}
\end{aligned}
$$

It is easily checked that $\partial o(\tilde{H}) / \partial \mu \geq 0$, where the equality sign only holds for $\tilde{H}=1$.

The second-order condition for a minimum is that the determinant of the left-hand side matrix is positive, implying

$$
\gamma<\gamma^{*} \equiv \frac{(1+\mu)\left(1-\eta^{f}\right)}{1-(1-\sigma) \eta^{f}}
$$

The inverse of the left-hand side matrix in (F.1) is

$$
\frac{-1}{\left(\gamma^{*}-\gamma\right)\left[1-(1-\sigma) \eta^{f}\right]}\left[\begin{array}{cc}
{\left[(1+\mu)\left(1-\eta^{f}\right)-\gamma\right] \sigma} & \gamma \sigma \\
-(1-\sigma) \eta^{f}\left(1-\eta^{f}\right) & 1-\eta^{f}
\end{array}\right],
$$

which can be used to derive the comparative statics, such as

$$
\begin{gathered}
\frac{\partial \ln \tilde{H}}{\partial \ln v}=\frac{v\left(1-\eta^{f}\right)}{(v+o(\tilde{H}))\left(\gamma^{*}-\gamma\right)}>0, \frac{\partial \ln \tilde{H}}{\partial \ln r}=\frac{(1-\sigma) \eta^{f}(1-\eta f)}{\left(\gamma^{*}-\gamma\right)\left[1-(1-\sigma) \eta^{f}\right]} \geqslant 0, \\
\frac{\partial \ln \tilde{H}}{\partial \theta}=-\frac{\left(\gamma^{*}-\gamma\right)+\gamma \tilde{H}^{-(1+\mu)}}{\left(\gamma^{*}-\gamma\right)(1+\mu)(1+\theta)}<0 \text { and } \\
\frac{\partial \ln \tilde{H}}{\partial \mu}=\frac{-1}{\left(\gamma^{*}-\gamma\right)(1+\mu)}\left[\left(\gamma^{*}-\gamma\right) \ln \tilde{H}+\gamma \frac{\tilde{H}^{(1+\mu)}-1}{(1+\mu) \tilde{H}^{1+\mu}}\right] \geqslant 0 \text { for } \tilde{H} \lessgtr 1 .
\end{gathered}
$$


Combining with the definition of $r$ and $v$, this gives for relative hours among others:

$$
\begin{gathered}
\frac{d \ln \tilde{H}}{d \ln A}=-\frac{1-\eta^{f}}{\left(\gamma^{*}-\gamma\right)\left[1-(1-\sigma) \eta^{f}\right]}\left\{(1-\sigma) \eta^{f}+\left[1-(1-\sigma) \eta f \frac{v+\rho}{v+\alpha(\tilde{H})}\right\}<0\right. \text { and } \\
\frac{d \ln \tilde{H}}{d \ln H^{c}}=-\frac{1-\eta^{f}}{\left(\gamma^{*}-\gamma\right)[1-(1-\sigma) \eta\}}\left\{(1-\sigma) \eta^{f}+[1-(1-\sigma) \eta] \frac{V}{V+\rho W H^{c}(1-A)+A W H^{c} \alpha(\dot{H})}\right\}<0 .
\end{gathered}
$$

As a consequence

$$
\frac{d \ln H}{d \ln H^{c}}=\frac{1}{1+\mu}\left[\mu+\frac{1-\eta^{f}}{\gamma^{*}-\gamma} \frac{(1+\mu) \rho(1-A)+(\mu-\theta) A}{A(v+o(\tilde{H}))}\right] .
$$

\section{F.2 Uncertainty}

Using the kinked compensation schedule (3.6) and production function (3.12), the expected values of the left-hand side of equations (3.16) and (3.17) are given by

$$
\begin{aligned}
& E[a o(\tilde{H})]=\frac{1+\theta_{o}}{1+\mu} E\left[a\left(y / y_{u}\right)^{(1+\mu) / \gamma}\right]+\frac{\mu-\theta_{o}}{1+\mu} A \\
& +\frac{\boldsymbol{\theta}_{o}-\boldsymbol{\theta}_{s}}{1+\mu} \int_{0}^{1} \int_{0}^{a^{1 / n} y_{*}} a\left[1-\left(y / y_{u}\right)^{(1+\mu) / \gamma}\right] g(q) p(a) d q d a, \\
& E\left[a o^{\prime}(\tilde{H}) \tilde{H}\right]=\left(1+\theta_{o}\right) E\left[a\left(y / y_{u}\right)^{(1+\mu) \gamma}\right]-\left(\theta_{o}-\theta_{s}\right) \int_{0}^{1} \int_{0}^{a^{1 / \alpha} y_{v}} a\left(y / y_{u}\right)^{(1+\mu) / \gamma} g(q) p(a) d q d a .
\end{aligned}
$$

Define the following weighted average of $\theta_{o}$ and $\theta_{s}$ :

$$
\theta_{u} \equiv\left[1-d\left(y_{w}\right)\right] \theta_{o}+d\left(y_{u}\right) \theta_{s}
$$

with

$$
d\left(y_{w}\right) \equiv \int_{0}^{1} \int_{0}^{a^{1 / \alpha} y_{\psi}} \frac{a y^{(1+\mu) \gamma \gamma}}{E\left(a y^{(1+\mu) \gamma \gamma}\right)} g(q) p(a) d q d a .
$$

The weight $d\left(y_{u}\right)$ is increasing in $y_{w}$ with $d(0)=0$ and $\lim d\left(y_{w}\right)=1$. Using the expression for $\theta_{u}$ to substitute out $\theta_{e}-\theta$, in (F.2) and (F.3) gives 


$$
E[a o(\tilde{H})]=\frac{1+\theta_{w}}{1+\mu} E\left[a\left(y / y_{v}\right)^{(1+\mu) / \gamma}\right]+\frac{\mu-\theta_{v}}{1+\mu} A+\Delta_{v} A
$$

and

$$
E\left[a o^{\prime}(\tilde{H}) \tilde{H}\right]=\left(1+\theta_{*}\right) E\left[a\left(y / y_{*}\right)^{(1+\mu) \gamma}\right],
$$

where $\Delta_{v} \equiv \frac{\theta_{0}-\theta_{2}}{1 \cdot \mu} b\left(y_{v}\right)$ and

$$
b\left(y_{v}\right)=\int_{0}^{1} \int_{0}^{a^{1 /} y_{*}}\left[\frac{a}{A}-\frac{a y^{(1+\mu) \gamma \gamma}}{E\left(a y^{(1+\mu) \gamma}\right)}\right] g(q) p(a) d q d a .
$$

Differentiating the latter expression yields

$$
b^{\prime}\left(y_{\nu}\right)=E\left(a^{(1+\tau) \gamma}\right)\left[\frac{1}{A}-\frac{y_{u}^{(1+\mu) \gamma}}{E\left(a y^{(1+\mu) \gamma}\right)}\right]
$$

and $b^{\prime \prime}\left(y_{v}\right)<0$. As $b^{\prime}(0)>0, \lim b^{\prime}\left(y_{v}\right)=-\infty$ and $b(0)=\lim b\left(y_{v}\right)=0$, this implies $b\left(y_{u}\right)>0$ for $y_{u}>$ $y_{\mathrm{x}} \rightarrow$

0 . As a result $\Delta_{u}>0$ for $\theta_{o}>\theta_{s}$.

Next, I prove that $\tilde{H}_{o} \leq h\left(v+\Delta_{\iota} r, \theta_{u}, \mu\right) \leq \tilde{H}_{s}$, where the equality signs only hold for $\theta_{o}=\theta_{s}$. For the first inequality notice that $\tilde{H}_{o}=h\left(v, r, \theta_{o}, \mu\right)$. As $\partial h / \partial v>0, \partial h / \partial \theta<0, \Delta_{u} \geq 0$ and $\theta_{o} \geq \theta_{u}$ the first inequality follows immediately. For the comparison with $\tilde{H}_{s}$, totally differentiate $h$ with respect to $\theta_{o}$

$$
\frac{d \ln h\left(v+\Delta_{u}, r, \theta_{u}, \mu\right)}{d \theta_{o}}=\frac{\partial \ln h\left(v+\Delta_{u}, r, \theta_{u}, \mu\right)}{\partial v} \frac{f\left(y_{u}\right)}{1+\mu}+\frac{\partial \ln h\left(v+\Delta_{u}, r, \theta_{u}, \mu\right)}{\partial \theta_{o}}\left[1-d\left(y_{u}\right)\right] .
$$

The first expression on the right-hand side is positive, the second negative. Using the partial derivatives from Section F.1 and rearranging, using the first-order condition $\frac{\gamma}{1-\eta^{f}}=\frac{\left(1+\theta_{v}\right) h^{1+\mu}}{v+\Delta_{v}+\alpha(h)}$, this total derivative can be written as

$$
\begin{aligned}
\frac{d \ln h\left(v+\Delta_{u}, r, \theta_{u}, \mu\right)}{d \theta_{0}}= & \frac{-1}{\left(\gamma^{*}-\gamma\right)(1+\mu)\left(1+\theta_{u}\right)} \times \\
& \left\{\frac{\left(1+\theta_{u}\right)\left(1-\eta^{f}\right)}{v+\Delta_{u}+o(h)}\left[1-\int_{0}^{1} \int_{0}^{a^{1 / k} y_{u}} \frac{a}{A} g(q) p(a) d q d a\right]+\left(\gamma^{*}-\gamma\right)\left[1-d\left(y_{u}\right)\right]\right\}<.
\end{aligned}
$$


So increasing the overtime premium starting from $\theta_{s}$ reduces $h$. Hence for $\theta_{o} \geq \theta_{s} h\left(v+\Delta_{w}, r, \theta_{w}, \mu\right)$ $\leq h\left(v, r, \theta_{n} \mu\right)=\tilde{H}_{s}$.

Consider the parameters $\delta$ and $\delta_{u}$ as defined around equation (3.15). Their ratio is given by $\delta_{\downarrow} / \delta=$ $E(y)^{1 / \gamma} / E\left(y^{1 / \gamma}\right)$. As the function $y^{1 / \gamma}$ is convex, Jensen's inequality implies $E\left(y^{1 / \gamma}\right)>E(y)^{1 / \gamma}$, hence $\delta_{u}<$ 8.

As $a$ and $q$ are distributed independently, the parameter $\delta_{u}$ can be rewritten as

$$
\delta_{u}=\left\{\frac{Q^{(1+\mu) \gamma \gamma}}{E\left[q^{(1+\mu) \gamma \gamma}\right]} \frac{A^{-(1+\mu-\gamma \tau) \gamma \gamma \tau}}{E\left[a^{-(1+\mu-\gamma \tau \gamma \gamma \tau}\right]}\right\}^{1 /(1+\mu)} .
$$

The function $q^{(1+\mu) / \gamma}$ is convex, as $(1+\mu) / \gamma>1$. Hence Jensen's inequality implies $E\left(q^{(1+\mu) / \gamma}\right)>Q^{(1+\mu) \gamma}$. Similarly, the function $a^{-(1+\mu-\gamma \tau) \gamma \tau}$ is convex, implying $E\left(a^{-(1+\mu-\gamma \tau) / \gamma \tau}\right)>A^{-(1+\mu-\gamma \tau) / \gamma \tau}$. Combining these two observations, $\delta_{u}<1$, as in Ehrenberg (1970).

Using the independence of $a$ and $q$, the parameter $\delta$ can be written as

$$
\delta=\left\{\frac{E\left(q^{1 / \gamma}\right)^{1+\mu}}{E\left[q^{(1+\mu) / \gamma}\right]} \frac{A E\left(a^{-1 / \gamma \tau}\right)^{1+\mu}}{E\left[a^{-(1+\mu-\gamma \tau / \gamma \tau}\right]}\right\}^{1 /(1+\mu)} .
$$

The function $x^{1+\mu}$ is strictly convex for $\mu>0$, so Jensen's inequality then implies $E\left(q^{(1+\mu) \gamma}\right)>$ $E\left(q^{1 / \gamma}\right)^{1+\mu}$. Accordingly, for a certain attendance rate $a=A, \delta \leq 1$. Demand uncertainty reduces expected hours only if the overtime premium is increasing at the margin $(\mu>0)$.

Finally, consider the impact of a stochastic attendance rate $a$. The function $x^{1+\mu-\gamma \tau}$ is concave for $\mu<\gamma \tau$ and this is assumed to hold as $\mu$ is small. So Jensen's inequality implies $E\left(a^{-(1+\mu-\gamma \tau) \gamma \tau}\right)<$ $E\left(a^{-1 / \gamma \tau}\right)^{(1+\mu-\gamma \tau)}$. Accordingly

$$
\frac{A E\left(a^{-1 / \gamma^{\tau}}\right)^{1+\mu}}{E\left[a^{-(1+\mu-\gamma \tau / \gamma \tau}\right]}>A E\left(a^{-1 / \gamma^{\tau} \tau}\right)^{\gamma \tau}>1,
$$

where the second inequality follows because the function $a^{-1 / \gamma t}$ is convex, implying $E\left(a^{-1 / \gamma t}\right)>A^{-1 / \gamma t}$. Thus, ignoring the impact of demand uncertainty, that is for $q=Q, \delta>1$ and stochastic absenteeism increases expected hours. 


\section{APPENDIX G DATA OVERTIME}

All data refer to the Dutch manufacturing sector, unless stated otherwise. All data come from the following three organisations:
CBS Statistics Netherlands
CPB Netherlands Bureau for Economic Policy Analysis
SZW Ministry of Social Affairs

Capital letters denote level, small letter denote logarithms or rates.

$E^{\prime} \quad$ Hours lost due to strikes. Source: CBS, Sociaal-Economische Maandstatistiek, various issues.

E Hours lost due to short-time. Source: CBS, Sociaal-Economische Maandstatistiek, various issues and SZW, private communication.

H Actual weekly hours operatives in reference week. Source: CBS, Sociaal-Economische Maandstatistiek, various issues and CBS, private communication.

$\hat{H} \quad$ Observed relative hours. Calculated as $\hat{H}=\left(H-H-H^{\prime}\right) / H^{r}$.

$H^{*} \quad$ Standard weekly hours operatives in reference week. Source: CBS, Sociaal-Economische Maandstatistiek, various issues and CBS, private communication.

$H^{d} \quad$ Weekly hours lost due to strikes. Calculated as $H^{d}=E^{d} /\left(H^{*} N\right)$.

$H^{\circ} \quad$ Observed weekly overtime hours per operative. Calculated as $H^{\circ}=H-H^{c}$.

$H^{P} \quad$ Weekly short-time hours per employee. Calculated as $H^{s}=E^{s} /\left(H^{\prime \prime} N\right)$.

$H^{*} \quad$ Normal number of weeks worked. Calculated as $H^{*}=H^{*} / H^{*}$.

$H^{y} \quad$ Normal annual working time. Source: CBS, Sociaal-Economische Maandstatistiek, various issues.

$N \quad$ Employment measured in full-time equivalents. Source: CBS, National Accounts, various issues.

$Q \quad$ Utilisation rate. Source: CBS, Conjunctuur-enquête, various issues. For the period before 1971 , linked to a CPB series of utilisation.

$z \quad$ Rate of absenteeism, not sector specific. Source: CBS, Sociaal-Economische Maandstatistiek, various issues.

$\Delta x \quad$ Growth rate of world trade. Source CPB, Centraal Economisch Plan, various issues.

The table on the following page gives the data used estimating the overtime equation. 
Data overtime equation

\begin{tabular}{|c|c|c|c|c|c|c|c|c|}
\hline & $H^{*}$ & $H$ & $H^{\circ}$ & H & $H^{d}$ & $Q$ & $z$ & $\Delta x$ \\
\hline 1960 & 47.3 & 48.7 & 1.44 & 0.0087 & 0.0070 & 0.891 & 0.058 & \\
\hline 1961 & 45.1 & 46.1 & 1.02 & 0.0005 & 0.0011 & 0.876 & 0.055 & 0.055 \\
\hline 1962 & 44.7 & 46.0 & 1.26 & & & & & 0.054 \\
\hline 1963 & 44.5 & 46. & 1.62 & 0.0048 & 0.0032 & 0.856 & 0.066 & 0.077 \\
\hline 1964 & 44.5 & 46.2 & 1.70 & 0.0008 & 0.0015 & 0.891 & 0.065 & 0.122 \\
\hline 1965 & 44.6 & 46.2 & 1.65 & 0.0091 & 0.0057 & 0.880 & 0.069 & 0.065 \\
\hline 1966 & 44.5 & 46.1 & 62 & 0.0127 & 0.0 & 0.848 & 0.072 & 0.049 \\
\hline 1967 & 44.1 & & & & 0.0 & & 0.066 & 0.021 \\
\hline 1968 & 43.5 & 45.3 & 1.79 & 0.0253 & 0.0012 & 0.847 & 0.072 & 0.116 \\
\hline 1969 & 43.3 & 45 & 1.78 & 0.0111 & 0.0030 & 0.873 & 0.078 & 0.105 \\
\hline 1970 & 42.4 & 44.2 & 1.79 & 0.0118 & 0.0162 & 0.881 & 0.077 & 0.104 \\
\hline 1971 & 42.2 & & & & 0.0 & 858 & 078 & 076 \\
\hline 1972 & 42.0 & 43 & 1. & & 0.0 & 0.847 & 0.078 & 0.093 \\
\hline 1973 & 41. & 43. & 1.5 & 0.0212 & 0.0 & 0.850 & 0.085 & 0.093 \\
\hline 1974 & 40.6 & $\cdot 41.9$ & 1.30 & 0.1173 & 0.0013 & 0.843 & 0.090 & 0.040 \\
\hline 1975 & 40.0 & 41.2 & 1.20 & 0.5552 & 0.0001 & 0.773 & 0.088 & -0.033 \\
\hline 1976 & 40.1 & 41. & 1.20 & 0.2514 & 0.00 & 0.777 & 0.093 & 0.126 \\
\hline 197 & 40. & $4 !$ & 1. & 0.2 & 0.0 & 0.790 & 0.095 & 0.032 \\
\hline 197 & 40.0 & & 1.10 & 0.1074 & 0.0006 & 0.797 & 0.100 & 0.053 \\
\hline 197 & 39. & & 1.20 & 0.0195 & 0.0060 & 0.820 & 0.100 & 0.084 \\
\hline 198 & 40. & 41 & 1.00 & 0.0874 & 0.0091 & 0.800 & 0.094 & 0.045 \\
\hline 1981 & 39.9 & 40.8 & 0.90 & 0.2206 & 0.0001 & 0.783 & 0.085 & 0.006 \\
\hline 198 & 40 & & & & & 0.7 & 0.081 & 0.014 \\
\hline 1983 & 39.9 & 40.7 & 0.80 & 0.1969 & 0.0003 & 0.800 & 0.075 & 0.024 \\
\hline 1984 & 39.6 & 40.5 & 0.90 & 0.0615 & 0.0019 & 0.830 & 0.072 & 0.082 \\
\hline 1985 & 39.4 & 40 & 1.00 & 0.00 & 0.0039 & 0.845 & 0.069 & 0.040 \\
\hline 1986 & 39.2 & 40.2 & 0.99 & 0.0077 & 0.0066 & 0.843 & 0.069 & 0.047 \\
\hline 1987 & 39.0 & 40 & 1. & 0.0164 & 0.0025 & 0.840 & 0.067 & 0.072 \\
\hline 1988 & 38.8 & 39.9 & 1.10 & 0.0113 & 0.0009 & 0.848 & 0.066 & 0.070 \\
\hline 1989 & 38.8 & 39.9 & 1.08 & 0.0034 & 0.0022 & 0.860 & 0.068 & 0.078 \\
\hline 1990 & 38.8 & 40.0 & 1.20 & 0.0052 & 0.0028 & 0.860 & 0.068 & 0.040 \\
\hline 1991 & 38.8 & 40.0 & 1.15 & 0.0139 & & 0.840 & 0.064 & 0.032 \\
\hline 1992 & 38.8 & 39.9 & 1.10 & 0.0100 & 0.0068 & 0.830 & 0.058 & 0.040 \\
\hline 1993 & 38. & 39. & 1.09 & 0.0122 & 0.0028 & 0.808 & 0.056 & -0.001 \\
\hline 1994 & 38.6 & 39.8 & 1.20 & 0.0070 & 0.0022 & 0.837 & 0.049 & 0.089 \\
\hline
\end{tabular}


To derive the comparative statics of the interior solution, totally differentiate the equations (4.11), (4.10) and (4.4) to obtain $B d z=G d x$, where the endogenous variables are $z=(\ln K, \ln N, \ln S)^{\prime}$ and the exogenous variables $x=(\ln Q, \ln A, \ln R, \ln Z, \ln V, \ln W, \ln H)^{\prime}$. The matrices $B$ and $G$ are given by

$$
B=\left[\begin{array}{lll}
-\frac{1}{\sigma} & \frac{1}{\sigma} & -\frac{1}{\sigma}+\frac{1-\varphi_{z}-\mu}{1-\eta^{\prime}} \\
-\left[\varphi_{z}+\frac{1-\sigma}{\sigma}(1-\mu)\right] \eta^{\prime} & {\left[\varphi_{z}+\frac{1-\sigma}{\sigma}(1-\mu)\right] \eta^{\prime}} & -\left\{\left[\varphi_{z}+\frac{1-\sigma}{\sigma}(1-\mu)\right] \eta^{\prime}+\theta\left[\varphi_{\gamma}\left(\eta^{\prime}-\mu\right)-\varphi_{z} \eta^{\prime}\right\}\right\} \\
\eta^{\prime} & 1-\eta^{\prime} & \eta^{\prime}-\mu
\end{array}\right]
$$

and

$$
G=\left[\begin{array}{ccccccc}
0 & -\frac{1-\sigma}{\sigma} & 1-\varphi_{z} & \varphi_{z} & -\varphi_{V} & -\left(1-\varphi_{V}\right) & -\left(1-\varphi_{V^{\prime}}-\varphi_{z}\right) \\
0 & -\frac{1-\sigma}{\sigma}(1-\mu) \eta^{\prime} & 0 & \varphi_{z} \eta^{\prime}-\varphi_{\nu}\left(\eta^{\prime}-\mu\right) & \varphi_{V}\left(\eta^{\prime}-\mu\right)-\varphi_{z} \eta^{\prime} & \varphi_{\nu}\left(\eta^{\prime}-\mu\right) \\
1 & -\left(1-\eta^{\prime}\right) & 0 & 0 & 0 & 0 & -\eta^{e}
\end{array}\right] .
$$

First consider the short-run model, where $K$ is fixed. As the capital stock is not necessarily fixed at its optimal level, $\varphi_{Z}$ should be replaced by $\Psi_{Z} \equiv \varphi_{Z} \frac{\varphi_{K}}{1-\varphi_{X}} \frac{1-\eta^{f}}{\eta^{f}}$ in the second row of the matrices $B$ and

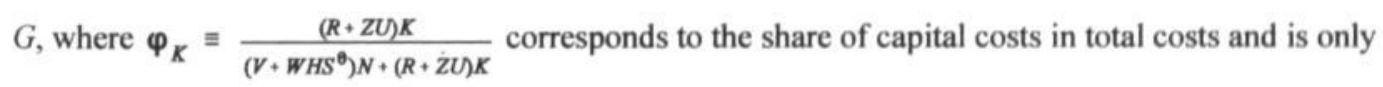
equal to $\eta^{\prime}$ in the long run, as implied by the first-order condition (4.11). Partitioning $B$ and $G$ appropriately gives the equation $B_{N S}(d \ln N, d \ln S)^{\prime}=G_{N S}(d \ln Q, d \ln K, d \ln A, d \ln Z, d \ln V, d \ln W$, $d \ln H)^{\prime}$. The inverse of the short-run Jacobian $B_{N S}$ is

$$
B_{N S}{ }^{-1}=\Lambda_{N S}{ }^{-1}\left[\begin{array}{cc}
\eta^{f}-\mu & {\left[\boldsymbol{\psi}_{Z}+\frac{1-\sigma}{\sigma}(1-\mu)\right] \eta^{f}+\theta\left[\varphi_{V}\left(\eta^{f}-\mu\right)-\boldsymbol{\psi}_{Z} \eta^{\prime}\right]} \\
-(1-\eta) & {\left[\boldsymbol{\psi}_{Z}+\frac{1-\sigma}{\sigma}(1-\mu)\right] \eta^{f}}
\end{array}\right],
$$

with

$$
\Lambda_{N S} \equiv(1-\mu)\left[\Psi_{Z}+\frac{1-\sigma}{\sigma}(1-\mu)\right] \eta^{f}+\theta\left(1-\eta^{f}\right)\left[\varphi_{V}\left(\eta^{f}-\mu\right)-\Psi_{Z} \eta^{f}\right]
$$

The second-order condition is $\Lambda_{N S}>0$. It is easily seen that $\partial \Lambda_{N S} / \partial \sigma<0$. Moreover, as $\theta<1$ and $\mu<$ $\eta$ in an interior solution, 


$$
\left.\Lambda_{N S}\right|_{\theta=1}=\theta \varphi_{V}\left(1-\eta^{f}\right)\left(\eta^{f}-\mu\right)+\Psi_{Z} \eta^{f}\left[1-\mu-\theta\left(1-\eta^{f}\right)\right]>\theta \varphi_{V}\left(1-\eta^{f}\right)\left(\eta^{f}-\mu\right)>0 .
$$

Hence a sufficient condition for the second-order condition is $\sigma \leq 1$, which is assumed to be satisfiec More generally, the second-order condition is always fulfilled for $\theta$ large enough and for lower valus of $\theta$ it sets an upperbound $\sigma_{N S}>1$ to the elasticity of substitution $\sigma$.

The comparative static effects can be obtained considering the sign distribution of the matrix $B_{N S}{ }^{-1} G_{N S}$.

Similarly, comparative static results for the long-run model can be obtained from the sign distribution of $B^{-1} G$, where the inverse of the Jacobian $B$ is given by

$$
B^{-1}=\Lambda_{s}^{-1}\left[\begin{array}{ccc}
-\Lambda_{N S} & {\left[\varphi_{Z}+\frac{1-\sigma}{\sigma}(1-\mu)\right]} & \Lambda_{S} \\
\Lambda_{K S} & \frac{\left(1-\varphi_{Z}-\mu\right) \eta^{f} \sigma-\mu\left(1-\eta^{f}\right)}{\sigma\left(1-\eta^{\prime}\right)} & \Lambda_{S} \\
{\left[\varphi_{Z}+\frac{1-\sigma}{\sigma}(1-\mu)\right] \eta^{f}} & -\frac{1}{\sigma} & 0
\end{array}\right],
$$

with

$$
\Lambda_{K S}=\cdot \mu\left[\varphi_{z}+\frac{1-\sigma}{\sigma}(1-\mu)\right] \eta^{f}+\theta \eta^{f}\left[\varphi_{V}\left(\eta^{f}-\mu\right)-\varphi_{z} \eta^{f}\right]
$$

and

$$
\Lambda_{s}=\frac{\left(1-\varphi_{z}-\mu\right)\left[(1-\mu)-\left(1-\varphi_{z}-\mu\right) \sigma\right] \eta^{f}+\theta\left(1-\eta^{f}\right)\left[\varphi_{V}\left(\eta^{f}-\mu\right)-\Psi_{z} \eta^{f}\right]}{\sigma\left(1-\eta^{\prime}\right)} .
$$

The second-order condition is $\Lambda_{s}>0$, which implies $\sigma<\sigma_{s}$, with

$$
\sigma_{s}=\frac{(1-\mu)\left(1-\varphi_{z}-\mu\right) \eta^{f}+\theta\left(1-\eta^{f}\right)\left[\varphi_{V}\left(\eta^{f}-\mu\right)-\varphi_{z} \eta^{f}\right]}{\left(1-\varphi_{z}-\mu\right)^{2} \eta^{f}} .
$$

Equation (4.10) implies $\theta\left(1-\varphi_{\gamma}\right)\left(1-\eta^{f}\right)=\left(1-\varphi_{z}\right) \eta^{f}-\mu$, so $\sigma_{s}$ can be rewritten as

$$
\begin{aligned}
\sigma_{s} & =1+\frac{\theta\left(1-\eta^{f}\right)\left[\varphi_{V}\left(\eta^{f}-\mu\right)-\varphi_{z} \eta^{f}\right]+\varphi_{Z}\left(1-\varphi_{z}-\mu\right) \eta^{f}}{\left(1-\varphi_{z}-\mu\right)^{2} \eta^{f}} \\
& =1+\frac{\theta \varphi_{V}\left[\left(1-\varphi_{z}\right) \eta^{f}-\mu\right]+\varphi_{Z}\left(1-\varphi_{z}\right) \eta^{f}}{\left(1-\varphi_{z}-\mu\right)^{2}} \frac{\left(1-\eta^{f}\right)}{\eta^{f}}>1 .
\end{aligned}
$$

Finaly some tedious algebra shows that $\sigma_{S}<\sigma_{N S}$ 


\section{APPENDIX J BARGAINING}

Consider the Nash-bargaining solution for the right-to-manage model with equal bargaining power $\beta$ for both issues. Employment $N$ and the capital stock $K$ are given by equations (6.4) and (6.5). Maximising the $\log$ Nash-maximand $\ln \Omega=\ln \Gamma+\beta \ln \Pi$ with respect to $H$ and $W$ gives (6.11) and (6.13), respectively. In short-hand, these first-order conditions can be rewritten as $\lambda_{r}(1-\omega)=\mu_{Y}-\mu_{H}$ and $\lambda_{Y}=\mu_{Y}$.

The second-order condition for maximisation with respect to $W$ (or $Y$ ) only is $\Lambda_{Y} \equiv \alpha_{Y}+\mu_{Y}+\gamma_{Y}-1$ $>0$, where $\gamma_{Y} \equiv \frac{d \ln \mu_{Y}}{d \ln Y}>0 .^{1}$ The second-order condition for maximisation with respect to $H$ only (given $W$ ) is

$$
\Lambda_{W} \equiv \Lambda_{Y}-2 \omega \Lambda_{0}+\omega \Lambda_{H}-\frac{\lambda_{Y}-\mu_{Y}}{\lambda_{Y}}\left[\gamma_{Y}+\gamma_{H}-\lambda_{Y}(1+\omega)\right]>0
$$

where $\Lambda_{H} \equiv \alpha_{H}+\mu_{H}+\gamma_{H}+1$ and $\Lambda_{0} \equiv \lambda_{Y}+\xi$. Assumption (6.3) guarantees that $\Lambda_{0}>0$.

For joint maximisation the equilibrium implies $\omega \mu_{Y}=\mu_{H}$. The corresponding second-order conditions are $\Lambda_{Y}>0$ and

$$
\Lambda \equiv \Lambda_{Y} \Lambda_{H}-\omega \Lambda_{0}^{2}>0 .
$$

It is then easily checked that in the equilibrium (J.2) is stronger than (J.1). Figure J.1 illustrates the second-order conditions (assuming $\lambda_{Y}=\mu_{Y}$ ).

For effort bargains, the Nash-maximand is maximised with respect to $H$ at given $Y$. The corresponding first-order condition is (6.12), or $\lambda_{Y} \omega=\mu_{H}$. Obviously, this equation can also be obtained subtracting (6.11) from (6.13). For joint maximisation, nothing new is implied, but (6.12) gives the expression for effort, i.e. $H$ at given $Y$ instead of $W$. The corresponding second-order condition for effort bargaining is $\Lambda_{H}>0$. As $\alpha_{H}>0, \mu_{H}>0$ and $\gamma_{H} \geq 0$, this is always satisfied and we even have $\Lambda_{H}>1$.

For the comparative statics of the first-order conditions, it is easier to analyse them in terms of $Y$ and $H$, first. Partial differentiation of (6.11), (6.12) and (6.13) gives, respectively

$$
\begin{gathered}
-\left[\Lambda_{Y}-\omega \Lambda_{0}-\frac{\lambda_{Y}-\mu_{Y}}{\lambda_{Y}}\left(\gamma_{Y}-\lambda_{Y}\right)\right] d \ln Y-\left[\omega \Lambda_{H}-\omega \Lambda_{0}+\frac{\lambda_{Y}-\mu_{Y}}{Y}\left(\omega \lambda_{Y}-\gamma_{H}\right)\right] d \ln H \\
=-(1-\omega) \frac{d U^{*}}{U-U^{*}}+\frac{1}{\lambda_{Y}}\left[\frac{\partial \mu_{Y}}{\partial Z}-\frac{\partial \mu_{H}}{\partial Z}\right] d Z, \\
-\Lambda_{0} d \ln Y+\Lambda_{H} d \ln H=-\frac{d U^{*}}{U-U^{*}}+\frac{\partial \ln \mu_{H}}{\partial Z} d Z,
\end{gathered}
$$

1 As $\mu_{\gamma}$ is a weighted sum of the elasticities $\varepsilon_{N \gamma}$ and $\varepsilon_{\Pi n} \gamma_{Y}$ is a weighted average of their relative changes $\gamma_{N}$ and $\gamma_{\mathrm{n}}$. Using Appendix I, this implies $\varphi_{r} \leq \gamma_{N} \leq \gamma_{Y} \leq \gamma_{\Pi}<1$. 


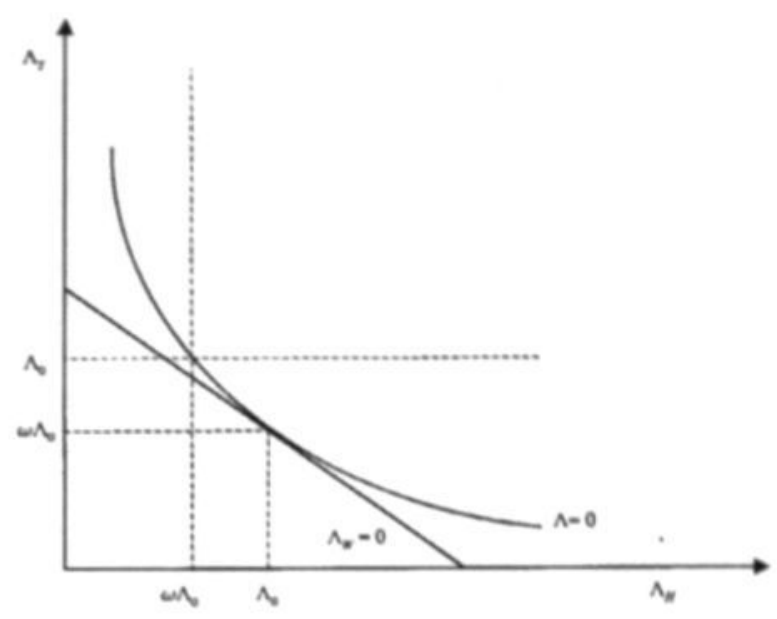

Figure J.1 Second-order conditions

$$
-\Lambda_{y} d \ln Y+\omega \Lambda_{0} d \ln H=-\frac{d U^{*}}{U-U^{*}}+\frac{\partial \ln \mu}{\partial Z} d Z
$$

As these expressions do not use any cross equation characteristics, they give the single equation properties of (6.11), (6.12) and (6.13), respectively. As $W=Y / H$, this can be easily rewritten in terms $W$ and $H$. For (J.3) this gives

$$
\Lambda_{W} d \ln H=-\left[\Lambda_{Y}-\omega \Lambda_{0}-\frac{\lambda_{Y}-\mu_{Y}}{\lambda_{Y}}\left(\gamma_{Y}+\lambda_{Y}\right)\right] d \ln W+(1-\omega) \frac{d U^{*}}{U-U^{*}}-\frac{1}{\lambda_{Y}}\left[\frac{\partial \mu_{Y}}{\partial Z}-\frac{\partial \mu_{H}}{\partial Z}\right] d Z
$$

Combining (J.4) and (J.5), gives the following comparative statics for the joint model (6.12) and (6.13):

$$
\begin{array}{ll}
\frac{\partial \ln Y}{\partial U^{a}}=\frac{\Lambda_{H}-\omega \Lambda_{0}}{\Lambda\left(U-U^{a}\right)}, & \frac{\partial \ln Y}{\partial Z}=\frac{-\left(\Lambda_{H} \frac{\partial \ln \mu_{Y}}{\partial Z}-\omega \Lambda_{0} \frac{\partial \ln \mu_{H}}{\partial Z}\right)}{\Lambda}, \\
\frac{\partial \ln H}{\partial U^{a}}=\frac{-\left(\Lambda_{Y}-\Lambda_{0}\right)}{\Lambda\left(U-U^{a}\right)} & \text { and } \quad \frac{\partial \ln H}{\partial Z}=\frac{\Lambda_{Y} \frac{\partial \ln \mu_{H}}{\partial Z}-\Lambda_{0} \frac{\partial \ln \mu_{Y}}{\partial Z}}{\Lambda} .
\end{array}
$$

For $W$, this implies

$$
\frac{\partial \ln W}{\partial U^{a}}=\frac{\Lambda_{Y}-(1+\omega) \Lambda_{0}+\Lambda_{H}}{\Lambda\left(U-U^{g}\right)} \quad \text { and } \quad \frac{\partial \ln W}{\partial Z}=\frac{-\left[\left(\Lambda_{H}-\Lambda_{0}\right) \frac{\partial \ln \mu_{Y}}{\partial Z}+\left(\Lambda_{Y}-\omega \Lambda_{0}\right) \frac{\partial \ln \mu_{H}}{\partial Z}\right]}{\Lambda} \text {. }
$$


For the sign distribution of the comparative statics, first notice that in the equilibrium $\Lambda_{Y}$ can be written as $\Lambda_{Y}=\omega_{Y}+\gamma_{Y}+\Lambda_{0}$. Hence $\Lambda_{Y} \gtrless \Lambda_{0}$ for $\omega_{Y}+\gamma_{Y} \gtrless 0$. Second, $\Lambda_{Y} \gtrless \omega \Lambda_{0}$ corresponds to $\omega \lessgtr \omega^{*} \equiv 1+\left(\omega_{Y}+\gamma_{Y}\right) / \Lambda_{0}$. As $\Lambda_{0}>0$ according to (6.3), this implies $\omega^{*} \gtrless 1$ for $\omega_{Y}+\gamma_{Y} \gtrless 0$. Moreover, rewriting yields $\Lambda_{Y}=\omega^{*} \Lambda_{0}$, hence the second-order condition $\Lambda_{Y}>0$ implies that $\omega^{*}>0$. Third, consumption being a normal good, i.e. $\alpha_{H}>\omega \xi$, guarantees that $\Lambda_{H}>\omega \Lambda_{0}$. Fourth, in equilibrium $\Lambda_{H}$ can be written as $\Lambda_{H}=\omega_{H}+\gamma_{H}+\omega \Lambda_{0}$. Hence, $\Lambda_{H} \gtrless \Lambda_{0}$ corresponds to $\omega \gtrless \omega^{h} \equiv$ $1-\left(\omega_{H}+\gamma_{H}\right) / \Lambda_{0}$, with $\omega^{h}<\min \left(1, \omega^{m}\right)$.

Rewriting, we have $\Lambda_{Y}=\omega^{*} \Lambda_{0}$ and $\Lambda_{H}=\left(1-\omega^{h}+\omega\right) \Lambda_{0}$. Hence the second-order condition (J.2) implies $\left(\omega^{\prime \prime}-1\right) \omega+\omega^{*}\left(1-\omega^{\prime \prime}\right)>0$. This is always satisfied for $\omega^{*} \geq 1$, but for $\omega^{w}<1$ (thus $\omega_{Y}+\gamma_{Y}<0$ ) this gives an upperbound (larger than $\omega^{\prime \prime}$ ) for $\omega$.

To derive the impact of the exogenous variables on hours, wages and remuneration, we need the properties of $\mu_{Y}$ and $\mu_{H}$. They are given in the following table. The impact of $Y, V$ and $R A_{N} / A_{K}$ on $\mu_{Y}$ operates through the dependence of the capital share $\eta^{\prime}$ on the capital labour ratio $k$.

Table J.1 Properties $\mu_{Y}$ and $\mu_{H}(\sigma \leq 1)$

\begin{tabular}{|c|c|c|c|c|c|c|c|c|c|}
\hline & $\theta$ & $\beta$ & $v$ & $\sigma$ & $\eta^{\prime}$ & $Y$ & $H$ & $V$ & $R A_{N} / A_{K}$ \\
\hline$\mu_{Y}$ & + & + & + & + & - & + & 0 & - & $-/ 0$ \\
\hline$\mu_{H}$ & + & + & + & 0 & 0 & 0 & $-/ 0$ & 0 & 0 \\
\hline$\mu_{r}-\mu_{H}$ & $\pm H \gtrless H_{n}$ & $\pm H \gtrless H^{i}$ & $\pm H \gtrless H^{d}$ & + & - & + & $+/ 0$ & - & $-/ 0$ \\
\hline $\ln \left(\mu_{\gamma} / \mu_{H}\right)$ & + & - & - & + & - & + & +10 & - & -10 \\
\hline
\end{tabular}




\section{APPENDIX K GENERAL EQUILIBRIUM}

Partial differentiation of equations (6.14), (6.19) and (6.20) gives, respectively

$$
\begin{gathered}
\left(\Lambda_{Y}-\Lambda_{0}\right) d \ln Y+\left(\Lambda_{H}-\omega \Lambda_{0}\right) d \ln H=\left(\frac{\partial \ln \mu_{H}}{\partial Z}-\frac{\partial \ln \mu_{Y}}{\partial Z}\right) d Z, \\
-\left[\Lambda_{Y}-\mu_{Y}(1-u)\right] d \ln Y+\omega\left[\Lambda_{0}-\mu_{Y}(1-u)\right] d \ln H=-\rho_{U} \mu_{Y} u d \ln B+d \ln u+\frac{\partial \ln \mu_{Y}}{\partial Z} d Z, \\
\left(1-\varphi_{V}\right)\left(1-\eta^{\prime}\right) d \ln Y-\eta^{e} d \ln H \\
=d v+\left(1-\eta^{\prime}\right) d \ln A_{N}+\eta^{\prime}\left(d \ln A_{K}-d \ln R\right)-\varphi_{V}\left(1-\eta^{\prime}\right) d \ln V,
\end{gathered}
$$

where $\rho_{U}=\frac{B U_{r}(B, 0)}{Y U_{r}(Y, H)}>0$.

For technical progress we have $\frac{\partial \ln \mu_{N}}{\partial \ln \Lambda_{N}}=\frac{\partial \ln \mu_{N}}{\partial \ln \Lambda_{K}}=0$ and $-\frac{\partial \ln \mu_{Y}}{\partial \ln \Lambda_{N}}=\frac{\partial \ln \mu_{Y}}{\partial \ln \Lambda_{K}}=\gamma_{A}$, with $\gamma_{A}=\frac{\gamma r-\bullet r}{1-\varphi r} \geq$

0. Combining (K.1) and (K.3), the impact of technical progress on $Y$ and $H$ can be shown to be

$$
\begin{array}{lrl}
\left.\frac{d \ln Y}{d \ln A_{N}}\right|_{d \ln A_{K}=d \ln A_{N}}=\frac{\Lambda_{H^{-}}-\omega \Lambda_{0}}{\Lambda^{*}}>0, & \left.\frac{d \ln H}{d \ln A_{N}}\right|_{d \ln A_{K}=d \ln A_{N}}=-\frac{\Lambda_{Y}-\Lambda_{0}}{\Lambda^{*}}, \\
\frac{d \ln Y}{d \ln A_{N}}=\frac{\eta^{e} \gamma_{A^{+}}+\left(1-\eta^{f}\right)\left(\Lambda_{H^{-}}-\omega \Lambda_{0}\right)}{\Lambda^{*}}>0 & \text { and } & \frac{d \ln H}{d \ln A_{N}}=\frac{\left(1-\eta^{\dagger}\right)\left[\left(1-\varphi_{V}\right) \gamma_{A^{-}}\left(\Lambda_{Y^{-}}-\Lambda_{0}\right)\right]}{\Lambda^{*}},
\end{array}
$$

with $\Lambda^{*} \equiv\left(1-\varphi_{V}\right)\left(1-\eta^{f}\right)\left[\lambda_{\text {II }}\left(\Lambda_{Y}-\Lambda_{0}\right)+\left(\Lambda_{H}-\omega \Lambda_{0}\right)\right]=-\varepsilon_{I I \gamma}\left[\lambda_{\text {II }}\left(\omega_{Y}+\gamma_{\gamma}\right)+\omega_{H}+\gamma_{H}\right]$. This is positive as long as $\omega_{Y}+\gamma_{Y}$ is not very negative. The numerator of the last derivative for $H$ can be written as $-(1-\eta)\left(\omega_{Y}+\varphi_{V}\right)$, whereas the numerator of the last derivative for $Y$ can be written as $(1-\eta)\left[\lambda_{\text {II }}\left(\omega_{Y}+\varphi_{V}\right)+\left(\omega_{H}+\gamma_{H}\right)\right]$. 
The main source of the data is the so-called long macro series (1948-1995) of the Netherlands Bureau for Economic Policy Analysis, CPB (1996). These data are, among others, based on the National Accounts of Statistics Netherlands. When necessary, growth rates are used to deal with the breaks in the National Accounts series. The data are available on request.

\section{List of variables}

In the following list capital letters are used to denote levels and small letters denote rates. In the text, however, small letters are also used to indicate natural logarithms of the corresponding variable.

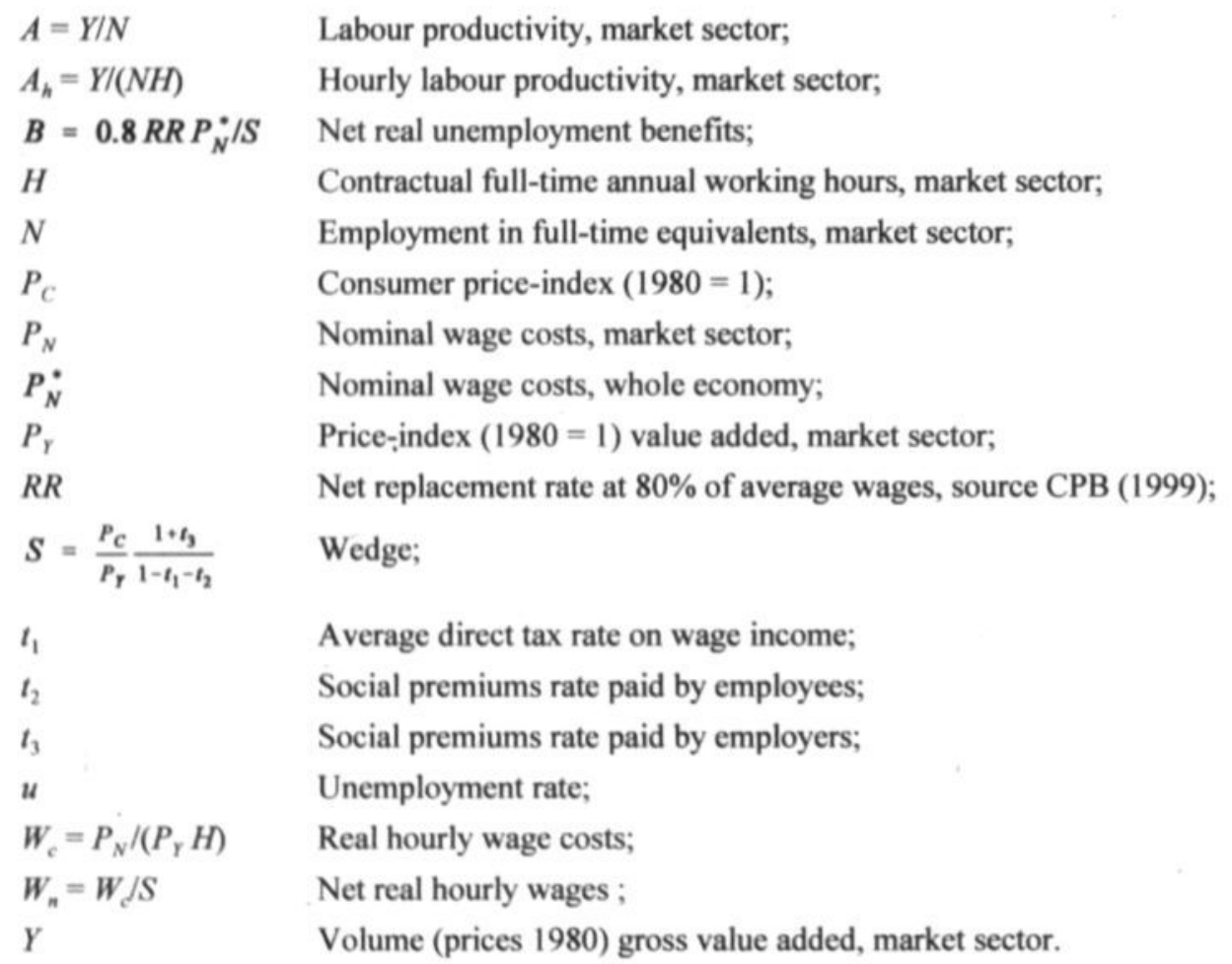




\section{References}

Abel A.B. (1981), A Dynamic Model of Investment and Capacity Utilization, Quarterly Journal of Economics, vol. 96, pp. 379-403.

Alchian A.A. and H. Demsetz (1972), Production, Information Costs, and Economic Organization, American Economic Review, vol. 62, pp. 777-795.

Alvi E. (1988), Information Revelation and Principal-Agent Contracts, Journal of Labor Economics, vol. 6, pp. 132-146.

Andersen T.M. (1987), Short- and Long-Run Consequences of Shorter Working Hours, pp. 147165 in Pedersen P.J. and R. Lund (eds.) (1987), Unemployment: Theory, Policy and Structure, Walter de Gruyter, Berlin.

Andrews M. and R. Simmons (1995), Are Effort Bargaining Models Consistent with the Facts? An Assessment of the Early 1980s, Economica, vol. 62, pp. 313-334.

Anxo D., G. Bosch, D. Bosworth et al. (eds.) (1995), Work Patterns and Capital Utilisation, An International Comparative Study, Kluwer Academic Publishers, Dordrecht.

Anxo D. and D. Taddei (1995), Shiftwork and Capital Operating Time in Industry: A Comparative International Survey, Ch. 5, pp. 121-148 in Anxo, Bosch, Bosworth et al. (1995).

van Ark B. and R.H. McGuckin (1999), International Comparisons of Labor Productivity and per Capita Income, Monthly Labor Review (July), pp. 33-41.

Ball R.J. and E.B.A. St. Cyr (1966), Short Term Employment Functions in British Manufacturing Industry, Review of Economic Studies, vol. 33, pp. 179-207.

Banerjee A., L. Cockerell and B. Russel (2001), An I(2) analysis of inflation and markup, Journal of Applied Econometrics, vol. 16 (3), pp. 221-240.

Bårdsen G. (1989), Estimation of Long Run Coefficients in Error Correction Models, Oxford Bulletin of Economics and Statistics, vol. 51 (3), pp. 345-350.

Barzel Y.(1973), The Determination of Daily Hours and Wages, Quarterly Journal of Economics, vol. 87, pp. 220-238.

Basu S., J.G. Frernald and M.D. Shapiro (2001), Productivity Growth in the 1990s: Technology, Utilization, or Adjustment, Carnegie-Rochester Conference Series on Public Policy, vol. 55, pp. 117-165.

Basu S. and M.S. Kimball (1997), Cyclical Productivity with Unobserved Input Variation NBFR Working Papaer 5915, NBER. 
Becker G.S. (1964), Human Capital, Columbia University Press, New York.

Bell D. (1982), Labour Utilization and Statutory Non-Wage Costs, Economica, vol. 49, pp. 335 343.

Bell D.N.F., R.A. Hart, O. Hubler et al. (2000), Paid and Unpaid Overtime Working in Germany and the UK, Discussion Paper 133, IZA, Bonn.

Bell L. and R. Freeman (1995), Why Do Americans and Germans Work Different Hours?, pp. 101131 in Buttler F., W. Franz, R. Schettkat et al. (eds.) (1995), Institutional Frameworks and Labor Market Performance, comparative views on the U.S. and German economies, Routledge, London.

Bell L. and R. Freeman (2001), The Incentive for Working Hard: Explaining Hours Worked Differences in the U.S. and Germany, in Wong G. and G. Picot (eds.) (2001), Working Time in Comparative Perspective, Volume I, Patterns, Trends, and Policy Implications of Earnings Inequality and Unemployment, Upjohn, Kalamazoo.

Bentivogli C. (1992), Time Allocation and Economic Welfare, Labour, vol. 6 (2), pp. 105-122. Bernanke B.S. (1986), Employment, Hours, and Earnings in the Depression: An Analysis of eight Manufacturing Industries, American Economic Review, vol. 76, pp. 82-109.

Betancourt R.R. and C.K. Clague (1981), Capital Utilization, A Theoretical and Empirical Analysis, Cambridge University Press, Cambridge.

Blanchard O. (2000), The Economics of Unemployment. Shocks, Institutions, and Interactions, Cambridge Mass.

Bodo G. and C. Giannini (1995), Average Working Time and the Influence of Contractual Hours: An Empirical Investigation for Italian Industry (1970-1981), Oxford Bulletin of Economics and Statistics, vol. 47, pp. 131-151.

Booth A. and M. Ravallion (1993), Employment and Length of the Working Week in a Unionized Economy in which Hours of Work Influence Productivity, The Economic Record, vol. 69, pp. 428-436.

Booth A. and F. Schiantarelli (1987), The Employment Effects of a Shorter Working Week, Economica, vol. 54, pp. 237-248.

Bosch G., P. Dawkins and F. Michon (eds.) (1994), Times are Changing, Working Time in 14 Industrialised Countries, ILO, Geneva.

Bosch G. and S. Lehndorff (2001), Working-time Reduction and Employment: experiences in Europe and economic policy recommendations, Cambridge Journal of Economics, vol. 25 (2), pp. 209-243.

Boswijk H.P. (1994), Testing for an Unstable Root in Conditional and Structural Error Correction Models, Journal of Econometrics, vol. 63, pp. 37-60. 
Boswijk H.P. and J.-P. Urbain (1997), Lagrange-Multiplier Tests for Weak Exogeneity: a Synthesis, Econometric Reviews, vol. 16 (1), pp. 21-38.

Bosworth D. and C. Cette (1995), Capital Operating Time: Measurement Issues, Ch. 4, pp. 89-121 in Anxo, Bosch, Bosworth et al. (1995).

Bosworth D. and D. Heathfield (1995), Work Patterns and Capital Operating Hours: Micro Foundations, Ch. 2, pp. 89-121 in Anxo, Bosch, Bosworth et al. (1995).

Bosworth D. and C. Pugh (1985), Optimal Capital Utilisation and Shiftworking, Scandinavian Journal of Economics, vol. 87, pp. 658-667.

Bosworth D.L. (1981), Specification of Factor Demand Models and Shiftworking, Scottish Journal of Political Economy, vol. 28, pp. 256-265.

Bovenberg A.L., J.J. Graafland and R.A. de Mooij (2000), Tax Reform and the Dutch labor Market: an Applied General Equilibrium Approach, Journal of Public Economics, vol. 78(1-2), pp. 193-214.

Broer D.P., D.A.G. Draper and F.H. Huizinga (2000), The Equilibrium Rate of Unemployment in the Netherlands, De Economist, vol. 148 (3), pp. 345-371.

Broer P., N. Draper and F. Huizinga (1999), The Equilibrium Rate of Unemployment, CPB Report $(99 / 1)$, pp. 28-33.

Broersma L., J. Koeman and C. Teulings (2000), Labour Supply, the Natural Rate, and the Welfare State in The Netherlands: The Wrong Institutions at the Wrong Point in Time, Oxford Economic Papers, vol. 52 (1), pp. 96-118.

Brown S. and J.G. Sessions (1996), The Economics of Absence: Theory and Evidence, Journal of Economic Surveys, vol. 10 (1), pp. 23-53.

Bulkley B. (1992), Does a Trade Union Set a Lower Effort Level than Would be Determined in a Competitive Labour Market?, Bulletin of Economic Research, vol. 44, pp. 153-160.

Bulkley G. and G.D. Myles (1996), Trade Unions, Efficiency Wages, and Shirking, Oxford Economic Papers, vol. 48, pp. 75-88.

Bulkley G. and G.D. Myles (1997), Bargaining over Effort, European Journal of Political Economy, vol. 13 (2), pp. 375-384.

Caballero R.J. and M.L. Hammour (1999), Jobless growth: appropriability, factor substitution and unemployment, Carnegie-Rochester Conference Series on Public Policy, vol. 48, pp. 51-94. Cahuc P. and P. Granier (1997), The Consequences of a Shorter Working Time: Some Lessons from a General Equilibrium Analysis, Recherches Economiques de Louvain, vol. 63 (1), pp. 1332.

Calmfors L. (1985), Work Sharing, Employment and Wages, European Economic review, vol. 27, pp. 293-309. 
Calmfors L. and M. Hoel (1988), Work Sharing and Overtime, Scandinavian Journal of Economics, vol. 90 (1), pp. 45-62.

Calmfors L. and M. Hoel (1989), Work Sharing, Employment and Shiftwork, Oxford Economic Papers, vol. 41, pp. 758-759.

Chapman S.J. (1909), Hours of Labour, The Economic Journal, vol. 19 (75), pp. 353-373.

Clark A. and A. Oswald (1993), Trade Union Utility Functions: A Survey of Union Leaders' Views, Industrial Relations, vol. 32 (3), pp. 391-411.

Coleman M.T. and J. Pencavel (1993), Changes in Work Hours of Male Employees, 1940-1988, Industrial and Labor Relations Review, vol. 46 (2), pp. 262-283.

Contensou F. and R. Vranceanu (1998), A Model of Working Time under Utility Competition in the Labor Market, Journal of Economics, vol. 67 (2), pp. 145-166.

Contensou F. and R. Vranceanu (2000), Working Time, Theory and Policy Implications, Edward Elgar, Cheltenham.

Cooper R. (1983), A Note on Overemployment/Underemployment in Labor Contracts under Asymmetric Information, Economic Letters, vol. 12, pp. 81-87.

Cooper R. (1985), Worker Asymmetric Information and Employment Distortions, Journal of Labor Economics, vol. 3, pp. 188-208.

Corneo G. (1994), La Réduction du Temps de Travail dans les Modèles de Chômage d'Équilibre: une Revue de la Littérature, Économie et Prévision, vol. 115, pp. 63-73.

CPB (1996), Lange macro-reeksen 1948-1995, CPB Netherlands Bureau for Economic Policy Analysis, Den Haag.

CPB (1999), Centraal Economisch Plan, CPB Netherlands Bureau for Economic Policy Analysis, Den Haag.

Deardorff A.V. and F.P. Stafford (1976), Compensation of Cooperating Factors, Econometrica, vol. 44 , pp. 671-684.

DeBeaumont R. and L.D. Singell (1999), The Return to Hours and Workers in U.S. Manufacturing: Evidence on Aggregation Bias, Southern Economic Journal, vol. 66 (2), pp. 336-352.

Delsen L. and A. Jacobs (1999), The Management of Redundancies in Europe: The Case of the Netherlands, Labour, vol. 13 (1), pp. 123-182.

Dickens W.T. and S.J. Lundberg (1993), Hours Restrictions and Labor Supply, International Economic Review, vol. 34 (1), pp. 169-192.

Dobbs I.M. (1992), The Effect of distinguishing Hours and Workers in Production on Labour Market Equilibrium, Scottish Journal of political economy, vol. 39 (1), pp. 14-20.

van Doorne-Huiskes A. and W. de Lange (1994), Netherlands, pp. 229-245 in Bosch G., P.

Dawkins and F. Michon (eds.) (1994), Times are Changing, ILO, Geneva. 
Doornik J.A. and D.F. Hendry (1997), Modelling Dynamic Systems using PcFiml 9.0 for Windows, International Thomson Business Press, London.

Drèze J. (1986), Work-sharing, Economic Policy, vol. 3, pp. 562-619.

Dupaigne M. (1998), Capital Operating Time and Economic Fluctuations, Recherches Economiques de Louvain, vol. 64 (3), pp. 243-267.

Dur R.A.J. (2001), Explaining Unemployment Trends in the Netherlands, Journal of Policy Modeling, vol. 23 (2), pp. 161-168.

Earle J.S. and J. Pencavel (1990), Hours of Work and Trade Unionism, Journal of Labor Economics, vol. 8, pp. S150-S174.

Ehrenberg R.G. (1970), Absenteeism and the Overtime Decision, American Economic Review, vol. 60 (3), pp. $352-357$.

Ehrenberg R.G. (1971), Fringe Benefits and Overtime Behavior, Lexington Books, Lexington Mass.

Engle R.F. and C.W. Granger (1987), Cointegration and Error Correction: Representation, Estimation and Testing, Econometrica, vol. 55, pp. 251-276.

Eurostat (1995), Working Time in the European Union: Estimated Actual Annual Working Time (1983-1993), Statistics in Focus, Population and Social Conditions (4), pp. 1-11.

Evans J.M., D.C. Lippoldt and P. Marianna (2001), Trends in working hours in OECD countries, Labour Market and Social Policy - Occasional Papers 45, OECD, Paris.

Fair R.C. (1969), The Short-Run Demand for Workers and Hours, North-Holland, Amsterdam. Feldstein M.S. (1967), Specification of the Labour Input in the Aggregate Production Function, Review of Economic Studies, vol. 34, pp. 375-386.

Feldstein M.S. (1976), Temporary Layoffs in the Theory of Unemployment, Journal of Political Economy, vol. 84, pp. 937-957.

FitzRoy F.R., M. Funke and M.A. Nolan (2002), Working Time, Taxation and Unemployment in General Equilibrium, European Journal of Political Economy, forthcoming.

Foss M.F. (1997), Shiftwork, Capital Hours and Productivity Change, Kluwer Academic,

Boston; Dordrecht and London.

Freeman R.B. (1998), Work-Sharing to Full Employment: Serious Option or Populist Fallacy?, pp. 195-222 in Freeman R.B. and P. Gottschalk (eds.) (1998), Generating Jobs, How to Increase Demand for Less-Skilled Workers, Russell Sage Foundation, New York.

Galeotti M., L. Maccini and F. Schiantarelli (2002), Inventories, Employment and Hours Discussion Paper 458, IZA.

Georgescu-Roegen N. (1970), The Economics of Production, American Economic Review, vol. 60 (Papers and Proceedings), pp. 1-9. 
Goerke L. (1998), Comment on "Trade Unions, Efficiency Wages, and Shirking" by Bulkley and Myles, Oxford Economic Papers, vol. 50, pp. 302-304.

Graafland J.J. and F.H. Huizinga (1999), Taxes and Benefits in a Non-Linear Wage Equation, De Economist, vol. 147 (1), pp. 39-54.

Green J. and C.M. Kahn (1983), Wage-Employment Contracts, The Quarterly Journal of Economics, vol. 98 (Supplement), pp. 173-187.

Greenwood J., Z. Hercowitz and G.W. Huffman (1988), Investment, Capacity Utilization, and the

Real Business Cycle, American Economic Review, vol. 78, pp. 402-417.

Hamermesh D.S. (1993), Labor Demand, Princeton University Press, Princeton.

Hart R.A. (1984a), The Economics of Non-Wage Labour Costs, Allen \& Unwin, London.

Hart R.A. (1984b), Worksharing and Factor Prices, European Economic Review, vol. 24, pp. 165-188.

Hart R.A. (1987), Working Time and Employment, Allen \& Unwin, Boston.

Hart R.A. and S. Kawasaki (1988), Payroll Taxes and Labour Demand, in R. Ehrenberg (ed.)

(1988), Research in Labor Economics, vol. 9, JAI Press, Greenwich, Conn.

Hart R.A., J.R. Malley and R.J. Ruffell (1996), What Shapes Are Overtime Premium Schedules?

Some Evidence from Japan, the UK, and the US, Economics Letters, vol. 53 (1), pp. 97-102.

Hart R.A. and P.G. McGregor (1988), The Returns to Labour Services in West German Manufacturing Industry, European Economic Review, vol. 32 (4), pp. 947-963.

Hart R.A. and R.J. Ruffell (1993), The Cost of Overtime Hours in British Production Industries, Economica, vol. 60 (238), pp. 183-201.

Hart R.A. and T. Sharot (1978), The Short-Run Demand for Workers and Hours: a Recursive

Model, The Review of Economic Studies, vol. 45, pp. 299-309.

Hartog J. (1999), Wither Dutch Corporatism? Two Decades of Employment Policies and Welfare Reforms, Scottish Journal of Political Economy, vol. 46 (4), pp. 458-487.

Hashimoto M. and J. Zhao (2000), The Labour Market Effects of Non-Wage Compensation, Labour Economics, vol. 7 (1), pp. 55-78.

Hoel M. and B. Vale (1986), Effects on Unemployment of Reduced Working Time in an Economy where Firms set Wages, European Economic Review, vol. 30 (5), pp. 1097-1104.

Houpis G. (1993), The Effect of Lower Hours of Work on Wages and Employment, Discussion

Paper 131, Center for Economic Performance.

Hunt J. (1998), Hours Reductions as Work-Sharing, Brookings Papers on Economic Activity, vol. 1998 (1), pp. 339-381.

Hunt J. (1999), Has Work-Sharing Worked in Germany?, The Quarterly Journal of Economics, vol. 114 (1), pp. 117-148.

Johansen S. and K. Juselius (1990), Maximum Likelihood Estimation and Inference on Cointegration - With Applications to the Demand for Money, Oxford Bulletin of Economics and Statistics, vol. 52, pp. 169-210. 
Goerke L. (1998), Comment on "Trade Unions, Efficiency Wages, and Shirking" by Bulkley and Myles, Oxford Economic Papers, vol. 50, pp. 302-304.

Graafland J.J. and F.H. Huizinga (1999), Taxes and Benefits in a Non-Linear Wage Equation, De Economist, vol. 147 (1), pp. 39-54.

Green J. and C.M. Kahn (1983), Wage-Employment Contracts, The Quarterly Journal of Economics, vol. 98 (Supplement), pp. 173-187.

Greenwood J., Z. Hercowitz and G.W. Huffman (1988), Investment, Capacity Utilization, and the Real Business Cycle, American Economic Review, vol. 78, pp. 402-417.

Hamermesh D.S. (1993), Labor Demand, Princeton University Press, Princeton.

Hart R.A. (1984a), The Economics of Non-Wage Labour Costs, Allen \& Unwin, London.

Hart R.A. (1984b), Worksharing and Factor Prices, European Economic Review, vol. 24, pp. 165-188.

Hart R.A. (1987), Working Time and Employment, Allen \& Unwin, Boston.

Hart R.A. and S. Kawasaki (1988), Payroll Taxes and Labour Demand, in R. Ehrenberg (ed.) (1988), Research in Labor Economics, vol. 9, JAI Press, Greenwich, Conn.

Hart R.A., J.R. Malley and R.J. Ruffell (1996), What Shapes Are Overtime Premium Schedules? Some Evidence from Japan, the UK, and the US, Economics Letters, vol. 53 (1), pp. 97-102. Hart R.A. and P.G. McGregor (1988), The Returns to Labour Services in West German Manufacturing Industry, European Economic Review, vol. 32 (4), pp. 947-963.

Hart R.A. and R.J. Ruffell (1993), The Cost of Overtime Hours in British Production Industries, Economica, vol. 60 (238), pp. 183-201.

Hart R.A. and T. Sharot (1978), The Short-Run Demand for Workers and Hours: a Recursive Model, The Review of Economic Studies, vol. 45, pp. 299-309.

Hartog J. (1999), Wither Dutch Corporatism? Two Decades of Employment Policies and Welfare Reforms, Scottish Journal of Political Economy, vol. 46 (4), pp. 458-487.

Hashimoto M. and J. Zhao (2000), The Labour Market Effects of Non-Wage Compensation, Labour Economics, vol. 7 (1), pp. 55-78.

Hoel M. and B. Vale (1986), Effects on Unemployment of Reduced Working Time in an Economy where Firms set Wages, European Economic Review, vol. 30 (5), pp. 1097-1104.

Houpis G. (1993), The Effect of Lower Hours of Work on Wages and Employment, Discussion Paper 131, Center for Economic Performance.

Hunt J. (1998), Hours Reductions as Work-Sharing, Brookings Papers on Economic Activity, vol. 1998 (1), pp. 339-381.

Hunt J. (1999), Has Work-Sharing Worked in Germany?, The Quarterly Journal of Economics, vol. 114 (1), pp. 117-148.

Johansen S. and K. Juselius (1990), Maximum Likelihood Estimation and Inference on Cointegration - With Applications to the Demand for Money, Oxford Bulletin of Economics and Statistics, vol. 52, pp. 169-210. 
Johansen S. and K. Juselius (1994), Identification of the Long-Run and the Short-Run Structure: An Application to the IS-LM model, Journal of Econometrics, vol. 63, pp. 7-36.

Johnson G.E. (1990), Work Rules, Featherbedding, and Pareto-optimal Union-Management Bargaining, Journal of Labor Economics, vol. 8 (1 supplement), pp. S237-S259.

Kalwij A.S. and M. Gregory (2000), Overtime hours in Great Britain over the period 1975 1998: a panel data analysis, Discussion Paper 153, IZA, Oxford.

Kapteyn A., A.S. Kalwij and A. Zaidi (2000), The Myth of Worksharing, Discussion Paper 188, IZA, Bonn.

Kooiman P. (1986), Some Empirical Models for Markets in Disequilibrium, Erasmus University Rotterdam, Rotterdam.

Krugman P. (1997), Is Capitalism too Productive?, Foreign Affairs, vol. 76 (5), pp. 79-94. Lambert J.-P. (1988), Disequilibrium Macro Models Based on Business Survey Data, Cambridge University Press, Cambridge.

Layard R. and S. Nickell (1990), Is Unemployment Lower if Unions Bargain over Employment, Quarterly Journal of Economics, vol. 105, pp. 773-787.

Layard R., S. Nickell and R. Jackman (1991), Unemployment, Macroeconomic Performance and the Labour Market, Oxford University Press, Oxford.

Leamer E.E. (1999), Effort, Wages, and the International Division of Labour, Journal of Political Economy, vol. 107 (6), pp. 1127-1162.

Leslie D. and J. Wise (1980), The Productivity of Hours in U.K. Manufacturing and Production Industries, Economic Journal, vol. 90, pp. 74-84.

Lewis H.G. (1969), Employer Interest in Employee Hours of Work, unpublished paper.

Lucas R.E. (1970), Capacity, Overtime, and Empirical Production Functions, American Economic Review, vol. 60 (Papers and Procedings), pp. 23-27.

Machin S. and A. Manning (1992), Testing Dynamic Models of Worker Effort, Journal of Labor Economics, vol. 10 (3), pp. 288-305.

Madan D.B. (1987), Optimal Duration and Speed in the Long Run, Review of Economic Studies, vol. 54 , pp. 695-700.

Maddison A. (1982), Phases of Capitalist Development, Oxford University Press, Oxford.

Maddison A. (1991), Dynamic forces in capitalist development, a long-run comparative view, Oxford University Press, Oxford.

Maddison A. (1995), Monitoring the world economy 1820-1992, OECD, Paris.

Manning A. (1987), An Integration of Trade Union Models in a Sequential Bargaining Framework, Economic Journal, vol. 97, pp. 121-139.

Manning A. (1994), How Robust is the Microeconomic Theory of the Trade Union?, Journal of Labor Economics, vol. 12 (3), pp. 430-459.

Manning A. (2001), Labour Supply, Search and Taxes, Journal of Public Economics, vol. 80 (3), pp. $409-434$. 
Marimon R. and F. Zilibotti (2000), Employment and Distributional Effects of Restricting Working Time, European Economic Review, vol. 44 (7), pp. 1291-1326.

Mayshar J. and Y. Halevy (1997), Shiftwork, Journal of Labor Economics, vol. 15 (1), pp. S198222.

Mendis L. and J. Muellbauer (1984), British Manufacturing Productivity 1955-83: Measurement Problems, Oil Shocks and Thatcher Effects, Nuffield College, Oxford; Nuffield College, Oxford.

Moore J. (1985), Optimal Labour Contracts When Workers Have a Variety of Privately Observed Reservation Wages, Review of Economic Studies, vol. 52 (1), pp. 37-67.

Moselle B. (1996), Efficiency wages and the hours/unemployment trade-off 1153, Center for Mathematical Studies in Economics and Management Science, Northwestern University, Evanston.

Muthoo A. (1999), Bargaining Theory with Applications, Cambridge University Press, Cambridge.

Muysken J., A.P. van Veen and E.R. de Regt (1999), Does a Shift in the Tax Burden Create Employment?, Applied Economics, vol. 31 (10), pp. 1195-1205.

Nadiri M.I. and S. Rosen (1969), Interrelated Factor Demand Functions, American Economic Review, vol. 59, pp. 457-471.

de Neubourg C. (1991), Where Have all the Hours Gone? Working Time Reduction Policies in the Netherlands, pp. 129-147 in Hinrichs K., W.K. Roche and C. Sirianni (eds.) (1991), Working time in transition: The political economy of working hours in industrial nations, Temple University Press, Philadelphia.

Nickell S. and M. Andrews (1983), Unions, Real Wages and Employment in Britain 1951-79, Oxford Economic Papers, vol. 35, pp. 183-206.

Nickell S., S. Wadhwani and M. Wall (1992), Productivity growth in the U.K. companies 19751986, Elropean Economic Review, vol. 36, pp. 1055-1091.

OECD (1998), Working Hours: latest trends and policy initiatives, pp. 153-188 in OECD (ed.) (1998), Employment Outlook, OECD, Paris.

Oi W.Y. (1962), Labor as a Quasi-Fixed Factor, Journal of Political Economy, vol. 80, pp. 538555.

Oi W.Y. (1981), Slack Capacity: Productive or Wasteful?, American Economic Review, vol. 71 (Papers and Procedings), pp. 64-69.

Oi W.Y. (2001), Effort, Productivity and pay mimeo, University of Rochester.

Osberg L. and S. Phipps (1993), Labour Supply with Quantity Constraints: Estimates from a Large Sample of Canadian Workers, Oxford Economic Papers, vol. 45 (2), pp. 269-291. 
Oswald A.J. (1993), Efficient Contracts are on the Labour Demand Curve, Theory and Facts, Labour Economics, vol. 1 (1), pp. 85-113.

Owen J.D. (1989), Reduced Working Hours, Cure for unemployment or Economic Burden, John Hopkins University Press, Baltimore.

Pencavel J. (1991), Labor Markets under Trade Unionism, Employment, Wages and Hours, Basil Blackwell, Oxford.

Perloff J.M. and R.C. Sickles (1987), Union Wage, Hours, and Earnings Differentials in the Construction Industry, Journal of Labor Economics, vol. 5 (2), pp. 174-210.

Pissarides C.A. (1998), The Impact of Employment Tax Cuts on Unemployment and Wages; The Role of Unemployment Benefits and Tax Structure, European Economic Review, vol. 42 (1), pp. 155-183.

Plessner Y. and S. Yitzhaki (1983), Unemployment and Wage Rigidity: the Demand Side, Oxford Economic Papers, vol. 35, pp. 202-212.

de Regt E.R. (1988), Labor Demand and Standard Working Time in Dutch Manufacturing, 19541982, ch. 10, pp. 185-205 in Hart R.A. (ed.) (1988), Employment, Unemployment and Labor Utilization, Unwin Hyman, Boston.

Roche W.K., B. Fynes and T. Morrisey (1996), Working time and employment: A review of international evidence, International Labour Review, vol. 135 (2), pp. 129-157.

Rocheteau G. (2000), Working Time Regulation in a Search Economy with Worker Moral Hazard, DEEP-HEC, University of Lausanne.

Rocheteau G. (2002), Working time regulation in a search economy with worker moral hazard, Journal of Public Economics, vol. 84 (3), pp. 387-425.

Rosen A. (1989), Bargaining over Effort, mimeo, London School of Economics.

Rosen S. (1968), Short-Run Employment Variation on Class-I Railroads in the US, 1947-1963, Econometrica, vol. 36, pp. 511-529.

Rosen S. (1985), Implicit Contracts: A Survey, Journal of Economic Literature, vol. 23, pp. 1144-1175.

Rubin M. and R. Richardson (1997), The Microeconomics of the shorter Working Week, Avebury, Aldershot.

Sampson A.A. (1993), Bargaining over Effort and the Monitoring Role of Unions, European Journal of Political Economy, vol. 9, pp. 371-381.

Schor J.B. (1991), The Overworked American: The Unexpected Decline of Leisure, basic Books, New York.

Shapiro C. and J. Stiglitz (1984), Equilibrium Unemployment as a Worker Discipline Device, American Economic Review, vol. 74, pp. 433-444. 
Shapiro M.D. (1993), Cyclical Productivity and the Workweek of Capital, American Economic Review, vol. 83 (2), pp. 229-233.

Shepard E. and T. Clifton (2000), Are Longer Hours Reducing Productivity in Manufacturing?, International Journal of Manpower, vol. 21 (7-8), pp. 540-552.

Sneessens H. (1983), Aggregation in Quantity Rationing Models, CORE, Louvain-la-Neuve. Sousa-Poza A. and F. Henneberger (2000), Work Attitudes, Work conditions and Hours Constraints: An Explorative, Cross-national Analysis, Labour, vol. 14 (3), pp. 351-372.

Spanos A. (1990), The Simultaneous-Equations Model Revisited: Statistical Adequacy and Identification, Journal of Econometrics, vol. 44, pp. 87-105.

Stiglitz J.E. (1986), Theories of Wage Rigidity, in Butkiewicz J.L., K.J. Koford and J.B. Miller (eds.) (1986), Keynes' Economic Legacy: Contempory Economic Theories, Praeger, New York.

Teulings C. and J. Hartog (1998), Corporatism or Competition? Labour contracts, institutions and wage structures in international comparison, Cambridge University Press, Cambridge.

Toedter K.-H. (1988), Effects of Shorter Hours on Employment in Disequilibrium Models, European Economic Review, vol. 32, pp. 1319-1333.

Trejo S.J. (1993), Overtime Pay, Overtime Hours, and Labor Unions, Journal of Labor Economics, vol. 11 (2), pp. 253-278.

Tummers M. and I. Woittiez (1991), A Simultaneous Wage and Labor Supply Model with Hours Restrictions, Journal of Human Resources, vol. 26 (3), pp. 393-423.

Urbain J.-P.(1995), Partial versus Full Systems Modelling of Cointegrated Systems, An Empirical Illustration, Journal of Econometrics, vol. 69, pp. 177-210.

van Veen A.P. (1997), Studies in Wage Bargaining, The Influence of Taxes and Social Security Contributions on Wages, Thesis, University Maastricht, Maastricht.

Vendrik M. (1993), Collective Habits and Social Norms in Labour Supply, From Micromotives to Macrobehaviour, Thesis, University Maastricht, Maastricht.

Verdoorn P.J. (1947), Arbeidsduur en Welvaartspeil, Stenfert Kroese, Leiden.

Walker T. (2000), The "Lump-of-Labor" case Against Work-Sharing, pp. 196-211 in Golden L. and D.M. Figart (eds.) (2000), Working Time, International trends, theory and policy perspectives, Routledge, London.

Winston G.C. (1974), Capital Utilization and Optimal Shift Work, Bangladesh Economic Review, vol. 2, pp. 515-558.

Winston G.C. and T.O. McCoy (1974), Investment and the Optimal Idleness of Capital, Review of Economic Studies, vol. 41, pp. 419-428.

Yaniv G. (1995), Burnout, Absenteeism, and the Overtime Decision, Journal of Economic Psychology, vol. 16 (2), pp. 297-309. 


\section{Samenvatting (Summary in Dutch)}

Dit proefschrift behandelt de relatie tussen de arbeidsduur en de economie. Al ruim een eeuw analyseren economen de invloed van de jaarlijkse arbeidsduur op werkgelegenheid, werkloosheid en andere indicatoren van economische bedrijvigheid. In het algemeen kan worden gesteld dat de toon van het economendebat over arbeidsduurverkorting voor het merendeel sceptisch is. Niettemin is de jaarlijkse arbeidsduur sinds 1870 geleidelijk aan met zo'n 50 procent gedaald. Met andere woorden, in de ogen van onze overgrootouders werken voltijd werknemers tegenwoordig nog slechts in deeltijd.

Een dergelijke forse daling van de jaarlijkse arbeidsduur heeft zich in alle ontwikkelde landen voorgedaan, maar de timing was wel verschillend. Zo waren Amerika en Frankrijk de eerste landen waar de 40-urige werkweek werd ingesteld, en volgde Nederland bijvoorbeeld pas gedurende de jaren zestig en zeventig van de vorige eeuw. In de jaren tachtig en negentig, is de jaarlijkse arbeidsduur met name op het Europese vasteland nog verder gedaald.

In hoofdstuk 1 van het proefschrift wordt deze ontwikkeling nader geschetst. Tevens worden in dat hoofdstuk enige empirische verbanden gelegd tussen de jaarlijkse arbeidsduur en andere economische variabelen. In een cross-sectie van OESO-landen is er een duidelijke negatieve samenhang tussen de arbeidsduur en de arbeidsproductiviteit. Evenzo is de arbeidsduur negatief gecorreleerd met het ledental van vakbonden. Er blijkt echter geen duidelijk verband te zijn tussen de arbeidsduur en het werkloosheidspercentage. Tenslotte hebben landen met een kortere arbeidsduur in het algemeen een lager bruto binnenlands product per hoofd van de bevolking.

Het moge duidelijk zijn dat deze empirische bevindingen niets zeggen over de eventuele causaliteit tussen de verschillende variabelen. Is de jaarlijkse arbeidsduur bijvoorbeeld kort omdat de arbeidsproductiviteit hoog is, of ligt de causaliteit andersom? Leidt een kortere arbeidsduur tot een verandering van de werkgelegenheid of de werkloosheid, of beïnvloedt de werkloosheid de feitelijke arbeidsduur? Het doel van het proefschrift is dan ook om een beter inzicht te krijgen in dergelijke verbanden tussen de arbeidsduur enerzijds, en enkele andere economische variabelen anderzijds. De nadruk ligt daarbij vooral op de werkgelegenheid, de lonen en de werkloosheid.

Het boek bestaat in essentie uit twee delen. In het eerste deel, wordt de invloed van de jaarlijkse arbeidsduur op de werkgelegenheid geanalyseerd. Daarbij staat in hoofdstuk 2 de werkgelegenheid 
in personen voorop, wordt overwerk nader geanalyseerd in hoofdstuk 3, terwijl in hoofdstuk 4 ploegenarbeid wordt behandeld. In hoofdstuk 5 wordt vervolgens geanalyseerd wat de invloed is van de arbeidsduur op loonvorming en werkloosheid. In het tweede deel, vanaf hoofdstuk 6, wordt de causaliteit vervolgens omgedraaid en wordt bekeken wat de determinanten zijn van de jaarlijkse arbeidsduur. Hoofdstuk 7 bevat een empirische analyse van de uurlonen en de jaarlijkse arbeidsduur voor de Nederlandse marktsector.

Een andere indeling kan worden gemaakt op basis van het niveau van de analyse. In de hoofdstukken 2 tot en met 4 wordt de vraag naar arbeid bekeken zonder rekening te houden met loonvorming en aanbod van arbeid. Het gaat hier dus telkens om een partiële analyse. In de hoofdstukken 5 en 6 wordt echter gebruik gemaakt van evenwichtsanalyse op de arbeidsmarkt. Het empirische slothoofdstuk sluit hierbij aan.

Deze structuur van het proefschrift komt in grote lijn ook overeen met de ontwikkelingen in de literatuur. In de jaren zeventig en tachtig had men met name aandacht voor de invloed van de arbeidsduur op de vraag naar arbeid. Vanaf medio jaren tachtig verschoof de aandacht geleidelijk aan naar de invloed op de loonvorming. Recentelijk zijn enkele papers verschenen die ook de determinanten van de arbeidsduur meenemen in de analyse.

Een belangrijk verschil met de bestaande literatuur is dat het proefschrift expliciet aandacht besteedt aan de invloed van de arbeidsduur op de productiviteit van kapitaal. Naarmate de arbeidsduur van het personeel afneemt, zal in het algemeen ook de kapitaalgoederenvoorraad minder lang worden benut. Kortom, de bedrijfstijd daalt. Dit thema wordt in hoofdstuk 2 uitgebreid geanalyseerd. Rekening houdend met de invloed van de arbeidsduur op de kapitaaldiensten en de bedrijfstijd, wordt het effect van arbeidsduurverkorting op de werkgelegenheid in personen kleiner, aangezien de productiviteit en de winstgevendheid dalen. Niettemin blijkt uit de analyse dat het effect afhangt van de oorspronkelijk arbeidsduur. Boven een bepaalde kritische grens neemt de werkgelegenheid in personen toe, maar daalt de arbeidsduur onder die grens, dan leidt arbeidsduurverkorting zelfs tot een vermindering van de werkgelegenheid. Het model uit dit hoofdstuk wordt in alle volgende hoofdstukken van het proefschrift gebruikt.

In het model van hoofdstuk 2 wordt geabstraheerd van overwerk. In de praktijk wordt daarentegen wel degelijk overwerk waargenomen. Modellen van de vraag naar arbeid die rekening houden met overwerk, leiden in het algemeen tot de conclusie dat verkorting van de normale arbeidsduur in een situatie met overwerk zelfs zal leiden tot een langere feitelijke arbeidsduur en minder werkgelegenheid. Bezien we echter de lange termijn ontwikkelingen van de feitelijke wekelijkse arbeidsduur, inclusief overwerk, dan blijkt deze de normale arbeidsduur vrijwel proportioneel te volgen. Een belangrijke vraag in hoofdstuk 3 is dan ook hoe we de modellen in overeenstemming kunnen brengen met de feiten. Een deel van antwoord is wellicht gelegen in meetfouten: er zijn aanwijzingen dat het waargenomen overwerk de feitelijke arbeidsduur overschat. 
Als dit het geval is, zou de feitelijke arbeidsduur gemiddeld genomen best overeen kunnen komen met de normale arbeidsduur, zodat de voorspellingen van de eerder genoemde modellen niet langer relevant zijn. Een tweede en vermoedelijk belangrijker element is dat overwerk wellicht wordt verklaard door factoren die normaliter niet in de analyse worden meegenomen. In hoofdstuk $3 \mathrm{ga} \mathrm{ik}$ met name in op de rol van onzekerheid over de vraag naar eindproducten en onzekerheid over ziekteverzuim. Het blijkt inderdaad dat beide factoren de gemiddelde arbeidsduur verhogen. Kortom, het waargenomen overwerk zou een gevolg kunnen zijn van wisselend ziekteverzuim en een schommelende vraag.

Hoofdstuk 3 wordt afgesloten met een korte empirische analyse voor de Nederlandse industrie. Daaruit blijkt inderdaad dat overwerk met name wordt belinvloed door ziekteverzuim en de bezettingsgraad. De normale arbeidsduur heeft daarentegen geen enkel effect, zodat de feitelijke arbeidsduur proportioneel is met de normale arbeidsduur. In lijn met dit resultaat, besteed ik in de rest van het proefschrift geen aandacht aan het onderscheid tussen de normale en de feitelijke arbeidsduur.

Hoofdstuk 4 behandelt een andere dimensie van de vraag naar arbeid, namelijk ploegenarbeid. Ofschoon de jaarlijkse arbeidsduur van werknemers sinds de jaren vijftig behoorlijk is gedaald, zijn er aanwijzingen dat de bedrijfstijd nagenoeg gelijk is gebleven. In dit hoofdstuk analyseer ik dan ook welke prikkels bedrijven hebben om ploegendiensten in te voeren. Inderdaad blijkt een kortere arbeidsduur een van de factoren te zijn die ertoe kan leiden de bedrijfstijd los te koppelen van de arbeidsduur.

Een belangrijke determinant van de effectiviteit van arbeidsduurverkorting is de invloed op de lonen. In hoofdstuk 5 wordt een vakbondsmodel geïntroduceerd om dit te analyseren. Het model voorspelt een U-vormig verband tussen de uurlonen en de arbeidsduur, terwijl de jaarlijkse beloning lijkt te dalen. Met andere woorden, arbeidsduurverkorting leidt tot matiging van de jaarlonen, terwijl het effect op de uurlonen afhankelijk is van de arbeidsduur: bij lange arbeidsduren zijn vakbonden zelfs bereid de uurlonen te matigen, maar bij een relatief korte arbeidsduur zullen de uurlonen stijgen, zij het minder dan proportioneel. Dit alles leidt er eveneens toe dat er een $\mathrm{U}$-vorming verband bestaat tussen de arbeidsduur en werkloosheid. De effectiviteit van arbeidsduurverkorting hangt dus af van de oorspronkelijke lengte van de werkweek. Bij te lange arbeidsduren helpt arbeidsduurverkorting wel degelijk.

In dat kader is het van belang te begrijpen hoe de jaarlijkse arbeidsduur wordt bepaald. Dat probleem wordt in hoofdstuk 6 behandeld. Er zijn vele modellen dienaangaande, met arbeidsaanbod modellen als een veel gebruikte mogelijkheid en bedrijven die de arbeidsduur bepalen als ander uiterste. Hoofdstuk 6 zet de alternatieven op een rij en gaat vervolgens met name in op de invloed van vakbonden. Inderdaad blijkt dat vakbonden een prikkel hebben om een kortere arbeidsduur te bedingen als de werkloosheid hoog is. Daarnaast blijken meer institutionele factoren, zoals 
onderhandelingsmacht en volgorde van de onderhandelingsagenda, een belangrijke invloed te hebben op de uitkomst.

Ondanks het feit dat er zo'n grote variëteit is aan modellen ter verklaring van de arbeidsduur, kunnen de modellen uit hoofdstuk 6 ook gebruikt worden om te onderzoeken wat de invloed is van productiviteitsgroei op de arbeidsduur en de lonen. De algemene voorspelling is dat een toenemende productiviteit leidt tot een kortere arbeidsduur en hogere lonen, zelfs als het individuele arbeidsaanbod licht stijgend verloopt.

In hoofdstuk 7 wordt tenslotte een simultaan model voor lonen en jaarlijkse arbeidsduur geschat. De data hebben betrekking op de Nederlandse marktsector. Gebruik makend van zogenaamde coÏntegratie analyse vind ik geen significant lange termijn effect van de arbeidsduur op de uurlonen. Op kortere termijn blijven de jaarlonen echter constant. Dit betekent dat arbeidsduurverkorting in Nederland heeft geleid tot loonmatiging, zij het met enige vertraging. Uurlonen hebben op hun beurt echter op lange termijn een vrij fors significant negatief effect op de jaarlijkse arbeidsduur. Dit kan niet uitsluitend worden toegeschreven aan arbeidsaanbodeffecten, hetgeen erop wijst dat vakbonden en bedrijven inderdaad invloed uitoefenen op de jaarlijkse arbeidsduur. Daar staat tegenover dat werkloosheid geen invloed heeft op de jaarlijkse arbeidsduur. Al met al impliceert dit dat de daling van de jaarlijikse arbeidsduur in de jaren zeventig en tachtig niet direct het gevolg was van de roep om arbeidsduurverkorting, maar het gevolg van productiviteitsgroei.

In hoofdstuk 8 beesindig ik het proefschrift met enkele conclusies, die in deze samenvatting zijn verwerkt. Al met al ontstaat een beeld dat arbeidsduurverkorting noch noodzakelijkerwijs goed noch noodzakelijkerwijs slecht is, het hangt van de omstandigheden af. 


\section{Curriculum Vitae}

Erik Ronald de Regt was born on March 9, 1957 in 's Gravenhage, The Netherlands. He grew up in de Bilt, Paris and Tervuren, Belgium. He attended the European School in Brussels until 1975. Between 1975 and 1981 he studied econometrics (Algemene Econometrie) at the Erasmus University Rotterdam, The Netherlands. In 1981 he graduated cum laude.

From November 1981 to December 1985 he worked as a research assistant at the Erasmus University Rotterdam in the Department of Macroeconomics. From 1986 onwards he has been assistant professor in the Department of Economics (Algemene Economie) of the Universiteit Maastricht, The Netherlands. The academic year 1988-1989 he spend as a research fellow at CORE in Louvain-la-Neuve, Belgium.

Erik de Regt has been teaching in macroeconomics, microeconomics, advanced industrial economics, labour economics and personnel economics. His research interests are mainly in labour and personnel economics. 


\section{Employment, Wages and Working Time}

Erik de Regt

Every now and then, especially during recessions, work-sharing returns as an item on the policy agenda. In times of high unemployment left-wing policy makers and unions tend to ask for a reduction in working time to spread the burden of unemployment. The idea is sympathetic, but professional economists tend to be rather sceptical about the merits of such a policy. In this thesis I have taken an intermediate position: work-sharing has pitfalls, but may also have some merits.

In the first part of the thesis I model the impact of reduced working time on employment, with an emphasis on the number of workers, overtime hours and shiftwork. Then I turn to the influence of working hours on union wage bargaining and unemployment. The theoretical model illustrates that work-sharing may reduce unemployment when the number of annual hours is relatively high, but will have the opposite effect when annual hours are relatively short.

The next part of the thesis considers the determinants of full-time working hours. In a union bargaining context, productivity growth and unemployment may both reduce annual hours. The empirical model for the Dutch market sector illustrates, however, that it is only productivity growth that matters. 